\title{
DELLA PROTEIN FUNCTION DURING DIFFERENTIAL GROWTH PROCESSES IN ARABIDOPSIS
}

DIRECTOR: MIGUEL ÁNGEL BLÁZQUEZ

DAVID ALABADÍ DIEGO

VALENCIA, JUNE 2011 

Summary 

The plant hormones gibberellins (GAs) regulate multiple processes of plant development, such as seed germination, photomorphogenesis, vegetative growth, and flower and fruit development. Most of this regulation occurs at the transcriptional level, through the activity of the DELLAs, which are nuclear-localized proteins subjected to GA-mediated proteolitic degradation. DELLAs do not bind DNA directly, but they have been shown to interact with DNA-binding transcription factors to regulate their targets. Moreover, DELLAs mobilizes distinct set of genes to trigger different GAs responses. In Arabidopsis, DELLAs are encoded by five genes, and genetic studies show that each DELLA displays specific, but also partially overlapping roles with respect to their paralogs. In this Thesis, we have addressed two issues: (1) the contribution of DELLA multiplication to the diversification of functions controlled by GAs; and (2) the identification of direct targets regulated by DELLAs in etiolated seedlings with special attention to those involved in differential growth processes.

Using combinations of mutants and transgenic lines expressing two phylogenetically distant DELLA genes ( $R G A$ and $R G L 2$ ), we have found that these two DELLA proteins can perform each other's role as long as they are expressed under the reciprocal promoters, indicating that DELLA subfunctionalization relies mainly on their differential expression patterns. In agreement with this, none of these DELLA proteins displayed significant differences in their ability to interact with several bHLH transcription factors, again suggesting that the function of each DELLA protein probably depends on the set of transcription factors to which they are exposed, and their mutual interactions.

To identify direct DELLA targets, we have performed transcriptomic analyses of darkgrown seedlings expressing an inducible version of gai-1, a stable, dominant allele of a DELLA gene. This approach rendered a list of over 150 genes differentially expressed between 30 and $240 \mathrm{~min}$ after induction of gai-1. Further in silico analysis of this set of targets has confirmed the functional interaction between DELLAs and bHLH transcription factors, but has also allowed the identification of additional transcription factor families putatively involved in transcriptional regulation by DELLAs.

The presence of several auxin-related genes among the primary targets of DELLA proteins has allowed us to establish a new role for GAs in the modulation of hypocotyl gravitropism through the repression of IAA19/MASSUGU2 expression by DELLAs. Our results also suggest that this regulatory module fine tunes the auxin-driven gravitropic response, providing flexibility under competing tropic stimuli. Moreover, the repression of HOOKLESS1 and the auxin efflux carriers PIN3 and PIN7 by DELLAs, is proposed as the molecular mechanism to explain the already known physiological regulation of apical hook development by GAs. 
Las hormonas vegetales giberelinas (GAs) regulan múltiples procesos del desarrollo de las plantas, como la germinación, la fotomorfogénesis, el crecimiento vegetativo y el desarrollo floral. Esta regulación ocurre principalmente sobre la transcripción a través de las proteínas DELLA, que son proteínas nucleares sometidas a degradación proteolítica inducida por GAs. Las DELLAs no unen DNA directamente pero son capaces de interaccionar con factores de transcripción que unen DNA para regular sus dianas. Además, las DELLAs movilizan diferentes grupos de genes según el proceso que estén controlando. En Arabidopsis, las DELLAs están codificadas por cinco genes y los estudios genéticos muestran que cada DELLA realiza funciones específicas pero también solapan con otras DELLAs en el control de determinados procesos. En esta Tesis hemos abordado dos cuestiones: (1) la contribución de la multiplicación de las DELLAs a la diversificación de funciones controlada por GAs y (2) la identificación de dianas directas reguladas por las DELLAs en plántulas etioladas, con especial atención a aquellas relacionadas con el crecimiento diferencial.

Usando una combinación de mutantes y líneas transgénicas que expresan dos DELLAs filogenéticamente alejadas (RGA y RGL2), hemos encontrado que estas dos proteínas DELLA pueden suplantar la función de la otra siempre que se expresen bajo el control de los promotores recíprocos, lo que indica que la subfuncionalización de las DELLA reside principalmente en sus diferentes patrones de expresión. En consonancia con esto, ninguna de estas dos proteínas mostró diferencias significativas en su capacidad de interaccionar con diferentes factores de transcripción de tipo bHLH, de nuevo sugiriendo que la función de cada proteína DELLA depende del grupo de factores de transcripción al que se vean expuestas, y su interacción con éstos.

Para identificar dianas directas de las DELLAs, hemos llevado a cabo un análisis transcriptómico en plántulas etioladas expresando una versión inducible por choque térmico de gai-1, un alelo de GAI resistente a degradación inducida por GAs. Con este abordaje se encontraron 150 genes diferencialmente expresados a tiempos cortos tras la inducción de gai-1. El análisis in silico de este grupo de genes confirmó la relación funcional entre las DELLA y los bHLH, pero además ha permitido la identificación de nuevas familias de factores de transcripción que podrían estar implicadas en la regulación transcriptional mediada por las DELLAs.

La presencia de varios genes relacionados con auxinas entre las dianas directas de las DELLA nos ha permitido encontrar un nuevo papel de las GAs en la modulación de la respuesta gravitrópica, a través de la repressión de IAA19 por las DELLA. Nuestros resultados también sugieren que este módulo sirve para matizar la respuesta a auxinas durante la respuesta gravitrópica, confiriendo flexibilidad bajo situaciones donde se enfrenten diferentes estímulos trópicos. Además, la repression de HOOKLESS1, PIN3 Y PIN7 por las DELLA, se propone como el mecanismo molecular que explicaría el papel ya conocido de las GAs en el control del desarrollo del gancho apical. 
Les hormones vegetals Giberelines (GAs) regulen múltiples processos del desenvolupament de les plantes, com la germinació, la fotomorfogénesis, el creixement vegetatiu i el desenvolupament floral. Aquesta regulació ocorre principalment sobre la transcripció a través de les proteïnes DELLA, que són proteïnes nuclears sotmeses a degradació proteolítica induïda per GAs. Les DELLAs no uneixen DNA directament però són capaces d'interaccionar amb factors de transcripció que uneixen DNA per regular les seves dianes. A més, les DELLAs mobilitzen diferents grups de gens segons el procés que estiguin controlant. En Arabidopsis, les DELLAs estan codificades per cinc gens i els estudis genètics mostren que cada DELLA realitza funcions específiques però també solapan amb altres DELLAs en el control de determinats processos. En aquesta Tesi hem abordat dues qüestions: (1) la contribució de la multiplicació de les DELLAs a la diversificació de funcions controlada per GAs i (2) la identificació de dianes directes regulades per les DELLAs en plántules etiolades, amb especial atenció a aquelles relacionades amb el creixement diferencial.

Usant una combinació de mutants i línies transgèniques que expressen dues DELLAs filogenéticament allunyades (RGA i RGL2), hem trobat que aquestes dues proteïnes DELLA poden suplantar la funció de l'altra sempre que s'expressin sota el control dels promotors recíprocs, la qual cosa indica que la subfuncionalizació de les DELLA resideix principalment en els seus diferents patrons d'expressió. D'acord amb això, cap d'aquestes dues proteïnes va mostrar diferències significatives en la seva capacitat d'interaccionar amb diferents factors de transcripció de tipus bHLH, de nou suggerint que la funció de cada proteïna DELLA depèn del grup de factors de transcripció al que es vegin exposades, i la seva interacció amb aquests.

Per identificar dianes directes de les DELLAs, hem dut a terme una anàlisi transcriptómic en plántules etioladas expressant una versió inducible per xoc tèrmic de gai-1, un al-lel de GAI resistent a degradació induïda per GAs. Amb aquest abordatge es van trobar 150 gens diferencialment expressats a temps curts després de la inducció de gai-1. L'anàlisi in silico d'aquest grup de gens va confirmar la relació funcional entre les DELLA i els bHLH, però a més ha permès la identificació de noves famílies de factors de transcripció que podrien estar implicades en la regulació transcriptional intervinguda per les DELLAs.

La presència de diversos gens relacionats amb auxines entre les dianes directes de les DELLA ens ha permès trobar un nou paper de les GAs en la modulació de la resposta gravitrópica, a través de la repressió de IAA19 per les DELLA. Els nostres resultats també suggereixen que aquest mòdul serveix per matisar la resposta a auxines durant la resposta gravitrópica, conferint flexibilitat sota situacions on s'enfrontin diferents estímuls tròpics. A més, la repressió de HOOKLESS1, PIN3 i PIN7 per les DELLA, es proposa com el mecanisme molecular que explicaria el paper ja conegut de les GAs en el control del desenvolupament del ganxo apical. 

Index 



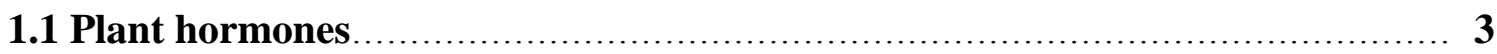

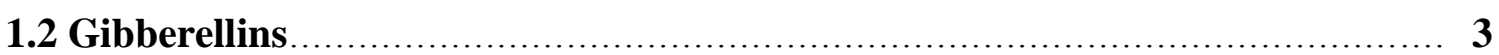

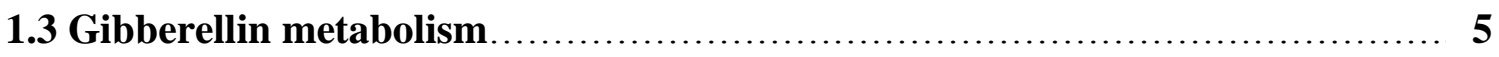

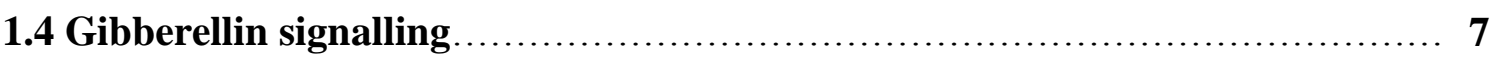

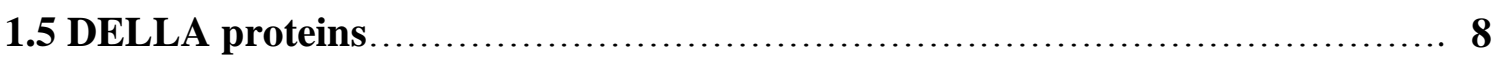

1.6 Gibberellin-induced DELLA degradation ...................................... 10

1.7 Transcriptional regulation by DELLA proteins............................. 12

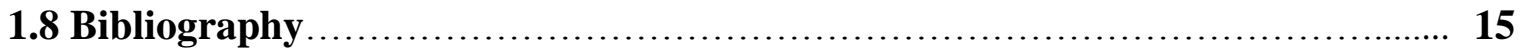

2. OBJECTIVES.

3. CHAPTER 1: Transcriptional diversification and functional conservation between DELLA proteins in Arabidopsis

3.1. Abstract

3.2. Introduction.

3.3. Materials and Methods.................................................... 30

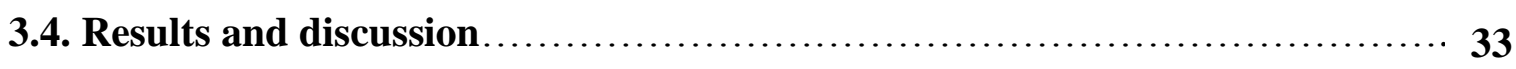

3.4.1. Phylogenetic relationships of DELLA proteins in Angiosperms................... 33

3.4.2. Expression of chimeric versions of DELLA genes............................. 34

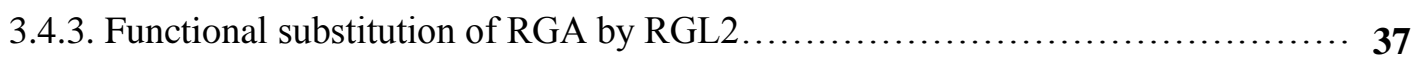

3.4.4. Functional substitution of RGL2 by RGA................................. 38

3.4.5. Conservation of DELLA protein interactions................................. 40

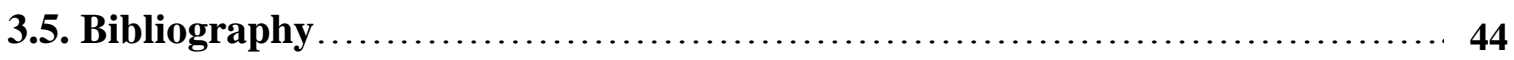

4. CHAPTER 2: GA signaling targets during etiolated growth in Arabidopsis. 49

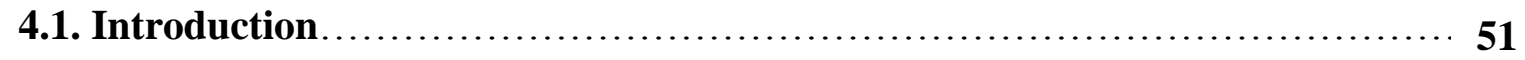

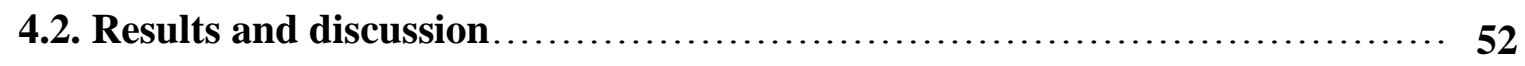

4.2.1. Identification of genes rapidly regulated by GAI in etiolated seedlings........... 52

4.2.2. Different and overlapping targets for GAI and RGA under different 
light conditions

4.2.3. GAI regulates target genes in part through PIFs and HY5 transcription factors

4.2.4. Promoter analysis of GAI regulated targets suggests new transcription factors mediating DELLAactivity 57

4.2.5. Gene ontology analysis of GAI-regulated genes. 58

4.2.6. Direct regulation of the GA pathway by DELLA proteins. 61

4.2.7. DELLA proteins mediate direct cross-regulation with auxin and ethylene pathways $\mathbf{6 2}$

4.2.8. DELLAs impinge on transcriptional networks 64

4.3. Conclusions 66

4.4. Materials and Methods. 66

4.5.Bibliography

\section{CHAPTER 3: A hormonal regulatory module that provides flexibility to}

tropic responses

5.1. Abstract 75

5.2. Introduction 76

5.3. Results. 77

5.3.1. Gibberellin deficiency enhances gravitropic reorientation. 77

5.3.2. Expression of IAA19/MSG2 is repressed by DELLA proteins 77

5.3.3. Physiological relevance of the regulation of gravitropism by gibberellins 82

5.4. Discussion. 83

5.5. Materials and Methods. 86

5.6. Bibliography. 88

\section{CHAPTER 4: Hierarchy of hormone action controlling apical hook} development in Arabidopsis.............................................. 93

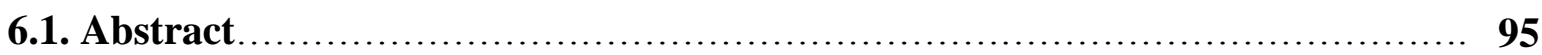

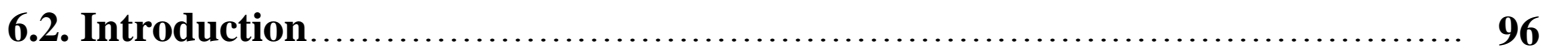

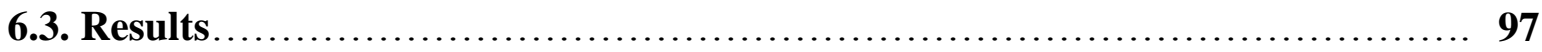

6.3.1. Dynamics of GA-regulated apical hook development........................ 97

6.3.2. GA control on hook development is dependent and independent upon ethylene $\quad \mathbf{9 8}$

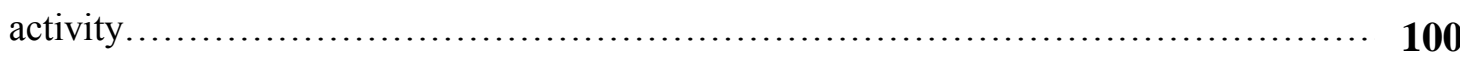


6.3.3. The expression of ACS5/ETO2, ACS8, and HLS1 genes is regulated by the GA pathway

6.3.4. GA-regulation of ACS5/ETO2 and ACS8 gene expression depends on the phase of hook development

6.3.5. GAs support ethylene production in etiolated seedling.

6.3.6. GAs regulate partly hook development by modulating PIF activity....

6.3.7. HLS1 activity mediates GA effect on hook development.

6.3.8. GAs are needed to sustain differential auxin response during apical hook development

6.3.9. GAs participate in maintaining PIN3 and PIN7 expression in the apical hook.

6.3.10. GA activity in the endodermis is required for apical hook development

6.4. Discussion.

6.4.1. GAs regulate hook formation independently of ethylene activity.

6.4.2. GAs prevent hook opening in cooperation with the ethylene pathway.

6.4.3. GAs regulate hook development by transcriptional regulation of auxin and ethylene pathways....

6.5. Experimental procedures.

6.6. Bibliography.

6.7. Supporting figures

\subsection{Contribution of gibberellins to plant plasticity resides partially on DELLA} protein subfuncionalization.

7.2. Regulation of transcriptional networks as a mechanism to improve plastic development

7.3. DELLA co-expressed as a source of new interactors.

7.4. Gibberellin modulation of differential growth processes.

7.5. Future perspectives. 



\section{Introduction}





\subsection{Plant hormones}

Pioneering studies during the 19th century demonstrated that plant growth processes were regulated by "substances" with a capacity to move from one part of the plant to another. Today, more than one hundred years later, most of these substances have been identified as small molecules derived from secondary metabolic pathways. In general, these compounds are present at very low concentrations and act either locally, at or near the site of synthesis, or in distant tissues. The first few plant regulators identified -the so-called "classical plant hormones"- are abscisic acid (ABA), auxins, gibberellins (GAs), brassinosteroids (BRs), cytokinin (CK), ethylene, jasmonic acid (JA), and salicylic acid (SA). Recently a new hormone called strigolactone has been discovered and it is possible that there still exist a few more unidentified growth regulators of this class. Collectively, these compounds regulate different aspects of plant life, from pattern formation to the response against biotic and abiotic stress. Hormones have been classically divided into two main categories according to their roles: growthrelated hormones (auxins, gibberellins, brassinosteroids, cytokinin) or stress-related hormones (ethylene, jasmonic acid, salicylic acid), but more recent studies have established the notion that many of these hormones in fact have an impact in both development and stress responses ((Jaillais and Chory, 2010), ((Bari and Jones, 2009). Although the physiological function of these compounds has been studied for decades, the last 15 years have seen a dramatic increase in our understanding of the molecular mechanisms underlying hormone homeostasis, transport and response. As explained below, GAs constitute an excellent study model to investigate how plants integrate environmental and endogenous information to modulate plant growth, and their signaling activity has become the main focus of this thesis.

\subsection{Gibberellins}

GAs form a big family of diterpenoid compounds found in plants, fungi and bacteria of which only a few regulate plant growth. The first GA was originally isolated in 1938 as a metabolite from the rice fungal pathogen Gibberella fujikuroi (Sawada) Wollenw. Infection of plants by the fungus resulted in exaggerated stem elongation, ultimately causing the plant to fall over (Yamaguchi, 2008). Further research showed 
that GAs synthesized by the fungus were the compounds responsible for the exaggerated growth and lodging. In the middle 50s, evidence was found that plants could also synthesize GAs, and their role as endogenous growth regulators began to be established (Radley, 1956; Phinney BO, 1957).

To understand the impact that GAs have on plant biology and agriculture, it is worth mentioning that the "Green Revolution" in the 1960s and 1970s, was associated with the use of new dwarf varieties of rice and other cereals, which now are wellcharacterized mutants in GA metabolism and GA signallingsignaling (Peng et al., 1999). Interestingly, these plants were not only smaller in size (with the associated benefits for agriculture, such as increased resources for grain production, higher yield per cultured surface, etc), but also displayed higher tolerance to severe weather conditions as wind or drought (Peng et al., 1999).

Molecular-genetic analysis of these varieties, and of equivalent mutants in model plants such as Arabidopsis, has shown that GAs not only regulate plant size, but also other developmental processes, such as germination and flowering, as well as the resistance to different stress factors (Table I.1).

Table 1: Biological processes regulated by GAs

\begin{tabular}{|c|c|c|}
\hline Biological process & Phenotype of GA-deficiency & Reference \\
\hline Germination & Impaired germination & $\begin{array}{l}\text { (Lee et al., 2002), (Ogawa } \\
\text { et al., 2003) }\end{array}$ \\
\hline Photomormophogenesis & $\begin{array}{l}\text { Derepressed photomorphogenesis in } \\
\text { darkness }\end{array}$ & $\begin{array}{l}\text { (Alabadí et al., 2004), } \\
\text { (Achard et al., 2007) }\end{array}$ \\
\hline Vegetative growth (roots, aerial part) & Impaired growth & $\begin{array}{l}\text { (Veen, 1980), (Peng et al., } \\
\text { 1997), (King et al., 2001), } \\
\text { (Fu and Harberd, 2003) }\end{array}$ \\
\hline Floral induction & Late flowering & $\begin{array}{l}\text { (Wilson et al., 1992), } \\
\text { (Blázquez et al., 1998) }\end{array}$ \\
\hline Flower development & Retarded growth of floral organs & (Yu et al., 2004) \\
\hline Pollen development & Male sterility & $\begin{array}{l}\text { (Wilson et al., 1992), } \\
\text { (Goto N, 1999) }\end{array}$ \\
\hline Fruit induction & Impaired fruit development & $\begin{array}{l}\text { (Garcia-Martinez et al., } \\
\text { 1997), (Singh et al., 2002) }\end{array}$ \\
\hline Abiotic stress & Increased tolerance & $\begin{array}{l}\text { (Achard et al., 2008), } \\
\text { (Achard et al., 2006) }\end{array}$ \\
\hline Biotic stress & Increased resistance & (Navarro et al., 2008) \\
\hline
\end{tabular}




\subsection{Gibberellin metabolism}

Gibberellins are synthesized from geranylgeranyl diphosphate (GGDP) through a long and complex metabolic pathway which involves several different enzymes and cell compartments (Figure I.1). The first step occurs within the plastid, where the geranyl-geranyl diphosphate (GGDP) is converted to ent-kaurene through the activity of ent-copalyl diphosphate synthase (CPS) and ent-kaurene synthase (KS) ((Sun and Kamiya, 1994; Aach H, 1997; Sun, 1997; Helliwell et al., 2001). Ent-kaurene is then converted to $\mathrm{GA}_{12}$ by ent-Kaurene oxidase $(\mathrm{KO})$, located in the membrane of the plastid, and ent-kaurenoic acid oxidase (KAO), located in the endoplasmic reticulum (Helliwell et al., 2001; Nelson et al., 2004; Appleford et al., 2006). Successive steps from $\mathrm{GA}_{12}$ to $\mathrm{GA}_{4}$-the main bioactive GA in Arabidopsis thaliana- occur in the cytoplasm through the activity of GA 20-oxidases (GA20ox) and GA 3-oxidases (GA3ox) (Spray et al., 1996; Itoh et al., 2001; Appleford et al., 2006). GA $_{12}$ is also a substrate for GA 13-oxidases (GA13ox) that will produce $\mathrm{GA}_{54}$ which is a precursor of $\mathrm{GA}_{1}$ - the main bioactive gibberellin in rice (Yamaguchi, 2008).

GAs are enzymatically inactivated by different means. The best characterized process is the 2-oxidation of the bioactive GAs, catalyzed by GA 2-oxidases (GA2ox). In fact, these enzymes can also oxidize the $\mathrm{C} 2$ of the precursors of bioactive GAs, so they also regulate substrate availability for GA3ox during GA synthesis (Thomas et al., 1999; Schomburg et al., 2003; Lee and Zeevaart, 2005). Another deactivation process found in rice is the 16 1 ,17-epoxydation of $\mathrm{GA}_{4}$ and its precursors (Zhu et al., 2006). The rice mutant eui, which lacks the corresponding gene -Eui-, accumulates huge amounts of bioactive GAs (Zhu et al., 2006). Another deactivation process more recently found in Arabidopsis involves the methylation of C6 carboxyl groups of bioactive GAs and their precursors by GA methyltransferases (GAMT). Accordingly, ectopic expression of GAMT genes in different plant species causes a GA-deficient dwarf phenotype (Varbanova et al., 2007). In addition, GAs can be converted into conjugates in plants (Schneider et al., 1992; Schliemann, 1994). Theoretically, conjugation of GAs to glucose might render inactive molecules, but there are no experimental data available to date regarding the effect of this process on the concentration of bioactive GAs. The discovery of GA-glycosyl transferases and reverse genetic studies will help to understand their role on GAs metabolism. 


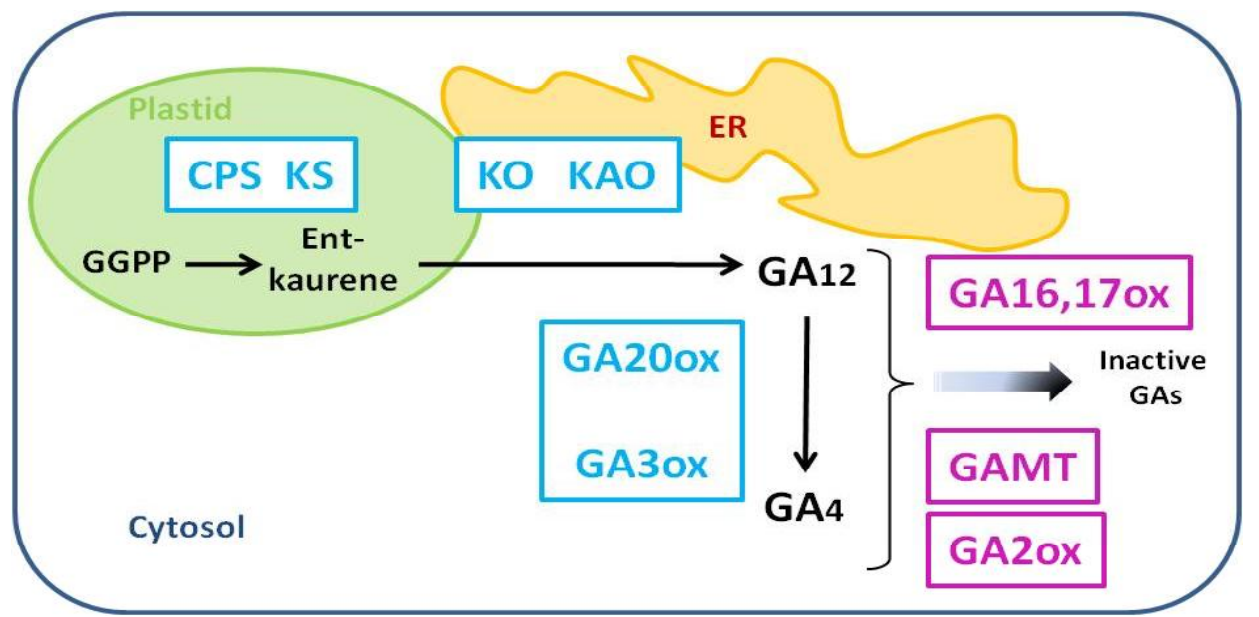

Fig I.1: Representation of predicted subcellular localization of GA metabolism enzymes and sequence or reations.

GGDP:geranylgeranyldiphosphate CPS:ent-copalyldiphosphatesynthase; KS,ent-kaurenesynthase; ER:endoplasmicreticulum, KO:ent-kaureneoxidase; KAO: ent-kaurenoicacidoxidase; GAMT:gibberellin methyltransferase; GA2ox,GA3ox,GA16,17ox,GA20ox:GAoxidases. Adapted from Yamaguchi, S. 2008

The levels of bioactive GAs level are maintained in plants through feedback and feedforward mechanisms (Hedden and Phillips, 2000; Olszewski et al., 2002). Transcript analysis shows that GA signaling targets GA20ox, GA3ox and GA2ox to establish homeostasis. For example expression levels of GA20ox and GA3ox is enhanced under GA deficiency conditions whereas expression level decreases after exogenous GA treatment (Chiang et al., 1995; Phillips et al., 1995; Yamaguchi et al., 1998; Xu et al., 1999; O'Neill and Ross, 2002). In contrast, GA2ox are upregulated after GA treatment (Thomas et al., 1999).

Apart from this mechanism where the GA pathway itself regulates bioactive GA levels, there are additional internal or external cues that can influence GA homeostasis. For instance, several hormones have been shown to affect the expression of GA metabolism genes such as GA20ox, GA3ox and GA2ox. Among them, auxins have been shown to induce the expression of GA metabolism genes in Arabidopsis (Frigerio et al., 2006) and other plants resulting in actual changes in GA concentration (Ross et al., 2000; Wolbang and Ross, 2001; Wolbang et al., 2004). Similarly, brassinosteroids have been proposed to induce the expression of AtGA20oxl (Bouquin et al., 2001). However it is not known whether this induction leads to increased levels of bioactive GA AtGA20oxl (Jager et al., 2005). On the other hand, a negative effect has been observed of ABA on these GA biosynthetic genes (Schomburg et al., 2003). In the case of ethylene both a positive and a negative effect on GA content have been observed 
depending on the developmental context (Hoffmann-Benning and Kende, 1992; Achard et al., 2007).

Likewise, environmental cues have been revealed as important modulators of the levels of bioactive GAs. Light is among the leading cues affecting developmental traits, and several reports have linked light signaling to the regulation of GA biosynthesis in seeds, through an increase in GA20ox and GA3ox expression, and repression of GA2ox (Yamaguchi et al., 1998; Oh et al., 2006; Seo et al., 2006; Yamauchi et al., 2007). Interestingly, the effect of light on GA biosynthesis is the opposite after germination, i.e. during seedling development. Illumination of etiolated seedlings causes a very rapid decrease in the expression of GA biosynthesis genes, accompanied by a comparable increase in the expression of GA2ox genes (Achard et al., 2007; Alabadí et al., 2008). Temperature is another important external cue that affects plant development in part through the modulation of bioactive GA levels. For instance, it has been shown that in dark-imbibed after-ripened Arabidopsis seeds, cold temperatures promote GA synthesis through up-regulation of GA20ox2 and GA3oxl and down-regulation of GA2ox2 (Yamauchi et al., 2004). Similarly to what happens with light, the effect of temperature in seedlings is opposite to the one in seeds: a shift to higher temperatures induces, in the hypocotyl, a fast up-regulation of GA20oxl and GA3oxl and down-regulation of GA2oxl to promote seedling growth (Stavang et al., 2009). Finally, stress is known to decelerate plant growth, and this is, in part, due to a decrease in GA content. It has been shown that Arabidopsis plants grown on higher salt concentrations have lower bioactive GA content (Achard et al., 2006), and upregulation of GA2ox7 expression has been proposed to be cause (Yamaguchi, 2008). All these observations point out that GA homeostasis is tightly regulated by different internal and external cues that will help to create a final output where optimal GA content is synthesized.

\subsection{Gibberellin signaling}

Most of the current knowledge of the molecular mechanism of GA signaling comes from the availability of mutants affected in their response to GAs. According to their phenotypes, three classes of mutants have been isolated in different plant species (Figure I.2): (1) Dominant GA-insensitive dwarves such as gai in Arabidopsis, D8 in maize, and Rht-Blb/Rht-Dlb in wheat (Koornneef, 1985; Harberd and Freeling, 1989; Peng and Harberd, 1993, 1997; Peng et al., 1999). Their dominant or semi-dominant 
behavior was taken as representative of gain-of-function alleles of GA signaling elements with a negative role. (2) Recessive GA-insensitive dwarves such as gidl and gid2 in rice or Atgidl and slyl in Arabidopsis (McGinnis et al., 2003; Sasaki et al., 2003; Ueguchi-Tanaka et al., 2005; Griffiths et al., 2006), initially thought to be loss-offunction alleles of GA signaling elements necessary for GA action. And (3) recessive slender mutants such as slrl-1 of rice or the quintuple della mutant of Arabidopsis (Ikeda et al., 2001; Feng et al., 2008) that mimick the exaggerated growth caused by continuous GA application (Potts, 1985).

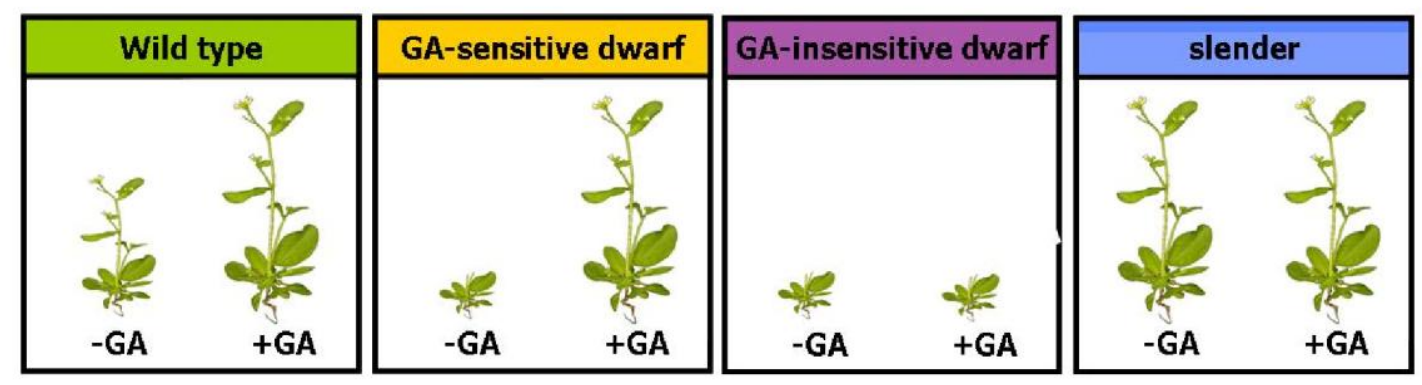

Figure I.2 Schematic representation of the three classes of GA mutants Adapted from Harberd, N et al, 2009

Studies of the above categories of mutants enabled a formal genetic definition of the mechanism by which GAs promote growth, long before the molecular basis of this mechanism was apparent. In fact the early hypothesis that GAs would act as "inhibitors of a repressor", formulated upon the study of slender pea mutants (Brian, 1957), has been later substantiated by molecular genetic approaches in Arabidopsis and rice (Harberd et al., 2009), and has resulted in a model known as the GA-GID1-DELLA mechanism of GA response regulation.

\subsection{DELLA proteins}

GA signaling is fairly simple judging from the limited number of components that integrate the pathway. The key components are the DELLA proteins, which act as the repressors whose activity needs to be counteracted by GAs. The first DELLA gene isolated was GAI from Arabidopsis (Koornneef, 1985), and it was soon realized that there were five DELLA paralogs in Arabidopsis (GAI, RGA, RGL1, RGL2 and RGL3) and closer relatives, while other plant species would have only one ortholog like SLRI in rice (Ikeda et al., 2001). All of them share three common features: (1) a DELLA 
domain within the N-terminus; (2) a GRAS region within the C-terminus; and (3) they are nuclear localized (Peng and Harberd, 1997; Ikeda et al., 2001; Silverstone et al., 2001; Lee et al., 2002; Wen and Chang, 2002).

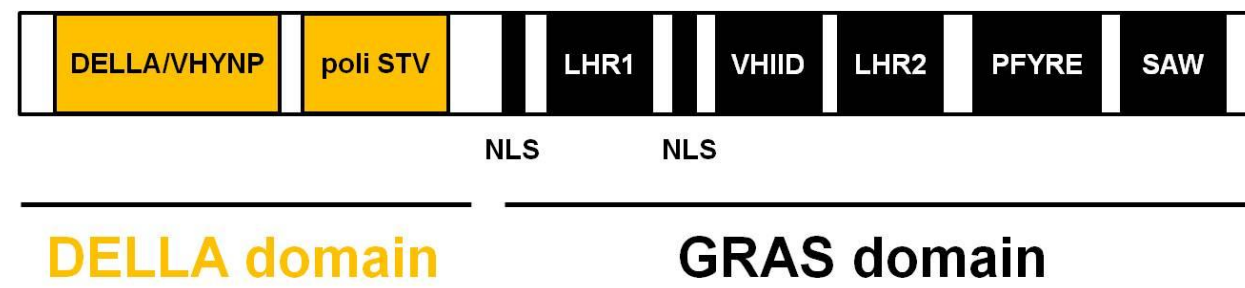

Figure I.3: Schematic representation of a DELLA protein

Studies with RGA:GFP fusions in Arabidopsis showed that DELLA proteins accumulate in the nuclei of cells with low GA concentration, but they suffer rapid destabilization in the presence of GAs (Silverstone et al., 2001). Moreover, GA-induced degradation is absolutely dependent on the DELLA motif, so that DELLA mutant alleles lacking this motif (such as gai-1 and $\mathrm{rga}-\Delta 17$ ) are stable even in the presence of GAs (Peng et al., 1997; Dill et al., 2001).

Contrary to rice, where a knockout mutant in the single DELLA gene displays a phenotype that resembles constitutive GA activity (Ikeda et al., 2001), redundancy of DELLA genes in Arabidopsis requires the combination of multiple knockouts to obtain a slender phenotype. Moreover, detailed analysis of single and multiple DELLA mutants in this species has revealed both distinct and overlapping functions for individual DELLAs in the regulation of plant development.

For instance, the growth defect caused by GA deficiency (such as in the gal-3 mutant) can be partially overcome by a knockout mutation in RGA but not GAI alone, although concurrent elimination of the two DELLA genes causes almost complete recovery of the wild-type size (Dill and Sun, 2001; King et al., 2001). This indicates that both RGA and GAI participate in the control of plant size, with RGA having a more prominent role. Interestingly, a different situation is found when analyzing flower development. The gal-3 mutant presents defective flowers with very short immature stamens and almost absent petals, which cannot be restored by simultaneous loss of RGA and GAI function. Full recovery of flower development can only be attained when $R G A, R G L 1$ and $R G L 2$ are inactivated, irrespective of the presence of GAI (Cheng et al., 2004). Regarding germination, RGL2 has been proposed as the main DELLA protein that needs to be inactivated during GA-induced breaking of dormancy (Lee et 
al., 2002). This idea was based on the observation that a single knockout of $R G L 2$, but not of any other DELLA gene, was able to rescue the germination defect of the gal-3 mutant. However, the other DELLA genes have also been found to regulate germination under different contexts. For instance, RGA and GAI also participate in far-red light mediated repression of germination through the stimulation of $\mathrm{ABA}$ biosynthesis (Piskurewicz et al., 2008).

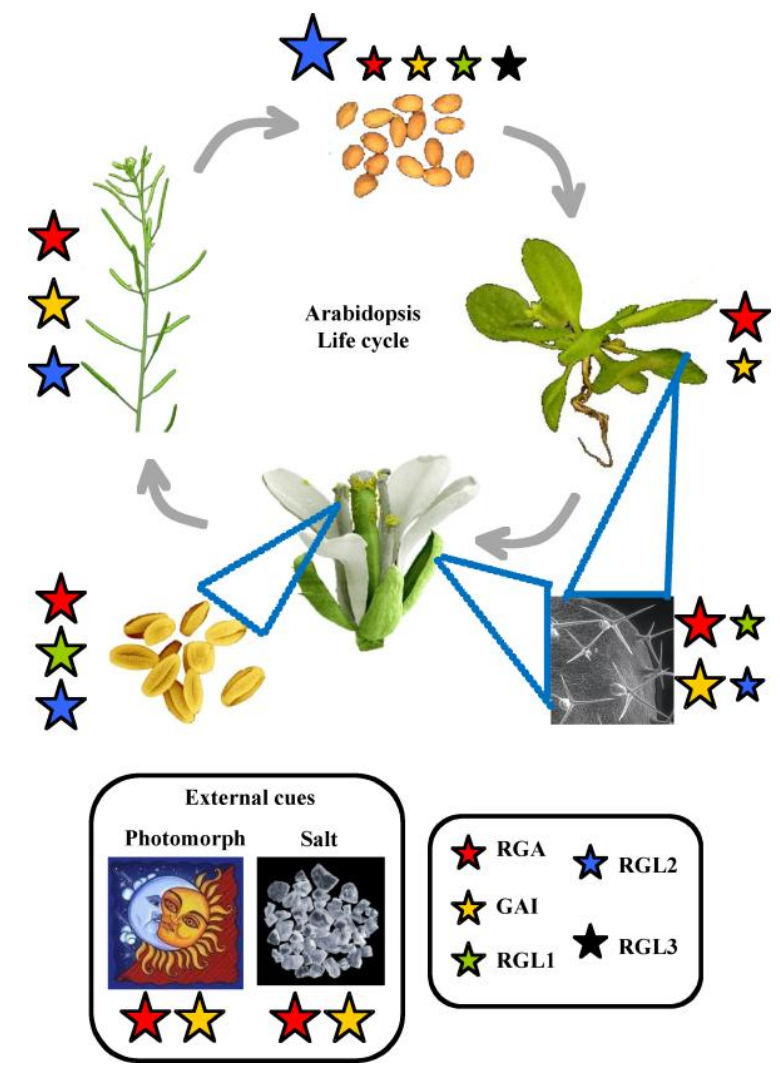

Figure I.4 Arabidopsis DELLA proteins subfuncionalization.

Each DELLA is represented with a differen color and the contribution of each one to a determinate process is related to the size of typography; the bigger the more important.

These results raise the question of what evolutionary mechanisms have prompted the subfunctionalization of DELLA genes in those plant species (such as the Brassicaceae) where recent duplications have occurred.

\subsection{Gibberellin-induced DELLA degradation}

According to the "inhibitor of an inhibitor" model, DELLA proteins restrain plant growth and other GA responses, while GAs exert their activity by releasing DELLA repression. As previously stated, this is achieved through the degradation of 
DELLA proteins, and the GA receptor is an essential component of the degradation machinery.

The soluble GA receptor is encoded by a single gene in rice (GA-INSENSITIVE DWARF1, GID1) (Ueguchi-Tanaka et al., 2005), and three paralogs in Arabidopsis (GIDla-c) with almost overlapping functions (Griffiths et al., 2006; Nakajima et al., 2006; Iuchi et al., 2007). The GID1 protein possesses a central pocket that accommodates bioactive GAs. Upon binding, GA causes an allosteric change in GID1 that results in the N-terminus forming a lid to the pocket (Murase et al., 2008; Shimada et al., 2008). Once in place, the outer surface of the lid interacts with the DELLA protein, specifically with the N-terminal region defined by the DELLA and VHYNP domains (Murase et al., 2008) (Fig I.3). The formation of the GA-GID1-DELLA complex is thought to induce a conformational change in the GRAS domain of the DELLA protein, which then interacts with GID1 and stabilizes the complex (Fig I.5). The stabilized complex is then recognized by a specific SCF E3 ubiquitin-ligase complex involving the F-box proteins AtSLY1 and AtSNE in Arabidopsis or OsGID2 in rice, respectively (McGinnis et al., 2003; Sasaki et al., 2003; Griffiths et al., 2006; Willige et al., 2007; Hirano et al., 2010; Ariizumi et al., 2011). In turn, SCF ${ }^{\text {SLY1/GID2 }}$ promotes the polyubiquitinylation and subsequent destruction of DELLAs by the 26S proteasome (Fig I. 6a) (McGinnis et al., 2003; Sasaki et al., 2003; Dill et al., 2004; Fu et al., 2004). Hence, OsGID1 single knockout mutants or AtGID1 triple knockout mutants display a severe GA deficiency phenotype which cannot be reverted by GA application, suggesting that these are very likely the only GA receptors in plants, at least relevant for growth regulation. Interestingly, one of the Arabidopsis GID proteins -AtGIDIb-is able to interact with DELLA proteins in the absence of GAs because its aminoacid sequence forms a partially closed lid independent of the presence of GAs and hence it is able to interact and promote the DELLA proteolytic degradation (Yamamoto et al., 2010). Soybean (Glycine max) and Brassica napus also have GID1s similar to AtGID1b, indicating that these unique GID1s occur in various dicots and may have important functions in these plants (Yamamoto et al., 2010). 
A

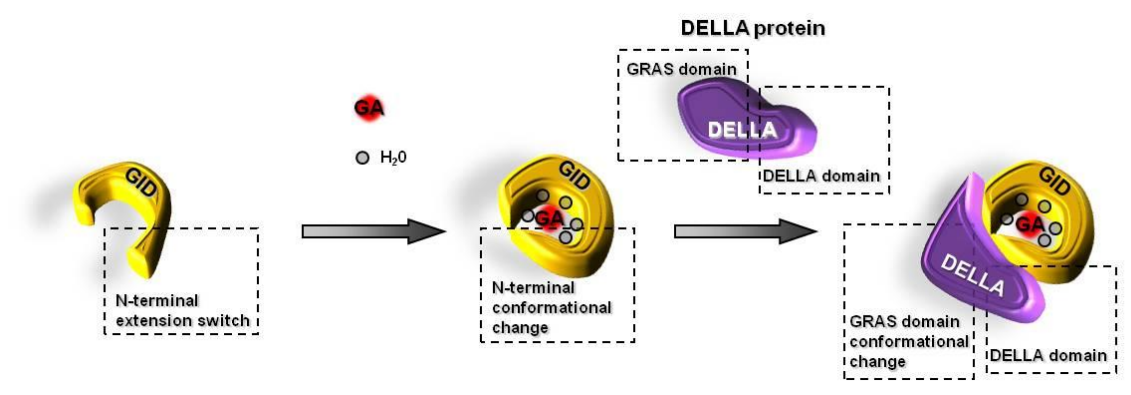

B

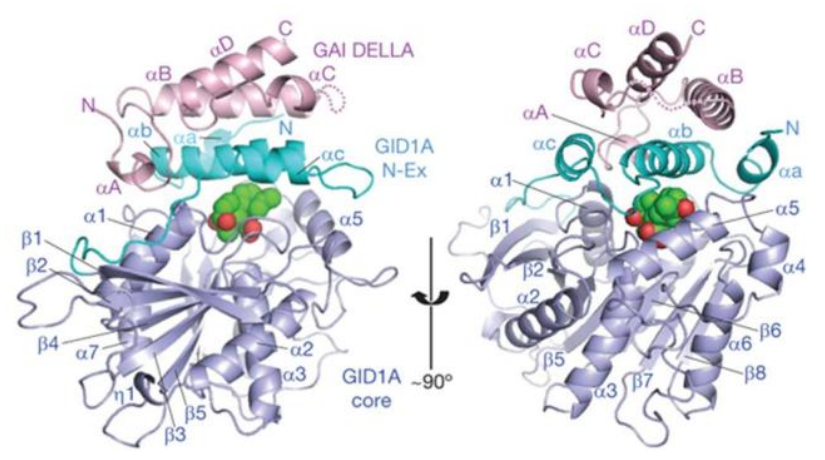

Figure I.5 GA-GID-DELLA complex

a) Schematic representation of the GA-GID-DELLA complex formation.

b) 3D model of the GA-GID-DELLA complex from two points of view.

Adapted from Murase, K. et al. 2008

\subsection{Transcriptional regulation by DELLA proteins}

There are many indications that GAs regulate growth and most of the other processes through changes in gene expression. Indeed, one of the earliest molecular events associated with GA signaling was the regulation of alpha-amylase gene expression in barley aleurone cells (Varner JE, 1965 ). More recently, transcriptomic analysis provided a fairly comprehensive view of the different changes and patterns of gene expression in response to GAs in different contexts, such as germination, vegetative growth and flower development (Ogawa et al., 2003; Cao et al., 2006; Nemhauser et al., 2006; Zentella et al., 2007; Hou et al., 2008). Two interesting conclusions can be drawn from these analyses. Firstly, GAs regulate distinct sets of genes in the different tissues examined and in the different developmental stages (Cao et al., 2006). And secondly, all the changes in gene expression in response to GAs are mediated by DELLA proteins (Cao et al., 2006). Of course, given that all these 
approaches provide a snapshot of gene expression in a specific moment of a plant's life, they do not distinguish between direct targets for GAs/DELLAs and secondary effects.

It seemed reasonable that DELLA proteins act as transcription factors, based on two additional observations: their C-terminus is similar to that of other GRAS proteins like SHORTROOT (SHR) and SCARECROW (SCR), which have been shown to regulate transcription (Levesque et al., 2006; Cui et al., 2007); and DELLA proteins accumulate in the nucleus (Silverstone et al., 1998; Ogawa et al., 2000). Although there is no evidence for direct interaction between DELLA proteins and DNA in vitro, chromatin immunoprecipitation (ChIP) experiments with a stable version of RGA have shown an association between DELLA proteins and the promoters of a few genes whose expression is regulated by GAs (Zentella et al., 2007). Therefore, the most likely possibility is that DELLA proteins interact with other DNA-binding transcription factors to modify their activity, and the identification of such partners of DELLA proteins would be pivotal to understand and manipulate GA signaling.

An important clue about the identity of such transcription factors was found in the study of the repression of photomorphogenesis that GAs exert in etiolated seedlings (Alabadí et al., 2004). The systematic analysis of multiple light signaling mutants under GA-deficient conditions revealed that only two types of transcription factors were required for the regulation of photomorphogenesis by DELLA proteins (Alabadí et al., 2008): the bZIP protein HY5 (ELONGATED HYPOCOTYL5), and two members of the PIF (PHYTOCHROME-INTERACTING FACTOR) family of bHLH transcription factors, PIF3 and PIF4. HY5 and PIFs have opposite roles in light signal transduction: while HY5 promotes photomorphogenesis (Ang and Deng, 1994; Lee et al., 2007), PIF proteins are required for etiolated growth and the repression of light-induced gene expression (Ni et al., 1998; Leivar et al., 2008; Leivar et al., 2009). The observation that hy5 mutants were more resistant to the accumulation of DELLA proteins, and pif mutants were hypersensitive in the same conditions was a strong indication that DELLAs might act through some of these transcription factors.

Indeed, PIF proteins have been found to interact physically with the LHR1 domain of DELLA proteins (Fig I.3) and through the bHLH domain, and this interaction prevents binding of the transcription factors to their target promoters and their subsequent activation (de Lucas et al., 2008; Feng et al., 2008). This important finding not only identifies PIFs as a transcription factors through which GAs regulate gene expression (Fig I.6), but it also provides a molecular framework for the interaction 
between GA and other signaling pathways, given that the availability of PIF proteins is strictly regulated by light and the circadian clock.

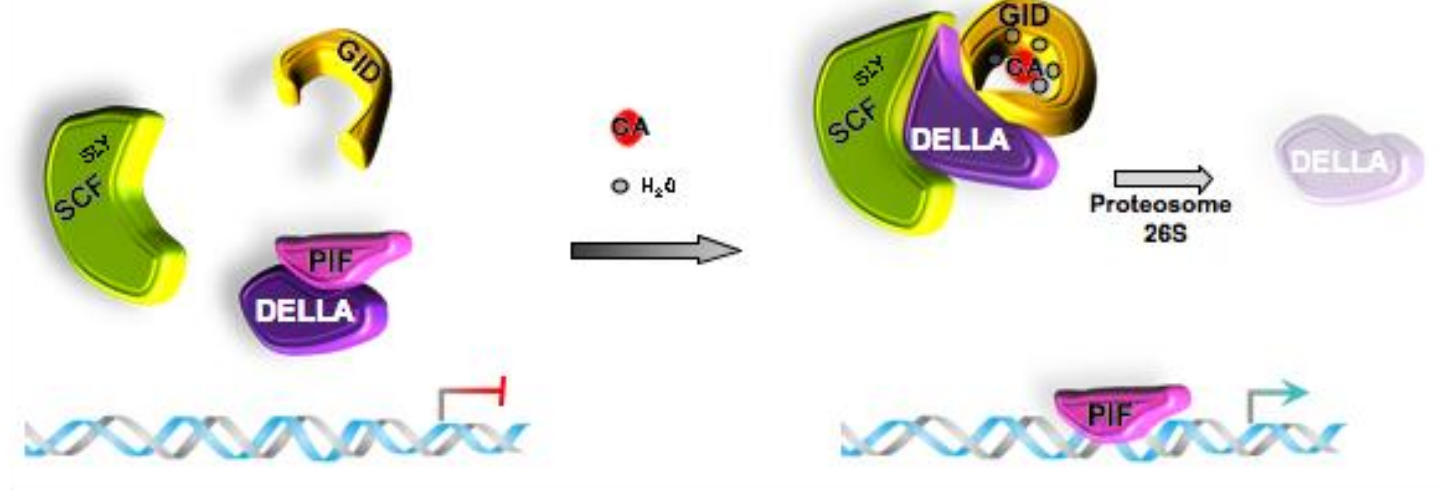

Figure 6: Transcriptional regulation by DELLA proteins.

Schematic representation of how GAs regulate transcription of target genes.

The physical interaction of DELLA proteins with other members of the bHLH family has been recently proved. DELLA can interact and sequester SPATULA (SPT) to control cotyledon expansion (Josse et al., 2011). Similarly, DELLAs can interact with ALCATRAZ (ALC) and avoid its function to control fruit patterning (Arnaud et al., 2010). Thus, inactivation of bHLH proteins through interaction with DELLA proteins seems to be a general mechanism of action of GA signaling pathway.

It is thought that DELLA proteins act as dimmers in planta through the interaction with their LHR1 domain (Fig I.3) (Itoh et al., 2002). As mentioned before, DELLA proteins belong to the GRAS family where many transcription factors are found. It was recently shown that DELLA can interact with one member of this family, SCARECROW-LIKE3 -SCL3- to control several aspects of plant development such as germination, hypocotyls length and root growth (Heo et al., 2011; Zhang et al., 2011).

But DELLA proteins seem to be able to interact with other protein different than transcription factors. This is the case for the interaction of DELLA with the JASMONATE ZIM-domain (JAZ) proteins, which are negative regulators of the jasmonate signaling pathway (Hou et al., 2010). In the absence of jasmonate, JAZ proteins accumulate in the nucleus sequestering the jasmonate-response transcription factor MYC2 (Chini et al., 2007). Interaction of DELLA proteins through the Nterminal region (DELLA domains and LHR1 (Fig I..3)) with JAZ proteins release MYC2 protein that can trigger the jasmonate response (Hou et al., 2010). 
Thus, different strategies seem to have evolved for the DELLA control of gene expression. Remarkably, the LHR1 domain seems to be most important regarding interaction with transcription regulation proteins. Hence, it will be important to identify additional interactors of DELLA proteins - possibly, but not only, transcription factors-, and also establish the list of direct target genes for DELLA proteins in specific tissues/processes.

\subsection{Bibliography}

Aach H BH, Robinson DG, Graebe JE (1997) ent -Kaurene synthase is located in proplastids of meristematic shoot tissues Planta 202: 211-219

Achard P, Baghour M, Chapple A, Hedden P, Van Der Straeten D, Genschik P, Moritz T, Harberd NP (2007) The plant stress hormone ethylene controls floral transition via DELLA-dependent regulation of floral meristem-identity genes. Proc Natl Acad Sci U S A 104: 6484-6489

Achard P, Cheng H, De Grauwe L, Decat J, Schoutteten H, Moritz T, Van Der Straeten D, Peng J, Harberd NP (2006) Integration of plant responses to environmentally activated phytohormonal signals. Science 311: 91-94

Achard P, Liao L, Jiang C, Desnos T, Bartlett J, Fu X, Harberd NP (2007) DELLAs Contribute to Plant Photomorphogenesis. Plant Physiol 143: 1163-1172

Achard P, Renou JP, Berthome R, Harberd NP, Genschik P (2008) Plant DELLAs restrain growth and promote survival of adversity by reducing the levels of reactive oxygen species. Curr Biol 18: 656-660

Alabadí D, Gallego-Bartolomé J, García-Cárcel L, Orlando L, Rubio V, Martínez C, Frigerio M, Iglesias-Pedraz JM, Espinosa A, Deng XW, Blázquez MA (2008) Gibberellins modulate light signaling pathways to prevent Arabidopsis seedling deetiolation in darkness. Plant J 53: 324-335

Alabadí D, Gil J, Blázquez MA, García-Martínez JL (2004) Gibberellins repress photomorphogenesis in darkness. Plant Physiol 134: 1050-1057

Ang LH, Deng XW (1994) Regulatory hierarchy of photomorphogenic loci: allele-specific and light-dependent interaction between the HY5 and COP1 loci. Plant Cell 6: 613-628

Appleford NE, Evans DJ, Lenton JR, Gaskin P, Croker SJ, Devos KM, Phillips AL, Hedden P (2006) Function and transcript analysis of gibberellin-biosynthetic enzymes in wheat. Planta 223: 568-582

Ariizumi T, Lawrence PK, Steber CM (2011) The role of two f-box proteins, SLEEPY1 and SNEEZY, in arabidopsis gibberellin signaling. Plant Physiol 155: 765-775

Arnaud N, Girin T, Sorefan K, Fuentes S, Wood TA, Lawrenson T, Sablowski R, Ostergaard L (2010) Gibberellins control fruit patterning in Arabidopsis thaliana. Genes Dev 24: 2127-2132

Bari R, Jones JD (2009) Role of plant hormones in plant defence responses. Plant Mol Biol 69: 473-488

Blázquez MA, Green R, Nilsson O, Sussman MR, Weigel D (1998) Gibberellins promote flowering of arabidopsis by activating the LEAFY promoter. Plant Cell 10: 791-800

Bouquin T, Meier C, Foster R, Nielsen ME, Mundy J (2001) Control of specific gene expression by gibberellin and brassinosteroid. Plant Physiol 127: 450-458

Brian PW (1957) The effects of some microbial metabolic products on

plant growth. Symp. Soc. Exp. Biol. 11: 166-182 
Cao D, Cheng H, Wu W, Soo HM, Peng J (2006) Gibberellin mobilizes distinct DELLAdependent transcriptomes to regulate seed germination and floral development in Arabidopsis. Plant Physiol 142: 509-525

Cheng H, Qin L, Lee S, Fu X, Richards DE, Cao D, Luo D, Harberd NP, Peng J (2004) Gibberellin regulates Arabidopsis floral development via suppression of DELLA protein function. Development 131: 1055-1064

Chiang HH, Hwang I, Goodman HM (1995) Isolation of the Arabidopsis GA4 locus. Plant Cell 7: 195-201

Chini A, Fonseca S, Fernandez G, Adie B, Chico JM, Lorenzo O, Garcia-Casado G, Lopez-Vidriero I, Lozano FM, Ponce MR, Micol JL, Solano R (2007) The JAZ family of repressors is the missing link in jasmonate signalling. Nature 448: 666-671

Cui H, Levesque MP, Vernoux T, Jung JW, Paquette AJ, Gallagher KL, Wang JY, Blilou I, Scheres B, Benfey PN (2007) An evolutionarily conserved mechanism delimiting SHR movement defines a single layer of endodermis in plants. Science 316: 421-425

de Lucas M, Davière JM, Rodríguez-Falcón M, Pontin M, Iglesias-Pedraz JM, Lorrain S, Fankhauser C, Blázquez MA, Titarenko E, Prat S (2008) A molecular framework for light and gibberellin control of cell elongation. Nature 451: 480-484

Dill A, Jung HS, Sun TP (2001) The DELLA motif is essential for gibberellin-induced degradation of RGA. Proc Natl Acad Sci U S A 98: 14162-14167

Dill A, Sun T (2001) Synergistic derepression of gibberellin signaling by removing RGA and GAI function in Arabidopsis thaliana. Genetics 159: 777-785

Dill A, Thomas SG, Hu J, Steber CM, Sun TP (2004) The Arabidopsis F-box protein SLEEPY1 targets gibberellin signaling repressors for gibberellin-induced degradation. Plant Cell 16: 1392-1405

Feng S, Martinez C, Gusmaroli G, Wang Y, Zhou J, Wang F, Chen L, Yu L, IglesiasPedraz JM, Kircher S, Schafer E, Fu X, Fan LM, Deng XW (2008) Coordinated regulation of Arabidopsis thaliana development by light and gibberellins. Nature 451: 475-479

Frigerio M, Alabadí D, Pérez-Gómez J, García-Cárcel L, Phillips AL, Hedden P, Blázquez MA (2006) Transcriptional regulation of gibberellin metabolism genes by auxin signaling in Arabidopsis. Plant Physiol 142: 553-563

Fu X, Harberd NP (2003) Auxin promotes Arabidopsis root growth by modulating gibberellin response. Nature 421: 740-743

Fu X, Richards DE, Fleck B, Xie D, Burton N, Harberd NP (2004) The Arabidopsis mutant sleepy1gar2-1 protein promotes plant growth by increasing the affinity of the SCFSLY1 E3 ubiquitin ligase for DELLA protein substrates. Plant Cell 16: 1406-1418

Garcia-Martinez JL, Lopez-Diaz I, Sanchez-Beltran MJ, Phillips AL, Ward DA, Gaskin P, Hedden P (1997) Isolation and transcript analysis of gibberellin 20-oxidase genes in pea and bean in relation to fruit development. Plant Mol Biol 33: 1073-1084

Goto N PR (1999) Role of gibberellin in the development of floral organs of the gibberellindeficient mutant, ga1-1, of Arabidopsis thaliana. Can J Bot 77: 944-954

Griffiths J, Murase K, Rieu I, Zentella R, Zhang ZL, Powers SJ, Gong F, Phillips AL, Hedden P, Sun TP, Thomas SG (2006) Genetic characterization and functional analysis of the GID1 gibberellin receptors in Arabidopsis. Plant Cell 18: $3399-3414$

Harberd NP, Belfield E, Yasumura Y (2009) The angiosperm gibberellin-GID1-DELLA growth regulatory mechanism: how an "inhibitor of an inhibitor" enables flexible response to fluctuating environments. Plant Cell 21: 1328-1339

Harberd NP, Freeling M (1989) Genetics of dominant gibberellin-insensitive dwarfism in maize. Genetics 121: 827-838

Hedden P, Phillips AL (2000) Gibberellin metabolism: new insights revealed by the genes. Trends Plant Sci 5: 523-530

Helliwell CA, Sullivan JA, Mould RM, Gray JC, Peacock WJ, Dennis ES (2001) A plastid envelope location of Arabidopsis ent-kaurene oxidase links the plastid and endoplasmic reticulum steps of the gibberellin biosynthesis pathway. Plant J 28: 201-208 
Heo JO, Chang KS, Kim IA, Lee MH, Lee SA, Song SK, Lee MM, Lim J (2011) Funneling of gibberellin signaling by the GRAS transcription regulator scarecrow-like 3 in the Arabidopsis root. Proc Natl Acad Sci U S A 108: 2166-2171

Hirano K, Asano K, Tsuji H, Kawamura M, Mori H, Kitano H, Ueguchi-Tanaka M, Matsuoka M (2010) Characterization of the Molecular Mechanism Underlying Gibberellin Perception Complex Formation in Rice. Plant Cell

Hoffmann-Benning S, Kende H (1992) On the role of abscisic Acid and gibberellin in the regulation of growth in rice. Plant Physiol 99: 1156-1161

Hou X, Hu WW, Shen L, Lee LY, Tao Z, Han JH, Yu H (2008) Global Identification of DELLA Target Genes during Arabidopsis Flower Development. Plant Physiol

Hou X, Lee LY, Xia K, Yan Y, Yu H (2010) DELLAs modulate jasmonate signaling via competitive binding to JAZs. Dev Cell 19: 884-894

Ikeda A, Ueguchi-Tanaka M, Sonoda Y, Kitano H, Koshioka M, Futsuhara Y, Matsuoka M, Yamaguchi J (2001) slender rice, a constitutive gibberellin response mutant, is caused by a null mutation of the SLR1 gene, an ortholog of the height-regulating gene GAI/RGA/RHT/D8. Plant Cell 13: 999-1010

Itoh H, Ueguchi-Tanaka M, Sato Y, Ashikari M, Matsuoka M (2002) The gibberellin signaling pathway is regulated by the appearance and disappearance of SLENDER RICE1 in nuclei. Plant Cell 14: 57-70

Itoh H, Ueguchi-Tanaka M, Sentoku N, Kitano H, Matsuoka M, Kobayashi M (2001) Cloning and functional analysis of two gibberellin 3 beta -hydroxylase genes that are differently expressed during the growth of rice. Proc Natl Acad Sci U S A 98: 89098914

Iuchi S, Suzuki H, Kim YC, Iuchi A, Kuromori T, Ueguchi-Tanaka M, Asami T, Yamaguchi I, Matsuoka M, Kobayashi M, Nakajima M (2007) Multiple loss-offunction of Arabidopsis gibberellin receptor AtGID1s completely shuts down a gibberellin signal. Plant J 50: 958-966

Jager CE, Symons GM, Ross JJ, Smith JJ, Reid JB (2005) The brassinosteroid growth response in pea is not mediated by changes in gibberellin content. Planta 221: 141-148

Jaillais Y, Chory J (2010) Unraveling the paradoxes of plant hormone signaling integration. Nat Struct Mol Biol 17: 642-645

Josse EM, Gan Y, Bou-Torrent J, Stewart KL, Gilday AD, Jeffree CE, Vaistij FE, Martinez-Garcia JF, Nagy F, Graham IA, Halliday KJ (2011) A DELLA in Disguise: SPATULA Restrains the Growth of the Developing Arabidopsis Seedling. Plant Cell

King KE, Moritz T, Harberd NP (2001) Gibberellins are not required for normal stem growth in Arabidopsis thaliana in the absence of GAI and RGA. Genetics 159: 767-776

Koornneef M, Elgersma, A., Hanhart, C.J., van Loenen-Martinet, E.P., van Rign, L., and Zeevaart, J.A.D. (1985) A gibberellin insensitive mutant of Arabidopsis thaliana. Physiol. Plant 65: 33-39

Lee DJ, Zeevaart JA (2005) Molecular cloning of GA 2-oxidase3 from spinach and its ectopic expression in Nicotiana sylvestris. Plant Physiol 138: 243-254

Lee J, He K, Stolc V, Lee H, Figueroa P, Gao Y, Tongprasit W, Zhao H, Lee I, Deng XW (2007) Analysis of transcription factor HY5 genomic binding sites revealed its hierarchical role in light regulation of development. Plant Cell 19: 731-749

Lee S, Cheng H, King KE, Wang W, He Y, Hussain A, Lo J, Harberd NP, Peng J (2002) Gibberellin regulates Arabidopsis seed germination via RGL2, a GAI/RGA-like gene whose expression is up-regulated following imbibition. Genes Dev 16: 646-658

Leivar P, Monte E, Oka Y, Liu T, Carle C, Castillon A, Huq E, Quail PH (2008) Multiple phytochrome-interacting bHLH transcription factors repress premature seedling photomorphogenesis in darkness. Curr Biol 18: 1815-1823

Leivar P, Tepperman JM, Monte E, Calderon RH, Liu TL, Quail PH (2009) Definition of Early Transcriptional Circuitry Involved in Light-Induced Reversal of PIF-Imposed Repression of Photomorphogenesis in Young Arabidopsis Seedlings. Plant Cell 21: 3535-3553 
Levesque MP, Vernoux T, Busch W, Cui H, Wang JY, Blilou I, Hassan H, Nakajima K, Matsumoto N, Lohmann JU, Scheres B, Benfey PN (2006) Whole-genome analysis of the SHORT-ROOT developmental pathway in Arabidopsis. PLoS Biol 4: e143

McGinnis KM, Thomas SG, Soule JD, Strader LC, Zale JM, Sun TP, Steber CM (2003) The Arabidopsis SLEEPY1 gene encodes a putative F-box subunit of an SCF E3 ubiquitin ligase. Plant Cell 15: 1120-1130

Murase K, Hirano Y, Sun TP, Hakoshima T (2008) Gibberellin-induced DELLA recognition by the gibberellin receptor GID1. Nature 456: 459-463

Nakajima M, Shimada A, Takashi Y, Kim YC, Park SH, Ueguchi-Tanaka M, Suzuki H, Katoh E, Iuchi S, Kobayashi M, Maeda T, Matsuoka M, Yamaguchi I (2006) Identification and characterization of Arabidopsis gibberellin receptors. Plant J 46: 880889

Navarro L, Bari R, Achard P, Lison P, Nemri A, Harberd NP, Jones JD (2008) DELLAs control plant immune responses by modulating the balance of jasmonic acid and salicylic acid signaling. Curr Biol 18: 650-655

Nelson DR, Schuler MA, Paquette SM, Werck-Reichhart D, Bak S (2004) Comparative genomics of rice and Arabidopsis. Analysis of 727 cytochrome P450 genes and pseudogenes from a monocot and a dicot. Plant Physiol 135: 756-772

Nemhauser JL, Hong F, Chory J (2006) Different plant hormones regulate similar processes through largely nonoverlapping transcriptional responses. Cell 126: 467-475

Ni M, Tepperman JM, Quail PH (1998) PIF3, a phytochrome-interacting factor necessary for normal photoinduced signal transduction, is a novel basic helix-loop-helix protein. Cell 95: 657-667

O'Neill DP, Ross JJ (2002) Auxin regulation of the gibberellin pathway in pea. Plant Physiol 130: $1974-1982$

Ogawa M, Hanada A, Yamauchi Y, Kuwahara A, Kamiya Y, Yamaguchi S (2003) Gibberellin biosynthesis and response during Arabidopsis seed germination. Plant Cell 15: $1591-1604$

Ogawa M, Kusano T, Katsumi M, Sano H (2000) Rice gibberellin-insensitive gene homolog, OsGAI, encodes a nuclear-localized protein capable of gene activation at transcriptional level. Gene 245: 21-29

Oh E, Yamaguchi S, Kamiya Y, Bae G, Chung WI, Choi G (2006) Light activates the degradation of PIL5 protein to promote seed germination through gibberellin in Arabidopsis. Plant J 47: 124-139

Olszewski N, Sun TP, Gubler F (2002) Gibberellin signaling: biosynthesis, catabolism, and response pathways. Plant Cell 14 Suppl: S61-80

Peng J, Carol P, Richards DE, King KE, Cowling RJ, Murphy GP, Harberd NP (1997) The Arabidopsis GAI gene defines a signaling pathway that negatively regulates gibberellin responses. Genes Dev 11: 3194-3205

Peng J, Harberd NP (1993) Derivative Alleles of the Arabidopsis Gibberellin-Insensitive (gai) Mutation Confer a Wild-Type Phenotype. Plant Cell 5: 351-360

Peng J, Harberd NP (1997) Gibberellin deficiency and response mutations suppress the stem elongation phenotype of phytochrome-deficient mutants of Arabidopsis. Plant Physiol 113: $1051-1058$

Peng J, Richards DE, Hartley NM, Murphy GP, Devos KM, Flintham JE, Beales J, Fish LJ, Worland AJ, Pelica F, Sudhakar D, Christou P, Snape JW, Gale MD, Harberd NP (1999) 'Green revolution' genes encode mutant gibberellin response modulators. Nature 400: 256-261

Phillips AL, Ward DA, Uknes S, Appleford NE, Lange T, Huttly AK, Gaskin P, Graebe JE, Hedden P (1995) Isolation and expression of three gibberellin 20-oxidase cDNA clones from Arabidopsis. Plant Physiol 108: 1049-1057

Phinney BO WC, Ritzel MB, Neely PM. (1957) Evidence for gibberellin-like substances from flowering plants. Proc. Nat. Acad. Sci. (U.S.A.) 43: 398-404

Piskurewicz U, Jikumaru Y, Kinoshita N, Nambara E, Kamiya Y, Lopez-Molina L (2008) The Gibberellic Acid Signaling Repressor RGL2 Inhibits Arabidopsis Seed 
Germination by Stimulating Abscisic Acid Synthesis and ABI5 Activity. Plant Cell 20: 2729-2745

Potts WC, Reid, J.B., andMurfet, I.C. (1985) Internode length in Pisum. Gibberellins and the slender phenotype. Physiol. Plant 63: 357-364

Radley M (1956) Occurrence of substances similar to gibberellic acid in higher plants. Nature 178: $1070-1071$

Ross JJ, O'Neill DP, Smith JJ, Kerckhoffs LH, Elliott RC (2000) Evidence that auxin promotes gibberellin A1 biosynthesis in pea. Plant J 21: 547-552

Sasaki A, Itoh H, Gomi K, Ueguchi-Tanaka M, Ishiyama K, Kobayashi M, Jeong DH, An G, Kitano H, Ashikari M, Matsuoka M (2003) Accumulation of phosphorylated repressor for gibberellin signaling in an F-box mutant. Science 299: 1896-1898

Schliemann GSaW (1994) Gibberellin conjugates: an overview Plant Growth Reg 15: 247-260

Schneider G, Jensen E, Spray CR, Phinney BO (1992) Hydrolysis and reconjugation of gibberellin A20 glucosyl ester by seedlings of Zea mays L. Proc Natl Acad Sci U S A 89: $8045-8048$

Schomburg FM, Bizzell CM, Lee DJ, Zeevaart JA, Amasino RM (2003) Overexpression of a novel class of gibberellin 2-oxidases decreases gibberellin levels and creates dwarf plants. Plant Cell 15: 151-163

Seo M, Hanada A, Kuwahara A, Endo A, Okamoto M, Yamauchi Y, North H, MarionPoll A, Sun TP, Koshiba T, Kamiya Y, Yamaguchi S, Nambara E (2006) Regulation of hormone metabolism in Arabidopsis seeds: phytochrome regulation of abscisic acid metabolism and abscisic acid regulation of gibberellin metabolism. Plant $\mathbf{J}$ 48: $354-366$

Shimada A, Ueguchi-Tanaka M, Nakatsu T, Nakajima M, Naoe Y, Ohmiya H, Kato H, Matsuoka M (2008) Structural basis for gibberellin recognition by its receptor GID1. Nature 456: $520-523$

Silverstone AL, Ciampaglio CN, Sun T (1998) The Arabidopsis RGA gene encodes a transcriptional regulator repressing the gibberellin signal transduction pathway. Plant Cell 10: $155-169$

Silverstone AL, Jung HS, Dill A, Kawaide H, Kamiya Y, Sun TP (2001) Repressing a repressor: gibberellin-induced rapid reduction of the RGA protein in Arabidopsis. Plant Cell 13: 1555-1566

Singh DP, Jermakow AM, Swain SM (2002) Gibberellins are required for seed development and pollen tube growth in Arabidopsis. Plant Cell 14: 3133-3147

Spray CR, Kobayashi M, Suzuki Y, Phinney BO, Gaskin P, MacMillan J (1996) The dwarf-1 (dt) Mutant of Zea mays blocks three steps in the gibberellin-biosynthetic pathway. Proc Natl Acad Sci U S A 93: 10515-10518

Stavang JA, Gallego-Bartolome J, Gomez MD, Yoshida S, Asami T, Olsen JE, GarciaMartinez JL, Alabadi D, Blazquez MA (2009) Hormonal regulation of temperatureinduced growth in Arabidopsis. Plant J 60: 589-601

Sun T-pK, Yuji (1997) Regulation and cellular localization of ent-kaurene synthesis Physiologia Plantarum 101: 701-708

Sun TP, Kamiya Y (1994) The Arabidopsis GA1 locus encodes the cyclase ent-kaurene synthetase A of gibberellin biosynthesis. Plant Cell 6: 1509-1518

Thomas SG, Phillips AL, Hedden P (1999) Molecular cloning and functional expression of gibberellin 2- oxidases, multifunctional enzymes involved in gibberellin deactivation. Proc Natl Acad Sci U S A 96: 4698-4703

Ueguchi-Tanaka M, Ashikari M, Nakajima M, Itoh H, Katoh E, Kobayashi M, Chow TY, Hsing YI, Kitano H, Yamaguchi I, Matsuoka M (2005) GIBBERELLIN INSENSITIVE DWARF1 encodes a soluble receptor for gibberellin. Nature 437: 693698

Varbanova M, Yamaguchi S, Yang Y, McKelvey K, Hanada A, Borochov R, Yu F, Jikumaru Y, Ross J, Cortes D, Ma CJ, Noel JP, Mander L, Shulaev V, Kamiya Y, Rodermel S, Weiss D, Pichersky E (2007) Methylation of gibberellins by Arabidopsis GAMT1 and GAMT2. Plant Cell 19: 32-45 
Varner JE CG, Chrispeels MJ. (1965 ) Gibberellic acid-controlled synthesis of alpha-amylase in barley endosperm. J Cell Physiol. 66: 55-67

Veen MKaJH (1980) Induction and analysis of gibberellin sensitive mutants in Arabidopsis thaliana (L.) heynh. . Theoretical and Applied Genetics 58: 257-263

Wen CK, Chang C (2002) Arabidopsis RGL1 encodes a negative regulator of gibberellin responses. Plant Cell 14: 87-100

Willige BC, Ghosh S, Nill C, Zourelidou M, Dohmann EM, Maier A, Schwechheimer C (2007) The DELLA Domain of GA INSENSITIVE Mediates the Interaction with the GA INSENSITIVE DWARF1A Gibberellin Receptor of Arabidopsis. Plant Cell

Wilson RN, Heckman JW, Somerville CR (1992) Gibberellin Is Required for Flowering in Arabidopsis thaliana under Short Days. Plant Physiol 100: 403-408

Wolbang CM, Chandler PM, Smith JJ, Ross JJ (2004) Auxin from the developing inflorescence is required for the biosynthesis of active gibberellins in barley stems. Plant Physiol 134: 769-776

Wolbang CM, Ross JJ (2001) Auxin promotes gibberellin biosynthesis in decapitated tobacco plants. Planta 214: 153-157

Xu YL, Li L, Gage DA, Zeevaart JA (1999) Feedback regulation of GA5 expression and metabolic engineering of gibberellin levels in Arabidopsis. Plant Cell 11: 927-936

Yamaguchi S (2008) Gibberellin metabolism and its regulation. Annu Rev Plant Biol 59: 225251

Yamaguchi S, Smith MW, Brown RG, Kamiya Y, Sun T (1998) Phytochrome regulation and differential expression of gibberellin 3beta-hydroxylase genes in germinating Arabidopsis seeds. Plant Cell 10: 2115-2126

Yamamoto Y, Hirai T, Yamamoto E, Kawamura M, Sato T, Kitano H, Matsuoka M, Ueguchi-Tanaka M (2010) A rice gid1 suppressor mutant reveals that gibberellin is not always required for interaction between its receptor, GID1, and DELLA proteins. Plant Cell 22: 3589-3602

Yamauchi Y, Ogawa M, Kuwahara A, Hanada A, Kamiya Y, Yamaguchi S (2004) Activation of gibberellin biosynthesis and response pathways by low temperature during imbibition of Arabidopsis thaliana seeds. Plant Cell 16: 367-378

Yamauchi Y, Takeda-Kamiya N, Hanada A, Ogawa M, Kuwahara A, Seo M, Kamiya Y, Yamaguchi S (2007) Contribution of gibberellin deactivation by AtGA2ox2 to the suppression of germination of dark-imbibed Arabidopsis thaliana seeds. Plant Cell Physiol 48: 555-561

Yu H, Ito T, Zhao Y, Peng J, Kumar P, Meyerowitz EM (2004) Floral homeotic genes are targets of gibberellin signaling in flower development. Proc Natl Acad Sci U S A 101: 7827-7832

Zentella R, Zhang ZL, Park M, Thomas SG, Endo A, Murase K, Fleet CM, Jikumaru Y, Nambara E, Kamiya Y, Sun TP (2007) Global analysis of della direct targets in early gibberellin signaling in Arabidopsis. Plant Cell 19: 3037-3057

Zhang ZL, Ogawa M, Fleet CM, Zentella R, Hu J, Heo JO, Lim J, Kamiya Y, Yamaguchi S, Sun TP (2011) Scarecrow-like 3 promotes gibberellin signaling by antagonizing master growth repressor DELLA in Arabidopsis. Proc Natl Acad Sci U S A 108: 21602165

Zhu Y, Nomura T, Xu Y, Zhang Y, Peng Y, Mao B, Hanada A, Zhou H, Wang R, Li P, Zhu X, Mander LN, Kamiya Y, Yamaguchi S, He Z (2006) ELONGATED UPPERMOST INTERNODE encodes a cytochrome P450 monooxygenase that epoxidizes gibberellins in a novel deactivation reaction in rice. Plant Cell 18: 442-456 


\section{Objectives}



Current knowledge about hormone signaling seems to establish a clear trend for future work, whose leitmotiv could be the establishment of the molecular models that explain: (1) crosstalk between signaling pathways; and (2) the fact that a single signal triggers different specific responses depending on the spatial and developmental context. Given the characteristics of GA action described in the previous sections, we have chosen GA signaling as a model to address the molecular mechanism for both the specificity of GA activity, and also the crosstalk between GA and other input signals.

For the first question, redundancy of DELLA genes in Arabidopsis offers an excellent playground to address the relative importance of promoter $v s$. coding region divergence in the subfunctionalization of duplicated genes, and its impact in GA signaling. For the second question, our strategy has been to focus in a particular process, known to be concurrently regulated by multiple signals, and dissect the participation of GAs at the molecular level. As noted above, cell expansion is a simple process that involves several players acting in a single spatial domain. Besides GAs, it is known to be regulated by light and by other hormones, including auxin, BRs, and ethylene. But an even more interesting situation is that of differential growth, by which the cells in one side of the organ expand more, compared to the cells in the opposite side. This results in the formation of a curvature, found in tropic responses (phototropism, gravitropism...) and in the apical hook of etiolated seedlings. Therefore, our purpose was to identify direct targets of DELLA proteins in differential growth and to investigate the participation of GAs in this context.

Consequently, the objectives of this work were:

1. To assess the ability of different DELLA proteins to perform each other's role. This would be addressed by expressing two DELLA genes under the control of the reciprocal promoters, and analyzing the ability of the chimeras to complement della mutant phenotypes (Chapter 1).

2. To identify direct target genes regulated by DELLA proteins in etiolated seedlings, focusing in those known to be related to the execution of differential growth. This would be approached through transcriptomic analysis of an inducible version of gai-1 and subsequent molecular studies (Chapters 2, 3 and 4). 

Chapter 1

\section{Transcriptional diversification and}

functional conservation between

\section{DELLA proteins in Arabidopsis}





\subsection{Abstract}

Plasticity and robustness of signaling pathways partly rely on genetic redundancy, although the precise mechanism that provides functional specificity to the different redundant elements in a given process is often unknown. In Arabidopsis, functional redundancy in gibberellin signaling has been largely attributed to the presence of five members of the DELLA family of transcriptional regulators. Here we demonstrate that two evolutionarily and functionally divergent DELLA proteins, RGL2 and RGA, can perform exchangeable functions when they are expressed under control of the reciprocal promoter. Furthermore, both DELLA proteins display equivalent abilities to interact with PIF4 and with other bHLH transcription factors with a reported role in the control of cell growth and seed germination. Therefore, we propose that functional diversification of Arabidopsis DELLA proteins has largely relied on changes in their gene expression patterns rather than in their ability to interact with different regulatory partners, model also supported by a clustering analysis of DELLA transcript profiles over a range of organs and growth conditions which revealed specific patterns of expression for each of these genes. 


\subsection{Introduction}

Gene duplications are considered as the major source for variation and the generation of evolutionary novelties (Ohno, 1970). Although the most common fate for duplicated genes is gene loss (Lynch and Conery, 2000), duplicated copies are released from mutational constraints, enabling the evolution of new functions (neofunctionalization) (Ohno, 1970; Taylor and Raes, 2004). Alternatively, both gene duplicates can undergo simultaneous reduction of their activity thereby maintaining the total capacity of the ancestral gene (sub-functionalization) (Force et al., 1999).

In addition to providing genetic robustness against deleterious mutations through functional redundancy, gene duplications seem also to be at the core of the mechanisms that provide an unusually high degree of plasticity and robustness to plant signaling pathways (Smith, 1990; Pickett and Meeks-Wagner, 1995; Casal et al., 2004). For instance, it has been proposed that the multiplicity of responses triggered by auxin is governed by the optimized interaction of more than 20 Aux/IAA-ARF pairs in each cell type (Weijers and Jurgens, 2004; Weijers et al., 2005). However, this phenomenon is less understood in other hormonal pathways, in which signaling is transduced by a set of structurally and phylogenetically related proteins that represent branching points in the action of a single given hormone. Such is the case for protein phosphatases type-2C in abscisic acid signaling (Rodriguez, 1998), the ARR response regulators in cytokinin signaling (To et al., 2004), and the JAZ family of proteins involved in jasmonic acid signaling (Chini et al., 2007) among others.

Much work has been devoted to understand the molecular mechanisms that allow the maintenance of gene duplicates in model organisms. Nonetheless, of particular relevance is establishing the extent of the relative contribution to the functional divergence of paralogous genes of variation in the regulatory sequences versus to those in the coding region. The accumulation of polymorphisms in the coding regions of amylase (Goto et al., 2005) and fatty-acid desaturase genes (Fang et al., 2009) in Drosophila, and B-defensins in mice and humans (Maxwell et al., 2003), underscore the importance of rapid variation in the coding sequence of recently duplicated genes to generate functional divergence. However, large-scale analyses of expression divergence among duplicated genes in yeast, plants and humans, provide a less clear-cut view. In particular, it has been shown that half of the recently duplicated genes in Arabidopsis (Blanc and Wolfe, 2004) or rice (Li et al., 2009) have divergent 
expression patterns, although no correlation is found between expression divergence and time since duplication (Haberer et al., 2004). Actually, it is likely that functional divergence between duplicated genes occurs through both mechanisms, as suggested by the analysis of paralogs of human transcription factors: if the DNA binding site motifs of the transcription factor paralogs are similar, their expression has diverged, while two paralogs that are highly expressed in a tissue tend to have dissimilar DNA binding site motifs (Singh and Hannenhalli, 2008).

Despite all suggestive evidence based on correlations obtained through genomic analyses of duplicated genes, direct experimental evidence for the relative importance of promoter vs coding sequence divergence is scarce. A significant exception is the demonstration that diversification of cis elements in the promoters have been essential to solve "adaptive conflicts" in the ancestor of the duplicated genes (Hittinger and Carroll, 2007). For this reason we chose to analyze the degree of conservation of the actual molecular activities of members belonging to a small family of Arabidopsis transcriptional regulators.

In Arabidopsis, functional redundancy in GA signaling has been largely attributed to the presence of five members of the DELLA family of nuclear-localized transcriptional regulators: GAI, RGA, RGL1, RGL2 and RGL3. These proteins accumulate under low GA concentrations and act as repressors of GA-activated processes, while a local increase in hormone concentration triggers proteasomedependent degradation of the DELLA proteins, by the concurrent action of the GA receptor GID1 and the E3 ubiquitin ligase $\mathrm{SCF}^{\mathrm{SLY} 1}$ complex (Dill et al., 2004; Griffiths et al., 2006; Nakajima et al., 2006). Molecular genetic analyses have shown that each member of the DELLA family performs specific but also overlapping roles in plant development. For example, GAI and RGA are the main regulators of cell expansion in vegetative tissues, since simultaneous loss of GAI and RGA function suppresses the dwarf phenotype of GA-deficient plants to a large extent (Dill and Sun, 2001; King et al., 2001). However, male fertility is primarily regulated by RGA (but not GAI), together with RGL1 and RGL2 (Cheng et al., 2004; Tyler et al., 2004). On the other hand, RGL2 has been proposed to be the main regulator of germination, since knock-out mutations in $R G L 2$, but not the other DELLA genes, allow germination of seeds also when GA synthesis is impaired (Lee et al., 2002; Tyler et al., 2004).

Sequence comparisons show a high degree of conservation between the five DELLA proteins, but also enough differences are observed in their $\mathrm{N}$-terminal third that 
might justify their different activities (Hussain et al., 2005). On the other hand, it cannot be ruled out that functional specificity of the DELLA genes relies on their different expression profiles, as evidenced by RT-qPCR expression analyses of different organs (Tyler et al., 2004). To distinguish between these two possibilities, we have examined the ability of RGL2 and RGA to perform exchangeable functions, by expressing RGL2 under the control of the $R G A$ promoter and vice versa.

\subsection{Materials and Methods}

Plant lines and growth conditions

Arabidopsis thaliana mutant plants (gal-3, gal-3 gai-t6, gal-3 gai-t6 rga-24, and $r g l 2-1$ ) were all in the Ler ecotype. For germination tests, Ler and rgl2-1 seeds were surface-sterilized and sown on sterile Whatman filter papers placed in plates of half-strength MS medium (Duchefa) with $0.8 \% \mathrm{w} / \mathrm{v}$ agar and $1 \% \mathrm{w} / \mathrm{v}$ sucrose, and stratified at $4^{\circ} \mathrm{C}$ for 7 days in darkness. gal, gal gai-t6 and gal gai-t6 rga-24 seeds were sterilized and imbibed at $4^{\circ} \mathrm{C}$ for 7 days in water containing $20 \mu \mathrm{M} \mathrm{GA}_{3}$. Before transfer to MS plates, they were extensively rinsed with sterile water to remove any remaining $\mathrm{GA}_{3}$.

Germination took place under continuous white fluorescent light (90-100 $\mu \mathrm{mol}$ $\mathrm{m}^{-2} \mathrm{sec}^{-1}$ ) at $23^{\circ} \mathrm{C}$ in a Percival growth chamber E-30B. Soil-grown plants were kept at $23^{\circ} \mathrm{C}$ in cabinets with $16-\mathrm{h}$ photoperiod.

Construction of vectors and generation of transgenic lines

For promoter-swapping experiments, 2-kb promoter regions of $R G A$ and $R G L 2$, which included the $5^{\prime}$ untranslated region, were PCR amplified from genomic DNA of wild-type Ler plants using the pairs of oligonucleotide primers:

pRGA-F-XbaI (TCTAGATATAACCTCATCCATCTATAG) and pRGA-RXbaI (TCTAGATTACAAGATCTGATGGAG) for pRGA; and pRGL2-F-XbaI (TCTAG ATCAGGATGCGAGGTTAAGAATGG) and pRGL2-R-HindIII (AAGCTTTTACTT TACTTCATGGGT) for $\mathrm{p} R G L 2$.

The PCR products were subcloned into pCR2.1 (Invitrogen) and transferred into the MCS of the Gateway ${ }^{\mathrm{TM}}$ binary vector pSBright (Bensmihen et al., 2004) by XbaI digestion in case of pRGA to generate pSBright-pRGA and XbaI/HindIII for pRGL2 to 
generate pSBright-pRGL2. The $R G A$ and $R G L 2$ cDNAs were obtained from the REGIA consortium as pDONR201 (Invitrogen) clones. Both cDNAs were subcloned into pSBright-pRGA or -pRGL2 using LR clonase (Invitrogen).

The constructs were introduced into the Agrobacterium tumefaciens strain C58 by electroporation, and these were then used to transform the Arabidopsis gal gai-t6 rga-24 and rgl2-1 mutants by the floral dip method (Clough and Bent, 1998). Transgenic seedlings in the $T_{1}$ and $T_{2}$ generations were selected based on their resistance to glufosinate. Transgenic lines with a 3:1 (resistant:sensitive) segregation ratio were selected and at least 19 homozygous lines were identified in the $\mathrm{T}_{3}$ generation for each construct. Data from two representative lines per construct are shown in this work.

Phylogenetic analysis

Iterative search by tblastn was done on the NCBI public database (http://www.ncbi.nlm.nih.gov) with the Arabidopsis thaliana DELLA amino acid sequences as baits, and representative full-length sequences were selected. Speciesspecific databases were also consulted to determine the number of DELLA genes present in each genome. Alignments of protein sequences were done with CLUSTALX (Thompson et al., 1997) and only the informative part of the alignments were used for subsequent analyses. A phylogenetic tree was obtained with the PhyML software v2.4.4 (Guindon and Gascuel, 2003) using the JTT amino acid substitution model as indicated upon comparison of the different models with Prottest (Abascal et al., 2005). The consensus tree was supported by Bootstrap analysis $(n=1000)$. Visualization and manipulation of trees were made with TreeView (Page, 1996).

\section{Real-time quantitative RT-PCR}

Total RNA from imbibed seeds was extracted using a modified RNAeasy Mini kit (Qiagen) protocol, where the grinded tissue was previously incubated with $600 \mu 1$ of RLT-PVP buffer (540RLT buffer from RNAeasy Mini Kit $+60 \mu 1$ PVP40 10\% $+6 \mu 1$ B-mercaptoethanol) followed by a $30 \mathrm{~s}$ centrifugation, recovery of the supernatant, and application to the lilac column. For adult plant tissues, total RNA extraction was carried out as described previously (Frigerio et al., 2006). cDNA synthesis and quantitative PCR, as well as primer sequences for amplification of GA metabolism and EF1- $\alpha$ genes, have been described previously (Frigerio et al., 2006). 
The primers used for the quantitative PCR analysis of mRNA levels of GFP, $R G A, \quad R G L 2, \quad G A I, \quad A T H B 16$ and AtMYB34 were, respectively: GFPqRT-F (TCATATGAAGCGGCACGACTT) and GFPqRT-R (GATGGTCCTCTCCTGCAC GTA); RGAqRT-F (ACTTCGACGGGTACGCAGAT) and RGAqRT-R (TGTCGT CACCGTCGTTCC); RGL2qRT-F (GACGGCGCGTAGAGTTCAC) and RGL2qRT-R (TGCATCCCTTGATTAAGCCC); GAIqRT-F (GCTTATGCAGGCTCTTGCG) and GAIqRT-R (AACCGGAAAACAGGAGGACC;) ATHB-16qRT-F (GCGCCGTTCTT AACGACGAAACAA) and ATHB-16qRT-R (TAAGAAACTCCCGCCAGTAACCGT); MYB34qRT-F (TTAACCGCGTCGCAAGCAAATACG) and MYB34qRT-R (TTGAGC AATGTGGAGGTCGGAGAA).

Protein extraction and western blot

Total proteins were extracted by homogenizing seedlings in one volume of cold extraction buffer [50 mM Tris- $\mathrm{HCl}$ pH 7.5, $150 \mathrm{mM} \mathrm{NaCl}, 1 \mathrm{mM}$ EDTA, 1 mM DTT, 10\% glycerol, $1 \mathrm{mM}$ PMSF, and 1xcomplete protease inhibitor cocktail (Roche)]. Extracts were centrifuged at $13000 \mathrm{~g}$ for $10 \mathrm{~min}$ at $4^{\circ} \mathrm{C}$. Protein concentration in the supernatants was quantified by the Bradford assay (Bradford, 1976). Aliquots (40 $\mu \mathrm{g}$ ) of denatured total proteins were separated in Precise ${ }^{\mathrm{TM}}$ 8\% Tris-HEPES-SDS gels (Pierce) and transferred onto PVDF membrane (Bio-Rad). RGA-GFP fusion was detected using the monoclonal anti-GFP antibody (clone JL-8) from Clontech.

Yeast two hybrid assay

For two-hybrid experiments, truncated forms of RGA and RGL2, lacking the DELLA domain, were PCR amplified from a first strand cDNA of Ler seedlings using the following combinations of oligonucleotide primers:

RGA1-F (CACCCTGGTTGACTCGCAAGAGAACG) and RGA1-R (GTCAAAC

TCAGTACGCCGCCG) for RGA; and RGL2-F (CACCCTCGTTGACTCTCAGGAG ACCG) and RGL2-R (GCCGCGACTCAGGCGAGTTTCC) for RGL2.

For PCR amplification of the complete coding regions for the PIF4, PIL2, PIL5 and SPT bHLH factors, the combinations of primers used were:

PIF4-F (CACCATGGAACACCAAGGTTGGAG) and PIF4-R (GGCTCACCAACCT

AGTGGTCC) for PIF4; PIL2-F (CACCATGATGTTCTTACCAACCG) and PIL2-R 
(CAGGGAGAATTCCTTCATCTG) for PIL2; PIL5-F (CACCATGCATCATTTTGTC CCTG) and PIL5-R (GTTAACCTGTTGTGTGGTTTC) for PIL5; and SPT-F (CACCATGATATCACAGAGAGAAGAAAG) and SPT-R (GGACACTGTTCAAGT AATTCG) for SPT.

The PCR products were subcloned into the $\mathrm{pENTR}^{\mathrm{TM}} / \mathrm{D}$ vector using the $\mathrm{pENTR}^{\mathrm{TM}} / \mathrm{D}-\mathrm{TOPO}^{\circledR}$ cloning kit (Invitrogen) and mobilized by LR clonase (Invitrogen) into the pGBKT7 and pGADT7 Gateway vectors (kindly provided by Marta Boter) generated by inserting the Gateway $c c d \mathrm{~B}$ cassette into the MCS NdeI $-X h o \mathrm{I} / S a l \mathrm{I}$ sites of these vectors.

Constructs were transformed into the AH109 yeast strain (MATa ura3-52 his3200 trp1-901 leu2-3,112 gal4A gal804 LYS2::GAL1 UAS GAL1 $1_{\mathrm{TATA}^{-}}$HIS3 GAL2 UAS- $^{-}$ GAL2 $2_{\mathrm{TATA}}-A D E 2$ URA3::MEL1 $1_{\mathrm{UAS}}-M E L 1_{\mathrm{TATA}}-l a c Z$ ), using the lithium acetate/PEG method, and yeast cells containing the different DELLA-BD and bHLH-AD fusion combinations were selected on SD-Leu-Trp and SD-Leu-Trp-His-Ade plates. Each construct was also transformed with the pGBKT7 or pGADT7 empty vectors to test for auto-activation activity. Protein extracts were obtained from the transformed yeast cells and western probed with anti-HA (Roche) and anti-GAL4BD (Santa Cruz) antibodies to ensure proper expression of the protein fusions.

\section{Confocal Microscopy}

Seedlings were rinsed for 2 min with $10 \mu \mathrm{g} / \mathrm{ml}$ propidium iodide (PI), then $5 \mathrm{~min}$ with water. Fresh stained seedlings were mounted on slides only with water. Images were taken using a Leica TCS SL confocal laser microscope (Leica, http://www.leica.com) with excitation at $488 \mathrm{~nm}$. For GFP detection, channel 1 was configured between $500-540 \mathrm{~nm}$; and for PI detection, channel 2 was configured between $590-660 \mathrm{~nm}$.

\subsection{Results and discussion}

\subsubsection{Phylogenetic relationships of DELLA proteins in Angiosperms}

Examination of public gene sequence databases and the available full genome sequences of several plant species indicates that, unlike in monocots, genes encoding DELLA proteins in dicots are frequently duplicated. In some cases, such as the 
Brassicaceae, the genomes contain up to five DELLA genes. To investigate the origin and the possible evolutionary history of these duplications, we assembled full-length sequences of DELLA proteins from different dicots and monocots, and analyzed their phylogenetic relationships. As shown in Figure 1.1A, two large clades (I and II) of DELLA proteins can be found in dicots. However, while species in the Rosids genera such as Populus, Pisum, Medicago and the Brassicaceae possess members in both subfamilies, species in the Asterids like Solanum lycopersicum and Latuca sativa posses either only one DELLA protein or two paralogs, respectively, that always group in clade I. In these cases, the absence of DELLA proteins associated with clade II could be a consequence of the lack of sequence information for these species, although a loss-offunction mutant identified in S. lycopersicum in the single reported DELLA gene displays a phenotype that covers all the functions attributed to GAs in this organism (Marti et al., 2007; Bassel et al., 2008; Jasinski et al., 2008). Hence, it is likely that it indeed represents the only functional DELLA gene in tomato.

The presence of two clades of DELLA proteins suggests that the diversification of this family was initiated by a duplication of a single ancestor within the Rosids. After this event, subsequent independent duplications would have given rise to the variety of DELLA proteins present in different species. In fact, the observation of syntenic regions in the Arabidopsis genome that include the five DELLA genes (Figure 1.1B) reveals a possible mechanism for the multiplication of these genes in the Brassicaceae, involving the rearrangement of large chromosomal fragments.

\subsubsection{Expression of chimeric versions of DELLA genes}

According to genetic analysis, repeated duplication of DELLA proteins in Arabidopsis has been accompanied by certain degree of functional diversification, given that mutants in the different DELLA genes are affected only in a subset of responses regulated by GAs.

To determine if this diversification has been caused by changes in the patterns of expression of these paralogs, or in the molecular activity of the different DELLA proteins, we decided to construct chimeric versions of two representative DELLA genes, one from each clade, under the control of their own and the reciprocal promoters (Figure 1.2A). 
A

B
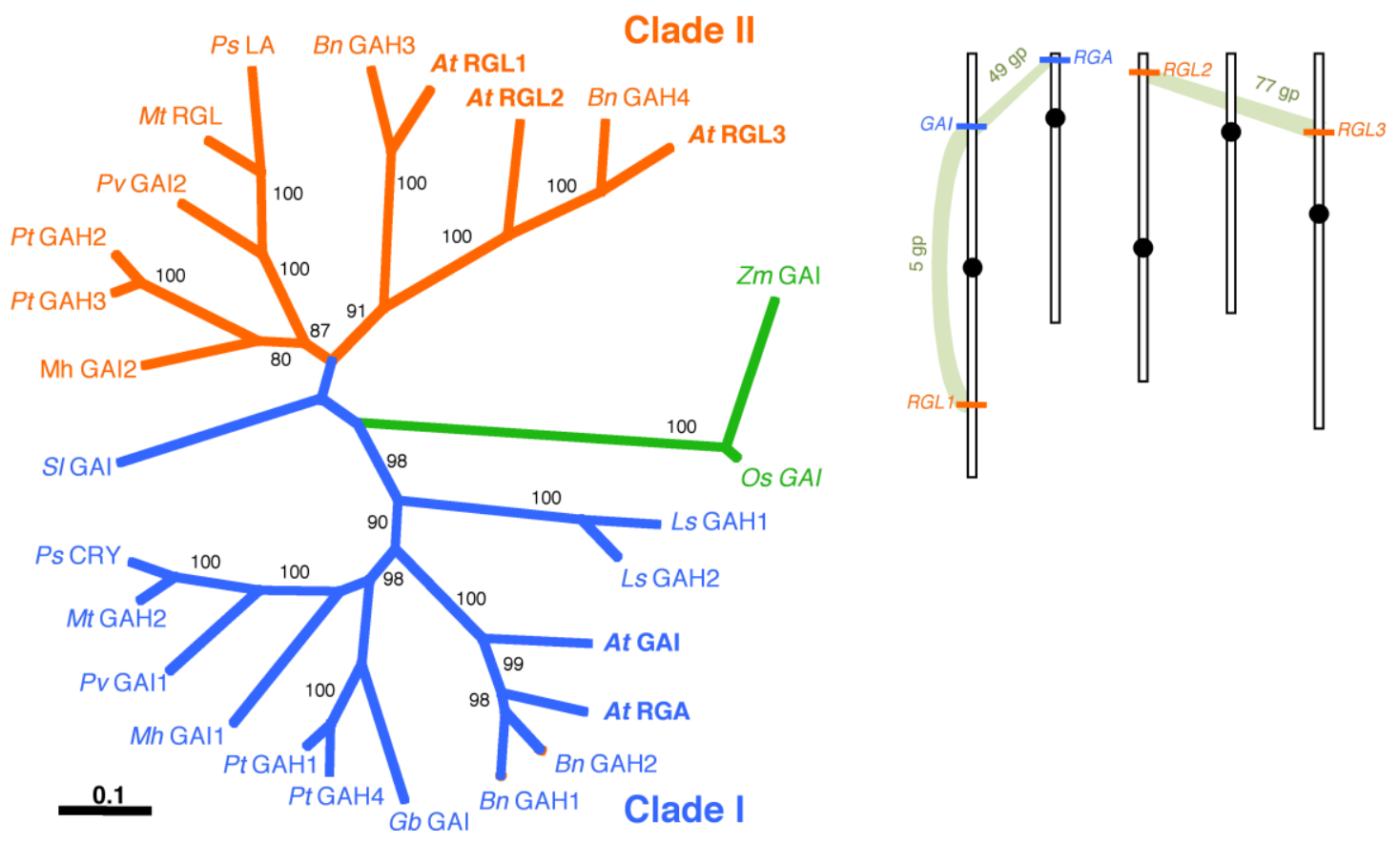

Figure 1.1 Repeated duplication of DELLA genes in dicots.

(A) Phylogenetic maximum likelihood tree of DELLA proteins displaying two large clades (blue and orange). See Material and Methods for details on sequence analysis. Arabidosis proteins are in bold. Numbers represent percentage bootstrap value $(\mathrm{n}=1000)$. Monocot sequences are depicted in green. $(B)$ Syntenic regions in Arabidopsis chromosomes that include DELLA genes. At, Arabidopsis thaliana; Bn, Brassica napus; Gb, Gossypium barbadense; Ls, Lactuca sativa; Mh, Malus hupehensis; Mt, Medicago truncatula; Os, Oryza sativa; Ps, Pisum sativum; Pt, Populus trichocarpa; Pv, Phaseolus vulgaris; Sl, Solanum lycopersicum; Zm, Zea mays. GAH stands for GAI Homolog. $g p$ is the number of gene pairs syntenically conserved between the indicated regions.

$R G A$ and $R G L 2$ were chosen because single loss-of-function mutants in each of these genes render a visible phenotype under certain conditions, a prerequisite to score the functionality of each chimera. For instance, seeds of the rgl2-1 mutant are able to germinate in the presence of paclobutrazol (PAC) (Lee et al., 2002); and mutation of $R G A$ in a gal-3 gai-t6 background rescues the dwarf phenotype caused by the lack of GA synthesis in this background (Dill and Sun, 2001).

Therefore, a 2-kb fragment of the RGL2 promoter was used to drive the expression of the $R G L 2$ (R2R2) or $R G A$ (R2RA) coding sequences fused to $G F P$ as a visualization marker, and the constructs were introduced into the rgl2-1 mutant. Nineteen and twenty-one independent transformants were isolated respectively. Given that RGL2 is expressed predominantly in seeds (Lee et al., 2002; Tyler et al., 2004), the expression of the corresponding transgenes was measured by RT-qPCR in the seeds of 
the transformants and, based on their expression level, two homozygous lines from each class were selected for further analyses: one representative of the lower-expressing lines, and one for the higher-expressing lines (Figure 1.2B). None of the transgenes displayed significant expression in tissues in which $R G L 2$ is not expressed (data not shown). Similarly, a 2-kb fragment of the $R G A$ promoter was fused to the $R G A$ (RARA) or RGL2 (RAR2) coding sequences and GFP, and the resulting constructs were introduced into the triple knockout line gal-3 gai-t6 rga-24. Twenty-two and twentyfive independent transformants were isolated. The functionality of the constructs was tested through the detection of the GFP-DELLA proteins in extracts of 7-day-old seedlings and, as expected, their stability was severely reduced after incubation of the seedlings with $50 \mu \mathrm{M} \mathrm{GA}_{3}$ for $3 \mathrm{~h}$ (Fig. 1.2C). Furthermore, the transgenic DELLA fusion proteins displayed nuclear localization (Fig. 1.2D), and two homozygous lines of each class were selected for further analyses.

A

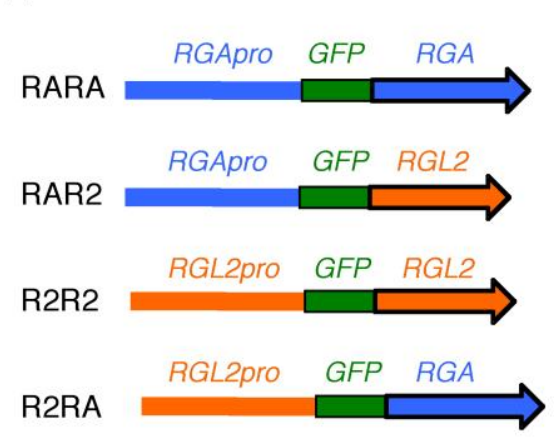

B

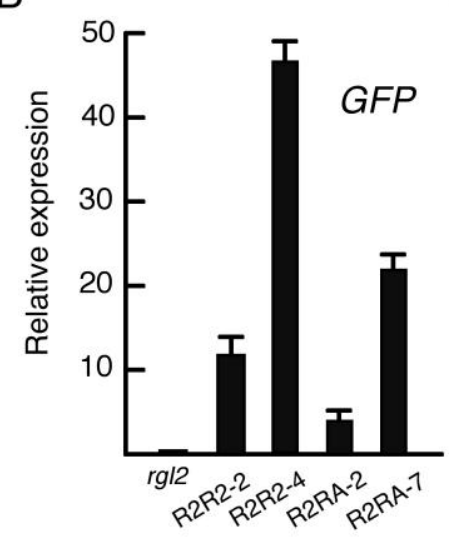

C

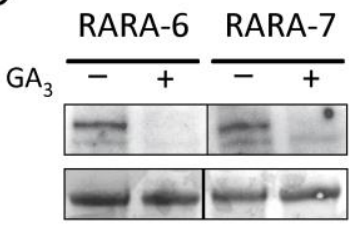

$\mathrm{GA}_{3} \frac{\text { RAR2-7 }}{-+} \frac{\text { RAR2-19 }}{-+}$

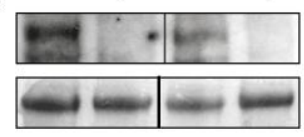

D
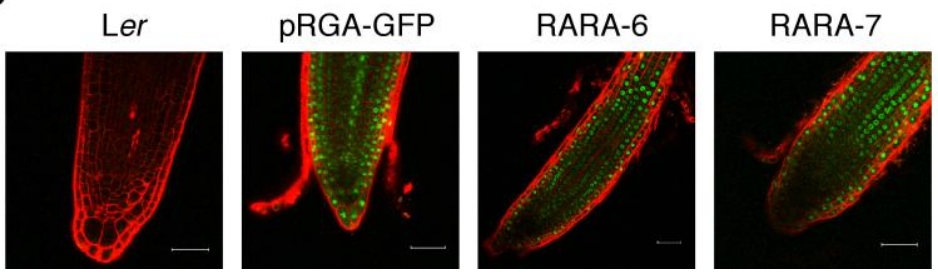

RAR2-7 RAR2-19
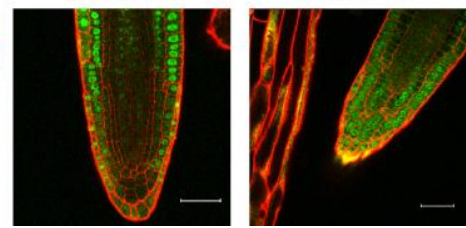

Figure 1.2. Transgenic lines expressing $R G A$ and $R G L 2$ under the control of their own and reciprocal promoters.

(A) Scheme of the constructs used in this study. (B) Expression of RGL2pro::GFP:DELLA transgenes, determined by RT-qPCR analysis of GFP in $r g l 2$ mutants. Error bars represent SD of three replicates.

(C) Production of functional DELLA protein in transgenic lines expressing RGApro::GFP:DELLA in gal gai-t6 rga-24 mutants, determined by western blot in seedlings with mock and $50 \mu \mathrm{M} \mathrm{GA}_{3}$ treatments. (D) Nuclear localization of DELLA proteins in the roots of transgenic plants described in (C). Line pRGA-GFP is used as control (Dill et al., 2001). Size bar is $40 \mu \mathrm{m}$. 


\section{Functional substitution of RGA by RGL2}

Loss of GAl, encoding ent-copalyldiphosphate synthase (Sun and Kamiya, 1994), blocks the early steps in GA biosynthesis and causes severe dwarfism due to the accumulation of DELLA proteins, which affect the size of the shoot, the leaves, the hypocotyls and other organs (Silverstone et al., 2001). This defect cannot be rescued by a mutation of $G A I$, due to redundancy with $R G A$, but simultaneous knockout mutations of both DELLA genes restores growth almost to the size of a wild type (Dill and Sun, 2001; King et al., 2001). On the other hand, the endogenous $R G L 2$ gene does not have a role in cell expansion, since mutations in this gene do not restore growth (Lee et al., 2002; Tyler et al., 2004), in agreement with the very low expression of $R G L 2$ in these tissues. However, our analysis of the RAR2 lines indicates that the RGL2 protein is capable of exerting RGA function when expressed under control of the $R G A$ promoter. As shown in Figure 1.3A, expression of RGA under the 2-kb RGA promoter could complement the loss of RGA function, to different extent depending on the line examined. Even more interestingly, expression of $R G L 2$ could also complement the lack of $R G A$ function to an equivalent extent, when expressed under the $R G A$ promoter. Such complementation ability was observed not only in leaves and shoots (Figures 1.3A and 1.3B), but also in etiolated hypocotyls (results not shown). Actually, the degree of stem dwarfism rescue was dependent on the age of the plant but not on the transgenic DELLA used (Figure 1.3B), an effect that might be caused by the lack of additional regulatory sequences lying beyond the $2-\mathrm{kb}$ promoter fragment used in this study.

RGA is also involved in feed-back regulation of GA metabolism genes in tissues in which $R G L 2$ is not normally expressed, such as hypocotyls, leaves and shoots (Silverstone et al., 1998; Dill and Sun, 2001; Frigerio et al., 2006). RGL2, when expressed under the control of the $R G A$ promoter, was able to restore feed-back control of the GA20ox1, GA20ox2 and GA2ox8 genes, which was lost in the gal-3 gai-t6 rga24 mutant (Figure 1.3C). Therefore, the RGL2 protein seems to display the biochemical activity characteristic of RGA function, functional divergence of these genes being caused, at least in this case, by changes in their spatial pattern of expression. To confirm this hypothesis, we performed the reciprocal analysis by testing the ability of RGA to substitute RGL2. 

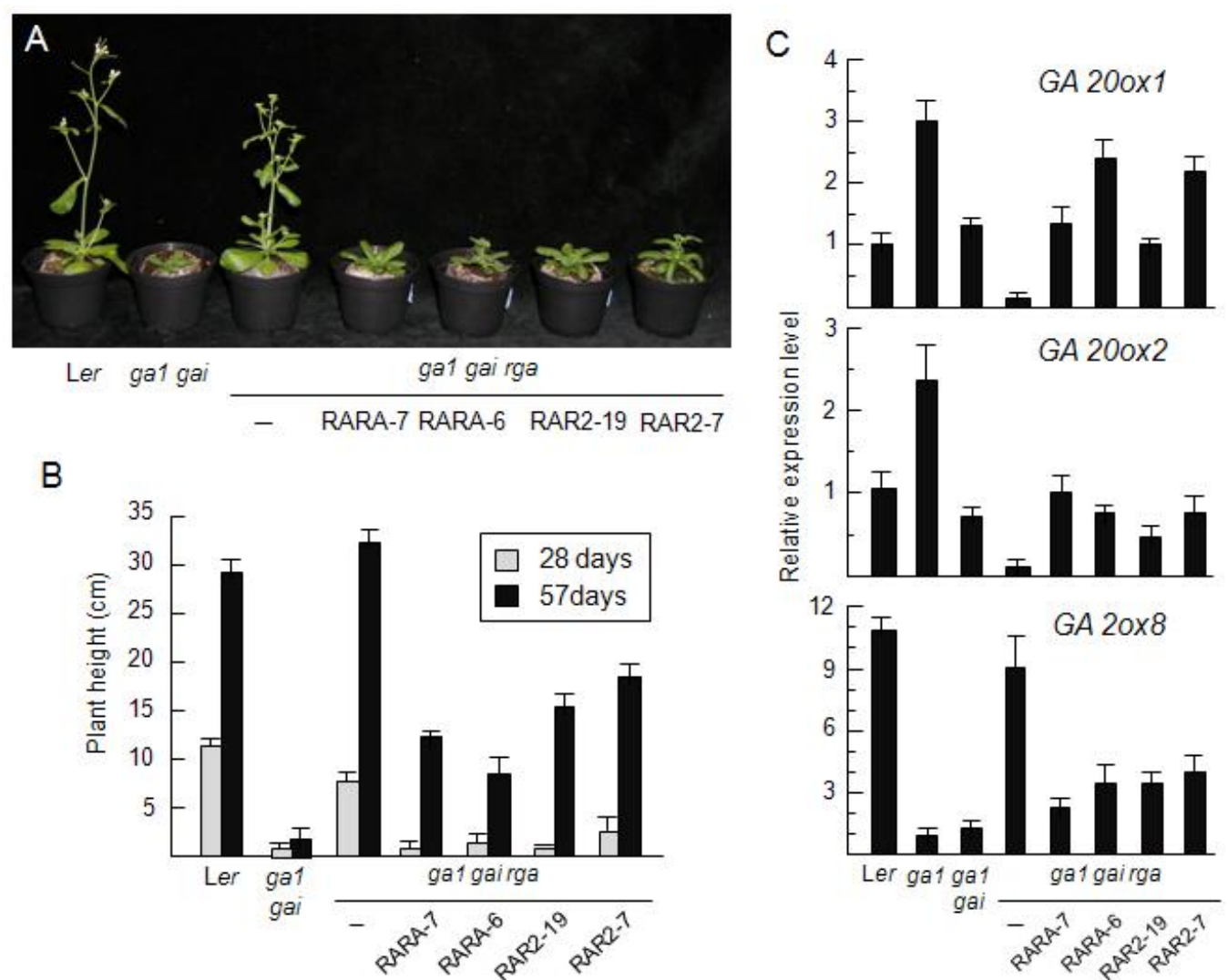

Figure 1.3. Complementation by $R G L 2$ of $r g a$ loss-of-function mutants.

(A) Photograph of four-week-old plants grown under long days. (B) Plant height at different ages of control plants and plants transformed with RGApro::GFP:DELLA, showing that RGA and RGL2 are capable of inhibiting shoot elongation to a similar extent when expressed under the $R G A$ promoter. Error bars represent SD ( $>15)$. (C) Expression of GA metabolism genes subject to regulation by RGA in shoots, measured by RT-qPCR, showing that RGA and RGL2 complement the loss of RGA function. Error bars represent SD of three replicates. Only two representative homozygous transgenic lines are shown for each construct, although equivalent results were observed for over 14 lines.

\subsubsection{Functional substitution of RGL2 by RGA}

A major function of RGL2 in seed physiology is revealed by the observation that GA-deficient seeds are able to germinate only if RGL2 activity is suppressed, but not when any of the other four DELLA genes are mutated (Lee et al., 2002; Cao et al., 2005). This is particularly evident for instance in the rgl2-1 allele, whose seeds germinate in the presence of 20 or even $120 \mu \mathrm{M}$ PAC, while these inhibitor concentrations reduce germination efficiency of wild-type seeds to values below $5 \%$ (Figure 1.4A). As expected, expression of RGL2 under the control of its 2-kb promoter region caused a decrease in germination of $\mathrm{rgl} 2 \mathrm{-1}$ in the presence of PAC, although it never reached the values of the wild type (Figure 1.4A). More importantly, expression of $R G A$ under the control of the $R G L 2$ promoter (R2RA lines) also complemented the 
rgl2-1 to an equivalent extent when compared to RGL2, indicating that RGA and RGL2 proteins can perform equivalent functions during seed germination, provided that they are both expressed under the RGL2 promoter. This conclusion was confirmed at the molecular level by measuring the expression level of ATHB-16 and MYB34 in germinating seeds, by RT-qPCR. These genes are normally up-regulated during germination and have been proposed to be repressed by RGL2 in imbibed seeds (Ogawa et al., 2003; Cao et al., 2006). As shown on Figure 1.4B, both marker genes were induced in rgl2-1 mutant seeds during germination in GA-limiting conditions, compared to seeds of the wild type and the transgenic lines expressing RGL2 and RGA under the control of the RGL2 promoter.

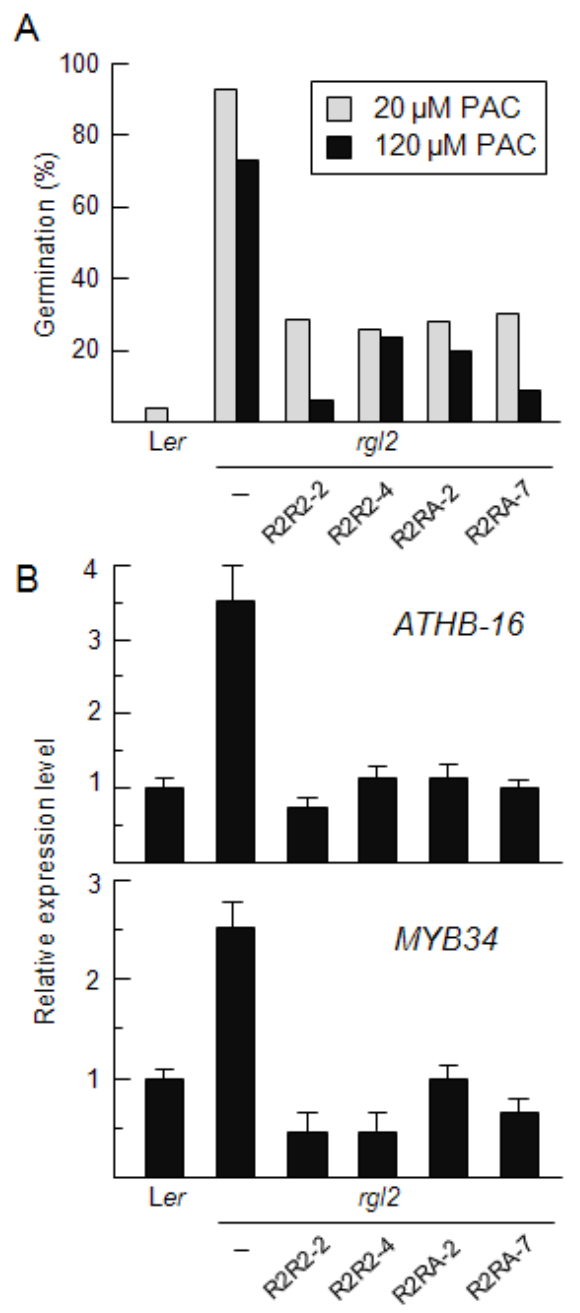

Figure 1.4. Complementation by $R G A$ of $r g l 2$ loss-of-function mutants.

(A) Germination of wild type and $r g l 2$ mutant seeds transformed with RGL2pro::GFP:DELLA under increasing concentrations of paclobutrazol (PAC). All lines tested germinated with almost $100 \%$ efficiency in the absence of PAC. $n>200$ seeds. (B) Expression of germination marker genes in seeds imbibed for 11 days in the presence of $20 \mu \mathrm{M}$ PAC, 6 days after exposure to light. Error bars represent SD of three replicates. Only two representative homozygous transgenic lines are shown for each construct, although equivalent results were observed for over 12 lines. 
The observation that the RGA protein can perform the function of RGL2 in seeds seems to be in conflict with the fact that RGA is also expressed in seeds, but suppression of this gene does not allow germination of GA-deficient seeds (Tyler et al., 2004; Cao et al., 2005). Where does the specificity of RGL2 function reside in wildtype seeds? One possibility is that expression of $R G A$ is restricted to cell types in the seed which are not relevant for germination. This is unlikely because RGA and GAI have indeed been found to contribute to control seed germination under normal conditions (Cao et al., 2005). Another possibility is that the $R G A$ and $R G L 2$ promoters are differentially regulated under GA deficiency, as suggested by the observation that the RGL2 protein is more abundant than RGA in seeds incubated with PAC (Piskurewicz et al., 2008). To explore this option, we analyzed the expression of GAI, $R G A$ and $R G L 2$ during seed imbibition and germination, in the GA-deficient gal mutant, and in its corresponding parental wild type. Interestingly, while $R G A$ and $R G L 2$ expression levels were equivalent in the wild type during germination (when seeds are exposed to light), RGL2 expression was highly predominant in GA-deficient seeds (Figure 1.5A). Besides, elements mediating GA-regulation of the $R G L 2$ promoter would lie- within the 2-kb fragment used in the R2R2 and R2RA lines, as confirmed by RTqPCR analysis of the GFP fusion transcript in germinating seeds of the transgenic lines in mock and GA-deficient (20 $\mu \mathrm{M}$ PAC) conditions (Figure 1.5B).

\subsubsection{Conservation of DELLA protein interactions}

The results presented here indicate that a major driving force in the subfunctionalization of DELLA proteins may in fact rely on different expression patterns arisen after duplication, hence pointing to variations in the promoters of the DELLA genes as the main cause for the differential roles of DELLAs in plant development. Common tools for promoter analysis did not allow the identification of specific sequences that explain the divergent behaviour of the DELLA promoters. However, cluster analysis of the expression of the five Arabidopsis DELLA genes using the over 100 conditions microarray data available through Genevestigator (Zimmermann et al., 2004) revealed a topology that faithfully reproduces the phylogenetic structure of the DELLA group (Figure 1.6; see also Figure 1.1A), suggesting an intimate link between the evolution of DELLA function and DELLA gene expression patterns. 
A

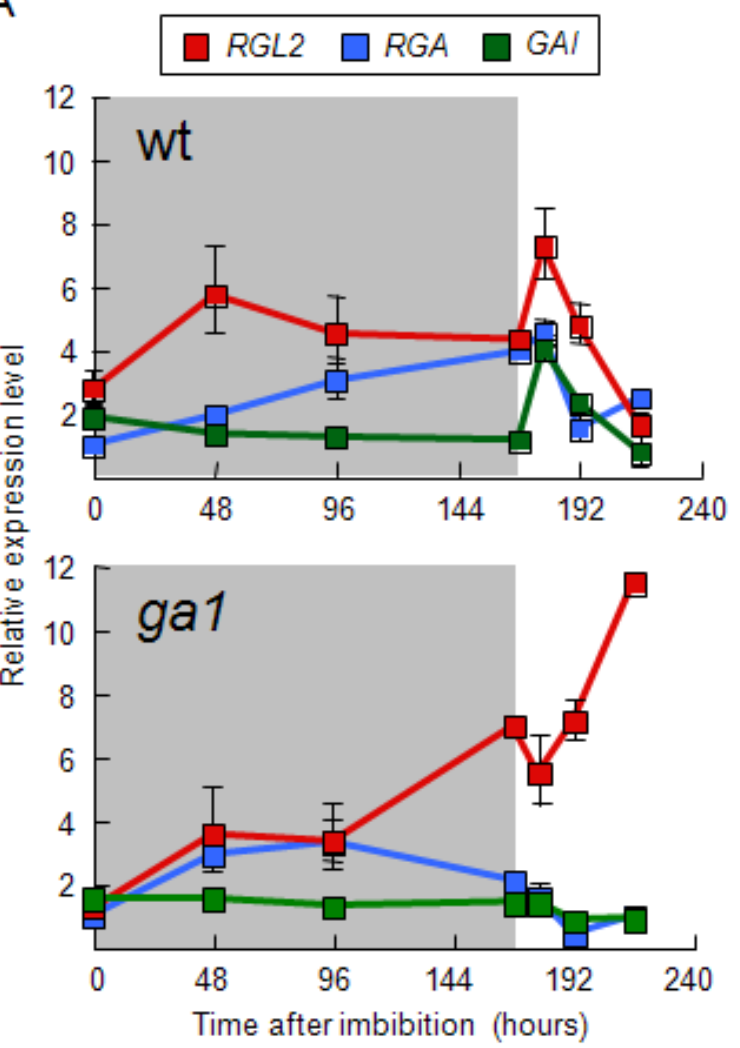

$\mathrm{B}$

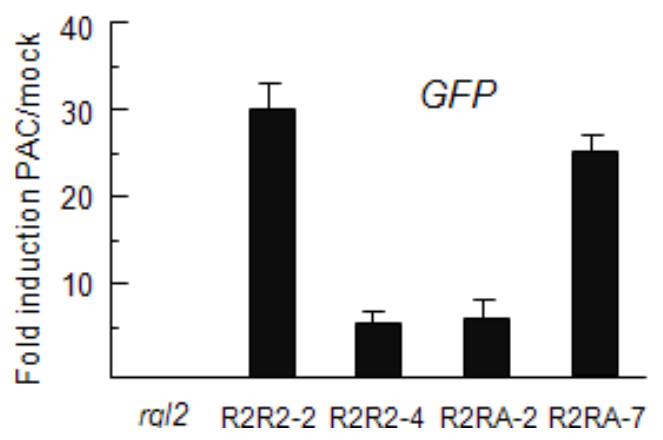

Figure 1.5. Expression of $D E L L A$ genes during seed imbibition and germination.

(A) Time course of the expression of GAI, RGA and RGL2 during imbibition of wild-type and gal mutant seeds in darkness (shaded area in the graphs) and after exposure to light, determined by RTqPCR. (B) Expression of RGL2pro::GFP:DELLA transgenes, determined by RT-qPCR analysis of GFP in $r g l 2$ mutants $48 \mathrm{~h}$ after exposure of imbibed seeds to light. In this experiment, seeds were incubated with mock or $20 \mu \mathrm{M}$ PAC solutions. Error bars represent SD of three biological replicates.

This view is coherent with the observation that at least one fifth of the alterations responsible for phenotypic evolution in multicellular organisms reside in regulatory regions (Stern and Orgogozo, 2008).

On the other hand, the study of the expression patterns of duplicate genes using microarrays has established a link between expression divergence and coding-sequence divergence in animals (Makova and Li, 2003; Conant and Wagner, 2004; Li et al., 
2005). Since the correlation between these two processes is less clear in Arabidopsis (Blanc and Wolfe, 2004), and there is experimental evidence that recently duplicated proteins in Arabidopsis undergo rapid changes in protein activity (Tominaga et al., 2007), we decided to investigate the extent of divergence in DELLA protein activity that could have arisen as a result of expression changes.

A

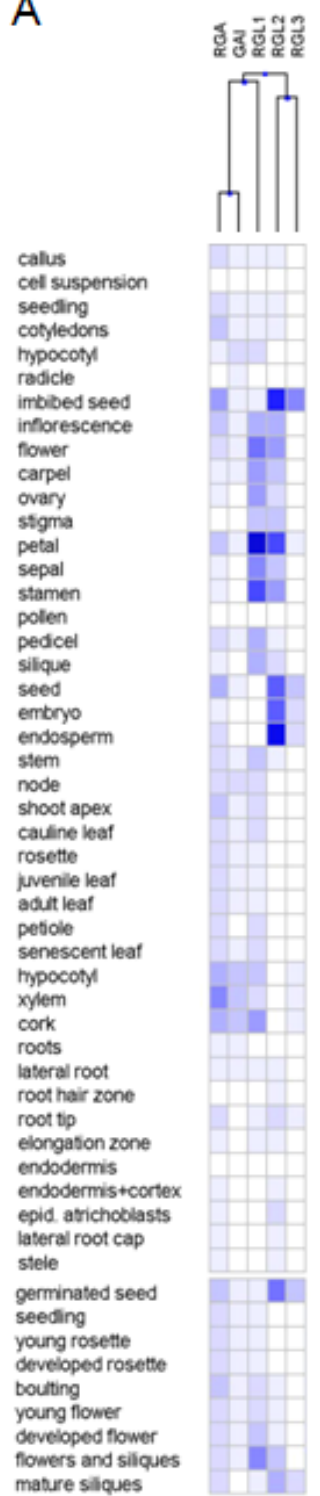

B

Arabidopsis thaliana (treatment)

- Biotic: Bemisia tabaci type B (+)

- Biotic: nematode1 (+)

-Biotic: P. infestans (+)

Biotic: P. syringae (avrRpm1) (+)

Biotic: P. syringae (hrpA) (+)

Biotic: P. syringae_3(+)

Biotic: P. syringae_4 (avrRpm1)

Biotic: P. syringae_4 (avrRps4)

- Chemical: 6-benzyl adenine (+)

Chemical: $\mathrm{CO} 2$ high

Chemical: isoxaben (+)

Chemical: ozone_1

- Chemical: syringolin $1(+)$

- Hormone: ABA_1 (+)

- Hormone: ABA_3 (+)

- Hormone: ABA_6 (+)

- Hormone: ACC_1 (+)

- Hormone: BL/ $\mathrm{H} 3 \mathrm{BO} 3(+)$

- Hormone: BL_1 (+)

- Hormone: GA3_1 (+)

- Hormone: IAA_1

- Hormone: MJ_1 (+)

- Hormone: zeatin (+)

- Light intensity. light_2

-PCD: senescence

-Stress: anoxia (+)

Stress: cold_2

Stress: heat_2

Stress: hypoxia (+)

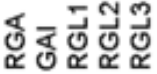
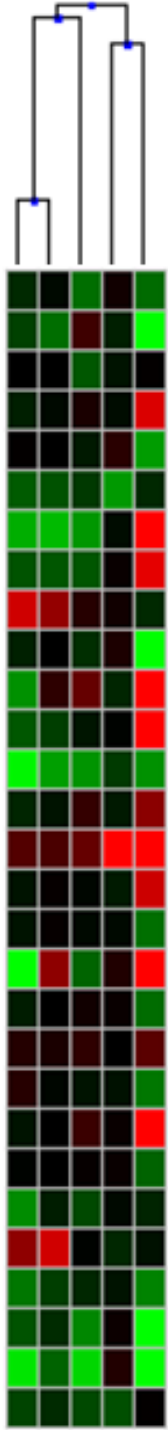

Figure 1.6. Cluster analysis of DELLA gene expression.

(A) Expression patterns of DELLA genes during plant development and across tissues. (B) Expression of DELLA genes in response to biotic and abiotic stress treatments. Multiple microarray data were analyzed with the tools provided by Genevestigator (Zimmermann et al., 2004) (https://www.genevestigator.ethz.ch), and the dendrogram displaying the relationships between DELLA gene expression patterns was constructed using all the experiments in the database. On the left panel, the intensity of the blue colour is proportional to the level of expression, while on the right panel, green and red colours indicate lower and higher levels, respectively, compared to the control situation in each treatment. 
Although biochemical activity of DELLA proteins is not yet fully established, at least two features have been defined that are intimately linked to the protein sequences: (i) they have been proposed to regulate gene expression through protein-protein interactions with transcription factors (TFs) of the bHLH family (de Lucas et al., 2008; Feng et al., 2008); and (ii) they interact physically with the GID1 GA receptors (Nakajima et al., 2006; Ueguchi-Tanaka et al., 2007; Murase et al., 2008). To evaluate the degree of conservation of the biochemical properties of these proteins, we examined the ability of RGA and RGL2 to interact with PIF4 and also with other bHLH TFs of subfamily 15, with a reported role in seed germination control (Penfield et al., 2005; Oh et al., 2006; Kim et al., 2008; Oh et al., 2009). As seen previously, RGA displayed strong interaction with PIF4 and a similar interaction ability was also observed for RGL2 (Figure 1.7). PIF4-DELLA interaction has been reported to involve the bHLH DNA recognition domain, which is highly conserved among members of subfamily 15 . Thus, it is possible that this interaction is not restricted to PIF3/PIF4 but involves other members of this gene family. In fact, we observed a strong interaction between RGA and RGL2 and the bHLH proteins PIL5, PIL2 and SPATULA (SPT), suggesting that DELLAs may interact with all members of this TF subfamily.

A

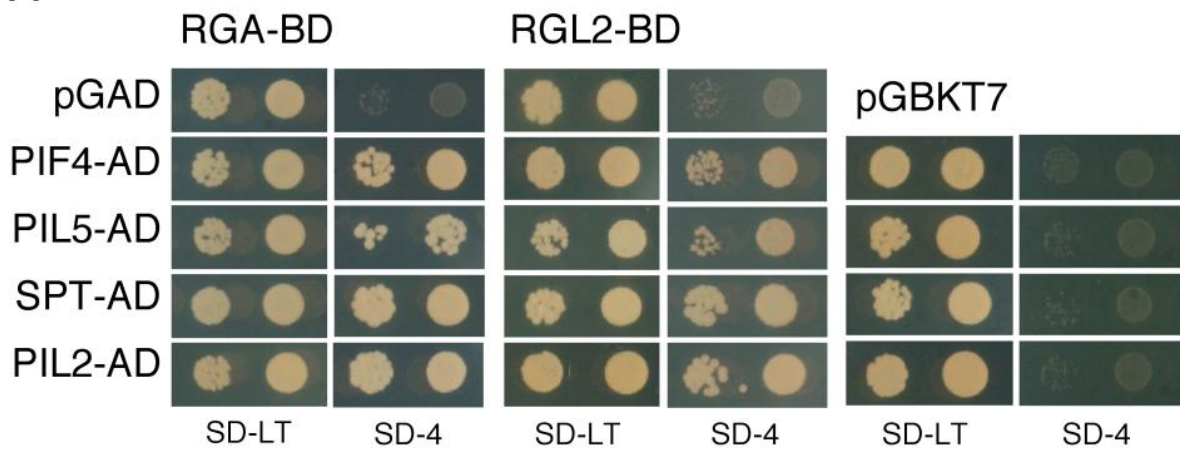

B

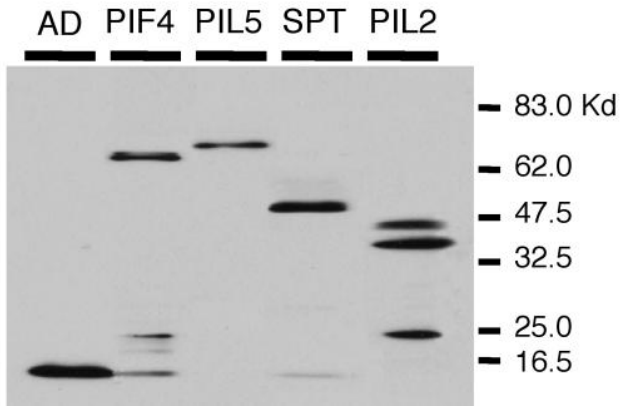

Figure 1.7. Conserved interaction between DELLA proteins and bHLH transcription factors.

(A) Growth of the yeast cells transformed with the DELLA-GAL4BD and bHLH-GAL4AD constructs on SD-Leu-Trp (SD-LT) and SD-Leu-Trp-His-Ade (SD-4) plates. (B) Western blot detection of the GAL4BD and GAL4AD fusion proteins using anti-GAL4BD and anti-HA antibodies. 
DELLA proteins have been also described to display differential abilities to interact with the three GID1 receptors in Arabidopsis, based on yeast two-hybrid analyses (Nakajima et al., 2006). Taking into account the reported differential expression pattern of the three Arabidopsis GID1 receptors and the five DELLA genes, it seems likely that GA signaling is governed by combinatorial tissue- and stage-specific expression patterns of DELLA proteins and most likely also by subsequent diversification of their interactors.

Therefore, the experimental evidence presented here demonstrates the existence of at least two levels of regulation that have contributed with different impact to the evolutionary fixation of diversity in GA signaling: first, and more critically, the subfunctionalization of DELLA gene expression patterns (either spatially or in terms of regulatory responses), and then a more recent optimization of protein interactions between DELLAs and different sets of TFs (and possibly other proteins) within the cellular context defined by the new expression domain for each DELLA protein. It remains to be assessed if the multiplication of DELLA genes in Rosids, and especially in the Brassicaceae, represents an improvement in the plasticity of the responses mediated by GAs.

\section{Acknowledgements}

We deeply appreciate the help of Marta Trénor and Laura García-Cárcel in the initial stages of this work. We also thank Tai-ping Sun (Duke University) and the Arabidpsis Biological Resource Center for seeds, Marta Boter for the pGBKT7 and pGADT7 Gateway vectors, Santiago Elena (IBMCP, CSIC-UPV) for useful comments on the manuscript, and François Parcy (IRTSV, CNRS-CEA) for fruitful discussions and hosting MAB. Work in the authors' laboratories is funded by grants BIO200760923 and BIO2005-07284 from the Spanish Ministry of Science and Innovation. JGB is the recipient of a CSIC I3P Fellowship and JAM is the recipient of a Fellowship from the Fundación "la Caixa".

\section{5. BIBLIOGRAPHY}

Abascal F, Zardoya R, Posada D (2005) ProtTest: selection of best-fit models of protein evolution. Bioinformatics 21: 2104-2105 
Bassel GW, Mullen RT, Bewley JD (2008) Procera is a putative DELLA mutant in tomato (Solanum lycopersicum): effects on the seed and vegetative plant. J Exp Bot 59: 585593

Bensmihen S, To A, Lambert G, Kroj T, Giraudat J, Parcy F (2004) Analysis of an activated ABI5 allele using a new selection method for transgenic Arabidopsis seeds. FEBS Lett 561: 127-131

Blanc G, Wolfe KH (2004) Functional divergence of duplicated genes formed by polyploidy during Arabidopsis evolution. Plant Cell 16: 1679-1691

Bradford MM (1976) A rapid and sensitive method for the quantitation of microgram quantities of protein utilizing the principle of protein-dye binding. Anal Biochem 72: 248-254

Cao D, Cheng H, Wu W, Soo HM, Peng J (2006) Gibberellin mobilizes distinct DELLAdependent transcriptomes to regulate seed germination and floral development in Arabidopsis. Plant Physiol 142: 509-525

Cao D, Hussain A, Cheng H, Peng J (2005) Loss of function of four DELLA genes leads to light- and gibberellin-independent seed germination in Arabidopsis. Planta 223: 105113

Casal JJ, Fankhauser C, Coupland G, Blázquez MA (2004) Signalling for developmental plasticity. Trends Plant Sci 9: 309-314

Cheng H, Qin L, Lee S, Fu X, Richards DE, Cao D, Luo D, Harberd NP, Peng J (2004) Gibberellin regulates Arabidopsis floral development via suppression of DELLA protein function. Development 131: 1055-1064

Chini A, Fonseca S, Fernandez G, Adie B, Chico JM, Lorenzo O, Garcia-Casado G, Lopez-Vidriero I, Lozano FM, Ponce MR, Micol JL, Solano R (2007) The JAZ family of repressors is the missing link in jasmonate signalling. Nature 448: 666-671

Clough SJ, Bent AF (1998) Floral dip: a simplified method for Agrobacterium-mediated transformation of Arabidopsis thaliana. Plant J 16: 735-743

Conant GC, Wagner A (2004) Duplicate genes and robustness to transient gene knock-downs in Caenorhabditis elegans. Proc Biol Sci 271: 89-96

de Lucas M, Davière JM, Rodríguez-Falcón M, Pontin M, Iglesias-Pedraz JM, Lorrain S, Fankhauser C, Blázquez MA, Titarenko E, Prat S (2008) A molecular framework for light and gibberellin control of cell elongation. Nature 451: 480-484

Dill A, Jung HS, Sun TP (2001) The DELLA motif is essential for gibberellin-induced degradation of RGA. Proc Natl Acad Sci U S A 98: 14162-14167

Dill A, Sun T (2001) Synergistic derepression of gibberellin signaling by removing RGA and GAI function in Arabidopsis thaliana. Genetics 159: 777-785

Dill A, Thomas SG, Hu J, Steber CM, Sun TP (2004) The Arabidopsis F-box protein SLEEPY1 targets gibberellin signaling repressors for gibberellin-induced degradation. Plant Cell 16: 1392-1405

Fang S, Ting CT, Lee CR, Chu KH, Wang CC, Tsaur SC (2009) Molecular evolution and functional diversification of fatty acid desaturases after recurrent gene duplication in Drosophila. Mol Biol Evol 26: 1447-1456

Feng S, Martinez C, Gusmaroli G, Wang Y, Zhou J, Wang F, Chen L, Yu L, IglesiasPedraz JM, Kircher S, Schafer E, Fu X, Fan LM, Deng XW (2008) Coordinated regulation of Arabidopsis thaliana development by light and gibberellins. Nature 451: 475-479

Force A, Lynch M, Pickett FB, Amores A, Yan YL, Postlethwait J (1999) Preservation of duplicate genes by complementary, degenerative mutations. Genetics 151: 1531-1545

Frigerio M, Alabadí D, Pérez-Gómez J, García-Cárcel L, Phillips AL, Hedden P, Blázquez MA (2006) Transcriptional regulation of gibberellin metabolism genes by auxin signaling in Arabidopsis. Plant Physiol 142: 553-563

Goto H, Szmidt AE, Yamazaki T, Inomata N (2005) Effect of nucleotide polymorphism in cis-regulatory and coding regions on amylase activity and fitness in Drosophila melanogaster. Heredity 95: 369-376 
Griffiths J, Murase K, Rieu I, Zentella R, Zhang ZL, Powers SJ, Gong F, Phillips AL, Hedden P, Sun TP, Thomas SG (2006) Genetic characterization and functional analysis of the GID1 gibberellin receptors in Arabidopsis. Plant Cell 18: 3399-3414

Guindon S, Gascuel $\mathbf{O}$ (2003) A simple, fast, and accurate algorithm to estimate large phylogenies by maximum likelihood. Syst Biol 52: 696-704

Haberer G, Hindemitt T, Meyers BC, Mayer KF (2004) Transcriptional similarities, dissimilarities, and conservation of cis-elements in duplicated genes of Arabidopsis. Plant Physiol 136: 3009-3022

Hittinger CT, Carroll SB (2007) Gene duplication and the adaptive evolution of a classic genetic switch. Nature 449: 677-681

Hussain A, Cao D, Cheng H, Wen Z, Peng J (2005) Identification of the conserved serine/threonine residues important for gibberellin-sensitivity of Arabidopsis RGL2 protein. Plant J 44: 88-99

Jasinski S, Tattersall A, Piazza P, Hay A, Martinez-Garcia JF, Schmitz G, Theres K, McCormick S, Tsiantis M (2008) PROCERA encodes a DELLA protein that mediates control of dissected leaf form in tomato. Plant J 56: 603-612

Kim DH, Yamaguchi S, Lim S, Oh E, Park J, Hanada A, Kamiya Y, Choi G (2008) SOMNUS, a CCCH-type zinc finger protein in Arabidopsis, negatively regulates lightdependent seed germination downstream of PIL5. Plant Cell 20: 1260-1277

King KE, Moritz T, Harberd NP (2001) Gibberellins are not required for normal stem growth in Arabidopsis thaliana in the absence of GAI and RGA. Genetics 159: 767-776

Lee S, Cheng H, King KE, Wang W, He Y, Hussain A, Lo J, Harberd NP, Peng J (2002) Gibberellin regulates Arabidopsis seed germination via RGL2, a GAI/RGA-like gene whose expression is up-regulated following imbibition. Genes Dev 16: 646-658

Li WH, Yang J, Gu X (2005) Expression divergence between duplicate genes. Trends Genet 21: $602-607$

Li Z, Zhang H, Ge S, Gu X, Gao G, Luo J (2009) Expression pattern divergence of duplicated genes in rice. BMC Bioinformatics 10 Suppl 6: S8

Lynch M, Conery JS (2000) The evolutionary fate and consequences of duplicate genes. Science 290: 1151-1155

Makova KD, Li WH (2003) Divergence in the spatial pattern of gene expression between human duplicate genes. Genome Res 13: 1638-1645

Marti C, Orzaez D, Ellul P, Moreno V, Carbonell J, Granell A (2007) Silencing of DELLA induces facultative parthenocarpy in tomato fruits. Plant J 52: 865-876

Maxwell AI, Morrison GM, Dorin JR (2003) Rapid sequence divergence in mammalian betadefensins by adaptive evolution. Mol Immunol 40: 413-421

Murase K, Hirano Y, Sun TP, Hakoshima T (2008) Gibberellin-induced DELLA recognition by the gibberellin receptor GID1. Nature 456: 459-463

Nakajima M, Shimada A, Takashi Y, Kim YC, Park SH, Ueguchi-Tanaka M, Suzuki H, Katoh E, Iuchi S, Kobayashi M, Maeda T, Matsuoka M, Yamaguchi I (2006) Identification and characterization of Arabidopsis gibberellin receptors. Plant J 46: 880889

Ogawa M, Hanada A, Yamauchi Y, Kuwahara A, Kamiya Y, Yamaguchi S (2003) Gibberellin biosynthesis and response during Arabidopsis seed germination. Plant Cell 15: $1591-1604$

Oh E, Kang H, Yamaguchi S, Park J, Lee D, Kamiya Y, Choi G (2009) Genome-Wide Analysis of Genes Targeted by PHYTOCHROME INTERACTING FACTOR 3-LIKE5 during Seed Germination in Arabidopsis. Plant Cell 21: 403-419

Oh E, Yamaguchi S, Kamiya Y, Bae G, Chung WI, Choi G (2006) Light activates the degradation of PIL5 protein to promote seed germination through gibberellin in Arabidopsis. Plant J 47: 124-139

Ohno S (1970) Evolution by gene duplication. Springer, New York

Page RD (1996) TreeView: an application to display phylogenetic trees on personal computers. Comput Appl Biosci 12: 357-358 
Penfield S, Josse EM, Kannangara R, Gilday AD, Halliday KJ, Graham IA (2005) Cold and light control seed germination through the bHLH transcription factor SPATULA. Curr Biol 15: 1998-2006

Pickett FB, Meeks-Wagner D (1995) Seing double: appreciating genetic redundancy. Plant Cell 7: 1347-1356

Piskurewicz U, Jikumaru Y, Kinoshita N, Nambara E, Kamiya Y, Lopez-Molina L (2008) The Gibberellic Acid Signaling Repressor RGL2 Inhibits Arabidopsis Seed Germination by Stimulating Abscisic Acid Synthesis and ABI5 Activity. Plant Cell 20: 2729-2745

Rodriguez PL (1998) Protein phosphatase 2C (PP2C) function in higher plants. Plant Mol Biol 38: $919-927$

Silverstone AL, Ciampaglio CN, Sun T (1998) The Arabidopsis RGA gene encodes a transcriptional regulator repressing the gibberellin signal transduction pathway. Plant Cell 10: $155-169$

Silverstone AL, Jung HS, Dill A, Kawaide H, Kamiya Y, Sun TP (2001) Repressing a repressor: gibberellin-induced rapid reduction of the RGA protein in Arabidopsis. Plant Cell 13: $1555-1566$

Singh LN, Hannenhalli S (2008) Functional diversification of paralogous transcription factors via divergence in DNA binding site motif and in expression. PLoS One 3: e2345

Smith H (1990) Signal perception, differential expression within multigene families and the molecular basis for phenotypic plasticity. Plant Cell Environ 13: 585-594

Stern DL, Orgogozo V (2008) The loci of evolution: how predictable is genetic evolution? Evolution 62: 2155-2177

Sun TP, Kamiya Y (1994) The Arabidopsis GA1 locus encodes the cyclase ent-kaurene synthetase A of gibberellin biosynthesis. Plant Cell 6: 1509-1518

Taylor JS, Raes J (2004) Duplication and divergence: the evolution of new genes and old ideas. Annu Rev Genet 38: 615-643

Thompson JD, Gibson TJ, Plewniak F, Jeanmougin F, Higgins DG (1997) The CLUSTAL_X windows interface: flexible strategies for multiple sequence alignment aided by quality analysis tools. Nucleic Acids Res 25: 4876-4882

To JP, Haberer G, Ferreira FJ, Deruere J, Mason MG, Schaller GE, Alonso JM, Ecker JR, Kieber JJ (2004) Type-A Arabidopsis response regulators are partially redundant negative regulators of cytokinin signaling. Plant Cell 16: 658-671

Tominaga R, Iwata M, Okada K, Wada T (2007) Functional analysis of the epidermalspecific MYB genes CAPRICE and WEREWOLF in Arabidopsis. Plant Cell 19: 22642277

Tyler L, Thomas SG, Hu J, Dill A, Alonso JM, Ecker JR, Sun TP (2004) Della proteins and gibberellin-regulated seed germination and floral development in Arabidopsis. Plant Physiol 135: 1008-1019

Ueguchi-Tanaka M, Nakajima M, Katoh E, Ohmiya H, Asano K, Saji S, Hongyu X, Ashikari M, Kitano H, Yamaguchi I, Matsuoka M (2007) Molecular interactions of a soluble gibberellin receptor, GID1, with a rice DELLA protein, SLR1, and gibberellin. Plant Cell 19: 2140-2155

Weijers D, Benkova E, Jager KE, Schlereth A, Hamann T, Kientz M, Wilmoth JC, Reed JW, Jurgens G (2005) Developmental specificity of auxin response by pairs of ARF and Aux/IAA transcriptional regulators. Embo J 24: 1874-1885

Weijers D, Jurgens G (2004) Funneling auxin action: specificity in signal transduction. Curr Opin Plant Biol 7: 687-693

Zimmermann P, Hirsch-Hoffmann M, Hennig L, Gruissem W (2004) GENEVESTIGATOR. Arabidopsis microarray database and analysis toolbox. Plant Physiol 136: 2621-2632 

Chapter 2

GA signaling targets during etiolated growth in Arabidopsis 



\subsection{Introduction}

Plants are sessile organisms that cannot change their location as a strategy to optimize their access to energy sources or in response to the environment. Thus, adjusting their growth and choosing the correct developmental program has to be precise and robust otherwise chances of survival could be reduced. This need has forced the development of very sophisticated sensing mechanisms and signal transduction pathways to respond properly to fluctuating environmental conditions. Plant hormones play an instructive role on this as they control many, if not all, developmental responses in plants (Alabadi et al., 2009; Jaillais and Chory, 2010).

Gibberellins (GAs) are one of the classical plant hormones. They regulate several processes during the plant life cycle such as germination, vegetative growth or flowering (Yamaguchi, 2008) through gene transcriptional regulation. (Ogawa et al., 2003; Cao et al., 2006; Zentella et al., 2007; Hou et al., 2008). This transcriptional regulation relies on the activity of the nuclear, GA-regulated DELLA proteins (Harberd et al., 2009). In brief, DELLAs accumulate in the absence of GAs blocking the transcriptional response to the hormone. When GA levels increase, the binding of the hormone to its receptor, GID1, promotes the formation of a GA-GID1-DELLA complex (Ueguchi-Tanaka et al., 2005; Shimada et al., 2008) that favors the recognition of the DELLA protein by the $\mathrm{SCF}^{\mathrm{SLY}}$ ubiquitin ligase (Hirano et al., 2010) and the subsequent ubiquitination. This modification leads to DELLA degradation by the $26 \mathrm{~S}$ proteosome (Fu et al., 2002; Itoh et al., 2003) and transcriptional changes to the hormone take place.

Two observations support the idea that DELLAs are transcriptional regulators: first, chromatin immunoprecipitation (ChIP) experiments reveal that DELLAs sit at the vicinity of promoters of certain GA-regulated genes (Zentella et al., 2007) (Zhang et al., 2011). Second, DELLAs interact physically with transcription factors and other transcriptional regulators. For example, they interact with bHLH transcription factors of the PIF clade and inhibit their ability to bind DNA (de Lucas et al., 2008; Feng et al., 2008), as well as with other members of the bHLH family (Arnaud et al., 2010; Gallego-Bartolome et al., 2010). Also, they interact with JAZ proteins, which are transcriptional regulators that negatively regulate jasmonate signaling (Hou et al., 2010), and with SCL3 (Heo et al., 2011; Zhang et al., 2011), a transcriptional regulator that belongs to the GRAS family. Other experimental approaches identified another transcription factor that mediates DELLA action, for instance, GAs impinge negatively 
on the stability of the transcription factor inducer of photomorphogenesis HY5 as a way to promote etiolated growth (Alabadi et al., 2008).

Despite recent advances mentioned above, a broader view of the mechanisms by which DELLA proteins regulate GA responses is lacking. A bottom-up strategy to dissect further this fundamental aspect of GA signaling is to identify and classify GA target genes according to their expression domain or the process in which they participate. In this regard, global analysis of DELLA-regulated transcription in two different developmental contexts -vegetative growth and floral development- has shown that only $3.6 \%$ of the target genes are shared between the two sets (Zentella et al., 2007; Hou et al., 2008). This observation underscores the importance of the developmental context in which GA signaling is investigated.

GAs are important regulators of the skotomorphogenic developmental program (Alabadí et al., 2004; Alabadí et al., 2008). In order to dissect how GAs regulate this process, we have searched for early target genes of DELLAs in etiolated seedlings. For that purpose, we have examined global, rapid changes in gene expression after compromising the GA signaling pathway in dark-grown seedlings. This approach allowed us 1) to identify which cellular pathways are directly regulated by GAs to promote skotomorphogenesis; and 2) to identify gene targets that will serve as markers to dissect further the mechanisms by which DELLAs regulate gene expression.

\subsection{Results \& Discussion}

\subsubsection{Identification of genes rapidly regulated by GAI in etiolated seedlings}

We sought to identify in a global and unbiased way genes whose expression was modulated rapidly in response to a change in GA activity in etiolated seedlings by using a transgenic line that expresses a gain-of-function version of GAI under the control of a temperature-inducible promoter, HS::gai-1 (Alabadí et al., 2008). To determine the

minimum duration of the heat-treatment needed to strongly induce gai-1 transcript accumulation yet causing the least disturb to seedlings, we placed 2-day-old etiolated HS::gai-1 seedlings at $37^{\circ} \mathrm{C}$ for 30,60 , or 120 minutes, and then analyzed expression of the transgene by qRT-PCR over a time-course (Figure 2.1A). The 30 minutes treatment was sufficient to induce strongly and transiently gai-1 transcript accumulation. Next, we checked whether this induction protocol had any effect modulating gene expression of known DELLA targets. We predicted that AtGA20ox2 and AtGA3ox1 genes that encode 
key enzymes in the GA biosynthetic pathway would respond rapidly to gai-1 accumulation in etiolated seedlings, based on previous genetic, transcriptomic, and molecular analyses (Peng et al., 1997; Dill et al., 2001; Zentella et al., 2007). As expected, transcripts of both genes accumulated transiently and strongly in seedlings subjected to a 30 minutes heat-shock. Their expression, however, was kept high after longer treatments (Figures 2.1B and 2.1C); moreover, expression of these genes did not change significantly in response to the temperature treatment in wild-type seedlings (data not shown). These results indicate that the induction protocol was appropriate to modulate expression of GAI target genes.

A

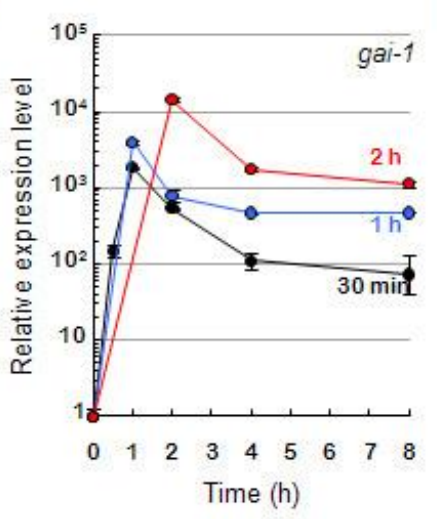

B

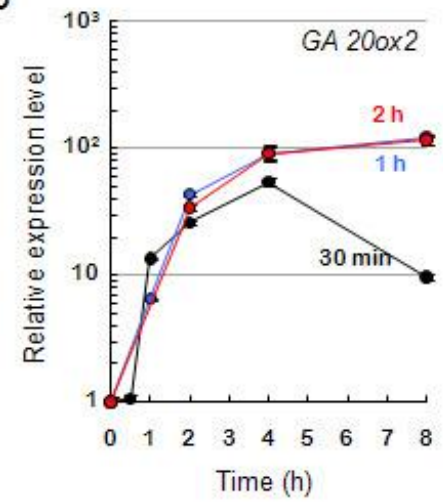

C

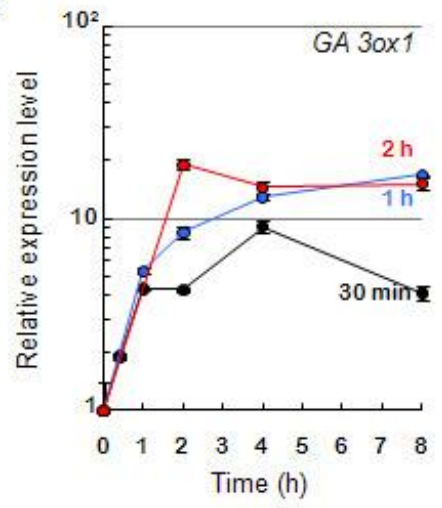

Figure 2.1 Effect on known DELLA targets after a transient induction of gai-1

Three-day-old, etiolated $H S::$ gai- 1 and wild type Col-0 plants grown at $22^{\circ} \mathrm{C}$ received thea $37^{\circ} \mathrm{C}$ heatshock treatment for different periods $\left(30 \mathrm{~min}, 1 \mathrm{~h}\right.$ or $2 \mathrm{~h}$ ) and then returned to $22^{\circ} \mathrm{C}$. Samples were collected at different time points after the treatment. Expression of the transgene (A) as well as of AtGA20ox2 (B) and AtGA3oxl (C) genes was monitored by qRT-PCR.

Thus, to identify early targets of GAI we interrogated the transcriptome of 2-day-old etiolated $H S: \because$ gai-1 seedlings at $0,1,2$, and 4 hours after starting a 30 minutes heat-shock at $37^{\circ} \mathrm{C}$. For that purpose, the same protocol was conducted with wild-type Col-0 seedlings, and RNA samples from whole transgenic seedlings at each 
time point were compared to the corresponding wild-type samples by using 70-mer oligonucleotide arrays representing the majority of the Arabidopsis genes (http://www.ag.arizona.edu/microarray); experiments were performed with three biological replicates. We used the Significance Analysis of Microarrays (Tusher et al., 2001) with a false discovery rate of $8.74 \%$ and a 1.5 -fold cutoff to identify 151 genes differentially expressed after the induction of gai-1 activity. This list represented our putative GAI-regulated genes (Table 2.S1); among them, 59 were downregulated and 92 induced (Figure 2.2A).

A

B

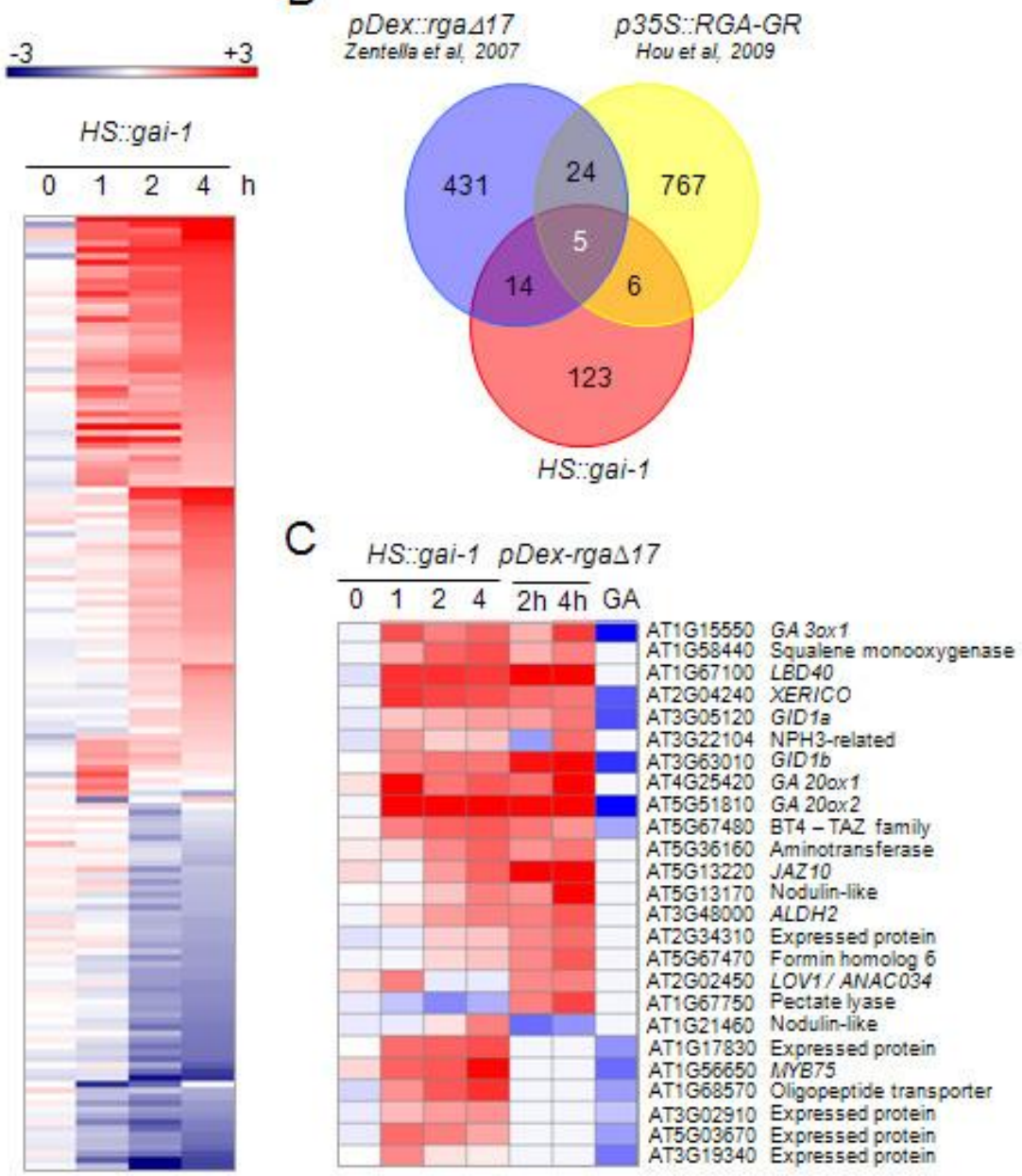

Figure 2.2 Early targets of gailargets and overlap with rgaA17 early targets.

(A) Heatmap representation of the 152 best scored genes (q-value $\leq 8$ ). (B) Overlapping genes among microarray data from pHsp::gai-1, rgaAl7 (Zentella et al, 2007) and Hou et al (2009) (C) Heatmap of overlapping genes among microarray data from $p H s p:: g a i-1$, rga 417 and GA3 treated seedlings (Zentella et al, 2007) 


\subsubsection{Different and overlapping targets for GAI and RGA under different light conditions.}

Recent studies have identified, by a similar approach, early target genes of the Arabidopsis DELLA protein RGA in shoots of light-grown seedlings (Zentella et al., 2007) or flowers of Arabidopsis (Hou et al., 2008), as well as genes responding rapidly to GAs (Zentella et al., 2007). Comparison of the sets of genes regulated by GAI and RGA showed little overlap: 19 and 11 GAI-regulated genes overlapped with RGA targets in seedlings (Zentella et al., 2007) and in flowers (Hou et al., 2008), respectively, what corresponds to $13 \%$ and $7 \%$ of GAI-regulated genes, and only 5 genes overlapped in all conditions (Figure 2.2B). Remarkably, 4 of them encode proteins that participate in the GA pathway (AtGA20oxl, AtGA20ox2, AtGA3ox1, $A t G I D 1 b$ ) supporting the strong involvement of DELLA proteins in its regulation. When we compared the GAI targets list with genes responsive to GA-treatment (Zentella et al., 2007), we found only 12 genes affected in both conditions, representing $\sim 8 \%$ of GAI-regulated genes (Figure 2.2C). The little overlap among all experiments is likely due to the different growing conditions used to perform them, i.e. etiolated seedlings in this study and light-grown seedlings or developing flowers. Consistent with this, DELLA proteins seem to be functionally redundant and their role on different developmental processes is a consequence of the different transcriptional regulation of their genes (Gallego-Bartolome et al., 2010). This suggests that each DELLA protein will face a different set of interacting partners depending on their expression domain or physiological condition, which will have a direct influence in determining the genes to be regulated.

Thus, despite that GAI and RGA perform widely overlapping roles in the control of growth in the light (Dill and Sun, 2001; King et al., 2001) and in darkness (Alabadí et al., 2004), likely differences in the pool of their protein partners in each condition will cause the divergence in the target genes.

\subsubsection{GAI regulates target genes in part through PIFs and HY5 transcription factors}

The proper control of the developmental switch between skotomorphogenesis and photomorphogenesis after germination is key for seedlings' survival. Light triggers this transition by activating positive elements of photomorphogenesis, like 
ELONGATED HYPOCOTYL5 (HY5), and inactivating negative elements such as the PHYTOCHROME-INTERACTING FACTORs, (PIFs). (Alabadi and Blazquez, 2008). Remarkably, GAs counterbalance the effect of light by impinging on the activity of these elements to promote skotomorphogenesis and to repress photomorphogenesis (Alabadí et al, 2008; Feng et al., 2008). Hence, given the functional relationship between GAs and these transcription factors, we compared the list of GAI targets with available lists of genes regulated by HY5 and the PIFs. We reasoned that this comparison would allow us to identify which GAI-regulated genes depend on the activity of these transcription factors, and then to draw a picture of the transcriptional network that mediates the GA-control on this developmental switch. First, we compared the GAI targets list with a dataset of genes bound in vivo by HY5, which was generated by ChIP-to-chip experiments of light-grown seedlings (Lee et al., 2007). Second, we compared the GAI targets list with a dataset of PIF regulated genes in dark-grown and in red-light treated seedlings (Leivar et al., 2009). As shown in Figure 2.3, almost half of the GAI regulated targets are either regulated by HY5, the PIFs, or both, suporting the relevance of these transcription factors mediating DELLA transcriptional regulation activity.

Among the genes regulated by GAI and directly bound by HY5, more than half behaved similarly in response to red-light, which promotes HY5 activity, while the rest behaved the opposite (Figure 2.3), suggesting that the later targets are likely regulated by DELLAs independently of HY5 activity. In the case of PIFs, it is well established that DELLAs have a negative effect on PIFs activity (de Lucas et al., 2008; Feng et al., 2008). Thus, the fact that not all common genes respond in a similar way to DELLA induction and to PIF deficiency, indicate that DELLA regulation of those genes is PIFindependent. Importantly, this might reveal that not all the pool of PIF proteins in a given cell is susceptible to DELLA inhibition. For instance, the apical hook and the starch accumulation in amyloplasts are restored when PIF1 is specifically missexpressed in the hypocotyl endodermis of the pifQ mutant (Kim et al., 2011). Similarly, expression in the same tissue of the wild type affects apical hook formation in such a way that is coherent with the inhibition of PIF activity (see Chapter 4; Gallego-Bartolomé et al., 2011b). Strikingly, DELLA accumulation does not prevent starch accumulation in the endodermis amyloplasts (data not shown), as would be 
expected based on the results by Kim et al (2011), and consistent with the idea above mentioned.

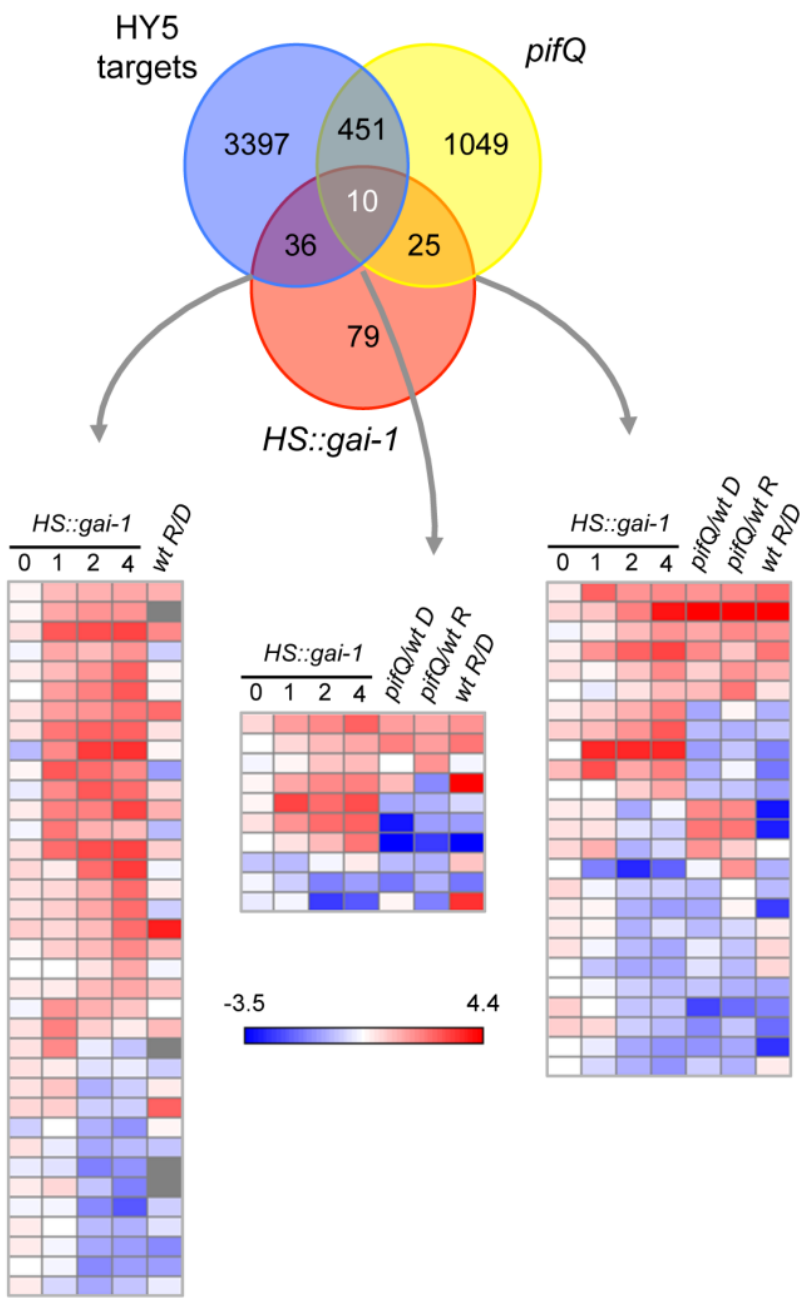

Figure 2.3. Metanalysis comparing microarray data from HS::gai-1, HY5 and PIF targets .

Venn diagram of microarray data from HS::gai-1, HY5 targets and quadruple pif mutant (pifQ) show common genes regulated by GAI, HY5 and PIF proteins. Heatmaps show the behaviour of common GAI-HY5, GAI-HY5-PIF and GAI-PIF targets in different light conditions.

Wt R/D, data comes from differential expressed genes under red light compared to dark in a WT. pifQ/wt D, data comes from differential expressed genes among quadruple pif mutant compared to wt in darkness. pifQ/wt $\mathbf{R}$, data comes from differential expressed genes among quadruple pif mutant compared to wt under red light.

\subsubsection{Promoter analysis of GAI regulated targets suggests new transcription factors mediating DELLA activity.}

Our results show that half of the GAI targets are likely regulated by HY5 or PIFs, suggesting that the rest of targets are regulated by other transcription factors. Next, we followed a bottom-up approach to identify which other transcription factors mediate the GAI activity by studying the regulatory regions in the promoters of GAI 
regulated genes. For that purpose we used the promoter searching tool ELEMENT (http://element.cgrb.oregonstate.edu/)(Nemhauser et al., 2004) which returns those 3$8 \mathrm{bp}$ sequences that are over-represented in the 1000bp upstream from the transcription start site of target genes compared to those regions through the whole Arabidopsis genome. The ELEMENT tool also clusters the highest count elements in the promoters of target genes that share a core element. Figure $2.4 \mathrm{~A}$ shows the logo representation (http://weblogo.berkeley.edu/;(Crooks et al., 2004)) of these clusters for GAI upregulated and GAI down-regulated target genes. The Dof (AAAG) (Yanagisawa, 2004) and the ARR1 (NGATT) (Sakai et al., 2000) binding sites were found among the clusters formed from the GAI-induced genes. Interestingly, both types of transcription factors have been related to GAs. In the case of Dof proteins, several studies carried out both in barley and in Arabidopsis reveal a role for transcription factors of this class in regulating GA signaling and biosynthesis, raising the possibility that they participate together with DELLA proteins in the feedback regulation of the GA pathway (Gabriele et al., 2010)(Mena et al., 2002; Zou et al., 2008). In the case of ARR1, it has been shown that it is transcriptionally up-regulated in response to DELLA accumulation in the transition zone of the root meristem(Moubayidin et al., 2010). If we interpret the enrichment of ARR1-binding sites in the GAI up-regulated gene set as an indication of its participation in the activity of GAI, the regulation of ARRl transcription by DELLAs suggests a sort of feedforward mechanism, in which one element -DELLA- promotes the expression of a second element -ARR1- to act together thereafter. In an effort to find DELLA regulatory sequences that operate in different contexts, we used the ELEMENT tool with the induced genes from $H S:: g a i-1$ and $R G A$ microarray experiments (Zentella et al., 2007; Hou et al., 2008) (Figure 2.4B). Among the elements clustered within the induced target genes there were two known regulatory sequences: G-box (CACGTG) (Giuliano et al., 1988; Riechmann et al., 1996) and a sequence similar to the CArG box (CC(A/T) $\left.)_{6} \mathrm{GG}\right)$ (Riechmann et al., 1996) which also includes a Dof binding site (AAAG) (Figure 2.4B). The presence of G-boxes suggests a common mechanism for DELLA gene induction based on interaction with G-box binding proteins. PIF proteins bind G-boxes. Thus, DELLA inhibition of repressor PIF proteins (de Lucas et al., 2008; Feng et al., 2008) would lead to an induction of target genes. Interestingly, bZIP proteins such as HY5 also bind G-boxes and its two relatives, the CG hybrid (GACGTG) and the CA hybrid (GACGTA) (Foster et al., 1994; Lee et al., 2007), which are present in the G-box containing logo (Figure 2.4B). This supports the 
role of HY5 on GA-mediated repression of photomorphogenesis (Alabadí et al., 2008) and suggest a wide role for HY5 on DELLA-induced gene transcription. Besides, further studies are awaiting to probe the relevance for the putative CArG box and, hence, MADS proteins in the DELLA-mediated regulation of transcription.

A

\begin{tabular}{|c|c|c|c|}
\hline INDUCED TARGETS & \multicolumn{2}{c}{ REPRESSED TARGETS } \\
\hline CIS element & Logo element \\
\hline Unknown
\end{tabular}

B

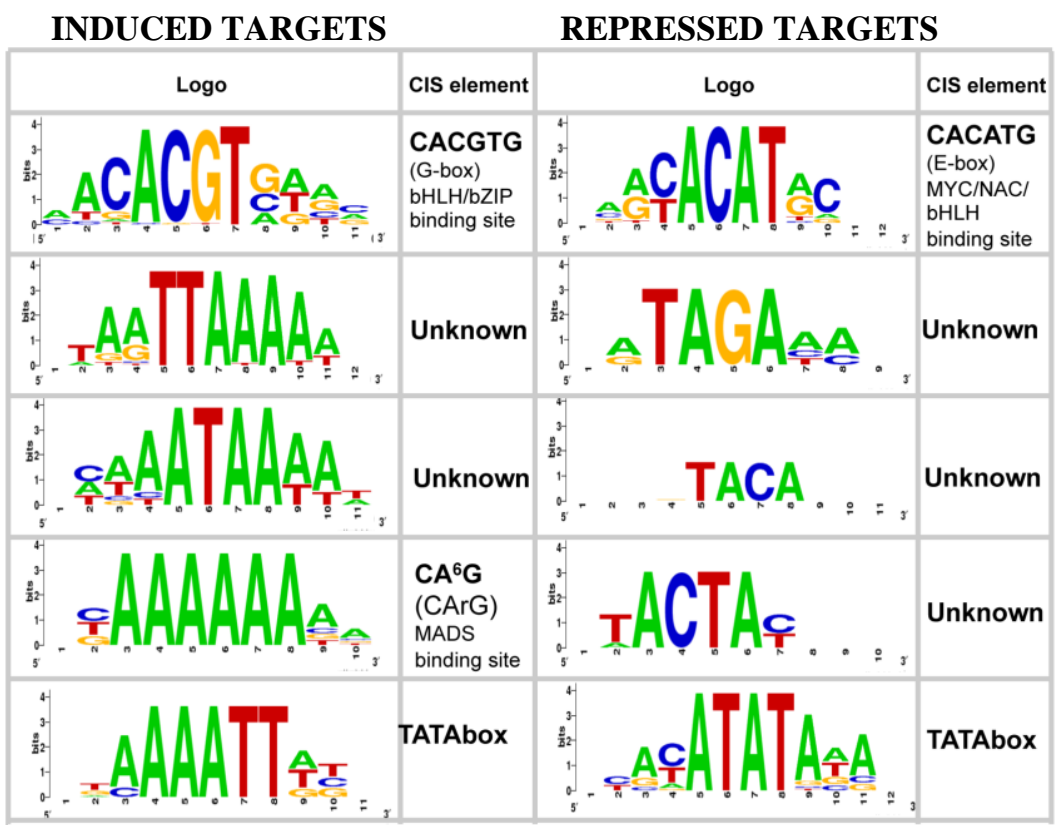

Figure 2.4. Logos from over-represented promoter CIS elements

(A) Logos from over-represented CIS elements in the promoters of induced and repressed HS:gai1 microarray targets. (B) Logos from a over-represented CIS elements in the promoters of induced and repressed genes coming from the pool of HS:gai1, rgaA17 (Zentella et al, 2007) and Hou et al (2009) microarray targets. 
On the other hand, among the GAI repressed genes, the E-box CATGTG and the ARR1 binding site (NGATT) were the only known regulatory sequences overrepresented (Figure 2.4). The enrichment of the ARR1-binding site in both up- and down-regulated genes is interesting and suggests a similar mechanism in the regulation of both sets of genes by DELLAs, which might recruit type B ARRs to the promoters, either activators or repressors. Importantly, the same E-box appeared over-represented when the analysis was conducted on the promoters of all DELLA down-regulated genes from the HS::gai-1 and RGA microarray experiments (Zentella et al., 2007; Hou et al., 2008) (Figure 2.4B). bHLH proteins, such as the brassinosteroid signaling elements BZR1 and BES1, are able to bind to E-boxes (CANNTG) (Moubayidin et al., 2010; Sun et al., 2010; Yu et al., 2011). . - The PIFs are also able to interact with E-boxes in vitro, though preferentially bind G-boxes (CACGTG; a particular class of E-box) in vivo (Giuliano et al., 1988; Huq and Quail, 2002; de Lucas et al., 2008; Feng et al., 2008). Moreover, this element -CATGTG- is enriched in promoters of dawn-phased cycling genes under short-day photocycles and it is important for gating their expression by the circadian clock (Michael et al., 2008). Thus, this E-box could point to a subset of DELLA regulated genes that are regulated by PIFs, which are themselves targets of the circadian clock, and on the other hand also suggests new interactions between the GA and brassinosteroid pathways. A direct, inhibitory interaction between the above mentioned transcription factors and DELLAs could be a plausible mechanism for the rapid, DELLA-mediated transcriptional regulation.

\subsubsection{Gene ontology analysis of GAI-regulated genes}

Next, to identify the basic biological processes that are regulated by GAs in etiolated seedlings at the molecular level, we tried to extract any significantly overrepresented Gene Ontology term (GO) (Ashburner et al., 2000) from our gene list by using the FatiGO algorithm (Al-Shahrour et al., 2005). This analysis suggests that GAI is closely involved in the control of GA homeostasis, growth, other hormone pathways, light, and stress responses and in controlling transcriptional networks (Table 2.1). 
Table 2.1 GO term of non redundant categories of HS::gai-1 targets

\begin{tabular}{|c|c|c|c|c|c|c|}
\hline \multicolumn{4}{|l|}{ BIOLOGICAL PROCCESS } & \multicolumn{3}{|l|}{ MOLECULAR FUNCTION } \\
\hline \multirow{2}{*}{$\begin{array}{l}\text { name } \\
\text { Response to gibberellin stimulus }\end{array}$} & p-value & \multicolumn{2}{|c|}{ genes in this group } & \multirow{2}{*}{$\begin{array}{l}\text { GO } \\
\text { oxidoreductase activity }\end{array}$} & \multicolumn{2}{|c|}{ p-value genes in this group } \\
\hline & $2,4 \mathrm{E}-09$ & AT2G01570 & RGA1 & & 6E-05 AT4G25420 & GA200X1 \\
\hline Gibberellic acid mediated signaling & $5,1 \mathrm{E}-08$ & AT3G05120 & GID1A & & AT1G60980 & ATGA200X4 \\
\hline \multirow[t]{11}{*}{ Gibberellin biosynthetic process } & $1,2 \mathrm{E}-06$ & AT2G37640 & EXP3 & & AT4G21200 & GA2OX8 \\
\hline & & AT1G67100 & LBD40 & & AT1G15550 & GA3OX1 \\
\hline & & AT1G66350 & RGL1 & & AT5G51810 & GA200X2 \\
\hline & & AT4G25420 & GA200X1 & & & \\
\hline & & AT5G25900 & GA3 & transcription factor activity & 2E-05 AT5G56860 & GNC \\
\hline & & АT3G63010 & GID1B & & АT3G60390 & НАT3 \\
\hline & & AT2G04240 & XERICO & & AT1G49560 & MYB TF \\
\hline & & AT1G15550 & GA3OX1 & & AT4G00050 & UNE10 \\
\hline & & AT5G51810 & GA200X2 & & AT5G28300 & trihelix DNA-bin \\
\hline & & AT5G67480 & BT4 & & AT1G56650 & PAP1 \\
\hline & & & & & АT3G50890 & AtHB28 \\
\hline \multirow[t]{20}{*}{ Regulation of transcription } & 0,00485 & AT3G28857 & PRE5 & & AT3G18010 & Wox1 \\
\hline & & AT4G39070 & STH7 & & AT4G32280 & IAA29 \\
\hline & & AT1G66380 & MYB114 & & AT1G53910 & RAP2.12 \\
\hline & & АТЗG60390 & HAT3 & & AT2G02450 & ANAC035 \\
\hline & & AT4G30180 & bHLH146 & & AT2G42380 & AtBZIP34 \\
\hline & & AT1G49560 & MYB TF & & AT1G66380 & MYB114 \\
\hline & & AT4G00050 & UNE10 & & AT4G39070 & STH7 \\
\hline & & AT5G28300 & trihelix DNA & bind & AT1G69690 & TCP TF \\
\hline & & AT1G53910 & RAP2.12 & & AT3G06590 & AlF2 \\
\hline & & AT5G14750 & ATMYB66 & & AT5G39860 & PRE1 \\
\hline & & AT1G14600 & Myb-like TF & & AT1G21910 & AtERF012 \\
\hline & & AT1G69690 & TCP TF & & AT2G01570 & RGA1 \\
\hline & & AT1G56650 & PAP1 & & AT4G30180 & bHLH146 \\
\hline & & AT3G06590 & AlF2 & & AT1G66350 & RGL1 \\
\hline & & AT5G15150 & ATHB-3 & & АT3G15540 & IAA19 \\
\hline & & AT2G01570 & RGA1 & & АT3G28730 & ATHMG \\
\hline & & AT5G41920 & SCL25 & & AT5G14750 & ATMYB66 \\
\hline & & AT4G32890 & GATA9 & & AT1G14600 & Myb-like TF \\
\hline & & AT1G21910 & AtERF012 & & AT5G41920 & SCL25 \\
\hline & & & & & AT5G15150 & ATHB-3 \\
\hline \multirow[t]{7}{*}{ response to red or far red light } & 0,00085 & AT2G01570 & RGA1 & & AT4G32890 & GATA9 \\
\hline & & AT5G04190 & PKS4 & & & \\
\hline & & AT2G37640 & EXP3 & monooxigenase activity & 0,0025 AT5G25900 & GA3 \\
\hline & & AT4G32280 & IAA29 & & AT4G28720 & YUCCA8 \\
\hline & & AT4G25260 & invertase inh & ibitor & AT2G26710 & BAS1 \\
\hline & & AT1G15550 & GA3OX1 & & AT1G58440 & $\mathrm{XF1}$ \\
\hline & & AT5G51810 & GA200X2 & & AT5G38970 & BR6OX1 \\
\hline \multirow[t]{6}{*}{ response to jasmonic acid stimilus } & 0,0193 & AT1G66350 & RGL1 & lyase activity & 0,0244 AT3G51430 & YLS2 \\
\hline & & AT2G01570 & RGA1 & & АТ3G07010 & pectate lyase \\
\hline & & AT1G66380 & MYB114 & & AT1G27980 & DPL1 \\
\hline & & AT5G13220 & $\mathrm{JAZ10}$ & & AT1G67750 & pectate lyase \\
\hline & & AT1G56650 & PAP1 & & AT5G28020 & CYSD2 \\
\hline & & & & & AT4G37770 & ACS8 \\
\hline \multirow[t]{6}{*}{ response to salt stress } & 0,0366 & AT1G13930 & response to & stress & AT5G36160 & putative C-S lya \\
\hline & & AT2G01570 & RGA1 & & & \\
\hline & & AT1G66350 & RGL1 & & & \\
\hline & & AT1G56650 & PAP1 & & & \\
\hline & & AT2G33380 & RD20 & & & \\
\hline & & AT2G04240 & XERICO & & & \\
\hline \multirow[t]{5}{*}{ unidimensional cell growth } & 0,0115 & AT5G51810 & GA200X2 & & & \\
\hline & & AT4G25420 & GA200X1 & & & \\
\hline & & AT2G37640 & EXP3 & & & \\
\hline & & AT2G20750 & ATEXPB1 & & & \\
\hline & & AT2G40610 & ATEXPA8 & & & \\
\hline
\end{tabular}

\subsubsection{Direct regulation of the GA pathway by DELLA proteins}

The control of the homeostasis of GA levels in the plant is finely achieved through feedback and feedforward mechanisms that require the activity of the different elements of the GA signaling pathways (Hedden and Phillips, 2000; Yamaguchi, 2008). Besides, this mechanism also operates to control the level of GA receptors' transcripts 
(Griffiths et al., 2006). Recently Zentella et al. (2007) demonstrated the involvement of the DELLA protein RGA in this mechanism, as they showed RGA directly upregulates the expression of AtGA20ox2, AtGA3ox1, GA INSENSITIVE DWARF1a (GIDIa), and $G I D 1 b$ genes. In addition to these genes, we found AtGA20oxl, and AtGA20ox4 among the GAI-upregulated genes, and AtGA2ox8, GAI, and RGLI among the GAIdownregulated genes (Table 2.S1). The regulation of these genes by GAI was confirmed by analyzing their transcript levels in several GA-related mutants and transgenic lines (Figure 2.5A). Control on the expression of the majority of genes was shared with RGA and with other DELLA proteins -see for example regulation of AtGA20x8 gene expression that was repressed by PAC treatment to similar levels in the wild type and in the double null mutant gai-t6 rga-24.

The rapid change in the expression of these genes in response to gai-1 accumulation suggested to us that they might be direct targets. Thus, we tested this possibility by using transgenic lines that express a translational fusion between gai-1 and the glucocorticoid receptor domain from rats, under the control of the GAI promoter (Gallego-Bartolomé et al., 2011a). Dexamethasone treatment mimicked the effect on target gene expression that a heat-shock treatment provokes in the HS::gai-1 line, and this effect was not abolished by cyclohexmide indicating these genes are directly regulated by GAI, i.e. independently of protein synthesis (Figure 2.5B). These results broaden our current understanding of DELLA control on the homeostasis of the GA pathway and indicate that in etiolated seedlings this control includes: 1) genes coding for GA 2-oxidases, which indicates that DELLA proteins directly participate in the feedforward mechanism. And 2) genes coding for DELLA proteins, indicating that DELLA activity negatively regulates the expression of their own genes.

\subsubsection{DELLA proteins mediate direct cross-regulation with auxin and} ethylene pathways

The GO analysis also identified several genes involved in other hormone pathways as over-represented in our gene list, including the negative auxin signaling intermediates AUXIN/INDOL-3-ACETIC ACID19 (Aux/IAA19) (Tatematsu et al., 2004) and $A u x / I A A 29$ and two auxin-inducible SMALL AUXIN UPREGULATED genes (Table 2.S1). Additionally, other hormone-related genes were found in the gene list in spite that they were not selected by the GO analysis. 
A
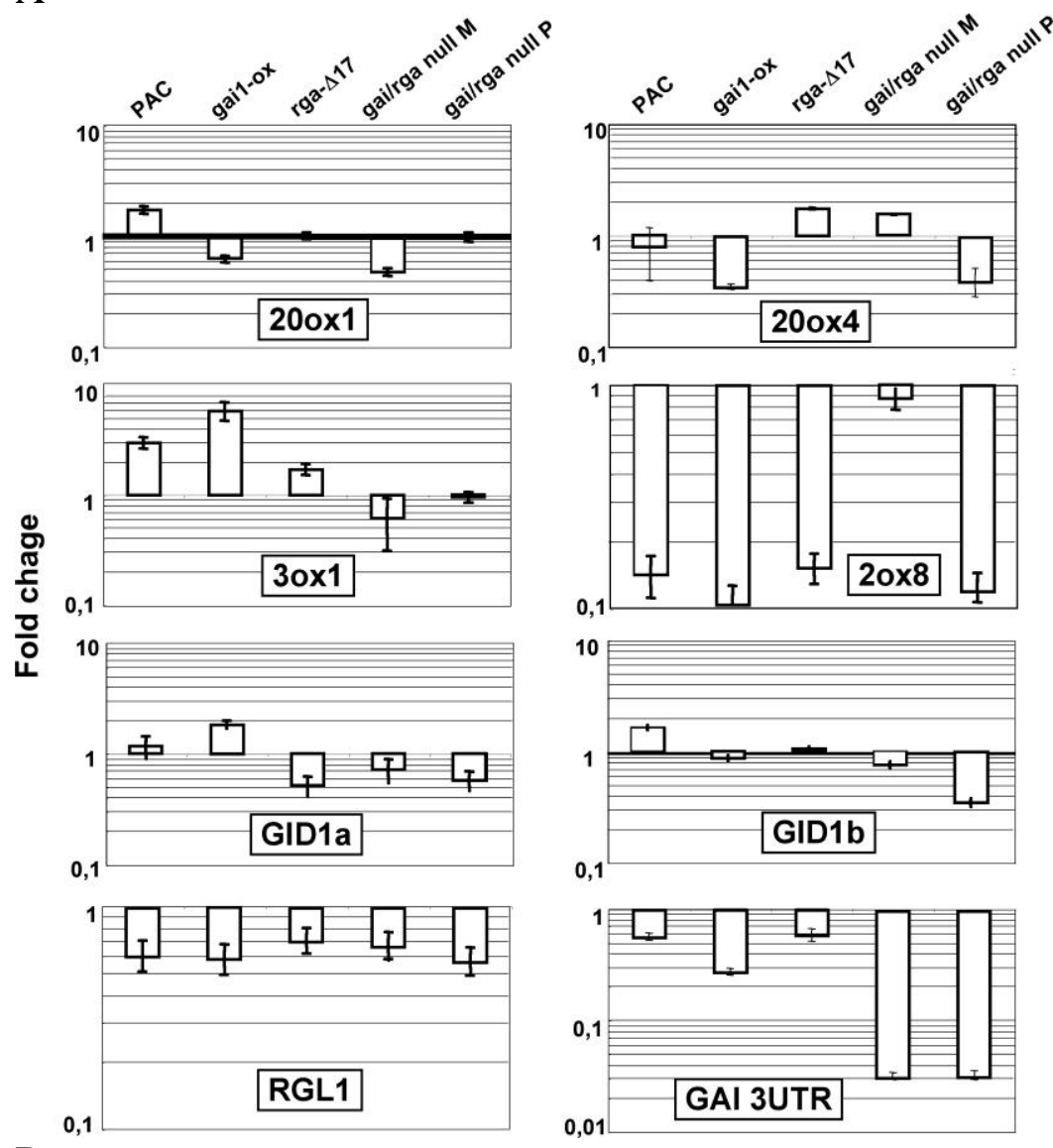

B
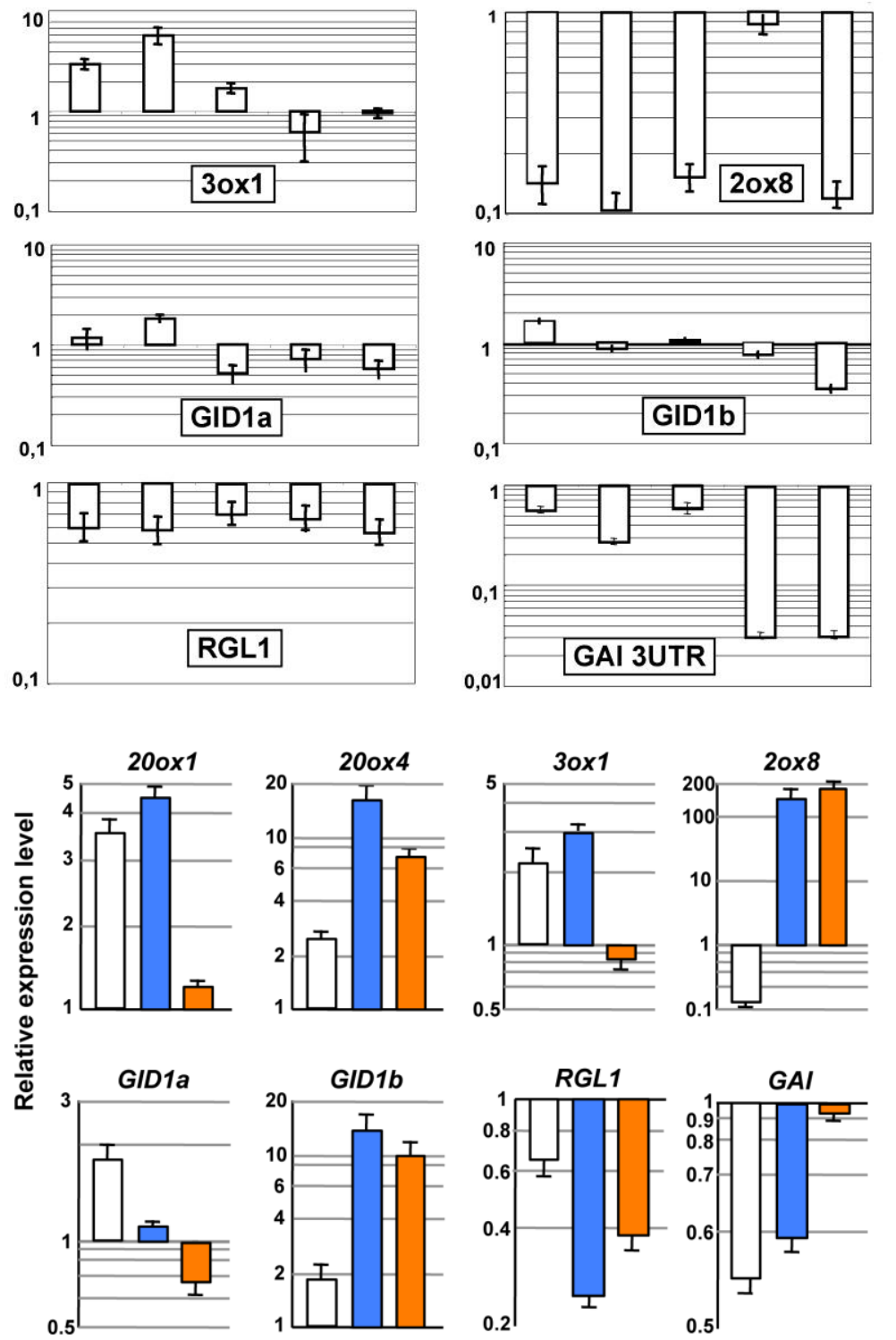

Figure 2.5. DELLA transcriptional regulation of GA metabolism and signaling genes.

A) Validation of gai- 1 target genes in independent experiment using PAC-grown seedlings and GA mutants. B) Direct regulation by gai-1 of target genes. Experiments with pGAI::gai-1-GR transgenic line demonstrated that "de novo" protein synthesis is not necessary for gai-1 modulation of target expression.

The list included INDOL-3-ACETIC ACID METHYLTRANSFERASE1 (IAMT1)

(Qin et al., 2005) and YUCCA3 (YUC3) involved in IAA inactivation (Li et al., 2007) and biosynthesis (Zhao et al., 2001), respectively, and the ethylene biosynthesis genes ACC SYNTHASE8 (ACS8) and ACS5/ETO2 (Vogel et al., 1998; Yamagami et al., 
2003). The GA control on the expression of some of these genes also involved other DELLA proteins, and their regulation by GAI resulted to be direct (Figure 2.6; (GallegoBartolome et al., 2011; Gallego-Bartolome et al., 2011)).

These results indicate the GA pathway may directly influence the metabolism and/or signaling cascades of other hormone pathways as a way to control different features of the skotomorphogenic developmental program. For instance, its effect on the auxin pathway through the control of $A u x / I A A 19$ expression seems to be relevant for GAs to confer certain plasticity to responses to tropic stimuli (Gallego-Bartolomé et al., 2011a), whereas cross-regulation of ethylene-related genes (ACS5 and ACS8) by GA proved to be relevant for the development of the apical hook (Gallego-Bartolomé et al, 2011b). It is worth noting that some of the putative pathway interactions reveled by our microarray analysis have not been previously described, for example the effect of the GA pathway might have on auxin metabolism, what adds new layers of complexity to the web of interactions involving hormone metabolism (Nemhauser et al., 2006).

\subsubsection{DELLAs impinge on transcriptional networks}

Several GO terms referring to transcription factors were also overrepresented among the GAI-regulated genes (Table 2.S1). The regulation by GAs of several genes of diverse families, including homeobox-leucine zipper (HOMEOBOX-LEUCINE ZIPPER PROTEIN3 and 7; HAT3 and HAT7) (Ciarbelli et al., 2008), MYB (PRODUCTION OF ANTHOCYANIN PIGMENT1, PAP1) (Borevitz et al., 2000), TCP (TCP15), and HLH (PACLOBUTRAZOL RESISTANT1 and 5; PRE1 and PRE5) (Lee et al., 2006), was confirmed in various GA-related mutants and transgenic lines (Figure 2.6). Importantly, the expression of these genes was directly regulated by GAI (Figure 2.6), which indicates that GA activity directly impinges cellular transcriptional networks to amplify its signal and thus to control the skotomorphogenic development. Remarkably, our results provide a molecular explanation for the observation that PRE1 expression, and likely that of PRE5, are induced by GAs and act as positive elements promoting several GA responses by acting downstream of GAI (Lee et al., 2006), and suggest that these HLH proteins also exert a role promoting skotomorphogenesis. Furthermore, this regulation might amplify the effect of the GA pathway on transcriptional networks since both proteins might act as dominant negative regulators of others bHLH by forming non DNA-binding heterodimers, as demonstrated, for 
instance, with the HLH protein HFR1 in the control of the shade avoidance response (Hornitschek et al., 2009).

In summary, our microarray analysis of early GAI targets indicates that DELLA activity directly participates in maintaining GA homeostasis and that modulates other hormone pathways and pre-existing transcriptional networks to control several aspects of etiolated growth.

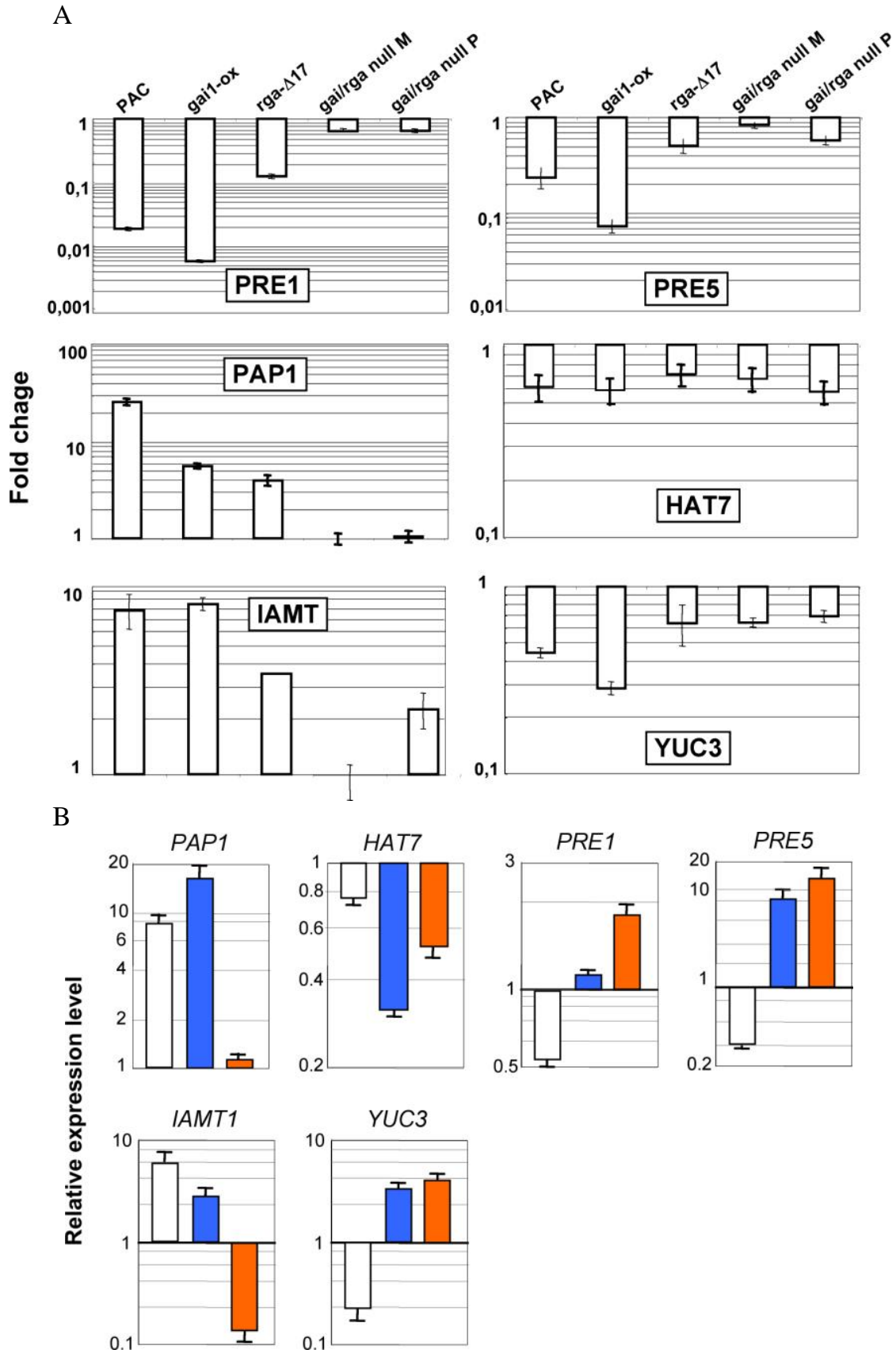

Figure 2.6. DELLA transcriptional regulation of transcription factor and hormone-related genes.

A) Validation of gai- 1 target genes in independent experiment using PAC-grown seedlings and GA mutants. B) Direct regulation by gai-1 of target genes. Experiments with $p G A I:: g a i-1-G R$ transgenic line demonstrated that "de novo" protein synthesis is not necessary for gai-1 modulation of target expression. 


\subsection{Conclusions}

The enormous plasticity in plant development depends on highly wired, interconnected signaling networks that properly integrate endogenous and environmental cues (Casal et al., 2003). In many cases, the cross-regulation between pathways occurs at the level of transcriptional regulation (Koppusamy et al., 2008). The output from the GA pathway largely relies on the activity of the transcriptional regulators DELLA proteins. Our transcriptomic analysis of DELLA responsive genes in etiolated seedlings reveals that the activity of the GA pathway has influence on other hormone pathways -ethylene and auxin- and on transcriptional networks that therefore amplify its signal. Importantly, it extends the repertoire of transcription factors that mediates this role to the Dof and type-B ARRs classes, and to E-box binding proteins beyond the PIFs and HY5, such as the brassinosteroid signaling elements BES1 and BZR1. Thus, the GA pathway contributes, at least at the transcriptional level, in the wiring of the signaling network that underlies plasticity.

\subsection{Materials \& Methods}

\section{Plant material and growth conditions}

Arabidopsis thaliana GA signaling dominant mutant rga- $\Delta 17$ (Dill et al., 2001), the double loss-of-function rga-24 gai-t6 (King et al., 2001) and pGAI::gai-1-GR (Gallego-Bartolomé et al, 2011a) are in the Ler background, while HS::gai-1 and the 35S::gai-1 (gai-1ox) (Alabadí et al., 2008) are derived from Col-0 accession. Seeds were sterilized and stratified for 6 days in water at $4^{\circ} \mathrm{C}$. Germination took place under white fluorescent light $\left(90-100 \mu \mathrm{mol} \mathrm{m} \mathrm{m}^{-2} \mathrm{~s}^{-1}\right)$ at $22^{\circ} \mathrm{C}$ for $6 \mathrm{~h}$ in a Percival growth chamber E-30B (http://www.percival-scientific.com). Seeds were plated in plates of half-strength MS medium with $0.8 \%(\mathrm{w} / \mathrm{v})$ agar and $1 \%(\mathrm{w} / \mathrm{v})$ sucrose supplemented with either $1 \square \mathrm{M} \mathrm{PAC}$ or mock treatment and grown in darkness at $22^{\circ} \mathrm{C}$ for 3 days. For short-term treatments, seedlings were incubated in the dark in water supplemented with $10 \mu \mathrm{M}$ CHX and/or $10 \square \mathrm{M}$ DEX. MS and PAC were from Duchefa (http://www.duchefa.com). DEX and CHX were from Sigma (http://www.sigmaaldrich.com). 


\section{Real-time quantitative RT-PCR}

RNA extraction, cDNA synthesis, quantitative RT-PCR (qRT-PCR), analysis, and primer sequences for amplification of AtGA20ox2 and EF1- $\alpha$ genes, used to normaliza all expression data, have been described (Frigerio et al., 2006). qRT-PCR oligonucleotides sequences for the other target genes are listed in the following table.

\begin{tabular}{l|c|l|l|}
\hline \multicolumn{1}{|c|}{ Gene } & $\begin{array}{c}\text { AGI } \\
\text { number }\end{array}$ & \multicolumn{1}{c|}{ forward primer (5' to 3') } & \multicolumn{1}{c}{ reverse primer (5' to 3') } \\
\hline 20ox1 & At4g25420 & CTTCCATCAACGTTCTCGAGC & GGTTTTGAAGGTCGATGAGAGG \\
20ox2 & At5g51810 & AGAAACCTTCCATTGACATTCCA & AGAGATCGATGAACGGGACG \\
20ox4 & At1g60980 & CTATCCAAAATGCAAGCAACCA & CAGTGAGGCCCCGTACCTAGT \\
2ox8 & At4g21200 & CATGGAGCAATGGCATGTACA & GGTTCGTCATCACACGGTGTT \\
3ox1 & At1g15550 & GATCTCCTCTTCTCCGCTGCT & GAGGGATGTTTTCACCGGTG \\
RGL1 & At1g66350 & TCAGTGGCGGTTAACTCGGT & GGGATGAGCTAAGAGGCGATG \\
GID1a & At3g05120 & GTGACGGTTAGAGACCGCGA & TCCCTCGGGTAAAAACGCTT \\
GID1b & At3g63010 & TCGCCCTGACGGTTCTTTC & TTACGGTCAAGGAACTCGGC \\
GAI 3'UTR & At1g14920 & AATGAATTGATCTGTTGAACCGG & GGCTTCGGTCGGAAATCTATC \\
PRE1 & At5g39860 & CAAATTTTGCCGGAGATTGG & GGCTGATGCCTTATCAGAACG \\
PRE5 & At3g28857 & CTCCGATGACCAGATGATCGA & GGCAAAAACTGACGGAGCTT \\
HAT7 & At5g15150 & TCCCTTCTTCGATCCGATCC & CAATATGGGTAGAGGTCGTGGTC \\
PAP1 & At1g56650 & TTGGTTCCTGAAGCGACGAC & GTCAAAAGCCAAGGTGTCCC \\
IAMT1 & At5g55250 & CTGCCTTCTCCTTGCATTGG & TATCCGTCACACTTTCCGGC \\
YUC3 & At1g04610 & AAGATCAAAATCGTCCCCGG & CTCAACTTTGCCTTTGCCGA
\end{tabular}

To analyze expression of transgenic gai-1 in the pHsp::gai-1 seedlings, we used an oligonucleotide annealing to the $5 \varnothing$ UTR of the HSP18.2 gene, which is included in the construct, as the forward primer ( $5 \phi$-CCCGAAAAGCAACGAACAAT-3ф), and an oligonucleotide annealing to the gai- 1 coding region as the reverse primer $(5 \phi-$ TCATTCATCATCATAGTCTTCTTATCTTGA-3ф).

\section{Gene expression analysis by long oligonucleotide microarrays}

Seeds of Arabidopsis Col-0 and HS::gai-1 transgenic line were sterilized, sown, stratified, and germinated as described above. Seedling were grown for 3 days in darkness at $22^{\circ} \mathrm{C}$. Then both wild type and transgenic seedlings were moved to $37^{\circ} \mathrm{C}$ for 30 minutes. After the heat-shock treatment plates were moved back to $22^{\circ} \mathrm{C}$. Samples were collected at time points $0,1,2$, and 4 hours after the beginning of the heat treatment. Three independent biological replicates were used for the analysis. Total RNA from whole seedlings was extracted as described above. RNA amplification, labeling, and hybridization of microarray slides were carried out as described (Bueso et 
al., 2007). Scanning of the slides, quantification of spots, and normalization were performed as previously described (Stavang et al., 2009).

\section{Promoter analysis}

Promoter analysis (http://element.cgrb.oregonstate.edu/) was done as previously described (14) using the ELEMENT webtool (http://element.cgrb.oregonstate.edu/). Logos were builted using the Weblogo webtool (http://weblogo.berkeley.edu/). The cluster lists are formulated by using the highest-count promoter core elements. All longer elements containing the core element are clustered together. PLACE database (http://www.dna.affrc.go.jp/PLACE/) was used to identify any known CIS-acting element.

\subsection{Bibliography}

Al-Shahrour F, Diaz-Uriarte R, Dopazo J (2005) Discovering molecular functions significantly related to phenotypes by combining gene expression data and biological information. Bioinformatics 21: 2988-2993

Alabadi D, Blazquez MA (2008) Integration of light and hormone signals. Plant Signal Behav 3: $448-449$

Alabadi D, Blazquez MA, Carbonell J, Ferrandiz C, Perez-Amador MA (2009) Instructive roles for hormones in plant development. Int J Dev Biol 53: 1597-1608

Alabadí D, Gallego-Bartolomé J, García-Cárcel L, Orlando L, Rubio V, Martínez C, Frigerio M, Iglesias-Pedraz JM, Espinosa A, Deng XW, Blázquez MA (2008) Gibberellins modulate light signaling pathways to prevent Arabidopsis seedling deetiolation in darkness. Plant J 53: 324-335

Alabadí D, Gil J, Blázquez MA, García-Martínez JL (2004) Gibberellins repress photomorphogenesis in darkness. Plant Physiol 134: 1050-1057

Arnaud N, Girin T, Sorefan K, Fuentes S, Wood TA, Lawrenson T, Sablowski R, Ostergaard L (2010) Gibberellins control fruit patterning in Arabidopsis thaliana. Genes Dev 24: 2127-2132

Ashburner M, Ball CA, Blake JA, Botstein D, Butler H, Cherry JM, Davis AP, Dolinski K, Dwight SS, Eppig JT, Harris MA, Hill DP, Issel-Tarver L, Kasarskis A, Lewis S, Matese JC, Richardson JE, Ringwald M, Rubin GM, Sherlock G (2000) Gene ontology: tool for the unification of biology. The Gene Ontology Consortium. Nat Genet 25: 25-29

Borevitz JO, Xia Y, Blount J, Dixon RA, Lamb C (2000) Activation tagging identifies a conserved MYB regulator of phenylpropanoid biosynthesis. Plant Cell 12: 2383-2394

Bueso E, Alejandro S, Carbonell P, Perez-Amador MA, Fayos J, Belles JM, Rodriguez PL, Serrano R (2007) The lithium tolerance of the Arabidopsis cat2 mutant reveals a crosstalk between oxidative stress and ethylene. Plant J 52: 1052-1065

Cao D, Cheng H, Wu W, Soo HM, Peng J (2006) Gibberellin mobilizes distinct DELLAdependent transcriptomes to regulate seed germination and floral development in Arabidopsis. Plant Physiol 142: 509-525 
Ciarbelli AR, Ciolfi A, Salvucci S, Ruzza V, Possenti M, Carabelli M, Fruscalzo A, Sessa G, Morelli G, Ruberti I (2008) The Arabidopsis homeodomain-leucine zipper II gene family: diversity and redundancy. Plant Mol Biol 68: 465-478

Crooks GE, Hon G, Chandonia JM, Brenner SE (2004) WebLogo: a sequence logo generator. Genome Res 14: 1188-1190

de Lucas M, Daviere JM, Rodriguez-Falcon M, Pontin M, Iglesias-Pedraz JM, Lorrain S, Fankhauser C, Blazquez MA, Titarenko E, Prat S (2008) A molecular framework for light and gibberellin control of cell elongation. Nature 451: 480-484

Dill A, Jung HS, Sun TP (2001) The DELLA motif is essential for gibberellin-induced degradation of RGA. Proc Natl Acad Sci U S A 98: 14162-14167

Dill A, Sun T (2001) Synergistic derepression of gibberellin signaling by removing RGA and GAI function in Arabidopsis thaliana. Genetics 159: 777-785

Feng S, Martinez C, Gusmaroli G, Wang Y, Zhou J, Wang F, Chen L, Yu L, IglesiasPedraz JM, Kircher S, Schafer E, Fu X, Fan LM, Deng XW (2008) Coordinated regulation of Arabidopsis thaliana development by light and gibberellins. Nature 451: 475-479

Foster R, Izawa T, Chua NH (1994) Plant bZIP proteins gather at ACGT elements. FASEB J 8: $192-200$

Frigerio M, Alabadí D, Pérez-Gómez J, García-Cárcel L, Phillips AL, Hedden P, Blázquez MA (2006) Transcriptional regulation of gibberellin metabolism genes by auxin signaling in Arabidopsis. Plant Physiol 142: 553-563

Fu X, Richards DE, Ait-Ali T, Hynes LW, Ougham H, Peng J, Harberd NP (2002) Gibberellin-mediated proteasome-dependent degradation of the barley DELLA protein SLN1 repressor. Plant Cell 14: 3191-3200

Gallego-Bartolome J, Arana MV, Vandenbussche F, Zadnikova P, Minguet EG, Guardiola V, Van Der Straeten D, Benkova E, Alabadi D, Blazquez MA (2011) Hierarchy of hormone action controlling apical hook development in Arabidopsis. Plant $\mathrm{J}$

Gallego-Bartolome J, Kami C, Fankhauser C, Alabadi D, Blazquez MA (2011) A hormonal regulatory module that provides flexibility to tropic responses. Plant Physiol

Gallego-Bartolome J, Minguet EG, Marin JA, Prat S, Blazquez MA, Alabadi D (2010) Transcriptional diversification and functional conservation between DELLA proteins in Arabidopsis. Mol Biol Evol 27: 1247-1256

Giuliano G, Pichersky E, Malik VS, Timko MP, Scolnik PA, Cashmore AR (1988) An evolutionarily conserved protein binding sequence upstream of a plant light-regulated gene. Proc Natl Acad Sci U S A 85: 7089-7093

Griffiths J, Murase K, Rieu I, Zentella R, Zhang ZL, Powers SJ, Gong F, Phillips AL, Hedden P, Sun TP, Thomas SG (2006) Genetic characterization and functional analysis of the GID1 gibberellin receptors in Arabidopsis. Plant Cell 18: $3399-3414$

Harberd NP, Belfield E, Yasumura Y (2009) The angiosperm gibberellin-GID1-DELLA growth regulatory mechanism: how an "inhibitor of an inhibitor" enables flexible response to fluctuating environments. Plant Cell 21: 1328-1339

Hedden P, Phillips AL (2000) Gibberellin metabolism: new insights revealed by the genes. Trends Plant Sci 5: 523-530

Heo JO, Chang KS, Kim IA, Lee MH, Lee SA, Song SK, Lee MM, Lim J (2011) Funneling of gibberellin signaling by the GRAS transcription regulator scarecrow-like 3 in the Arabidopsis root. Proc Natl Acad Sci U S A 108: 2166-2171

Hirano K, Asano K, Tsuji H, Kawamura M, Mori H, Kitano H, Ueguchi-Tanaka M, Matsuoka M (2010) Characterization of the Molecular Mechanism Underlying Gibberellin Perception Complex Formation in Rice. Plant Cell

Hornitschek P, Lorrain S, Zoete V, Michielin O, Fankhauser C (2009) Inhibition of the shade avoidance response by formation of non-DNA binding bHLH heterodimers. Embo J 28: 3893-3902 
Hou X, Hu WW, Shen L, Lee LY, Tao Z, Han JH, Yu H (2008) Global identification of DELLA target genes during Arabidopsis flower development. Plant Physiol 147: 11261142

Hou X, Lee LY, Xia K, Yan Y, Yu H (2010) DELLAs modulate jasmonate signaling via competitive binding to JAZs. Dev Cell 19: 884-894

Huq E, Quail PH (2002) PIF4, a phytochrome-interacting bHLH factor, functions as a negative regulator of phytochrome B signaling in Arabidopsis. EMBO J 21: 2441-2450

Itoh H, Matsuoka M, Steber CM (2003) A role for the ubiquitin-26S-proteasome pathway in gibberellin signaling. Trends Plant Sci 8: $492-497$

Jaillais Y, Chory J (2010) Unraveling the paradoxes of plant hormone signaling integration. Nat Struct Mol Biol 17: 642-645

King KE, Moritz T, Harberd NP (2001) Gibberellins are not required for normal stem growth in Arabidopsis thaliana in the absence of GAI and RGA. Genetics 159: 767-776

Lee J, He K, Stolc V, Lee H, Figueroa P, Gao Y, Tongprasit W, Zhao H, Lee I, Deng XW (2007) Analysis of transcription factor HY5 genomic binding sites revealed its hierarchical role in light regulation of development. Plant Cell 19: 731-749

Lee S, Yang KY, Kim YM, Park SY, Kim SY, Soh MS (2006) Overexpression of PRE1 and its homologous genes activates Gibberellin-dependent responses in Arabidopsis thaliana. Plant Cell Physiol 47: 591-600

Leivar P, Tepperman JM, Monte E, Calderon RH, Liu TL, Quail PH (2009) Definition of early transcriptional circuitry involved in light-induced reversal of PIF-imposed repression of photomorphogenesis in young Arabidopsis seedlings. Plant Cell 21: 35353553

Li L, Hou X, Tsuge T, Ding M, Aoyama T, Oka A, Gu H, Zhao Y, Qu LJ (2007) The possible action mechanisms of indole-3-acetic acid methyl ester in Arabidopsis. Plant Cell Rep

Mena M, Cejudo FJ, Isabel-Lamoneda I, Carbonero P (2002) A role for the DOF transcription factor BPBF in the regulation of gibberellin-responsive genes in barley aleurone. Plant Physiol 130: 111-119

Michael TP, Breton G, Hazen SP, Priest H, Mockler TC, Kay SA, Chory J (2008) A morning-specific phytohormone gene expression program underlying rhythmic plant growth. PLoS Biol 6: e225

Moubayidin L, Perilli S, Dello Ioio R, Di Mambro R, Costantino P, Sabatini S (2010) The rate of cell differentiation controls the Arabidopsis root meristem growth phase. Curr Biol 20: 1138-1143

Nemhauser JL, Hong F, Chory J (2006) Different plant hormones regulate similar processes through largely nonoverlapping transcriptional responses. Cell 126: $467-475$

Nemhauser JL, Mockler TC, Chory J (2004) Interdependency of brassinosteroid and auxin signaling in Arabidopsis. PLoS Biol 2: E258

Ogawa M, Hanada A, Yamauchi Y, Kuwahara A, Kamiya Y, Yamaguchi S (2003) Gibberellin biosynthesis and response during Arabidopsis seed germination. Plant Cell 15: $1591-1604$

Peng J, Carol P, Richards DE, King KE, Cowling RJ, Murphy GP, Harberd NP (1997) The Arabidopsis GAI gene defines a signaling pathway that negatively regulates gibberellin responses. Genes Dev 11: 3194-3205

Qin G, Gu H, Zhao Y, Ma Z, Shi G, Yang Y, Pichersky E, Chen H, Liu M, Chen Z, Qu LJ (2005) An indole-3-acetic acid carboxyl methyltransferase regulates Arabidopsis leaf development. Plant Cell 17: 2693-2704

Riechmann JL, Krizek BA, Meyerowitz EM (1996) Dimerization specificity of Arabidopsis MADS domain homeotic proteins APETALA1, APETALA3, PISTILLATA, and AGAMOUS. Proc Natl Acad Sci U S A 93: 4793-4798

Sakai H, Aoyama T, Oka A (2000) Arabidopsis ARR1 and ARR2 response regulators operate as transcriptional activators. Plant J 24: 703-711 
Shimada A, Ueguchi-Tanaka M, Nakatsu T, Nakajima M, Naoe Y, Ohmiya H, Kato H, Matsuoka M (2008) Structural basis for gibberellin recognition by its receptor GID1. Nature 456: 520-523

Stavang JA, Gallego-Bartolome J, Gomez MD, Yoshida S, Asami T, Olsen JE, GarciaMartinez JL, Alabadi D, Blazquez MA (2009) Hormonal regulation of temperatureinduced growth in Arabidopsis. Plant J 60: 589-601

Sun Y, Fan XY, Cao DM, Tang W, He K, Zhu JY, He JX, Bai MY, Zhu S, Oh E, Patil S, Kim TW, Ji H, Wong WH, Rhee SY, Wang ZY (2010) Integration of brassinosteroid signal transduction with the transcription network for plant growth regulation in Arabidopsis. Dev Cell 19: 765-777

Tatematsu K, Kumagai S, Muto H, Sato A, Watahiki MK, Harper RM, Liscum E, Yamamoto KT (2004) MASSUGU2 encodes Aux/IAA19, an auxin-regulated protein that functions together with the transcriptional activator NPH4/ARF7 to regulate differential growth responses of hypocotyl and formation of lateral roots in Arabidopsis thaliana. Plant Cell 16: 379-393

Tusher VG, Tibshirani R, Chu G (2001) Significance analysis of microarrays applied to the ionizing radiation response. Proc Natl Acad Sci U S A 98: 5116-5121

Ueguchi-Tanaka M, Ashikari M, Nakajima M, Itoh H, Katoh E, Kobayashi M, Chow TY, Hsing YI, Kitano H, Yamaguchi I, Matsuoka M (2005) GIBBERELLIN INSENSITIVE DWARF1 encodes a soluble receptor for gibberellin. Nature 437: 693698

Vogel JP, Woeste KE, Theologis A, Kieber JJ (1998) Recessive and dominant mutations in the ethylene biosynthetic gene ACS5 of Arabidopsis confer cytokinin insensitivity and ethylene overproduction, respectively. Proc Natl Acad Sci U S A 95: 4766-4771

Yamagami T, Tsuchisaka A, Yamada K, Haddon WF, Harden LA, Theologis A (2003) Biochemical diversity among the 1-amino-cyclopropane-1-carboxylate synthase isozymes encoded by the Arabidopsis gene family. J Biol Chem 278: $49102-49112$

Yamaguchi S (2008) Gibberellin metabolism and its regulation. Annu Rev Plant Biol 59: 225251

Yanagisawa S (2004) Dof domain proteins: plant-specific transcription factors associated with diverse phenomena unique to plants. Plant Cell Physiol 45: 386-391

Yu X, Li L, Zola J, Aluru M, Ye H, Foudree A, Guo H, Anderson S, Aluru S, Liu P, Rodermel S, Yin Y (2011) A brassinosteroid transcriptional network revealed by genome-wide identification of BESI target genes in Arabidopsis thaliana. Plant J 65: 634-646

Zentella R, Zhang ZL, Park M, Thomas SG, Endo A, Murase K, Fleet CM, Jikumaru Y, Nambara E, Kamiya Y, Sun TP (2007) Global analysis of della direct targets in early gibberellin signaling in Arabidopsis. Plant Cell 19: 3037-3057

Zhang ZL, Ogawa M, Fleet CM, Zentella R, Hu J, Heo JO, Lim J, Kamiya Y, Yamaguchi S, Sun TP (2011) Scarecrow-like 3 promotes gibberellin signaling by antagonizing master growth repressor DELLA in Arabidopsis. Proc Natl Acad Sci U S A 108: 21602165

Zhao Y, Christensen SK, Fankhauser C, Cashman JR, Cohen JD, Weigel D, Chory J (2001) A role for flavin monooxygenase-like enzymes in auxin biosynthesis. Science 291: 306-309

Zou X, Neuman D, Shen QJ (2008) Interactions of two transcriptional repressors and two transcriptional activators in modulating gibberellin signaling in aleurone cells. Plant Physiol 148: 176-186 

Chapter 3

A hormonal regulatory module that provides flexibility to tropic responses 



\section{1. Abstract}

Plants orient their growth depending on directional stimuli such as light and gravity, in a process known as tropic response. Tropisms result from asymmetrical accumulation of auxin across the responding organ relative to the direction of the stimulus, which causes differential growth rates on both sides of the organ. Here we show that gibberellins (GAs) attenuate the gravitropic reorientation of stimulated hypocotyls of dark-grown Arabidopsis seedlings. We show that the modulation occurs through induction of the expression of the negative regulator of auxin signaling IAA19/MSG2. The biological significance of this regulatory mechanism involving GAs and auxin seems to be the maintenance of a high degree of flexibility in tropic responses. This notion is further supported by observations that GA-deficient seedlings showed a much lower variance in the response to gravity compared to wild-type seedlings and that the attenuation of gravitropism by GAs resulted in an increased phototropic response. This suggests that the interplay between auxin and GAs may be particularly important for plant orientation under competing tropic stimuli. 


\subsection{INTRODUCTION}

One hundred and thirty years ago, Darwin described that plants can sense their environment and orient themselves for optimal growth and development (Darwin, 1880). Among the signals that promote a tropic response in plants, gravity is unique in that it is constant and unidirectional. Besides, it generally induces the underground tissues to bend towards the signal, and the aerial parts against the stimulating vector. Like in other tropisms, when plants perceive a change in their position relative to the gravity vector, they respond by differential growth on either side of the affected organ (Esmon et al., 2005), and several hormones have been involved in the control of these responses. Among them, auxin is instrumental because it forms a lateral gradient in response to the stimulus and thus establishes the framework for differential growth (Rashotte et al., 2000; Esmon et al., 2006). The differential response to auxin on either side of an organ has been shown to depend on the correct functioning of polar auxin transport and activity of auxin efflux carriers (Friml et al., 2002), and also on the activity of specific Aux/IAA and AUXIN RESPONSE FACTOR (ARF) transcriptional regulators (Harper et al., 2000; Tatematsu et al., 2004). Moreover, brassinosteroids have been proposed to enhance tropic reorientation by facilitating polar auxin transport (Meudt, 1987; Li et al., 2005; Kim et al., 2007).

Gibberellins (GAs) are also known to promote cell expansion (Cowling and Harberd, 1999). The molecular mechanism of GA signaling proceeds through GAinduced degradation of repressor proteins of the DELLA family by the proteasome, thereby activating transcription of growth-promoting genes (Schwechheimer, 2008). Given that GAs regulate growth, sometimes as a subsidiary signal of auxin action (Frigerio et al., 2006), the obvious hypothesis is that GAs would mediate the promotion of differential growth during gravitropic reorientation. However, here we show molecular evidence for a different role of GAs on gravitropism through the attenuation of auxin responsiveness, that results in an increased ability to modulate growth under competing tropic signals. 


\subsection{RESULTS}

\subsubsection{Gibberellin deficiency enhances gravitropic reorientation}

To test if GAs are necessary for the promotion of the differential cell expansion that underlies a tropic response, we examined the response of Arabidopsis etiolated hypocotyls to a gravitropic stimulus, under GA-limiting conditions. Surprisingly, paclobutrazol (PAC)-induced deficiency in GA biosynthesis not only did not impair gravitropic reorientation but, on the contrary, the hypocotyls of GA-deficient seedlings displayed an enhanced response to the gravitropic stimulus and a faster reorientation (Fig. 3.1A). This effect was observed at a low PAC concentration that did not inhibit seed germination, and was fully reverted by $\mathrm{GA}_{3}$ application, demonstrating the specificity of the inhibitor. Moreover, an enhanced rate of response was also evident in the gai- $1 D$ and $r g a-\Delta 17$ mutants, which express dominant versions of the DELLA proteins GIBBERELLIN INSENSITIVE (GAI) and REPRESSOR OF GA1 (RGA) respectively, that constitutively block GA-induced growth (Peng et al., 1997; Dill et al., 2001), (Fig. 3.1B, 3.1C). Since GA-deficiency also causes dwarfism, it is possible that the enhanced gravitropic response were due to an intrinsic capacity of smaller seedlings to display differential growth and bending. However, this is not the case, because transient induction of the dominant allele gai-1D increased the response to a gravitropic stimulus without affecting the size of the seedlings (Alabadí et al., 2008) (Fig. 3.1D). Therefore, we conclude that GAs attenuate the gravitropic response in aerial tissues, and that this regulation is likely a direct consequence of DELLA activity.

\subsubsection{Expression of IAA19/MSG2 is repressed by DELLA proteins}

DELLA proteins regulate gene expression in response to GAs (Zentella et al., 2007; de Lucas et al., 2008; Feng et al., 2008). Thus, to elucidate the molecular mechanism that underlies the regulation of gravitropism by GAs, we investigated by microarray analysis the transcriptional changes associated with transient expression of gai-1D in two-day-old dark-grown seedlings, i.e. under conditions where it promotes gravitropism (Fig. 3.1D).

To achieve transient expression of gai-1D, we used a transgenic line harbouring the gai-1D gene under the control of a heat-shock inducible promoter (Alabadí et al., 2008). Incubation of 3 -day-old etiolated seedlings at $37^{\circ} \mathrm{C}$ for $30 \mathrm{~min}$ led to altered 
A
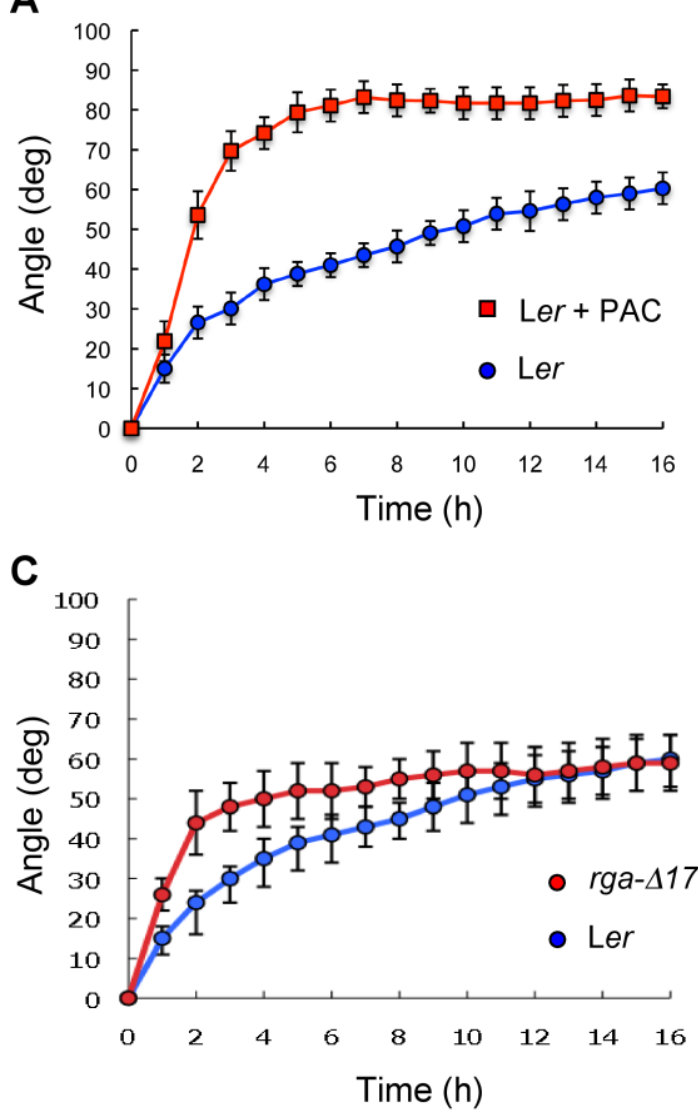

B

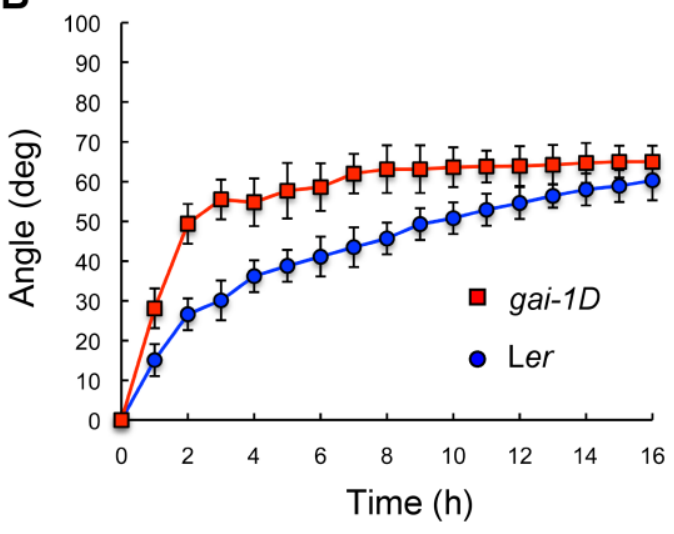

D

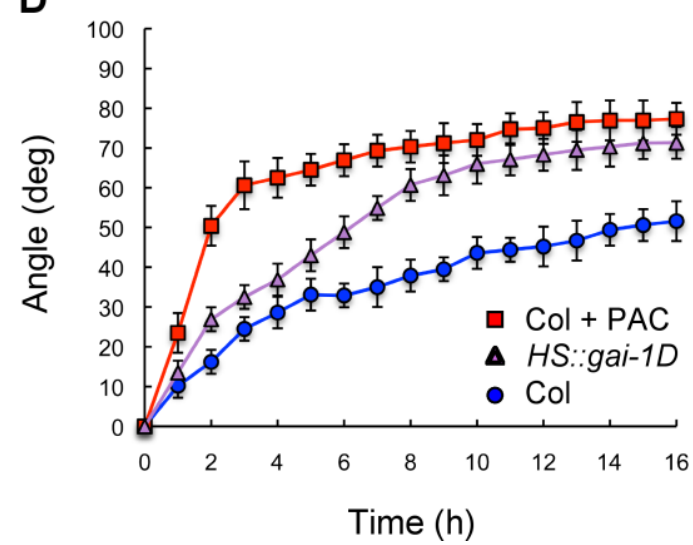

Fig. 3.1 Gravitropic reorientation of hypocotyls of GA deficient seedlings.

(A), (B), (C) Seedlings derived from Ler were grown for 3 days in darkness, and the plates were turned $90^{\circ}$ at time 0 . (D) Col and $H S::$ gai-1D seedlings were grown for 3 days in darkness and subject to a 30-min heat shock at $37^{\circ} \mathrm{C}$ before turning the plates $90^{\circ}$. Reorientation of the hypocotyls was monitored in darkness as explained in Materials and Methods. When used, paclobutrazol (PAC) concentration was $0.4 \mu \mathrm{M}$. Error bars represent SD ( $\mathrm{n}>16$ individual seedlings). The effect of PAC, gai- $1 D$ and rga 17 and $H S::$ gai- $1 D$ with respect to the wild type was statistically significant $(\mathrm{p}<0.05)$ as indicated by a two-way ANOVA test.

expression of around 150 genes 4 hours after the inductive stimulus when compared with wild-type seedlings subject to the same treatment (Chapter II).

Remarkably, expression of IAA19/MASSUGU2 (IAA19/MSG2), which encodes a member of the Aux/IAA family of proteins that negatively regulate auxin signaling (Tatematsu et al., 2004; Overvoorde et al., 2005), was steadily downregulated (Fig. 3.2A). The two closest paralogs of IAA19/MSG2, IAA5 and IAA6/SHORT HYPOCOTYL1 (IAA6/SHY1), were also repressed following gai-1D induction (Fig. 3.2A), and the expression of all these genes was consistently lower in dark-grown seedlings of the gai- $1 D$ and rga- $\Delta 17$ mutants, or in the presence of $1 \mu \mathrm{M}$ PAC (Fig. $3.2 \mathrm{~B})$. 
To determine if the regulation of these genes by GAI was direct, we constructed a glucocorticoid-inducible version of gai-1D by fusing it to the rat glucocorticoid receptor domain (GR) (Lloyd et al., 1994; Aoyama and Chua, 1997), under the control of the GAI promoter. As expected, induction of gai-1D translocation into the nucleus by dexamethasone application caused repression of IAA19/MSG2, IAA5 and IAA6/SHY1, and this repression was not blocked by cycloheximide (Fig. 3.2C).

A

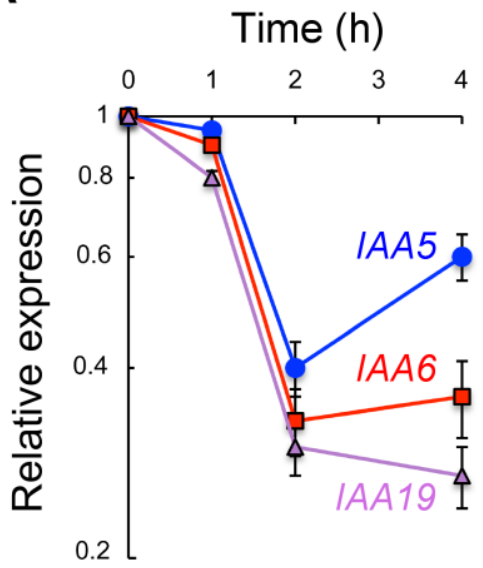

B

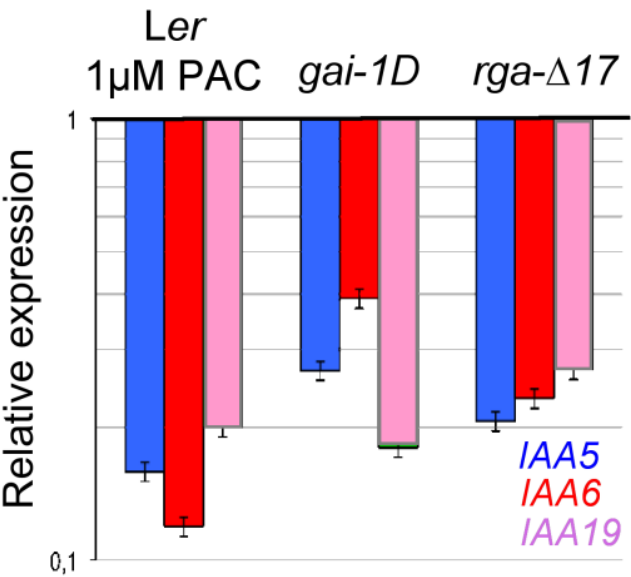

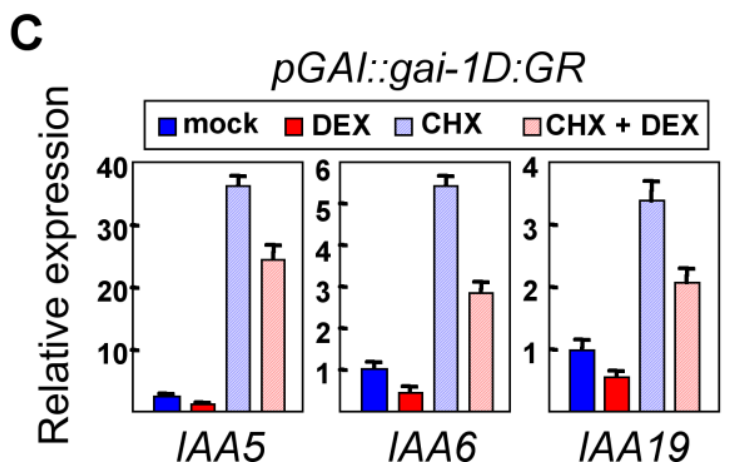

Fig. 3.2 Regulation of Aux/IAA gene expression by DELLA proteins.

(A) Expression of IAA5, IAA6 and IAAI9 determined by RT-qPCR in 3-day-old dark-grown HS::gai$1 D$ seedlings after a 30 -min heat shock at $37^{\circ} \mathrm{C}$. Values at each time-point are relative to the expression of each gene in seedlings not subject to heat shock (A). Error bars represent s.e.m. $(n=3$ biological replicates).

(B) The expression of IAA5, IAA6, and IAA19 was determined by RT-qPCR in 3-day-old wild-type and mutant seedlings grown in darkness. The values indicate the expression level of each gene relative to the value of the wild type grown in MS. Error bars represent SD (n=3).

(C) Expression of IAA5, IAA6 and IAA19 determined by RT-qPCR in 3-day-old dark-grown seedlings expressing a fusion between gai-1D and the glucocorticoid receptor $(G R)$ under the control of the GAI promoter. 3-day-old dark-grown seedlings were transferred into flasks and incubated with soft shaking for $6 \mathrm{~h}$ with a mock solution or with $10 \mu \mathrm{M}$ dexamethasone (DEX) to allow gai-1D:GR moving to the nucleus and regulate target genes. Alternatively, seedlings were also incubated with $10 \mu \mathrm{M}$ cycloheximide $(\mathrm{CHX})$ to prevent de novo protein synthesis during mock or DEX treatments. Values are relative to the expression of each gene in mock-treated seedlings. Error bars represent s.e.m. $(n=3$ biological replicates). 
The repression of IAA19/MSG2 expression upon GA deficiency was also evident in etiolated seedlings harbouring a transcriptional fusion between the IAA19/MSG2 promoter and the GUS reporter gene (Fig.3.3A). Higher expression levels were detected, as previously reported (Tatematsu et al., 2004), in the apical part of darkgrown seedlings, and the level of expression decreased upon PAC application in a dosedependent manner (Fig 3.3B).

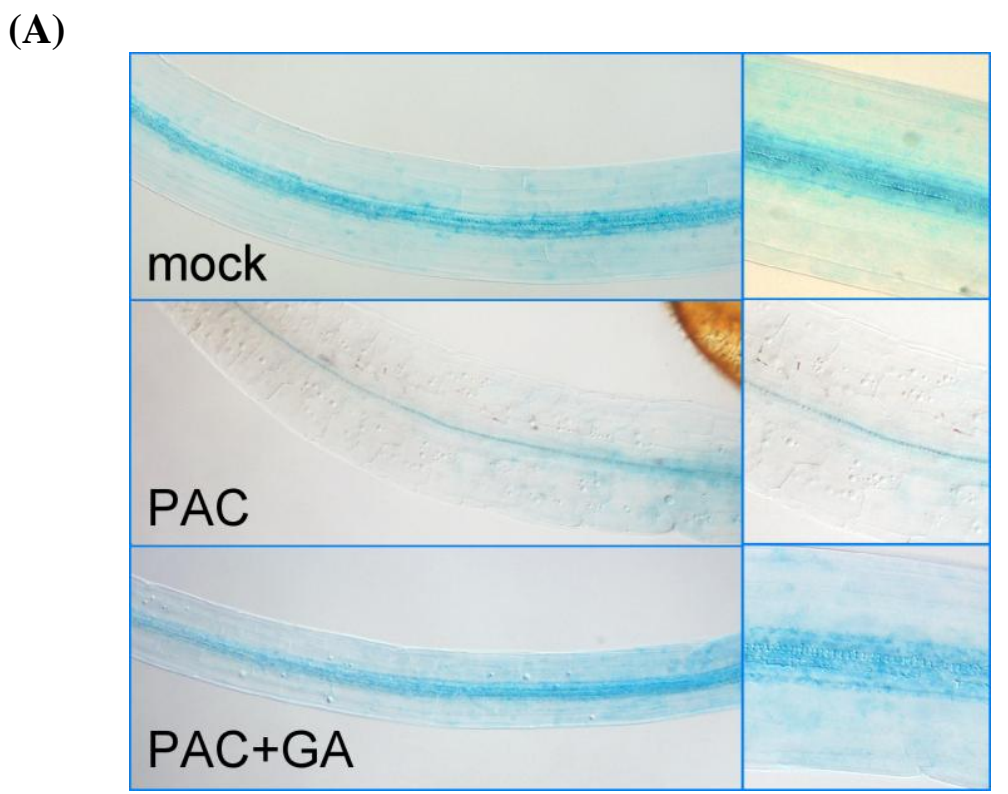

(B)

\section{PAC $(\mu \mathrm{M})$}

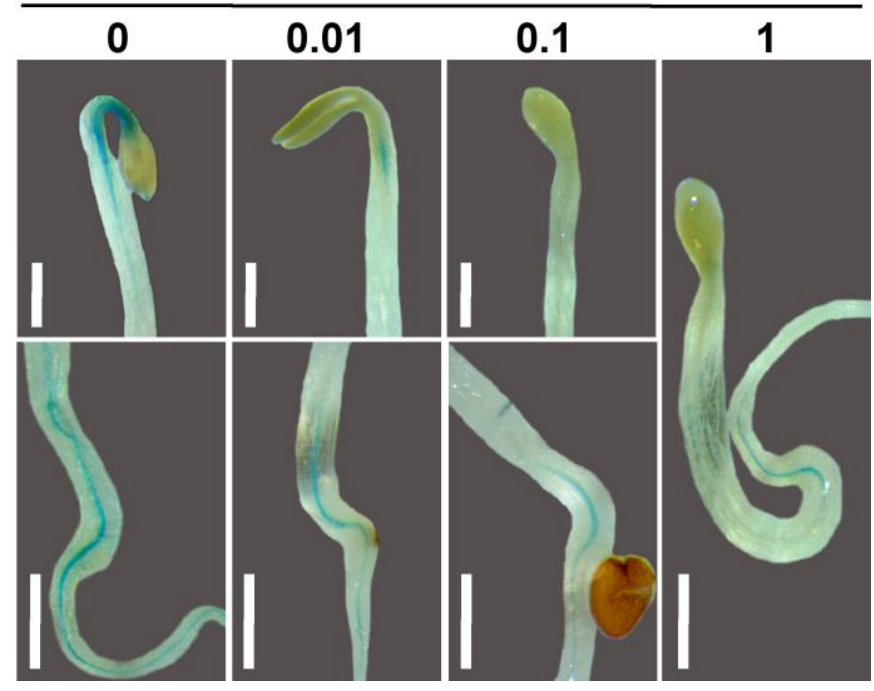

Fig. 3.3 Transcriptional regulation of MSG2/IAA19 by GA in etiolated seedlings

(A) Transcriptional regulation of MSG2/IAA19 by GA in etiolated seedlings during gravitropic reorientation. PAC concentration was $1 \mu \mathrm{M}$. GA $\mathrm{GA}_{3}$ concentration was $10 \mu \mathrm{M}$ (B) Localization of MSG2/IAA19 expression in etiolated seedlings. Photographs reproduce the reported expression of $M S G 2$ in the apex of hypocotyls and in the upper part of the roots. Scale bars represent $0.5 \mathrm{~mm}$. 
The observation that IAA19/MSG2 is a direct target for GAI transcriptional regulation provides a likely mechanism for the attenuation of gravitropism by GAs. The dominant msg2-1 mutation that prevents IAA19/MSG2 destabilization by auxin has been shown to impair gravitropic responses presumably by blocking ARF activity (Tatematsu et al., 2004). Thus, to investigate the degree of involvement of IAA19/MSG2 in the repression of the gravitropic response by GAs, we asked whether DELLA accumulation would alleviate the agravitropic phenotype of the seedlings that carry the hyperstable allele msg2-1. In agreement with our observation that PAC decreases the activity of the IAA19/MSG2 promoter (Fig. 3.4), growth of etiolated seedlings in the presence of $0.4 \mu \mathrm{M}$ PAC prevented the accumulation in the nuclei of msg2-1:GFP protein expressed from the IAA19/MSG2 promoter (Muto et al., 2007) (Fig. 3.4A). And, concurrently, this treatment restored an almost normal reorientation capacity to msg2-1 mutant seedlings (Fig. 3.4B). We thus conclude that GAs modulate gravitropism at least partly through the transcriptional regulation of IAA19/MSG2 expression.

A

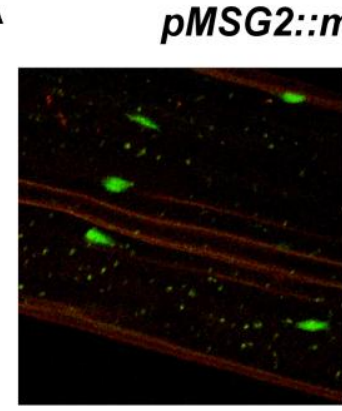

mock

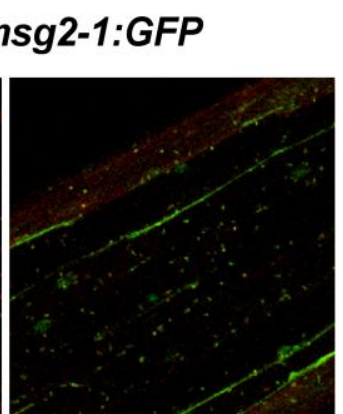

PAC

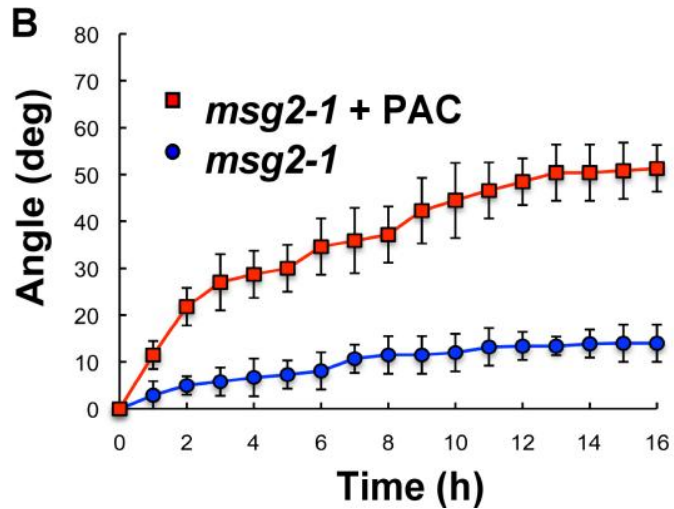

Time (h)

Fig. 3.4 Involvement of IAA19/MSG2 in the regulation of gravitropism by GA.

(A) Reduction of IAA19/Msg2-1 protein levels caused by impairement of GA biosynthesis. A pMSG2::msg2-1:GFP transgenic line was grown for 3 days in darkness with and without $0.4 \mu \mathrm{M}$ PAC, and GFP fluorescence in hypocotyls was visualized under a confocal microscope. (B) Gravitropic reorientation of hypocotyls of $m s g 2-1$ seedlings. Seedlings were grown for 3 days in darkness on control media or in media supplemented with $0.4 \mu \mathrm{M}$ PAC, and the plates were turned $90^{\circ}$ at time 0 . Reorientation of the hypocotyls was monitored in darkness as explained in Materials and Methods. Error bars represent SD ( $\mathrm{n}>16$ individual seedlings). 
5.3.3. Physiological relevance of the regulation of gravitropism by gibberellins

The results shown here indicate that GAs -and hence the level of DELLA proteins- influence the gravitropic response of aerial tissues, but what is the physiological relevance of this regulation? Can changes in DELLA abundance within the physiological range still affect gravitropism? Indeed, seedlings of the quadruple DELLA KO mutant did suffer a delay in the gravitropic response when grown in the light (Fig. 3.5A), a situation that causes DELLA accumulation in the wild type (Achard et al., 2007), confirming that the ability to respond to gravistimulation directly depends on the relative concentration of DELLA proteins. In agreement with this, a quadruple DELLA KO mutant did not show any difference, compared to the wild type, in the speed or extent of reorientation after gravistimulation in darkness, when GAs are not in limiting concentrations (Fig. 3.).

A

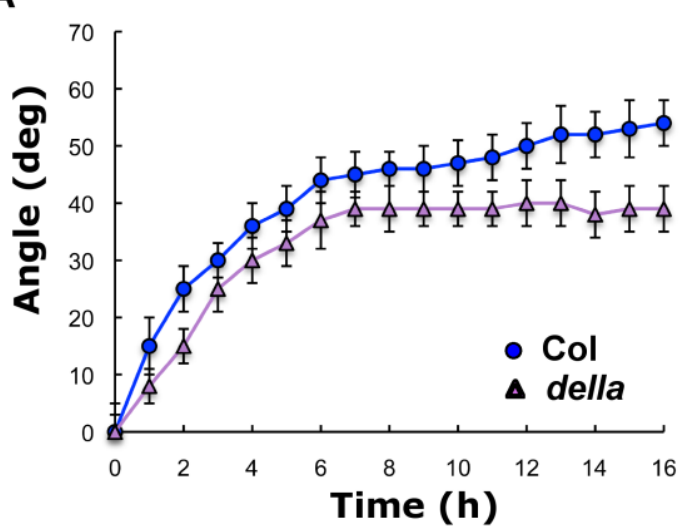

B

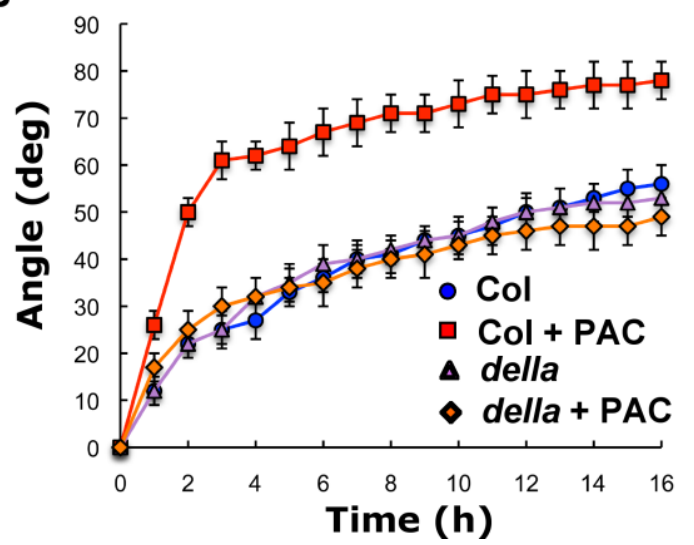

Fig. 3.5 Gravitropic reorientation of hypocotyls of quadruple della (gai rga rgll rgl2) knockout mutants.

Seedlings were grown for 3 days in darkness on MS, and the plates were turned $90^{\circ}$ at time 0 . In (A), seedlings were exposed to $150 \mu \mathrm{mol} \mathrm{m} \mathrm{m}^{-1}$ of white light during $8 \mathrm{~h}$ prior to reorientation, while in (B), dark-grown seedlings were used. All values between 2 and 16 hours in (A) are statistically different $(\mathrm{p}<0.01)$ between the della mutant and the parental control. PAC concentration was $0.4 \mu \mathrm{M}$. Error bars represent SD ( $>46$ individual seedlings). The behaviour of the della mutant was statistically significant $(\mathrm{p}<0.05)$ with respect to the wild type as indicated by a two-way ANOVA test.

However, a more critical consequence of the attenuation of auxin responsiveness by GAs is the increase in variance of the gravitropic response when large populations of Arabidopsis seedlings were examined right after germination. As shown in Fig. 3.6A, individual seedlings grown for 3 days in darkness displayed certain degree of 
inclination (between 5 and $10^{\circ}$ ) with respect to the gravity vector under normal GA concentrations, but this variation practically disappeared when GA biosynthesis or GA signaling were compromised (with PAC, or in the gai-1D mutant). The mechanism by which GAs cause this variance is very likely equivalent to the one through which GAs control gravitropic reorientation (i.e., through IAA19/MSG2), given that $m s g 2-1$ mutants showed a much larger variance compared to the wild type, which was consequently reduced by PAC (Fig. 3.6A).

To study whether the increase in variance of the gravitropic response caused by GAs could confer any adaptive advantage, we examined the behavior of seedling populations grown under two competing signals: a light source perpendicular to the gravity vector (i.e., photo- versus gravitropism). As shown in Fig. 3.6B, the increased gravitropic response caused by the presence of PAC, led to a reduction in phototropic orientation in wild-type seedlings. This effect was also observed when phototropic reorientation was monitored after illumination of dark-grown seedlings with lateral blue light (Fig. 3.6C). On the contrary, the aphototropic phototropinl (photl) mutant, impaired in the main light receptor that regulates phototropism (Esmon et al., 2005), still responded to $\mathrm{PAC}$ with a severe increase in gravitropic response arguing against the direct regulation of phototropism by GAs (Tsuchida-Mayama et al., 2010). Competition between gravi- and phototropism has been proposed to be mediated by the phyA photoreceptor (Lariguet and Fankhauser, 2004; Whippo and Hangarter, 2004; Iino, 2006). Interestingly, the phytochrome A (phyA) mutant shows reduced response to PAC (Fig. 3.6B) suggesting a connection between GA action and the regulation of gravitropism by phyA. These observations highlight a specific role of GA-induced regulation of gravitropic response in a situation of competing environmental signals.

\subsection{DISCUSSION}

The work presented here reveals an unexpected role for GAs in the control of the response of plants to gravity, and highlights the physiological relevance of a novel interaction between DELLA proteins and the expression of $A u x / I A A$ genes.

The main line of evidence that supports the relevance of IAA19/MSG2 in the control of gravitropism by GAs is the observation that the agravitropic phenotype caused by the dominant $m s g 2-1$ allele was alleviated by inhibiting GA biosynthesis 
(Fig. 3.4B). This result at least indicates that transcriptional regulation of IAA19/MSG2 by GAs has a significant impact in the gravitropic response of etiolated seedlings. Our work also shows that the regulation of IAA19/MSG2 expression by DELLA proteins does not require protein synthesis (Fig. 3.2C).

A

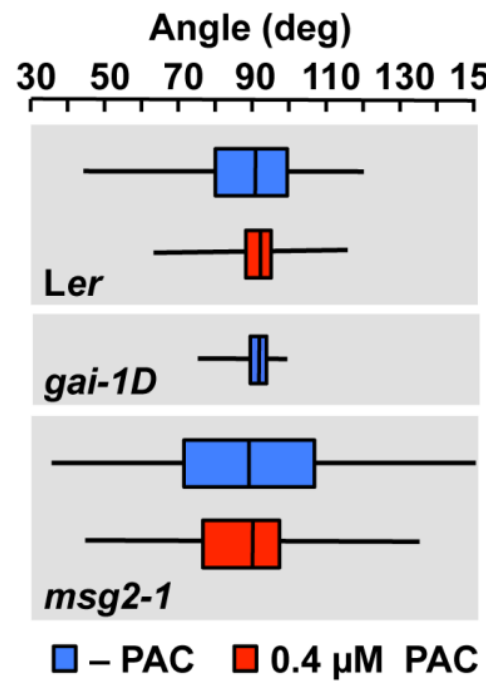

B

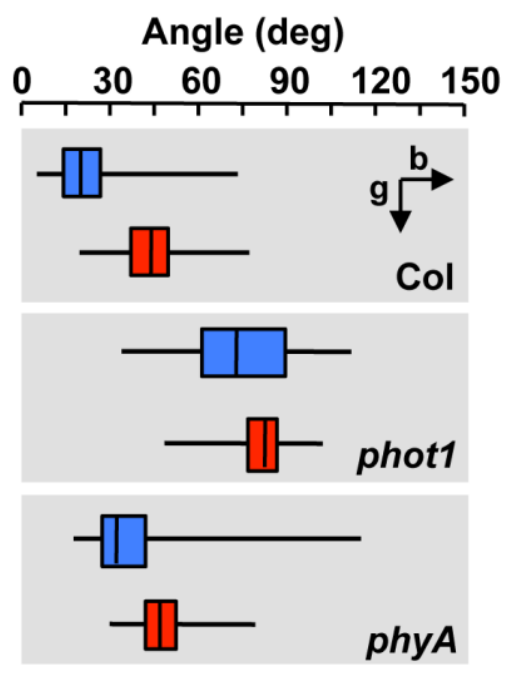

C

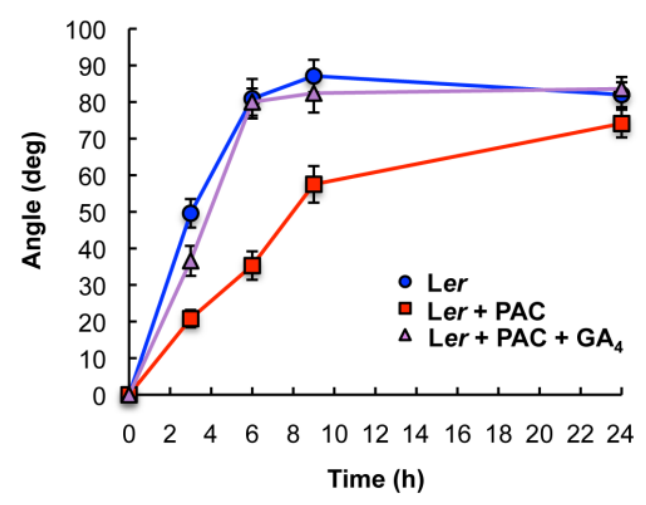

Fig. 3.6 Physiological relevance of the regulation of gravitropism by GAs.

(A) Distribution of hypocotyl orientation of 3-day-old seedlings in darkness in the presence and absence of PAC. Seedlings were grown on vertical MS plates and the angle with respect to a horizontal line was recorded, with $90^{\circ}$ being perfectly vertical.

(B) Distribution of hypocotyl orientation of 3-day-old seedlings under continuous unilateral blue light $\left(10 \mathrm{nmol} \mathrm{m} \mathrm{m}^{-2} \mathrm{~s}^{-1}\right)$, coming from the left as indicated by the arrow. The angle with respect to a horizontal line was recorded, with $90^{\circ}$ being perfectly vertical. Boxes represent the middle quartiles around the median (bisecting line), while the whiskers represent the upper and lower quartiles. The data represent the values of $65-130$ seedlings.

(C) Effect of GA deficiency on phototropic reorientation. Seedlings were grown for 3 days in darkness in the presence or abscence of $0.4 \mu \mathrm{M} \mathrm{PAC}$ and $10 \mu \mathrm{M} \mathrm{GA}_{4}$, and illuminated with $10 \mu \mathrm{mol}$ $\mathrm{m}^{-2} \mathrm{~s}^{-1}$ lateral blue light at time 0 . Monitorization of reorientation was carried out as explained in Materials and Methods. 
Since DELLA proteins do not bind DNA directly, it is highly likely that they regulate transcription of IAA9/MSG2 through the interaction with other transcription factors. Two such mechanisms have been proposed so far: the inhibition of DNA binding of members of the PHYTOCHROME-INTERACTING FACTOR (PIF) family of bHLH transcription factors (de Lucas et al., 2008; Feng et al., 2008), and the inhibitory interaction with JASMONATE-ZIM-DOMAIN (JAZ) proteins (Hou et al., 2010), which in turn regulate MYC2 activity in jasmonic acid signaling. There are no indications that JA signaling is involved in gravitropic responses, but it is reasonable to think that DELLA proteins interact with PIFs already present at high levels in darkgrown seedlings to directly regulate the expression of the target $A u x / I A A$ genes. In agreement with this model, the expression of IAA19 is strongly reduced in etiolated pifq mutants (Leivar et al., 2009), although there is no experimental evidence to date showing direct interaction between any PIF transcription factor and the IAA19 promoter.

A critical issue in the control of the gravitropic response is the spatial localization of the machinery that perceives gravity and directs reorientation. Starchloaded amyloplasts have been shown to be an integral part of the mechanism that allows gravity perception (Boonsirichai et al., 2003), and cells accumulating amyloplasts are located in the tip of the roots and in the endodermis of aerial tissues, such as the hypocotyl. Given that GAs affect gravitropic responses in hypocotyls, it is tempting to suggest that GA signaling interferes with the early events after gravity perception in the endodermis, but this hypothesis requires additional experimental evidence.

In any case, our observation that GAs regulate the gravitropism at an early stage does not diminish the role of the auxin gradient as the driving force in the orientation of the plant with respect to the gravity vector. Rather, GAs would act by fine tuning the formation of this gradient and modulating the responsiveness to this gradient in auxin responding cells. However, we cannot rule out that GAs also affect auxin relocalization, therefore establishing a reinforcing mechanism.

Interestingly, our results do not support an important role of GAs in the execution of cell expansion during gravitropic reorientation, but highlight a function of GAs in the generation of variance in the response. A higher degree of variance or noise 
in biological responses is a trait often selected by nature, and proposed to be at the core of the mechanisms that drive robust morphogenesis (Houchmandzadeh et al., 2002; Yucel and Small, 2006), and speciation (Braendle and Felix, 2008). In microorganisms, even adaptation of a population to the environment seems to be based, to some extent, on cell-to-cell variance within genetic circuits (Balaban et al., 2004; Sanchez and Kondev, 2008). Not many molecular mechanisms have been proposed that explain the generation of noise in cellular systems (Casal et al., 2004), and the attenuation of auxin response by GAs might represent one of such mechanisms to provide flexibility in situations under which plants face competing tropic signals. Such could be the case of plants that must optimize their access to light because of neighbors' proximity. The observation that DELLA protein concentration decreases in seedlings during the shade avoidance response (Djakovic-Petrovic et al., 2007) supports this scenario. In that case, part of the shade avoidance mechanism may involve the attenuation of gravitropism to allow bending against the gravity vector.

\subsection{MATERIALS AND METHODS}

\section{Plants and growth conditions}

Arabidopsis thaliana GA signaling dominant mutants gai-1D and rga- $\Delta 17$, and the quadruple loss-of-function rga-24 gai-t6 rgl2-1 rgll-1 (Cheng et al., 2004) are in the Ler background, while the other lines used in this work, such as msg2-1 (Tatematsu et al., 2004), photl (Huala et al., 1997), phyA (Nagatani et al., 1993), HS::gai-1D (Alabadí et al., 2008), pMSG2::GUS (Tatematsu et al., 2004), and pMSG2::msg21:GFP (Muto et al., 2007), are derived from Col-0 accession. For all experiments, seeds were surface sterilized and stratified for $4-7$ days at $4^{\circ} \mathrm{C}$ in darkness. Germination was induced under continuous white fluorescent light $\left(90-100 \mu \mathrm{mol} \mathrm{m}^{-2} \mathrm{~s}^{-1}\right)$ for 8 hours, and then the plates were kept in darkness at $22^{\circ} \mathrm{C}$.

\section{Construction of transgenic lines}

To obtain the transgenic line pGAI::gai-1D:GR, the gai-1D coding sequence was amplified from genomic DNA of the gai-1D mutant with primers: GAId-BamHI-F (GGA TCC ATG AAG AGA GAT CAT CAT CAT CA) and GAId-SacI-R (GAG CTC 
ATT GGT GGA GAG TTT CCA AGC CGA) and cloned into the pCR2.1 vector (Invitrogen), and the BamHI-SacI fragment was subcloned into pGreen0029-35S::GR (Hellens et al., 2000) to give rise to pG35::gai-1D:GR. The GAI promoter was PCR amplified from genomic DNA using oligos pGAI-KpnI-F (GGT ACC TGG GAC CAC AGT CTA AAT GGC GT) and pGAI-XbaI-R (TCT AGA GGT TGG TTT TTT TTC AGA GAT GGA), cloned into the pCR2.1 vector, and the KpnI-XbaI fragment transferred into pG35::gai-1D:GR to construct pGAI::gai-1D:GR. Agrobacterium C58 pSOUP cells were transformed with pGAI::gai1-GR and Arabidopsis Ler plants were transformed using the floral dip method (Clough and Bent, 1998). Transgenic seedlings with a 3:1 segregation ratio for kanamycin resistance conferred by the transgene marker were selected for further work.

\section{Gene expression analysis}

Total RNA extraction, cDNA synthesis and quantitative PCR, were carried out as described previously (Frigerio et al., 2006) using EF1- $\alpha$ expression for normalization. The primers used were: IAA19 (CTC GGG CTT GAG ATA ACG GA and CCA CAT CTC TCC CCG GAA), IAA5 (AAC TAC GGC TAG GTC TTC CCG and AGA TGG ACT CAC CGG AGA CG) and IAA6 (TGG CAA AGG AAG GTC TAG CAC and TGG AAG ACC CAA TCG AAG CT).

GUS staining was carried out as described previously (Frigerio et al., 2006).

Detailed description of the microarray experiment will be published somewhere else. Briefly, HS::gai-1D and Col-0 seedlings were grown for 3 days at $22^{\circ} \mathrm{C}$ in darkness on half strength MS medium (Duchefa) with $0.8 \% \mathrm{w} / \mathrm{v}$ agar and $1 \% \mathrm{w} / \mathrm{v}$ sucrose, and then the plates were transferred to $37^{\circ} \mathrm{C}$ for $30 \mathrm{~min}$. Samples were collected before, and 1, 2, $4 \mathrm{~h}$ after the beginning of the heat treatment. Three independent biological replicates were used for the analysis. RNA amplification, labeling, and hybridization of microarray slides (70-mer oligonucleotide arrays that represent the majority of the Arabidopsis genes: http://www.ag.arizona.edu/microarray) were carried out as previously described (Bueso et al., 2007). Hybridization was set up to isolate genes differentially expressed in HS::gai-1D compared to Col-0 at each time point. 


\section{Tropism tests}

To determine the angle of seedling emergence, seedlings were grown for 3 days in darkness at $22^{\circ} \mathrm{C}$ in a vertical orientation on plates containing half strength $\mathrm{MS}$ medium (Duchefa) with $0.8 \% \mathrm{w} / \mathrm{v}$ phytoagar and without sucrose, and supplemented with mock or $0.4 \mu \mathrm{M}$ PAC. After 3 days the plates were photographed.

For reorientation experiments, the conditions were the same as above but after 3 days of growth the plates were reoriented $90^{\circ}$ relative to the initial growth angle. Reorientation was recorded every hour under infrared light using CCD cameras coupled to Metamorph software as described by Schepens et al (Schepens et al., 2008).

To test blue light-induced phototropism, seedlings were grown for 3 days under $10 \mathrm{nmol} \mathrm{m} \mathrm{s}^{-1}$ of continuous unilateral blue light at $22^{\circ} \mathrm{C}$ in a vertical orientation on plates containing half strength MS medium (Duchefa) with $0.8 \% \mathrm{w} / \mathrm{v}$ phytoagar and without sucrose and supplemented with mock or $0.4 \mu \mathrm{M}$ PAC. After 3 days, the plates were photographed.

In all cases, angles were measured using Image $\mathrm{J}$ software.

\section{Acknowledgements}

We thank Kiyosi Tatematsu and the Arabidopsis Biological Resource Center for providing us with mutant and transenic lines. We also thank François Parcy (PSVCNRS, Grenoble) for fruitful discussions and hosting MAB, and Cristina Ferrándiz (IBMCP, Valencia) and Detlef Weigel (MPI for Developmental Biology, Tubingen) for very useful comments on the manuscript. JGB is the recipient of a CSIC JAE Fellowship.

\subsection{BIBLIOGRAPHY}

Achard P, Liao L, Jiang C, Desnos T, Bartlett J, Fu X, Harberd NP (2007) DELLAs Contribute to Plant Photomorphogenesis. Plant Physiol 143: 1163-1172

Alabadí D, Gallego-Bartolomé J, García-Cárcel L, Orlando L, Rubio V, Martínez C, Frigerio M, Iglesias-Pedraz JM, Espinosa A, Deng XW, Blázquez MA (2008) Gibberellins modulate light signaling pathways to prevent Arabidopsis seedling deetiolation in darkness. Plant J 53: 324-335

Aoyama T, Chua NH (1997) A glucocorticoid-mediated transcriptional induction system in transgenic plants. Plant J 11: 605-612 
Balaban NQ, Merrin J, Chait R, Kowalik L, Leibler S (2004) Bacterial persistence as a phenotypic switch. Science 305: 1622-1625

Boonsirichai K, Sedbrook JC, Chen R, Gilroy S, Masson PH (2003) ALTERED RESPONSE TO GRAVITY is a peripheral membrane protein that modulates gravityinduced cytoplasmic alkalinization and lateral auxin transport in plant statocytes. Plant Cell 15: 2612-2625

Braendle C, Felix MA (2008) Plasticity and errors of a robust developmental system in different environments. Dev Cell 15: 714-724

Bueso E, Alejandro S, Carbonell P, Perez-Amador MA, Fayos J, Belles JM, Rodriguez PL, Serrano R (2007) The lithium tolerance of the Arabidopsis cat 2 mutant reveals a crosstalk between oxidative stress and ethylene. Plant J 52: 1052-1065

Casal JJ, Fankhauser C, Coupland G, Blázquez MA (2004) Signalling for developmental plasticity. Trends Plant Sci 9: 309-314

Cheng H, Qin L, Lee S, Fu X, Richards DE, Cao D, Luo D, Harberd NP, Peng J (2004) Gibberellin regulates Arabidopsis floral development via suppression of DELLA protein function. Development 131: 1055-1064

Clough SJ, Bent AF (1998) Floral dip: a simplified method for Agrobacterium-mediated transformation of Arabidopsis thaliana. Plant J 16: 735-743

Cowling RJ, Harberd NP (1999) Gibberellins control Arabidopsis hypocotyl growth via regulation of cellular elongation. J Exp Bot 50: 1351-1357

Darwin C (1880) The Power of Movement in Plants. John Murray, London

de Lucas M, Davière JM, Rodríguez-Falcón M, Pontin M, Iglesias-Pedraz JM, Lorrain S, Fankhauser C, Blázquez MA, Titarenko E, Prat S (2008) A molecular framework for light and gibberellin control of cell elongation. Nature 451: 480-484

Dill A, Jung HS, Sun TP (2001) The DELLA motif is essential for gibberellin-induced degradation of RGA. Proc Natl Acad Sci U S A 98: 14162-14167

Djakovic-Petrovic T, de Wit M, Voesenek LA, Pierik R (2007) DELLA protein function in growth responses to canopy signals. Plant J 51: 117-126

Esmon CA, Pedmale UV, Liscum E (2005) Plant tropisms: providing the power of movement to a sessile organism. Int J Dev Biol 49: 665-674

Esmon CA, Tinsley AG, Ljung K, Sandberg G, Hearne LB, Liscum E (2006) A gradient of auxin and auxin-dependent transcription precedes tropic growth responses. Proc Natl Acad Sci U S A 103: 236-241

Feng S, Martinez C, Gusmaroli G, Wang Y, Zhou J, Wang F, Chen L, Yu L, IglesiasPedraz JM, Kircher S, Schafer E, Fu X, Fan LM, Deng XW (2008) Coordinated regulation of Arabidopsis thaliana development by light and gibberellins. Nature 451: 475-479

Frigerio M, Alabadí D, Pérez-Gómez J, García-Cárcel L, Phillips AL, Hedden P, Blázquez MA (2006) Transcriptional regulation of gibberellin metabolism genes by auxin signaling in Arabidopsis. Plant Physiol 142: 553-563

Friml J, Wisniewska J, Benkova E, Mendgen K, Palme K (2002) Lateral relocation of auxin efflux regulator PIN3 mediates tropism in Arabidopsis. Nature 415: 806-809

Harper RM, Stowe-Evans EL, Luesse DR, Muto H, Tatematsu K, Watahiki MK, Yamamoto K, Liscum E (2000) The NPH4 locus encodes the auxin response factor ARF7, a conditional regulator of differential growth in aerial Arabidopsis tissue. Plant Cell 12: 757-770

Hellens RP, Edwards EA, Leyland NR, Bean S, Mullineaux PM (2000) pGreen: a versatile and flexible binary Ti vector for Agrobacterium-mediated plant transformation. Plant Mol Biol 42: 819-832

Hou X, Lee LY, Xia K, Yan Y, Yu H (2010) DELLAs modulate jasmonate signaling via competitive binding to JAZs. Dev Cell 19: 884-894

Houchmandzadeh B, Wieschaus E, Leibler S (2002) Establishment of developmental precision and proportions in the early Drosophila embryo. Nature 415: 798-802

Huala E, Oeller PW, Liscum E, Han IS, Larsen E, Briggs WR (1997) Arabidopsis NPH1: a protein kinase with a putative redox-sensing domain. Science 278: 2120-2123 
Iino M (2006) Toward understanding the ecological functions of tropisms: interactions among and effects of light on tropisms. Curr Opin Plant Biol 9: 89-93

Kim TW, Lee SM, Joo SH, Yun HS, Lee Y, Kaufman PB, Kirakosyan A, Kim SH, Nam KH, Lee JS, Chang SC, Kim SK (2007) Elongation and gravitropic responses of Arabidopsis roots are regulated by brassinolide and IAA. Plant Cell Environ 30: 679689

Lariguet P, Fankhauser C (2004) Hypocotyl growth orientation in blue light is determined by phytochrome A inhibition of gravitropism and phototropin promotion of phototropism. Plant J 40: 826-834

Leivar P, Tepperman JM, Monte E, Calderon RH, Liu TL, Quail PH (2009) Definition of Early Transcriptional Circuitry Involved in Light-Induced Reversal of PIF-Imposed Repression of Photomorphogenesis in Young Arabidopsis Seedlings. Plant Cell 21: 3535-3553

Li L, Xu J, Xu ZH, Xue HW (2005) Brassinosteroids stimulate plant tropisms through modulation of polar auxin transport in Brassica and Arabidopsis. Plant Cell 17: 27382753

Lloyd AM, Schena M, Walbot V, Davis RW (1994) Epidermal cell fate determination in Arabidopsis: patterns defined by a steroid-inducible regulator. Science 266: 436-439

Meudt WJ (1987) Investigations on the Mechanism of the Brassinosteroid Response: VI. Effect of Brassinolide on Gravitropism of Bean Hypocotyls. Plant Physiol 83: 195-198

Muto H, Watahiki MK, Nakamoto D, Kinjo M, Yamamoto KT (2007) Specificity and similarity of functions of the Aux/IAA genes in auxin signaling of Arabidopsis revealed by promoter-exchange experiments among MSG2/IAA19, AXR2/IAA7, and SLR/IAA14. Plant Physiol 144: 187-196

Nagatani A, Reed JW, Chory J (1993) Isolation and Initial Characterization of Arabidopsis Mutants That Are Deficient in Phytochrome A. Plant Physiol 102: 269-277

Overvoorde PJ, Okushima Y, Alonso JM, Chan A, Chang C, Ecker JR, Hughes B, Liu A, Onodera C, Quach H, Smith A, Yu G, Theologis A (2005) Functional genomic analysis of the AUXIN/INDOLE-3-ACETIC ACID gene family members in Arabidopsis thaliana. Plant Cell 17: 3282-3300

Peng J, Carol P, Richards DE, King KE, Cowling RJ, Murphy GP, Harberd NP (1997) The Arabidopsis GAI gene defines a signaling pathway that negatively regulates gibberellin responses. Genes Dev 11: 3194-3205

Rashotte AM, Brady SR, Reed RC, Ante SJ, Muday GK (2000) Basipetal auxin transport is required for gravitropism in roots of Arabidopsis. Plant Physiol 122: 481-490

Sanchez A, Kondev J (2008) Transcriptional control of noise in gene expression. Proc Natl Acad Sci U S A 105: 5081-5086

Schepens I, Boccalandro HE, Kami C, Casal JJ, Fankhauser C (2008) PHYTOCHROME KINASE SUBSTRATE4 Modulates Phytochrome-Mediated Control of Hypocotyl Growth Orientation. Plant Physiol 147: 661-671

Schwechheimer C (2008) Understanding gibberellic acid signaling--are we there yet? Curr Opin Plant Biol 11: 9-15

Tatematsu K, Kumagai S, Muto H, Sato A, Watahiki MK, Harper RM, Liscum E, Yamamoto KT (2004) MASSUGU2 encodes Aux/IAA19, an auxin-regulated protein that functions together with the transcriptional activator NPH4/ARF7 to regulate differential growth responses of hypocotyl and formation of lateral roots in Arabidopsis thaliana. Plant Cell 16: 379-393

Tsuchida-Mayama T, Sakai T, Hanada A, Uehara Y, Asami T, Yamaguchi S (2010) Role of the phytochrome and cryptochrome signaling pathways in hypocotyl phototropism. Plant J

Úbeda-Tomás S, Swarup R, Coates J, Swarup K, Laplaze L, Beemster GT, Hedden P, Bhalerao R, Bennett MJ (2008) Root growth in Arabidopsis requires gibberellin/DELLA signalling in the endodermis. Nat Cell Biol 10: 625-628

Whippo CW, Hangarter RP (2004) Phytochrome modulation of blue-light phototropism. Plant Cell Environ 27: 1223-1228 
Yucel G, Small S (2006) Morphogens: precise outputs from a variable gradient. Curr Biol 16: R29-31

Zentella R, Zhang ZL, Park M, Thomas SG, Endo A, Murase K, Fleet CM, Jikumaru Y, Nambara E, Kamiya Y, Sun TP (2007) Global analysis of della direct targets in early gibberellin signaling in Arabidopsis. Plant Cell 19: 3037-3057 

Chapter 4

\section{Hierarchy of hormone action controlling apical} hook development in Arabidopsis 



\subsection{ABSTRACT}

The apical hook develops in the upper part of the hypocotyl when seeds buried in the soil germinate, and serves to protect cotyledons and the shoot apical meristem from possible damage caused by pushing through the soil. The curvature is formed through differential cell growth occurring at the two opposite sides of the hypocotyl, and it is established by a gradient of auxin activity and refined by the coordinated action of auxin and ethylene. Here we show that gibberellins (GAs) promote hook development through the transcriptional regulation of several genes of the ethylene and auxin pathways in Arabidopsis. The level of GA activity determines the speed of hook formation and the extent of the curvature during the formation phase independently of ethylene, likely by modulating auxin transport and response through $H L S 1, P I N 3$, and PIN7. Moreover, GAs cooperate with ethylene in preventing hook opening, in part through the induction of ethylene production mediated by ACS5/ETO2 and ACS8. 


\subsection{INTRODUCTION}

The acquisition of developmental innovations has accompanied the evolution of land plants (Langdale, 2008). A key innovation in seed plants is skotomorphogenesis (Wei et al., 1994), an alternative to photomorphogenesis when seeds face germination in darkness, for example when they are buried in the soil. Importantly, skotomorphogenesis provides protection to emerging seedlings while pushing through the soil, especially to the shoot apical meristem (SAM) and cotyledons (Kami et al., 2010). In dicotyledonous plants, these vital structures are protected by an apical hook in the hypocotyl that "pulls" them through the soil. Indeed, hookless mutants are not able to emerge when seeds germinate buried in the soil (Harpham, 1991).

The apical hook is mainly formed through differential elongation between the cells at opposite sides of the hypocotyl (Raz and Ecker, 1999). Hook development follows three phases: formation, maintenance, and opening (Raz and Ecker, 1999; Vandenbussche et al., 2010; Zadnikova et al., 2010). The formation phase extends from the time when germination is completed until the hook curvature reaches $\sim 180^{\circ}$ and it usually takes $\sim 24 \mathrm{~h}$ in Arabidopsis thaliana. Then, the curvature is actively maintained in parallel to extensive hypocotyl elongation. Hook maintenance can be interrupted by light, and then full opening is completed typically in $6 \mathrm{~h}$ (Liscum and Hangarter, 1993; Wu et al., 2010). If seedlings are kept in the dark, the hook is maintained for $24 \mathrm{~h}$, and opening is completed 70-90 h later (Vandenbussche et al., 2010; Zadnikova et al., 2010).

The differential cell growth that underlies hook development is caused by an asymmetrical accumulation of auxin (Kuhn and Galston, 1992; Lehman et al., 1996). Pharmacological treatments or mutations that affect either auxin accumulation (Boerjan et al., 1995; Zhao et al., 2001; Stepanova et al., 2008), transport (Lehman et al., 1996; Chaabouni et al., 2009; Vandenbussche et al., 2010; Zadnikova et al., 2010), or signalling (Stowe-Evans et al., 1998; Nagpal et al., 2000; Li et al., 2004; Tatematsu et al., 2004; Yang et al., 2004; Zadnikova et al., 2010) influence apical hook development. Auxin accumulation marks the side with the lower growth rate in the apical hook (Kuhn and Galston, 1992; Raz and Ecker, 1999). 
Besides auxin, other hormones participate in apical hook development. For example, exogenous treatment with ethylene induces the formation of exaggerated hooks whereas ethylene insensitive mutants are hookless (Guzman and Ecker, 1990). Similarly, gibberellins (GAs) are also required for correct hook development, given that a block in either GA synthesis or signalling results in a hookless phenotype (Achard et al., 2003; Alabadí et al., 2004; Vriezen et al., 2004).

The concurrence of multiple hormones controlling a given output is a common theme in plant development (Alabadí and Blázquez, 2009), although their precise mode of action is not always clear. For instance, in the case of hook development, ethylene influences the auxin pathway (Li et al., 2004; Stepanova et al., 2008; Vandenbussche et al., 2010; Zadnikova et al., 2010), suggesting that ethylene requires auxin to control hook formation; but on the other hand, ethylene application is able to reverse the hook phenotype of the auxin mutant nph4 (Harper et al., 2000). Additionally, GAs act through ethylene in the control of hook development (Achard et al., 2003; Vriezen et al., 2004), but no molecular mechanism has been found yet.

To unveil the hierarchy of hormone action during hook development, we have investigated in detail the requirement for each hormone in a dynamic way from the time of hook formation to its opening phase, we have searched for gene targets downstream of GA action in the context of hook development, and we have tested the physiological relevance for this regulatory interactions in vivo.

\subsection{RESULTS}

\subsubsection{Dynamics of GA-regulated apical hook development}

To determine the phase of apical hook development in which GA activity is required, we performed a kinematic analysis of this process in Ler wild type plants untreated and treated with the GA biosynthesis inhibitor paclobutrazol (PAC), as well as in gai-1 and quintuple della mutants. gai-1 encodes a dominant version of the DELLA protein GAI that constitutively inhibits GA signalling; the della mutant, which lacks all DELLA proteins of Arabidopsis, shows a fully activated GA pathway (Peng et al., 1997; Feng et al., 2008). Untreated wild type seedlings displayed the three phases of 
hook development (Figure 4.1a) (Vandenbussche et al., 2010; Zadnikova et al., 2010). On the contrary, seedlings were not able to form the apical hook when treated with 0.2 $\mu \mathrm{M}$ PAC; instead, they gradually entered into the opening phase (Figure 4.1a). gai-1 mutants behaved similarly to PAC-treated seedlings although they started to form the hook, reaching a maximum angle of $121.4 \pm 9.5^{\circ} 20 \mathrm{~h}$ after germination (Figure $4.1 \mathrm{~b}$ ). Notably, della seedlings showed exaggerated apical hooks (the maximum angle was $241.8 \pm 7.9^{\circ}$ ) as a consequence of a faster kinetics of hook formation during the initial phase, whereas they behaved as the wild type during the other phases.

These results indicate that GA signalling is both necessary and limiting during the formation phase, and therefore the magnitude of hook curvature depends on this activity during the initial phase. In addition, GA activity is also necessary, yet not limiting, to delay hook opening.

(a)

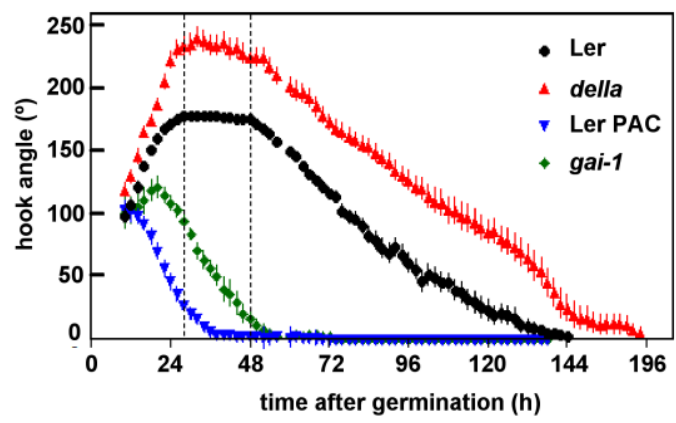

(b)

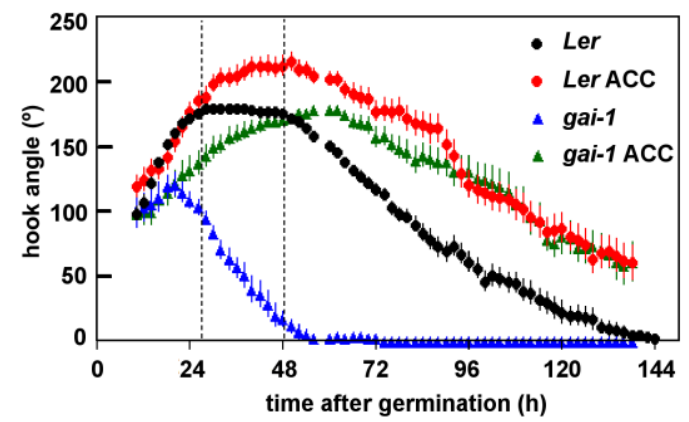

Figure 4.1 Regulation of apical hook development by GAs and ethylene.

(a) Kinematic analysis of hook development in Ler wild type seedlings mock-treated and treated with $0.2 \mathrm{mM}$ PAC, as well as in mock-treated gai-1 and della seedlings.

(b) Kinematic analysis of hook development in Ler wild type and gai-1 seedlings grown on control medium or with $10 \mathrm{mM}$ ACC. Dotted vertical lines represent the transition between phases. All error bars represent s.e.m. $(n>20)$.

\subsubsection{GA control on hook development is dependent and independent upon} ethylene activity

Exaggerated apical hooks also appear when ethylene activity is high (Guzman and Ecker, 1990). The exaggerated curvature in response to the ethylene precursor 1aminocyclopropane-1-carboxylate acid (ACC) was due to a delay in the transition between formation and maintenance phases (Figure 4.2a) (Vandenbussche et al., 2010; Zadnikova et al., 2010). Importantly, it was the level of GA activity, and not of 
ethylene, which set up the speed of hook formation (Figures 4.2a,c and 4.1b). This suggests that both hormones act through different mechanisms during the initial phase, since ethylene is also necessary for hook formation (Vandenbussche et al., 2010). To test if GA-mediated hook formation depends to some extent on ethylene activity, we analyzed hook development in the ethylene insensitive mutant ein2-1 (Guzman and Ecker, 1990). ein2-1 seedlings failed to complete hook formation (Vandenbussche et $a l ., 2010)$, whereas it was partially restored by GA-treatment (Figure 4.1c).

Analysis of mutants with low or null hormone activity suggested that both hormones are important to prevent hook opening (Figure 4.1a,c) (Vandenbussche et al., 2010). The kinetics of hook opening was very similar in della and in wild type seedlings, and it remained unaltered when the latter were treated with a saturating amount of ACC (Figure 4.1b). Remarkably, the exaggerated hooks of della seedlings did not open after ACC-treatment (Figure 4.1b).

These results indicate that 1) GAs determine the rate of the hook formation and the extent of the curvature reached during this phase; 2) this role is partially independent of ethylene; 3) ethylene is necessary to complete this phase, although the response seems saturated; and 4) both hormones act jointly to prevent hook opening.

(a)

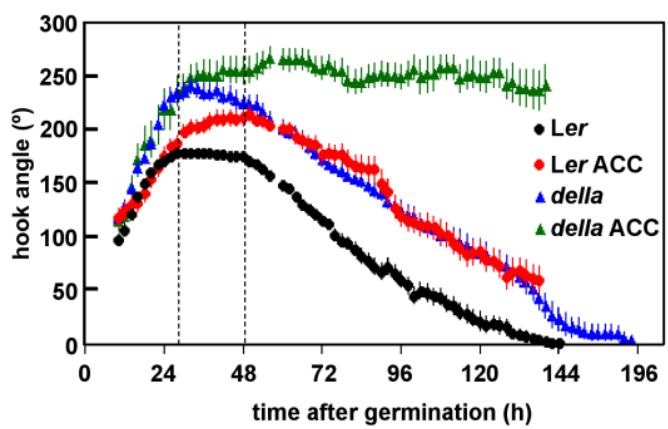

(b)

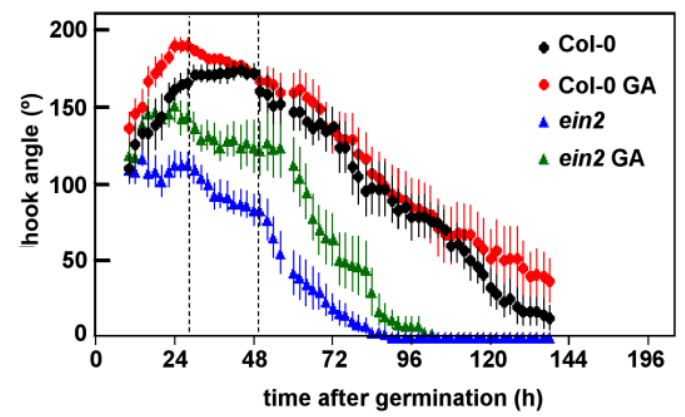

Figure 4.2 Regulation of apical hook development by GAs and ethylene.

(a,b) Kinematic analysis of hook development in Ler wild type and della seedlings grown on control medium or with $10 \mu \mathrm{M}$ ACC (b), as well as Col-0 wild type and ein2-1 seedlings grown on control medium or with $50 \mu \mathrm{M}$ gibberellic acid $\left(\mathrm{GA}_{3}\right)(\mathrm{c})$. Dotted vertical lines represent the transition between phases. All error bars represent s.e.m. $(n>20)$. 
6.3.3. The expression of $A C S 5 / E T O 2, A C S 8$, and $H L S 1$ genes is regulated by the GA pathway

To elucidate the molecular mechanism by which GAs regulate hook development, we searched through microarray analysis for genes that could be relevant for this process among those rapidly regulated by gai-1 in 2-day-old pHsp::gai-1 etiolated seedlings (Alabadí et al., 2008) (Chapter 2: Gallego-Bartolomé, Alabadí, Blázquez, unpublished). We found that the ethylene biosynthesis genes $A C C$ SYNTHASE8 (ACS8) and ACS5/ETO2 (Vogel et al., 1998; Yamagami et al., 2003), and the ethylene-induced gene HOOKLESS1 (HLS1) (Lehman et al., 1996), were downregulated by gai-1. Analyses in pHsp::gai-1, ProRGA:GFP-(rga-417), and Pro35S:gai-1 lines (Alabadí et al., 2008; Dill et al., 2001), and in gai-t6 rga-24 double loss-of-function mutants (Dill and Sun, 2001; King et al., 2001) confirmed their regulation by DELLAs (Figure 4.3a,b).

Their rapid response to gai-1 suggested that they might be direct targets. To confirm this, we examined their expression in ProGAI:gai-1-GR seedlings (GallegoBartolomé, Alabadí, Blázquez, submitted). As a control, we included the DELLAinduced gene AtGA20ox2 gene in the analysis (Zentella et al., 2007) (Figure 4.3b). Dexamethasone (DEX)-treatment repressed and induced HLS1 and AtGA20ox, respectively, and this effect was not abolished by cycloheximide (CHX) indicating that regulation by gai-1 is independent of protein synthesis (Figure 4.3c). However, downregulation of ACS5/ETO2 and ACS 8 by gai-1 requires the synthesis of a protein intermediate. The strong upregulation of ACS 8 by CHX could mask any effect of gai-1, and therefore we could not rule out the possibility of a direct effect of the DELLA protein. The transcription factor PIF5 promotes ACS8 expression in etiolated seedlings (Khanna et al., 2007). Since DELLAs regulate transcription by inhibiting several transcription factors of the PIF clade (de Lucas et al., 2008; Feng et al., 2008; Arnaud et al., 2010), we tested whether this is the case for PIF5. GAI and PIF5 interacted in vivo in Nicotiana benthamiana leaves as shown by co-immunoprecipitation (Figure 4.3d) and bimolecular fluorescence complementation (BiFC) (Figure 4.S1). Remarkably, chromatin immunoprecipitation (ChIP) showed that PIF5 binds in vivo to a G-box in the ACS8 promoter in a GA-dependent manner in Arabidopsis (Figure 4.3e), suggesting DELLAs may repress ACS8 expression by inhibiting PIF5. 
ACS5/ETO2- and ACS8-mediated ethylene production contributes to hook development (Vogel et al., 1998; Tsuchisaka et al., 2009), and the activity of HLS1 is central to mediate fully this effect (Roman et al., 1995; Lehman et al., 1996). Thus, our gene expression analysis suggests that GAs regulate hook development through the control of HLS1 gene expression through direct regulation by DELLA proteins and via ethylene biosynthesis (Figure 4.3f).

\subsubsection{GA-regulation of $A C S 5 / E T O 2$ and $A C S 8$ gene expression depends on} the phase of hook development

To examine the temporal and spatial distribution of ACS5/ETO2 and ACS8 expression during hook development and their response to GAs, we used the ProACS5:GUS and ProACS8:GUS reporters (Tsuchisaka and Theologis, 2004). Their spatial and temporal expression patterns were similar (Figures 4.4a,b and 4.S2). Staining was detected mainly in the hypocotyl vasculature, reaching the apical hook 36 $\mathrm{h}$ after germination. Both the timing and the extent of their response to GAs were somewhat different. The regulation of ProACS5:GUS expression upon GAs was evident $36 \mathrm{~h}$ after germination. Remarkably, GAs became limiting $36 \mathrm{~h}$ later, when GAtreatment resulted in augmented expression (Figure 4.4a). The dependence of ProACS8:GUS on GAs was also evident $36 \mathrm{~h}$ after germination (Figure 4.4b), although the response was already saturated. As expected, the PAC-effect on both reporter lines was reversed completely by simultaneous treatment with GAs (Figure 4.S2). Hence, both the basal expression and the responsiveness to GAs of ACS5/ETO2 and ACS8 are subject to developmental regulation in the apical hook.

\subsubsection{GAs support ethylene production in etiolated seedlings}

Staining patterns of ProACS5:GUS and, to a lesser extent, of ProACS8:GUS in response to GAs support the idea that GAs promote ethylene biosynthesis in etiolated seedlings. To test it we measured ethylene production in etiolated Ler wild type and della seedlings. The ability of wild type seedlings to produce ethylene decreased steadily during the first days after germination (Figure 4.4c). This trend was reversed in della seedlings, which produced more ethylene than the wild type after the second day. This timing is coincident with the dependence of ACS8 and ACS5/ETO2 expression 
(a)

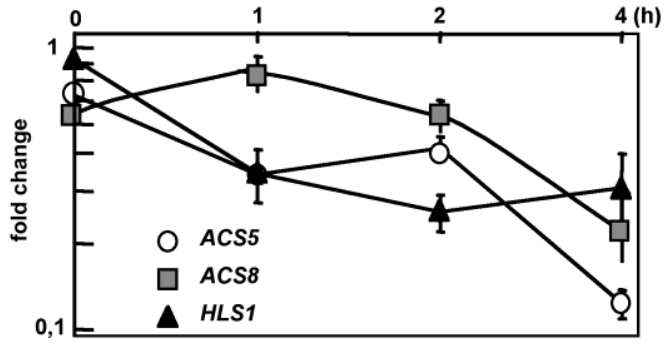

(c)

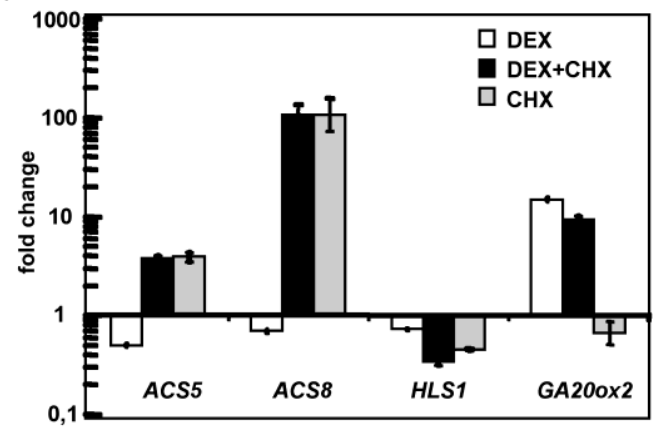

(e)

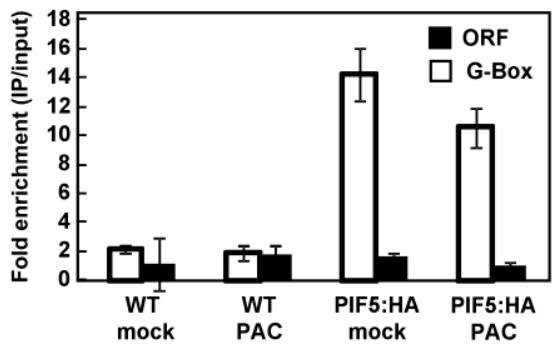

(b)

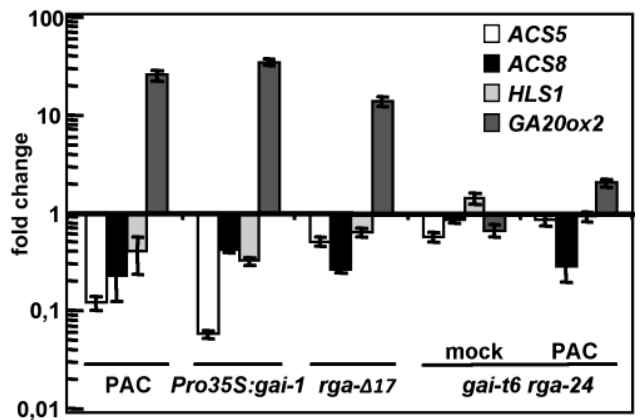

(d)

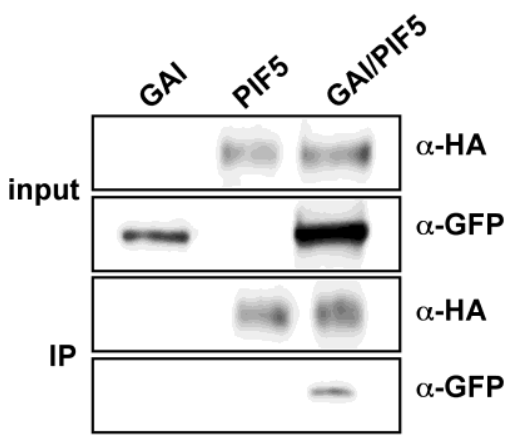

(f)

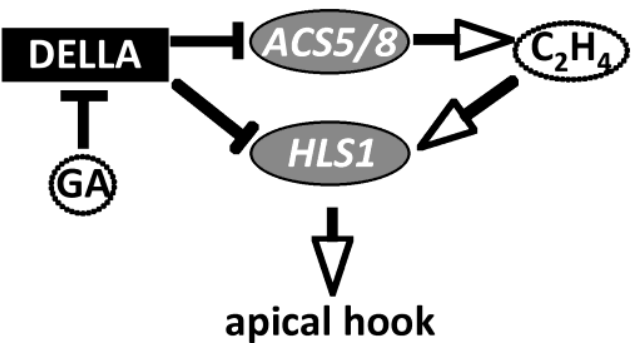

Figure 4.3 GAs regulate the ethylene pathway in etiolated seedlings.

(a) Expression of ACS5/ETO2, ACS8, and HLS1 in 2-d-old pHsp::gai-1 seedlings subjected to a 30 min treatment at $37^{\circ} \mathrm{C}$; control seedlings were kept at $20^{\circ} \mathrm{C}$. Expression was determined by qRT-PCR and normalized to the respective control treatment.

(b) Thirty six-hour-old wild type Ler and gai-t6 rga-24 seedlings were grown on control medium or with $0.2 \mu \mathrm{M}$ PAC. Expression was determined by qRT-PCR. PAC, fold change between PAC- and mock-treated wild type Ler seedlings; Pro35S:gai-1, fold change between transgenic and wild type Col-0 seedlings; rga- $\Delta 17$, fold change between ProRGA:GFP-(rga- $\Delta 17)$ and wild type Ler seedlings; gai-t6 rga-24 mock, fold change between gai-t6 rga-24 and wild type Ler seedlings; gai-t6 rga-24 PAC, fold change between PAC-treated and mock-treated gai-t6 rga-24 seedlings.

(c) Two-day-old ProGAI:gai-1-GR etiolated seedlings were incubated for $5 \mathrm{~h}$ in water or in water supplemented with either $10 \mu \mathrm{M}$ DEX, $10 \mu \mathrm{M}$ CHX, or both. (a-c) Expression was determined by qRT-PCR and normalized to the respective control treatment. Data represent mean and standard deviation of three technical replicates. Experiments were repeated twice with similar results.

(d) co-IP showing the interaction between GAI and PIF5. YFP-GAI and HA-PIF5 were expressed either alone or together in leaves of Nicotiana benthamiana. Nuclear proteins were immunoprecipitated with anti-HA antibody-coated paramagnetic beads and detected by immunoblotting with either anti-HA or anti-GFP antibodies.

(e) qRT-PCR of a regulatory (G-box) or a control (ORF) sequence in the ACS8 locus after ChIP with anti-HA. Analysis was performed in 36-hour-old Col-0 wild type and Pro35S:PIF5-HA seedlings grown on control medium or with $0.2 \mu \mathrm{M}$ PAC. Enrichment of the regulatory and control ORF sequences is shown after normalization to the input value. Data represent mean and standard deviation of three technical replicates from a representative experiment out of three biological replicates.

(f) Model: GAs control hook development by transcriptional regulation of HLS1, either directly or

indirectly through regulation of ethylene biosynthesis. 
(a)

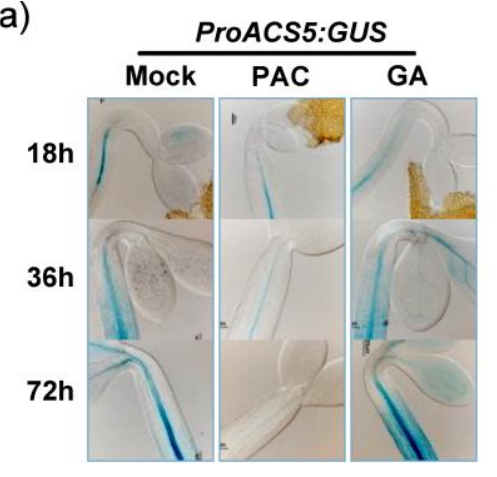

(b)

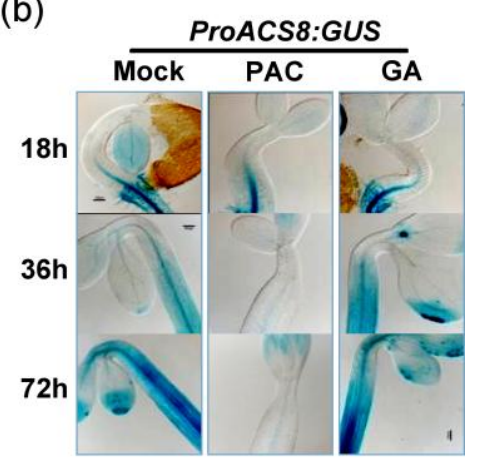

(c)

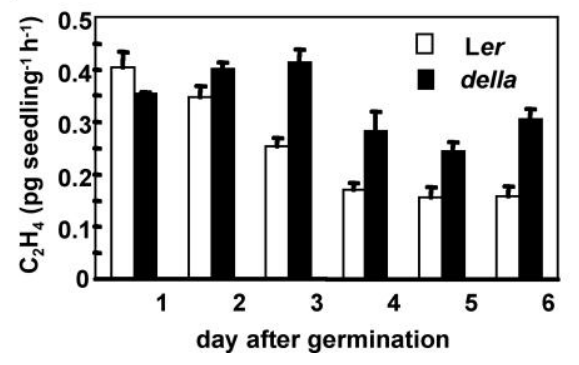

Figure 4.4 Regulation of the ethylene pathway by GAs.

(a,b) Expression patterns of ProACS5:GUS (a) and ProACS8:GUS (b) during hook development in seedlings grown on control medium or with $0.2 \mu \mathrm{M}$ PAC or $50 \mu \mathrm{M} \mathrm{GA}_{3}$.

(c) GAs promote ethylene production in etiolated seedlings. The ability to produce ethylene per day was measured in wild type Ler and quintuple della etiolated seedlings. Three independent sets of biological material were used for calculating mean values. Error bars represent s.e.m. The experiments were done twice with similar results.

upon GA activity (Figure 4.4a,b). Thus, the GA pathway may contribute to reach the minimum threshold level of ethylene needed to sustain a proper transition to hook maintenance and to delay hook opening in the wild type.

\subsubsection{GAs regulate partly hook development by modulating PIF activity}

The regulation of ACS 8 by the DELLA-PIF5 interaction (Figures 4.3d,e and 4.S1), together with the fact that PIF1, PIF3, and PIF5 promote hook development (Khanna et al., 2007; Leivar et al., 2008; Kim et al., 2011) suggests that PIFs could mediate the GA-regulation of this process. Indeed, pif5 mutants showed a slight hypersensitivity in PAC-induced repression of ACS 8 and hook opening, whereas Pro35S:PIF5-HA seedlings were resistant (Figure 4.5a,b). In additional support of this hypothesis, pif1 pif3 pif4 pif5 (pif1/3/4/5) seedlings (Leivar et al., 2008; Shin et al., 2009) did not form the apical hook and they immediately entered into the opening phase, whilst GA-treatment delayed hook opening for a few hours (Figure 4.5c). Analysis of the pif3/4/5 mutant corroborated the significant role of PIF1 in this process, 
since these seedlings were able to delay the opening phase (Figure 4.5d). Remarkably, PIF1 was able to restore the GA-responsiveness during the formation phase. These results indicate that PIF activity is necessary at least for hook formation and that there is a temporal coincidence in the need of GA and PIF activities, suggesting a functional relationship in the control of this process.

(a)

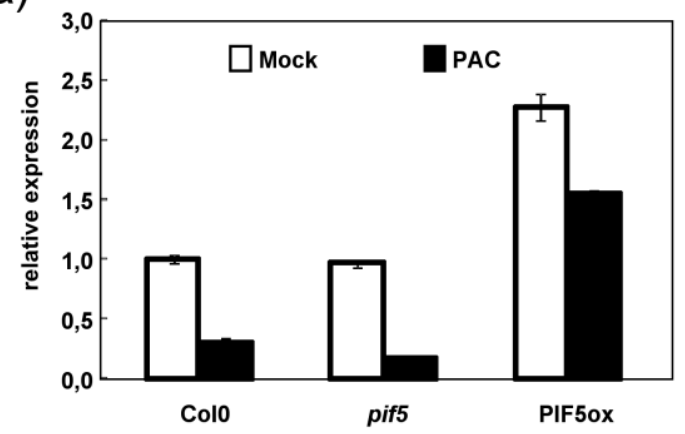

(c)

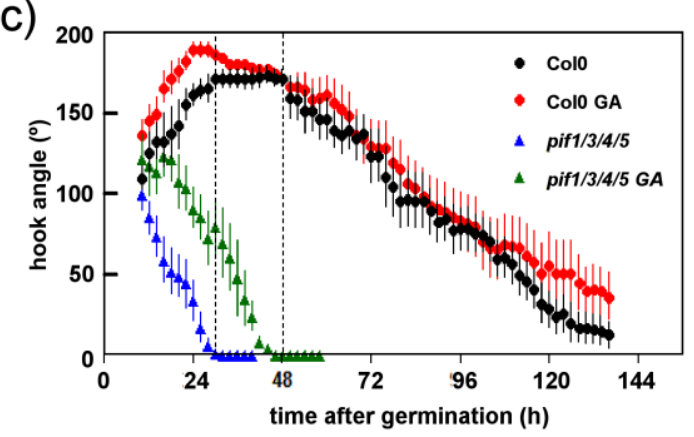

(b)

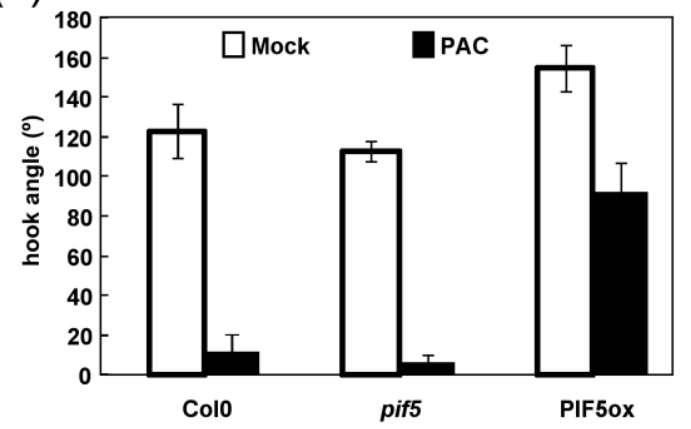

(d)

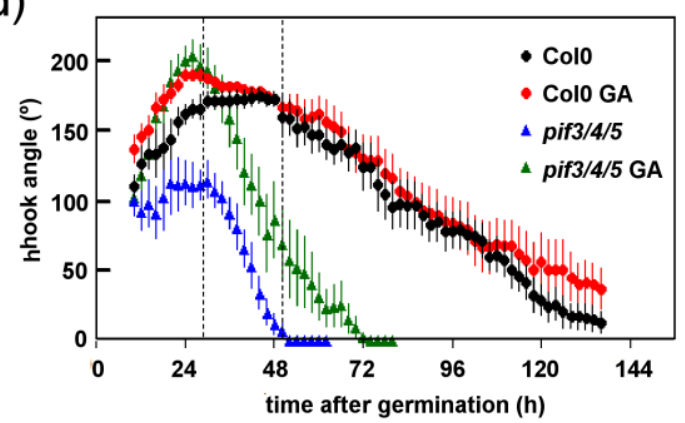

Figure 4.5 The activity of PIF transcription factors mediate the GA control on hook development.

(a) qRT-PCR analysis of ACS8 expression in 3-day-old wild type Col-0, pif5, and Pro35S:PIF5-HA seedlings grown on control medium (M) or with $0.2 \mu \mathrm{M}$ PAC. All data were normalized to the expression value in the control wild type. Data represent mean and standard deviation of three technical replicates. Experiments were repeated twice with similar results.

(b) Hook angle of 3-day-old wild type Col-0, pif5, and Pro35S:PIF5-HA seedlings grown on control medium (M) or with $0.2 \mu \mathrm{M}$ PAC. Error bars represent s.e.m. (n>20).

$(\mathrm{c}, \mathrm{d})$ Kinematic analysis of hook development in Col-0 wild type and pifl/3/4/5 (c) and pif3/4/5 (d) seedlings grown on control medium or with $50 \mu \mathrm{M} \mathrm{GA}_{3}$. Dotted vertical lines represent the transition between phases. Error bars represent s.e.m. $(n>20)$.

\subsubsection{HLS1 activity mediates GA effect on hook development}

The partially ethylene-independent control of GAs on hook formation (Figure 4.2a) is consistent with a model by which GAs regulate HLS1 directly (Figure 4.3f), and with GA activity being necessary to allow ethylene to exert its control on apical hooking (Achard et al., 2003; Vriezen et al., 2004). One-day-resolution analysis of hook development indicated that HLS1 is needed early after germination in the dark (Raz and 
Ecker, 1999). Our kinematic analysis confirmed previous results showing that hls $1-1$ mutation prevented hook formation (Figure 4.6a). The dynamics of hook development was very similar in hls $1-1$ mutants and in PAC-treated seedlings (Figures 4.1a and 4.6a), indicating that there is a temporal coincidence in the requirement of both activities during hook development. Besides, the hook phenotype of hlsl-l seedlings was not affected by exogenous GA-treatment, whereas the wild type showed exaggerated hooks (Figure 4.6a).

To confirm that GAs regulate hook development through HLS1, we analyzed the effect that uncoupling HLS1 expression from GA-regulation had on the GA-control of hook development. For that purpose, we prepared Pro35S:YFP-HLS1 transgenic lines and analyzed their response to PAC. As hypothesized, Figure 4.6b shows that apical hooks of Pro35S:YFP-HLS1 seedlings were partially resistant to PAC-induced opening. Furthermore, time-course analysis of HLS1 expression showed that GA activity is needed to sustain its expression during hook development (Figure 4.6c). Nonetheless, HLS1 transcript level was not increased in della mutants indicating that its regulation by GAs is already saturated.

\subsubsection{GAs are needed to sustain differential auxin response during apical}

\section{hook development}

Asymmetrical auxin accumulation and response is essential for the differential cell growth underlying apical hook development (Lehman et al., 1996; Li et al., 2004; Vandenbussche et al., 2010; Wu et al., 2010; Zadnikova et al., 2010). Moreover, HLS1 is critical to establish the auxin response in the hook, since the asymmetric distribution of ProDR5:GUS staining in the apical hook is lost in hlsl (Li et al., 2004). Given the regulation of HLS1 expression by GAs, we examined whether the ProDR5:GUS response was altered by GAs. By $18 \mathrm{~h}$ after germination, ProDR5:GUS staining was apparent at the concave side of the hook in control seedlings (Figure 4.7a,b) (Vandenbussche et al., 2010; Zadnikova et al., 2010). 
(a)

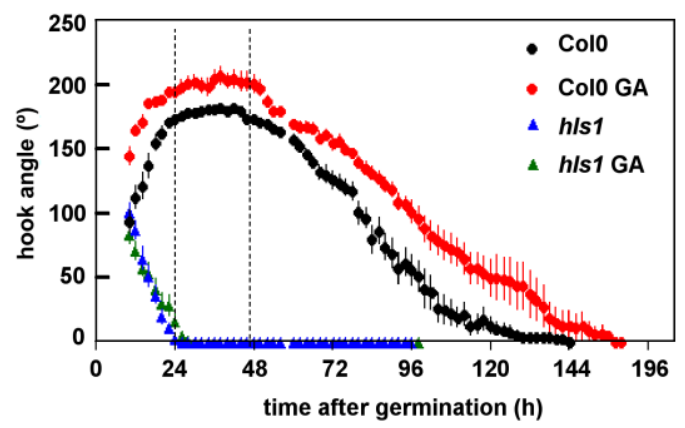

(b)

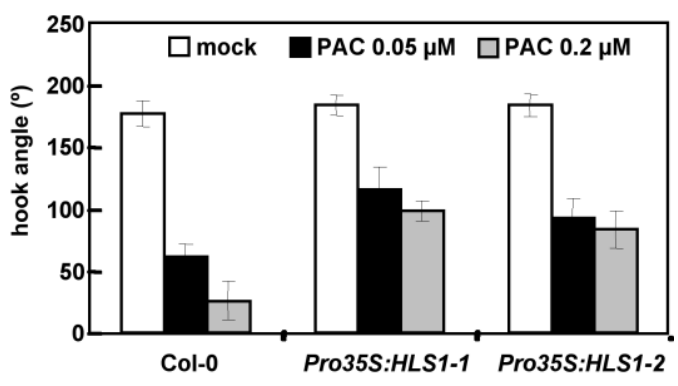

(c)

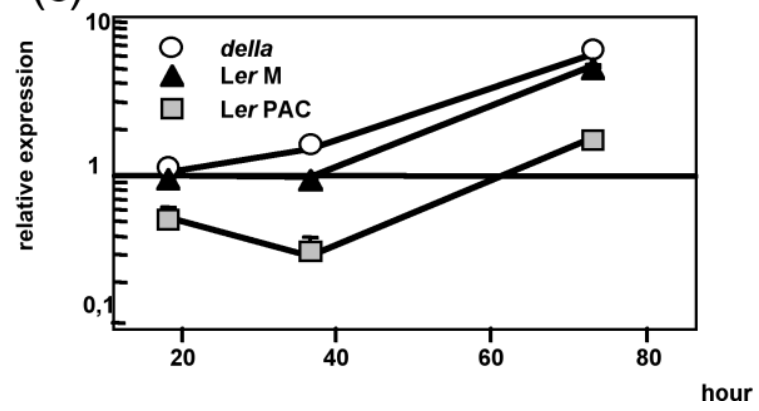

Figure 4.6 HLS1 activity mediates the GA control on hook development.

(a) Kinematic analysis of hook development in Col-0 wild type and $h l s 1-1$ seedlings grown on control medium or with $50 \mu \mathrm{M} \mathrm{GA}_{3}$. Dotted vertical lines represent the transition between phases. Error bars represent s.e.m. (n>20).

(b) Hook angle of 1-day-old wild type Col-0 and Pro35S:HLS1 seedlings grown on control medium or with 0.05 or $0.2 \mu \mathrm{M}$ PAC. Error bars represent s.e.m. $(\mathrm{n}>20)$.

(c) qRT-PCR analysis of HLS1 expression during hook development in wild type Ler seedlings grown on control medium (M) or with $0.2 \mu \mathrm{M}$ PAC, as well as in quintuple della seedlings. Thirty-six and 72 $\mathrm{h}$ data points were normalized to the expression value in the control wild type at the time point $18 \mathrm{~h}$. Data represent mean and standard deviation of three technical replicates. Experiments were repeated twice with similar results.

Neither the intensity of the staining at the concave side nor the number of seedlings with differential staining was influenced by GA-treatment at this stage of development. Nevertheless, the percentage of seedlings with staining at the inner side of the hook was lower after treatment with $0.2 \mu \mathrm{M}$ PAC. This result suggests that GAs are necessary to support differential auxin response during the formation phase. Stronger GAdependence was observed during the maintenance and opening phases. At these two stages no ProDR5:GUS expression was detected at the upper zone of the hypocotyl of any PAC-treated seedling, where the apical hook should form, whereas GA-treatment enhanced the differential ProDR5:GUS staining at the concave side of the hook (Figure 4.7a,b). As expected, the PAC-effect was reversed completely by simultaneous treatment with GAs (Figure 4.S2). 
Remarkably, the ProDR5:GUS expression pattern is very similar in PAC-treated (Figure 4.7a) and in $h l s l$ seedlings (Li et al., 2004). Despite the driving role proposed for HLS1 during apical hook development, its activity is not sufficient in the absence of polar auxin transport (Lehman et al., 1996). In agreement, ACC-treatment does not revert the effects of the polar auxin transport inhibitor naphthylphthalamic acid (NPA) (Zadnikova et al., 2010). Similarly, $50 \mu \mathrm{M} \mathrm{GA}$-treatment did not revert either the hookless phenotype or the altered ProDR5:GUS staining pattern caused by NPAtreatment (Figure $4.7 \mathrm{c}, \mathrm{d}$ ), which suppressed the exaggerated hooks of della seedlings (Figure 4.7d). The effects of GA- and ethylene-treatments on ProDR5:GUS during maintenance and opening phases are similar (Vandenbussche et al., 2010; Zadnikova et al., 2010). Nevertheless, GAs might control auxin response independently of ethylene during the formation phase (Figure 4.2a). In fact, whereas indole-3-acetic acid (IAA)treatment restores the apical hook to ethylene-insensitive mutants (Vandenbussche et $a l ., 2010)$, it was not able to restore it to PAC-treated seedlings and to hls $1-1$ mutants (Figure 4.7e). In summary, these results draw new similarities between GAs and HLS1 activity, which suggests that they participate in the same pathway in the establishment and/or the interpretation of the auxin gradient during apical hook development.

\subsubsection{GAs participate in maintaining PIN3 and PIN7 expression in the} apical hook

Genetic analyses have implicated AUX1, LAX3, PIN1, PIN3, PIN4, and PIN7 in driving the auxin flux during apical hook development, and ethylene regulates the transcription of several of their genes (Vandenbussche et al., 2010; Zadnikova et al., 2010). We asked whether GAs would also influence the expression of these genes. Expression of PIN1, PIN4, and AUX1 was not altered by GAs during hook development (data not shown). Sustained expression of PIN3 was dependent upon GAs during the maintenance and opening phases, whereas this dependence was evident earlier for PIN7 (Figure 4.8a,b). These results are consistent with results of Figure 4.7e, and suggest that GAs might also promote hook development by maintaining proper expression of PIN genes needed to distribute the auxin flux from cotyledons (Zadnikova et al., 2010). 
(a)

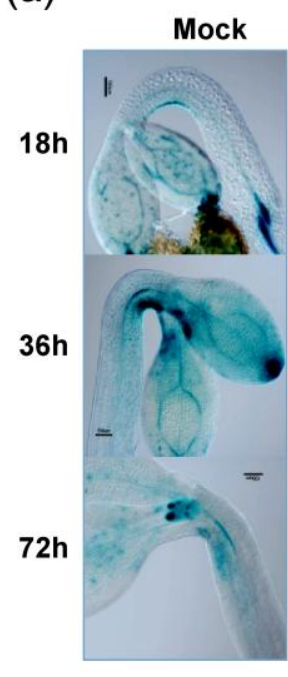

(c)

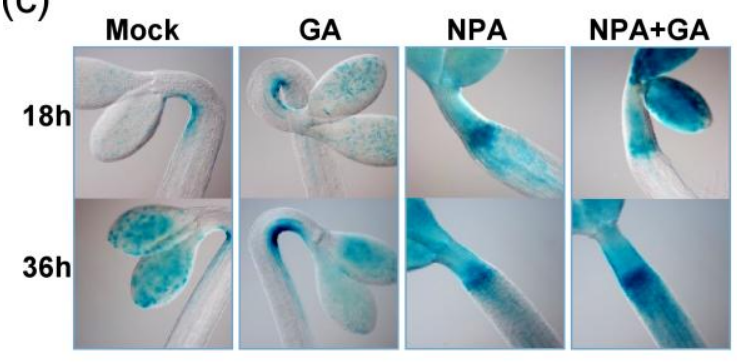

(b)

(d)

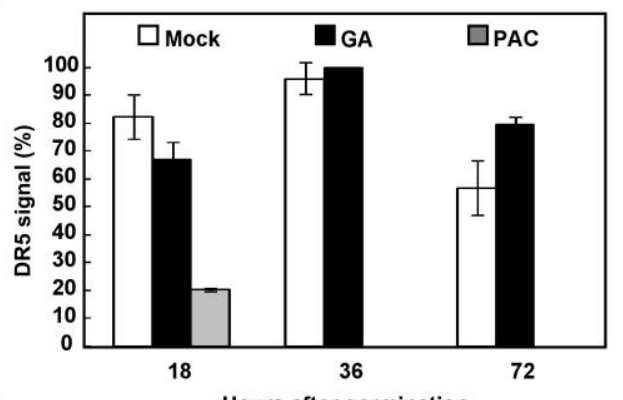

(e)
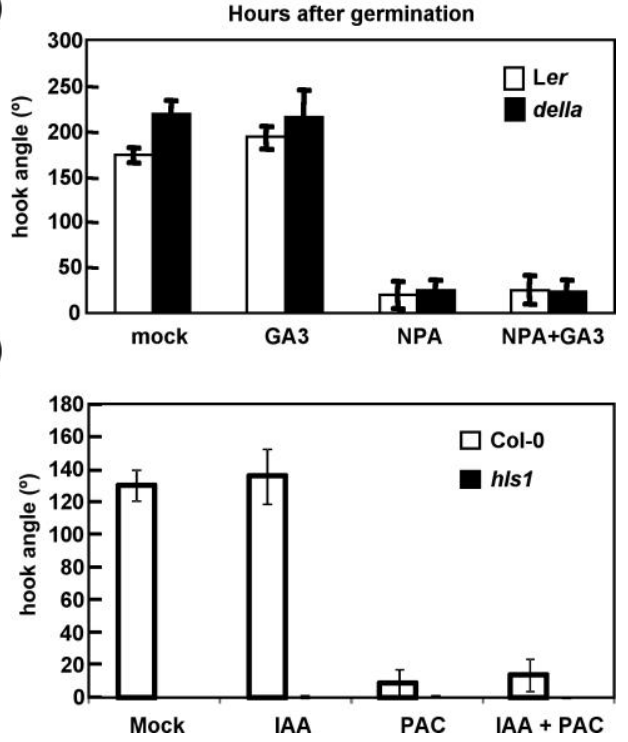

Figure 4.7 GAs regulate the differential auxin response in the apical hook.

(a,b) Expression pattern of ProDR5:GUS during hook development in seedlings grown on control media or with $0.2 \mu \mathrm{M}$ PAC or $50 \mu \mathrm{M} \mathrm{GA}_{3}$. Pictures of representative seedlings are shown (a). The percentage of seedlings showing DR5 signal at the inner side of the hook is represented in (b). Data are mean of thee biological replicates, $\mathrm{n}>25$ each. Error bars are s.d.

$(\mathrm{c}, \mathrm{d})$ Polar auxin transport mediates the GA regulation on hook development. Pictures of representative 1-day-old wild type Col-0 seedlings grown in control medium or with $50 \mu \mathrm{M} \mathrm{GA}_{3}, 5$ $\mu \mathrm{M}$ NPA, or both (c). Hook angle of 1-day-old Ler wild type and della seedlings grown in control medium or with $50 \mu \mathrm{M} \mathrm{GA}_{3}, 5 \mu \mathrm{M} \mathrm{NPA}$, or both (d).

(e) Hook angle of 1-day-old Col-0 wild type and hls $1-1$ seedlings grown in control medium or with $0.1 \mu \mathrm{M}$ IAA, $0.2 \mu \mathrm{M}$ PAC, or both. All error bars represent s.e.m. $(\mathrm{n}>20)$.

To challenge this hypothesis, we investigated the response of pin3 pin7 mutants to GAs. Double mutant seedlings were not able to complete hook formation and, importantly, they were resistant to GA-treatment (Figure 4.8e). Interestingly, single mutants had contrasting behaviors: pin3 mutants showed a milder defect on hook formation than $\operatorname{pin} 7$, whereas their response to GAs was quite affected; pin7 seedlings responded to GAs similarly to the wild type despite having more disturbed hook formation than $\operatorname{pin} 3$ (Figure 4.8c,d). 


\subsubsection{GA activity in the endodermis is required for apical hook} development

Missexpression approaches have shown that the context outlined by the cell type may be determinant to define the output of hormone pathways (Jaillais and Chory, 2010). For instance, DELLA activity in the endodermis controls meristem size and overall growth in the root (Úbeda-Tomás et al., 2008; Ubeda-Tomas et al., 2009), whereas the epidermis is the key tissue for brassinosteroids to control shoot growth (Savaldi-Goldstein et al., 2007). Thus, we examined whether GAs regulate hook development in a tissue-specific manner. We expressed gai-1 exclusively in the endodermis under the control of the SCARECROW promoter (ProSCR:gai-YFP-GR) (Úbeda-Tomás et al., 2008), or in the epidermis under the control of the MERISTEM LAYER1 promoter (ProML1:GFP-gai-1; Figure 4.S3).

Expression of gai-1 in the endodermis but not in the epidermis impaired hook formation similar to the PAC-treatment or the gai-1 mutation (Figure 4.9a). Since the $S C R$ promoter is active in the hook endodermis starting $22 \mathrm{~h}$ after germination (Vandenbussche et al., 2010), our results indicate that GA activity is necessary in the endodermis for the correct progression of hook development at least during the late formation phase, whereas it is dispensable in the epidermis.

These results support further the functional relationship between GAs and PIFs sustaining hook development, since expression of PIF1 only in the endodermis of the pifl/3/4/5 mutant restores the hook (Kim et al., 2011), indicating there is also a spatial coincidence in the requirement of both activities.

Next, to place the transcriptional network regulated by GAs in the context of the endodermis, we examined the activity of ProDR5:GUS, ProPIN3:GUS, and ProPIN7:GUS in F1 seedlings from crosses between the reporter lines and Ler wild type, ProML1:GFP-gai-1-11, and ProSCR:gai-YFP-GR seedlings. Impairing GA signaling in the endodermis had the same effect on the expression of ProDR5:GUS and ProPIN3:GUS than PAC-treatment, whereas no effect was observed when GA signaling was blocked in the epidermis (Figure 4.9b). A tissue-independent effect was observed, however, when ProPIN7:GUS expression was examined. These results suggest that GAs control PIN3 expression mainly from the endodermis and that confinement of its expression to the vascular bundle by PAC-treatment or ProSCR:gai-YFP-GR expression (see a magnification in Figure 4.9c), may impair to some extent the auxin 
flux towards outer tissues, in agreement with the disappearance of ProDR5:GUS from the concave side.

(a)

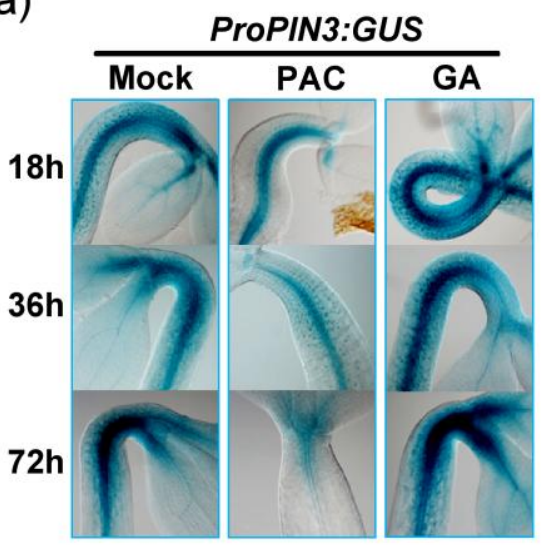

(c)

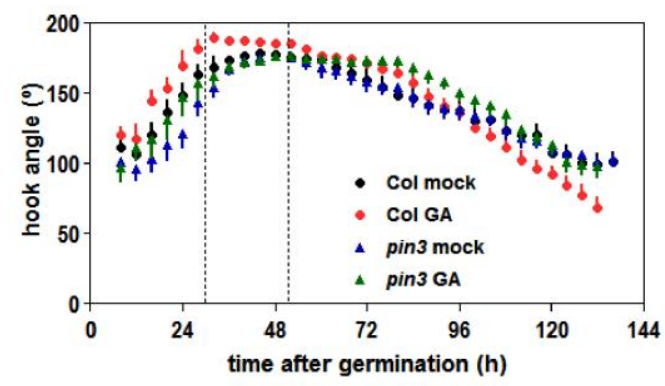

(b)

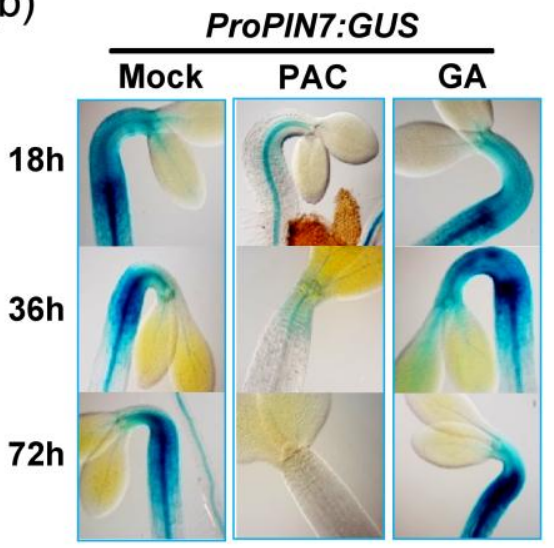

(d)

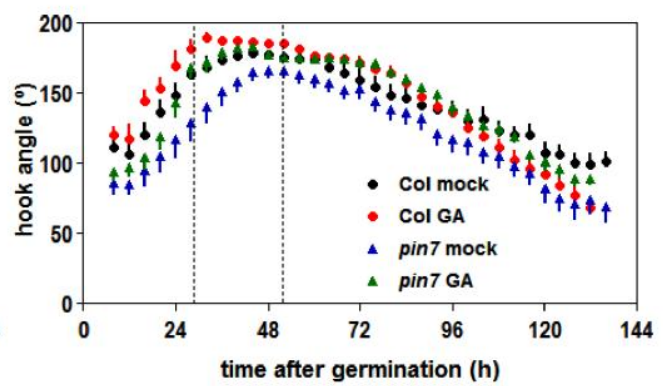

(e)

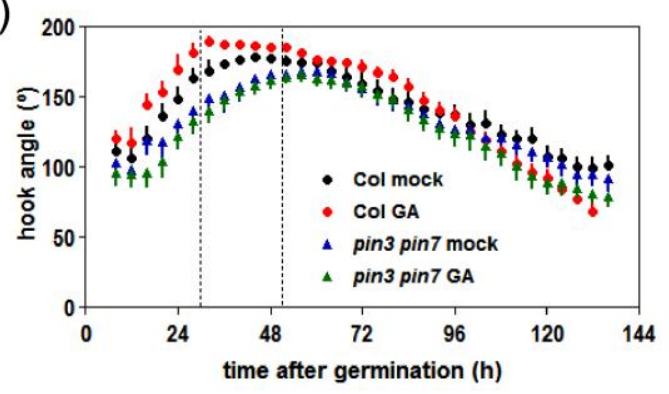

Figure 4.8 The contribution of PIN3 and PIN7 to GA-mediated hook development.

(a,b) Expression patterns of ProPIN3:GUS (a) and ProPIN7:GUS (b) during hook development in seedlings grown on control medium or with $0.2 \mu \mathrm{M}$ PAC or $50 \mu \mathrm{M} \mathrm{GA}_{3}$.

(c,d) Kinematic analysis of hook development in Col-0 wild type and pin3-5 (c) and pin7-1 (d) seedlings grown on control medium or with $50 \mu \mathrm{M} \mathrm{GA}_{3}$. Dotted vertical lines represent the transition between phases. Error bars represent s.e.m. $(\mathrm{n}>15)$.

Kinematic analysis of hook development in Col-0 wild type and $\operatorname{pin} 3-3 \operatorname{pin} 7^{\wedge} E n$ double mutant seedlings grown on control medium or with $50 \mu \mathrm{M} \mathrm{GA}_{3}$. Dotted vertical lines represent the transition between phases. Error bars represent s.e.m. $(\mathrm{n}>15)$.

In support of this, PIN3 is present in endodermis, cortex, and epidermis, whereas PIN7 and PIN4 are predominant in outer tissues (Zadnikova et al., 2010). The mild hook phenotype of pin3 mutants indicate that other efflux carriers are involved, although less relevant for the GA-control on the hook. Moreover, GAs may impinge on 
other branches of the network, most likely $H L S 1$, to regulate hook development from the endodermis.

(a)

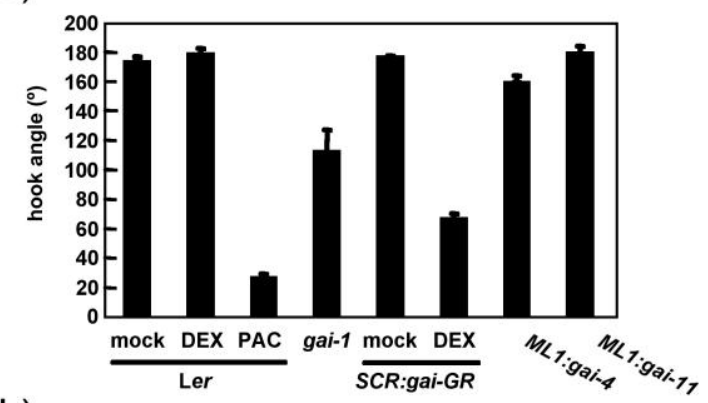

(b)

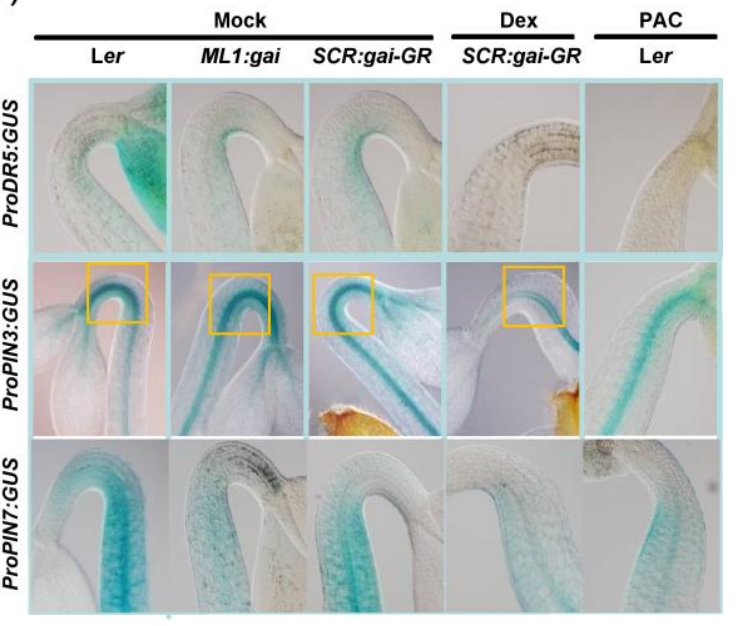

(c)

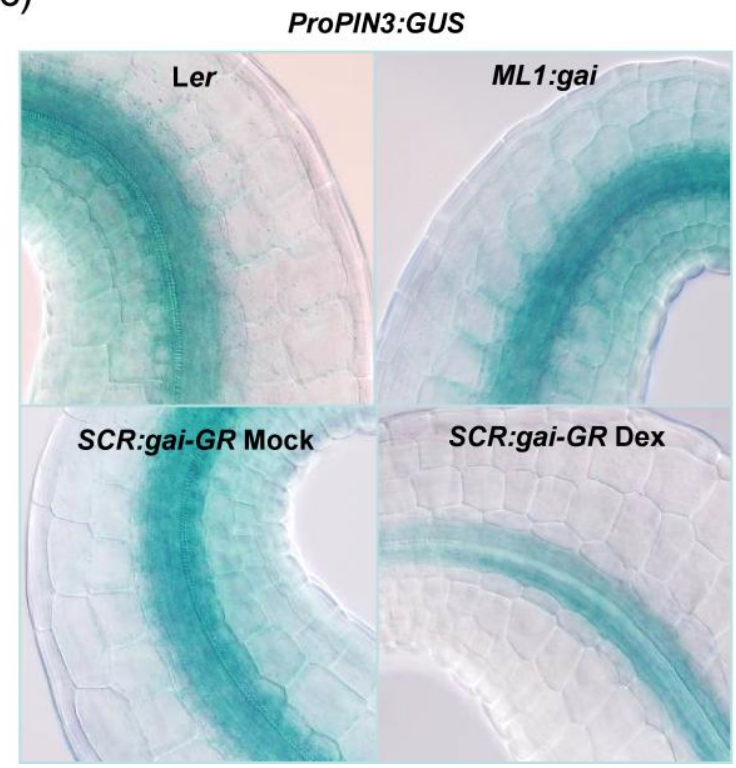

Figure 4.9 GA activity in the endodermis controls hook development.

(a) Hook curvature was measured in 1-day-old Ler wild type seedlings grown on control medium or in medium with $10 \mu \mathrm{M}$ DEX or with $0.2 \mu \mathrm{M}$ PAC; in gai-1, ProML1:GFP-gai-1-4 and ProML1:GFP-gai-1-11 (ML1:gai) seedlings grown on control medium, and in ProSCR:gai-YFP-GR (SCR:gai-GR) seedlings grown on control medium or with $10 \mu \mathrm{M}$ DEX. All error bars represent s.e.m. ( $>20)$. (b,c) GUS staining of 1-day-old F1 etiolated seedlings from the crosses indicated in the main text, grown on control medium or in medium with $10 \mu \mathrm{M}$ DEX or with $0.2 \mu \mathrm{M}$ PAC (b). See a magnification of regions within orange squares in (c). Pictures of representative seedlings are shown. 


\subsection{DISCUSSION}

The establishment of an apical hook is an intrinsic part of the skotomorphogenic developmental program and it depends on differential cell elongation on opposite sides of hypocotyls. The instructive molecular framework that guarantees this differential growth relies in the end on asymmetrical auxin response (Lehman et al., 1996). Ethylene signalling represents one module of regulation that sustains this basic framework (Stepanova et al., 2008; Vandenbussche et al., 2010; Zadnikova et al., 2010), in a large part targeting HLS1 transcription (Li et al., 2004; Chaabouni et al., 2009). Our results show that GAs impinge both on the ethylene pathway and on auxin distribution and response, and therefore it represents a new layer of regulation that ensures proper progression through all phases of hook development (Figure 4.10).

\subsubsection{GAs regulate hook formation independently of ethylene activity}

Sustained asymmetric auxin activity is necessary during all phases for proper hook development (Lehman et al., 1996; Chaabouni et al., 2009; Wu et al., 2010; Zadnikova et al., 2010). Ethylene plays its major role in a time-window that encompasses maintenance and opening phases and overlaps with a period of augmented sensitivity to the hormone (Raz and Ecker, 1999), whereas its role during the formation phase is minor (Figure 4.10b) (Raz and Ecker, 1999; Knee et al., 2000; Vandenbussche et al., 2010; Zadnikova et al., 2010). On the contrary, the GA pathway performs a prominent role during the initial phase, when the strength of its activity determines the speed of hook formation and the extent of hook curvature (Figure 4.1a). Importantly, this role of GAs is mostly independent of ethylene (Figure 4.1c). The high demand of GA activity for apical hooking is reminiscent of germination. The apical hook starts to form immediately after germination in darkness is completed. Germinating seeds require high levels of GAs to break dormancy (Ogawa et al., 2003; Cao et al., 2005; Penfield et al., 2006). Our results suggest that this high GA activity might extend into the early stages of hook development to ensure a sustained GA response. Both processes may have similar mechanistic basis, the same GA response initiated in embryos during germination may continue later on in etiolated seedlings to promote apical hook development. In agreement, mutants with a hyperactive GA pathway show 
exaggerated growth of the embryo's axis (Cao et al., 2005) and exaggerated hook curvature (Figure 4.1a). Moreover, GA biosynthesis and response take place mainly in the hypocotyl endodermis and cortex during germination (Yamaguchi et al., 2001; Ogawa et al., 2003). Remarkably, sustained GA activity specifically in hypocotyl endodermis is required for proper progression through hook formation (Figure 4.9).

\subsubsection{GAs prevent hook opening in cooperation with the ethylene pathway}

GAs are also required to prevent hook opening. This task is performed jointly with ethylene, and the transition to this phase is prevented only when the two hormones become not limiting (Figure 4.2b). This response suggests that this process might be controlled by a signalling element whose activity is regulated in cooperation by both pathways. For example, DELLA proteins could inactivate an ethylene-regulated transcription factor that negatively regulates opening, similar to their negative effect on PIFs (de Lucas et al., 2008; Feng et al., 2008). The apical hook, on the other hand, is not a vital structure when seedlings grow in vitro. The timing and kinetics of hook opening may respond solely to endogenous cues under these conditions. The identification of GAs and ethylene as elements imposing a brake to hook opening suggests that both pathways are targets of light signalling during de-etiolation. In fact, the GA pathway is downregulated by light (Reid et al., 2002; Achard et al., 2007; Zhao et al., 2007; Alabadí et al., 2008), which might help to turn off the hormonal network that prevents hook opening (see below). The activity of ethylene is high in etiolated seedlings (Zhong et al., 2009), so it is reasonable to think that it is also reduced during de-etiolation. Indeed, light impinges negatively on ethylene signalling rather on ethylene levels to promote hook opening in Arabidopsis (Knee et al., 2000). Besides, the expression of the ethylene- and GA-induced gene HLS1 is repressed by light, which surely contributes to hook opening (Li et al., 2004).

\subsubsection{GAs regulate hook development by transcriptional regulation of} auxin and ethylene pathways

How do GAs regulate progression through hook development? Our results indicate that GAs exert this regulation, or at least part of it, by transcriptional regulation of several elements of the signalling network that controls apical hooking. First, GAs 
impinge on the core of the mechanism by regulating expression of auxin transporter genes PIN3 and PIN7 (Figure 4.8). Second, GAs influence the expression of two ACS genes involved in ethylene biosynthesis, ACS5/ETO2 and ACS8 (Figures 4.3a-c and $4.3 \mathrm{a}, \mathrm{b}$ ), as well as the expression of the ethylene-induced gene HLS1 (Figures 4.3a-c and 4.6c), whose activity is necessary to control auxin responses in the hook (Lehman et al., 1996; Li et al., 2004). The kinetics of their transcriptional response suggests that DELLAs operate through different regulatory mechanisms depending on each case. Regulation of PIN3 and PIN7 seems an indirect consequence of DELLAs' activity (data not shown). A similar case is found at the root meristem, where DELLAs downregulate PIN expression indirectly through ARR1 and SHY2 (Dello Ioio et al., 2008; Moubayidin et al., 2010). The downregulation of HLS1 and ACS8 is a direct consequence, whilst the fast regulation of ACS5/ETO2 requires the synthesis of a protein intermediate (Figure 4.3c). Remarkably, DELLAs directly inhibit the activity of PIF5 to repress the expression of ACS 8 (Figure 4.3d,e), as previously seen with PIF3 and PIF4 for light-regulated genes (de Lucas et al., 2008; Feng et al., 2008). The expression of both HLS1 and ACS5/ETO2 is lower in pif1/3/4/5 mutants than in the wild type (Leivar et al., 2009; Shin et al., 2009), suggesting that PIFs mediate their regulation by DELLAs as well. Nonetheless, the influence of PIFs may be indirect given that there are no G-boxes in the upstream promoter region of both genes.

Several pieces of evidence support the idea that regulation of $A C S$ genes by GAs is relevant for ethylene production in etiolated seedlings. First, the della mutant produces more ethylene than the wild type (Figure 4.4c). Second, the timing for increased ethylene production in della mutants correlates with the increased expression of ACS5/ETO2 upon GA-treatments (Figure 4.4a); the contribution of ACS8 activity to the extra ethylene in the della mutant may be lower. Third, this timing also coincides with the window of maximum ethylene sensitivity in the apical hook (Raz and Ecker, 1999). And fourth, ACS5/ETO2 and ACS8 contribute to ethylene-induced hook development (Vogel et al., 1998; Tsuchisaka et al., 2009).

The close connection of GAs with the auxin and ethylene pathways (Figure 4.10) is manifested by the strong hook phenotype observed when the GA activity is compromised. Despite the role of the GA-mediated ethylene production may be minor, the regulation of $H L S 1$ and the auxin transporters surely have a deep contribution to hook development. For instance, the hookless phenotype caused by low GA levels is 
alleviated by overexpressing HLS1 (Figure 4.6b). This idea is supported further by the staining patterns of ProDR5:GUS which are shared by PAC- or NPA-treatment (Figure $5 \mathrm{a}, \mathrm{c}$ ) and the hls 1 mutant (Li et al., 2004), and by the inability of IAA-treatment to restore the apical hook to PAC-treated and hlsl seedlings (Figure 4.7e). We propose that GAs sustain differential auxin transport and response during the formation phase and that at least the latter might be mediated by HLS1 activity. This is based in three observations: first, there is a coincidence in the temporal requirement of HLS1 and GA activities during hook formation (Figures 4.1a and 4.6a). Second, $h l s l$ is epistatic over GA-application (Figure 4.6a). And third, HLS1 expression is directly downregulated by DELLAs (Figure 4.3c). Notwithstanding, whereas GA activity is limiting to drive hook formation (Figure 1a), it is saturated to promote HLS1 expression (Figure 4.6c). This suggests that there is another mechanism by which GAs regulate the formation phase besides transcriptional regulation of the HLS1 gene.

(a)

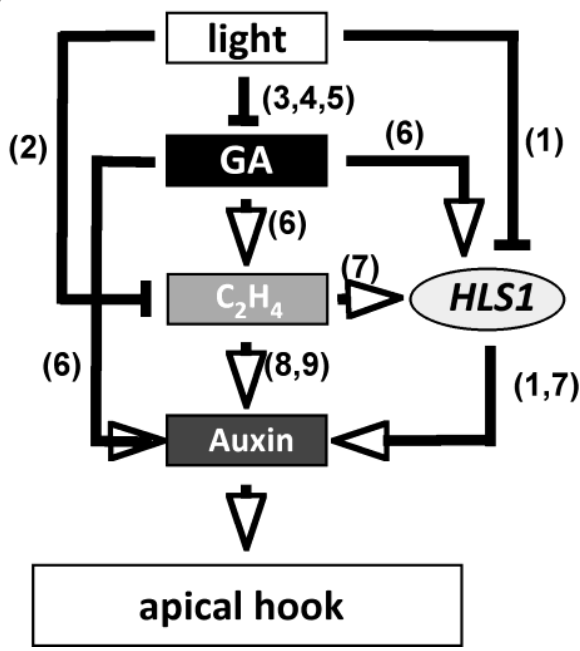

(b)

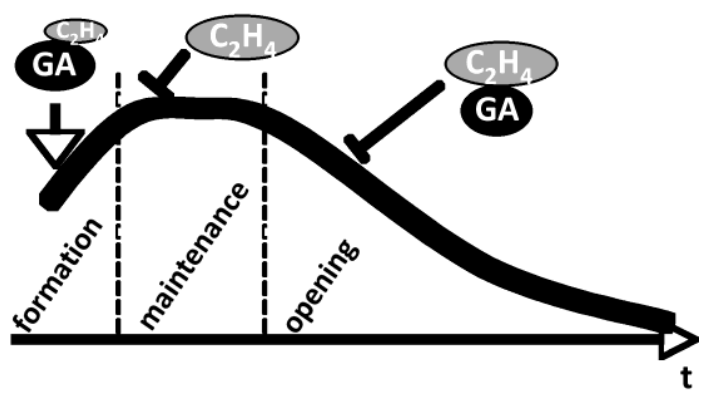

Figure 4. 10 Models explaining the pathway interactions and the timing of GA and ethylene action.

(a,b) In etiolated seedlings proper activity of auxin is crucial for hook development (a). Its activity is sustained by GAs and ethylene at different levels, including auxin biosynthesis, transport, and response. Part of the GA control is exerted from the endodermis, for instance transcriptional regulation of PIN3. GAs and ethylene may exert this role independently or through common downstream signaling elements. Light act negatively on several branches of the hormonal network to promote hook opening. The contribution of the activity of the GA and ethylene pathways is different depending on the phase of hook development (b). GAs promote hook formation partly in a ethyleneindependent manner, likely through HLS1, and the contribution of ethylene to this phase seems to be minor, whereas both pathways cooperate to prevent hook opening.

Note: References for Figure 4.10 are included separately at the end of the references section. 


\subsection{EXPERIMENTAL PROCEDURES}

\section{Plant lines and growth conditions}

Arabidopsis thaliana accessions Ler and Col-0 were used as wild types. Mutants and transgenic lines used have been described: quintuple della (Feng et al., 2008), gai-1 (Peng et al., 1997), gai-t6 rga-24 (Dill and Sun, 2001; King et al., 2001), pRGA::GFP(rga-417) (Dill et al., 2001), ProHsp:gai-1 and Pro35S:gai-1 (Alabadí et al., 2008), ProSCR:gai-YFP-GR (Úbeda-Tomás et al., 2008), and ProGAI:gai-1-GR (GallegoBartolomé, Alabadí, Blázquez, submitted); ein2-1 and hls1-1 (Guzman and Ecker, 1990), and pACS5::GUS and ProACS8:GUS (Tsuchisaka and Theologis, 2004); ProPIN7:GUS, pin7-1, and pin3-5 (Benkova et al., 2003), ProPIN3:GUS (Friml et al., 2002); Pro35S:PIF5-HA (Lorrain et al., 2008), and pif3/4/5 and pif1/3/4/5 (Leivar et al., 2008; Shin et al., 2009). The pin3-3 pin $7^{\wedge} E n$ double mutant has been kindly provided by Dr Ykä Helariutta (Helsinki University).

Seeds were sterilized and stratified for 6 days in water at $4^{\circ} \mathrm{C}$. Germination took place under white fluorescent light $\left(90-100 \mu \mathrm{mol} \mathrm{m} \mathrm{s}^{-1}\right)$ at $22^{\circ} \mathrm{C}$ for $6 \mathrm{~h}$ in a Percival growth chamber E-30B (http://www.percival-scientific.com). Seeds were plated in plates of half-strength MS medium with $0.8 \%$ (w/v) agar and 1\% (w/v) sucrose supplemented with either $0.2 \mu \mathrm{M}$ PAC, $50 \mu \mathrm{M} \mathrm{GA}_{3}, 10 \mu \mathrm{M}$ ACC, $10 \mu \mathrm{M}$ DEX, $0.1 \mu \mathrm{M}$ IAA or $5 \mu \mathrm{M}$ NPA and grown in darkness at $22^{\circ} \mathrm{C}$. For exogenous GA-treatment, seeds were stratified in $50 \mu \mathrm{M} \mathrm{GA}_{3}$. For short-term treatments, seedlings were incubated in the dark in water supplemented with $10 \mu \mathrm{M}$ CHX and/or $10 \mu \mathrm{M}$ DEX. MS, PAC, GA 3 , ACC, IAA and NPA were from Duchefa (http://www.duchefa.com). DEX and CHX were from Sigma (http://www.sigmaaldrich.com). Plates were placed vertically for kinematic analyses.

\section{Real-time analysis of apical hook development}

Real-time imaging of apical hook development and hook angle measurement were performed as described (Vandenbussche et al., 2010; Zadnikova et al., 2010). 


\section{Analysis of reporter lines}

$\beta$-glucuronidase (GUS) staining was performed as described (Zadnikova et al., 2010).

Construction of vectors and generation of transgenic lines The pENTR223 vector carrying the HLSI or ORF was obtained from the Arabidopsis Biological Resource Center (ABRC) and transferred into the pEarleyGate104 vector (Earley et al., 2006) by Gateway technology using the LR clonase (Invitrogen, http://www.invitrogen.com) to create $p E G:: H L S 1 o x$.

The construction of ProML1:GFP-gai-1was as follows. The gai-1 coding sequence was amplified from genomic DNA of the gai-1 mutant with primers GAIdf (ATGAAGAGAGATCATCATCATCA) and GAIdr (ATTGGTGGAGAGTTTCCAAGCCGA) that included the attB1 and attB2 Gateway recombination sites (not shown), respectively. The PCR product was cloned into pDONR221 (Invitrogen) by BP reaction, and then into the binary vector pSBright:GFP (Bensmihen et al., 2005) by LR reaction to give rise to pSBright:GFP-gai-1 construct. The ML1 promoter was PCR-amplified using primers described (An et al., 2004) and that included the HindIII recognition site. The PCR product was cloned into the $p C R 2.1$ vector and sequenced. After digestion with HindIII, the ML1 promoter was cloned into the HindIII site of pSBright:GFP-gai-1, to create ProML1:GFP-gai-1.

Constructs were introduced in Agrobacterium strain C58 and used to transform Arabidopsis Col-0 wild type plants, pEG:HLSlox, or Ler, ProML1:GFP-gai-1. Transgenic seedlings in the $\mathrm{T}_{1}$ and $\mathrm{T}_{2}$ generations were selected on $50 \mu \mathrm{M}$ glufosinate ammonium (Sigma). Transgenic lines with a 3:1 (resistant:sensitive) segregation ratio were selected, and 10 homozygous lines were identified in the $\mathrm{T}_{3}$ generation. Data from two representative lines are shown.

\section{Real-time quantitative RT-PCR}

RNA extraction, cDNA synthesis, quantitative RT-PCR (qRT-PCR), analysis, and primer sequences for amplification of AtGA20ox2 and EF1- $\alpha$ genes have been described (Frigerio et al., 2006). qRT-PCR oligonucleotides for ACS5/ETO2, ACS8, and HLS1 genes were: qRT-ACS5f (GCTGGTTCGACATCTGCGA), qRT-ACS5r (AGGCTCTGCAAGGCAAAACAT), 
(GGTGCTACTCCGGCTAACGA),

qRT-ACS8r

(TCCAGGATCAGCGAGACAAAA), qRT-HLS1f (CGATACCGTCCGTTTTCGAA), and qRT-HLS1r (GCCTTAGCCAAGTTATGCGC).

\section{Ethylene measurements}

Ethylene measurements were performed as described (Thain et al., 2004), with the following modifications. 150-200 seeds were sterilized and sown in a $10 \mathrm{ml}$ chromatography vial containing $5 \mathrm{ml}$ of half-strength MS with $1 \%(\mathrm{w} / \mathrm{v})$ sucrose and $0.8 \%(\mathrm{w} / \mathrm{v})$ agar. The vial was kept 5 days at $4^{\circ} \mathrm{C}$ in darkness and subsequently exposed to white light for $6 \mathrm{~h}$ at $21^{\circ} \mathrm{C}$ to stimulate germination. Seedlings were grown in darkness (capped vials wrapped in aluminium foil). Every $24 \mathrm{~h}$, the vials were flushed with hydrocarbon free air (Air Liquide, http://www.es.airliquide.com/) and ethylene in the headspace was detected with an ETD-300 photo-acoustic ethylene detector (Sensor Sense, http://www.sense.com.br).

\section{Confocal microscopy}

Images were taken using a Leica TCS SL confocal laser microscope (Leica Microsystems GmbH, http://www.leica-microsystems.com/) with excitation at $488 \mathrm{~nm}$.

\section{BIFC and co-IP assays}

BIFC vectors $p M D C 43-Y F N$ and $p M D C 43-Y F C$ were provided by Dr Alejandro Ferrando (IBMCP). pENTR vectors carrying the coding sequence of PIF5 and GAI were generated by the REGIA project (Paz-Ares and The Regia, 2002). PIF5 and GAI coding sequences were transferred into $p M D C 43-Y F C$ and $p M D C 43-Y F N$, and into pEarleyGate201 and pEarleyGate104 (Earley et al., 2006) for BIFC and co-IP, respectively, by Gateway using the LR clonase (Invitrogen). Each construct was introduced into Agrobacterium C58 cells, which were used subsequently to infiltrate leaves of Nicotiana benthamiana. BIFC analysis was performed as described (Scacchi et al., 2009).

For co-IP, nuclear proteins were isolated from formaldehyde-fixed leaves. Immunoprecipitation was carried out with anti-HA antibody-coated paramagnetic beads (Miltenyi Biotec, http://www.miltenyibiotec.com/en/default.aspx) following manufacturer's instructions. HA- and YFP-tagged proteins in the input and immunoprecipitated were detected by immunoblotting using anti-HA (Roche, 
https://www.roche-applied-science.com)

and

anti-GFP

(Clontech,

http://www.clontech.com/) antibodies.

\section{ChIP and PCR amplification}

Seedlings of Arabidopsis Col-0 and Pro35S:PIF5-HA transgenic line were grown at $22^{\circ} \mathrm{C}$ for 3 days in darkness before fixation. ChIP assays were performed as described (Hornitschek et al., 2009). qPCR oligonucleotides to amplify the region around the G-box were pACS8-F-1 (ATGGAAATTCACATCGTGCCTA) and pACS8R-1 (GATGTCAGAGAAGAATGAGCACGT). The ORF region was amplified with the same oligonucleotides used to analyze ACS8 gene expression by RT-qPCR.

\section{ACKNOWLEDGEMENTS}

We thank Dr Antonella Locascio for the generation of the GAI construct for BiFC, and the ABRC, Malcolm Bennett, Christian Fankhauser, Nicholas Harberd, Ykä Helariutta, Peter Quail, Tai-pin Sun, and Susana Úbeda-Tomás for seeds. Work in the laboratory of M.A.B. and D.A. is supported by grants from the Spanish Ministry of Science and Innovation (BIO2007-60293 and Consolider-TRANSPLANTA). Work in the laboratories of D.V.D.S. and E.B. is funded by the Research Foundation Flanders (FWO, projects G.0524.07 and G.0298.09) and by the European Research Council (Starting Independent Research Grant ERC-2007-Stg-207362-HCPO), respectively. J.G.-B. was supported by a JAE pre-doctoral fellowship from the CSIC. F.V. is a postdoctoral fellow of the Research Foundation Flanders (FWO).

\subsection{BIBLIOGRAPHY}

Achard P, Liao L, Jiang C, Desnos T, Bartlett J, Fu X, Harberd NP (2007) DELLAs Contribute to Plant Photomorphogenesis. Plant Physiol 143: 1163-1172

Achard P, Vriezen WH, Van Der Straeten D, Harberd NP (2003) Ethylene regulates arabidopsis development via the modulation of DELLA protein growth repressor function. Plant Cell 15: 2816-2825

Alabadí D, Blázquez MA (2009) Molecular interactions between light and hormone signaling to control plant growth. Plant Mol Biol 69: 409-417

Alabadí D, Gallego-Bartolomé J, García-Cárcel L, Orlando L, Rubio V, Martínez C, Frigerio M, Iglesias-Pedraz JM, Espinosa A, Deng XW, Blázquez MA (2008) Gibberellins modulate light signaling pathways to prevent Arabidopsis seedling deetiolation in darkness. Plant J 53: 324-335 
Alabadí D, Gil J, Blázquez MA, García-Martínez JL (2004) Gibberellins repress photomorphogenesis in darkness. Plant Physiol 134: 1050-1057

An H, Roussot C, Suarez-Lopez P, Corbesier L, Vincent C, Pineiro M, Hepworth S, Mouradov A, Justin S, Turnbull C, Coupland G (2004) CONSTANS acts in the phloem to regulate a systemic signal that induces photoperiodic flowering of Arabidopsis. Development 131: 3615-3626

Arnaud N, Girin T, Sorefan K, Fuentes S, Wood TA, Lawrenson T, Sablowski R, Ostergaard L (2010) Gibberellins control fruit patterning in Arabidopsis thaliana. Genes Dev 24: 2127-2132

Benkova E, Michniewicz M, Sauer M, Teichmann T, Seifertova D, Jurgens G, Friml J (2003) Local, efflux-dependent auxin gradients as a common module for plant organ formation. Cell 115: 591-602

Bensmihen S, Giraudat J, Parcy F (2005) Characterization of three homologous basic leucine zipper transcription factors (bZIP) of the ABI5 family during Arabidopsis thaliana embryo maturation. J Exp Bot 56: 597-603

Boerjan W, Cervera MT, Delarue M, Beeckman T, Dewitte W, Bellini C, Caboche M, Van Onckelen H, Van Montagu M, Inze D (1995) Superroot, a recessive mutation in Arabidopsis, confers auxin overproduction. Plant Cell 7: 1405-1419

Cao D, Hussain A, Cheng H, Peng J (2005) Loss of function of four DELLA genes leads to light- and gibberellin-independent seed germination in Arabidopsis. Planta 223: 105113

Chaabouni S, Jones B, Delalande C, Wang H, Li Z, Mila I, Frasse P, Latche A, Pech JC, Bouzayen M (2009) Sl-IAA3, a tomato Aux/IAA at the crossroads of auxin and ethylene signalling involved in differential growth. J Exp Bot 60: 1349-1362

de Lucas M, Davière JM, Rodríguez-Falcón M, Pontin M, Iglesias-Pedraz JM, Lorrain S, Fankhauser C, Blázquez MA, Titarenko E, Prat S (2008) A molecular framework for light and gibberellin control of cell elongation. Nature 451: 480-484

Dello Ioio R, Nakamura K, Moubayidin L, Perilli S, Taniguchi M, Morita MT, Aoyama T, Costantino P, Sabatini S (2008) A genetic framework for the control of cell division and differentiation in the root meristem. Science 322: 1380-1384

Dill A, Jung HS, Sun TP (2001) The DELLA motif is essential for gibberellin-induced degradation of RGA. Proc Natl Acad Sci U S A 98: 14162-14167

Dill A, Sun T (2001) Synergistic derepression of gibberellin signaling by removing RGA and GAI function in Arabidopsis thaliana. Genetics 159: 777-785

Earley KW, Haag JR, Pontes O, Opper K, Juehne T, Song K, Pikaard CS (2006) Gatewaycompatible vectors for plant functional genomics and proteomics. Plant J 45: 616-629

Feng S, Martinez C, Gusmaroli G, Wang Y, Zhou J, Wang F, Chen L, Yu L, IglesiasPedraz JM, Kircher S, Schafer E, Fu X, Fan LM, Deng XW (2008) Coordinated regulation of Arabidopsis thaliana development by light and gibberellins. Nature 451: 475-479

Frigerio M, Alabadí D, Pérez-Gómez J, García-Cárcel L, Phillips AL, Hedden P, Blázquez MA (2006) Transcriptional regulation of gibberellin metabolism genes by auxin signaling in Arabidopsis. Plant Physiol 142: 553-563

Friml J, Wisniewska J, Benkova E, Mendgen K, Palme K (2002) Lateral relocation of auxin efflux regulator PIN3 mediates tropism in Arabidopsis. Nature 415: 806-809

Guzman P, Ecker JR (1990) Exploiting the triple response of Arabidopsis to identify ethylenerelated mutants. Plant Cell 2: 513-523

Harper RM, Stowe-Evans EL, Luesse DR, Muto H, Tatematsu K, Watahiki MK, Yamamoto K, Liscum E (2000) The NPH4 locus encodes the auxin response factor ARF7, a conditional regulator of differential growth in aerial Arabidopsis tissue. Plant Cell 12: $757-770$

Harpham NVJ (1991) The Effect of Ethylene on the Growth and Development of Wild-type and Mutant Arabidopsis thaliana (L.) Heynh. Ann Bot 68: 55-61 
Hornitschek P, Lorrain S, Zoete V, Michielin O, Fankhauser C (2009) Inhibition of the shade avoidance response by formation of non-DNA binding bHLH heterodimers. Embo J 28: 3893-3902

Jaillais Y, Chory J (2010) Unraveling the paradoxes of plant hormone signaling integration. Nat Struct Mol Biol 17: 642-645

Kami C, Lorrain S, Hornitschek P, Fankhauser C (2010) Light-regulated plant growth and development. Curr Top Dev Biol 91: 29-66

Khanna R, Shen Y, Marion CM, Tsuchisaka A, Theologis A, Schafer E, Quail PH (2007) The basic helix-loop-helix transcription factor PIF5 acts on ethylene biosynthesis and phytochrome signaling by distinct mechanisms. Plant Cell 19: 3915-3929

Kim K, Shin J, Lee SH, Kweon HS, Maloof JN, Choi G (2011) Phytochromes inhibit hypocotyl negative gravitropism by regulating the development of endodermal amyloplasts through phytochrome-interacting factors. Proc Natl Acad Sci U S A 108: 1729-1734

King KE, Moritz T, Harberd NP (2001) Gibberellins are not required for normal stem growth in Arabidopsis thaliana in the absence of GAI and RGA. Genetics 159: 767-776

Knee EM, Hangarter RP, Knee M (2000) Interactions of light and ethylene in hypocotyl hook maintenance in Arabidopsis thaliana seedlings. Physiol Plant 108: 208-215

Kuhn H, Galston AW (1992) Physiological asymmetry in etiolated pea epicotyls: relation to patterns of auxin distribution and phototropic behavior. Photochem Photobiol 55: 313318

Langdale JA (2008) Evolution of developmental mechanisms in plants. Curr Opin Genet Dev 18: $368-373$

Lehman A, Black R, Ecker JR (1996) HOOKLESS1, an ethylene response gene, is required for differential cell elongation in the Arabidopsis hypocotyl. Cell 85: 183-194

Leivar P, Monte E, Oka Y, Liu T, Carle C, Castillon A, Huq E, Quail PH (2008) Multiple phytochrome-interacting bHLH transcription factors repress premature seedling photomorphogenesis in darkness. Curr Biol 18: 1815-1823

Leivar P, Tepperman JM, Monte E, Calderon RH, Liu TL, Quail PH (2009) Definition of Early Transcriptional Circuitry Involved in Light-Induced Reversal of PIF-Imposed Repression of Photomorphogenesis in Young Arabidopsis Seedlings. Plant Cell 21: 3535-3553

Li H, Johnson P, Stepanova A, Alonso JM, Ecker JR (2004) Convergence of signaling pathways in the control of differential cell growth in Arabidopsis. Dev Cell 7: 193-204

Liscum E, Hangarter RP (1993) Light-Stimulated Apical Hook Opening in Wild-Type Arabidopsis thaliana Seedlings. Plant Physiol 101: 567-572

Lorrain S, Allen T, Duek P, Whitelam GC, Fankhauser C (2008) Phytochrome-mediated inhibition of shade avoidance involves degradation of growth-promoting bHLH transcription factors. Plant J 53: 312-323

Moubayidin L, Perilli S, Dello Ioio R, Di Mambro R, Costantino P, Sabatini S (2010) The rate of cell differentiation controls the Arabidopsis root meristem growth phase. Curr Biol 20: 1138-1143

Nagpal P, Walker LM, Young JC, Sonawala A, Timpte C, Estelle M, Reed JW (2000) AXR2 encodes a member of the Aux/IAA protein family. Plant Physiol 123: 563-574

Ogawa M, Hanada A, Yamauchi Y, Kuwahara A, Kamiya Y, Yamaguchi S (2003) Gibberellin biosynthesis and response during Arabidopsis seed germination. Plant Cell 15: $1591-1604$

Paz-Ares J, The Regia C (2002) REGIA, an EU project on functional genomics of transcription factors from Arabidopsis Thaliana. Comp Funct Genomics 3: 102-108

Penfield S, Gilday AD, Halliday KJ, Graham IA (2006) DELLA-mediated cotyledon expansion breaks coat-imposed seed dormancy. Curr Biol 16: 2366-2370

Peng J, Carol P, Richards DE, King KE, Cowling RJ, Murphy GP, Harberd NP (1997) The Arabidopsis GAI gene defines a signaling pathway that negatively regulates gibberellin responses. Genes Dev 11: 3194-3205 
Raz V, Ecker JR (1999) Regulation of differential growth in the apical hook of Arabidopsis. Development 126: 3661-3668

Reid JB, Botwright NA, Smith JJ, O'Neill DP, Kerckhoffs LH (2002) Control of gibberellin levels and gene expression during de-etiolation in pea. Plant Physiol 128: 734-741

Roman G, Lubarsky B, Kieber JJ, Rothenberg M, Ecker JR (1995) Genetic analysis of ethylene signal transduction in Arabidopsis thaliana: five novel mutant loci integrated into a stress response pathway. Genetics 139: 1393-1409

Savaldi-Goldstein S, Peto C, Chory J (2007) The epidermis both drives and restricts plant shoot growth. Nature 446: 199-202

Scacchi E, Osmont KS, Beuchat J, Salinas P, Navarrete-Gomez M, Trigueros M, Ferrandiz C, Hardtke CS (2009) Dynamic, auxin-responsive plasma membrane-tonucleus movement of Arabidopsis BRX. Development 136: 2059-2067

Shin J, Kim K, Kang H, Zulfugarov IS, Bae G, Lee CH, Lee D, Choi G (2009) Phytochromes promote seedling light responses by inhibiting four negatively-acting phytochrome-interacting factors. Proc Natl Acad Sci U S A 106: 7660-7665

Stepanova AN, Robertson-Hoyt J, Yun J, Benavente LM, Xie DY, Dolezal K, Schlereth A, Jurgens G, Alonso JM (2008) TAA1-mediated auxin biosynthesis is essential for hormone crosstalk and plant development. Cell 133: 177-191

Stowe-Evans EL, Harper RM, Motchoulski AV, Liscum E (1998) NPH4, a conditional modulator of auxin-dependent differential growth responses in Arabidopsis. Plant Physiol 118: 1265-1275

Tatematsu K, Kumagai S, Muto H, Sato A, Watahiki MK, Harper RM, Liscum E, Yamamoto KT (2004) MASSUGU2 encodes Aux/IAA19, an auxin-regulated protein that functions together with the transcriptional activator NPH4/ARF7 to regulate differential growth responses of hypocotyl and formation of lateral roots in Arabidopsis thaliana. Plant Cell 16: 379-393

Thain SC, Vandenbussche F, Laarhoven LJ, Dowson-Day MJ, Wang ZY, Tobin EM, Harren FJ, Millar AJ, Van Der Straeten D (2004) Circadian rhythms of ethylene emission in Arabidopsis. Plant Physiol 136: 3751-3761

Tsuchisaka A, Theologis A (2004) Unique and overlapping expression patterns among the Arabidopsis 1-amino-cyclopropane-1-carboxylate synthase gene family members. Plant Physiol 136: 2982-3000

Tsuchisaka A, Yu G, Jin H, Alonso JM, Ecker JR, Zhang X, Gao S, Theologis A (2009) A combinatorial interplay among the 1-aminocyclopropane-1-carboxylate isoforms regulates ethylene biosynthesis in Arabidopsis thaliana. Genetics 183: 979-1003

Ubeda-Tomas S, Federici F, Casimiro I, Beemster GT, Bhalerao R, Swarup R, Doerner P, Haseloff J, Bennett MJ (2009) Gibberellin signaling in the endodermis controls Arabidopsis root meristem size. Curr Biol 19: 1194-1199

Úbeda-Tomás S, Swarup R, Coates J, Swarup K, Laplaze L, Beemster GT, Hedden P, Bhalerao R, Bennett MJ (2008) Root growth in Arabidopsis requires gibberellin/DELLA signalling in the endodermis. Nat Cell Biol 10: 625-628

Vandenbussche F, Petrasek J, Zadnikova P, Hoyerova K, Pesek B, Raz V, Swarup R, Bennett M, Zazimalova E, Benkova E, Van Der Straeten D (2010) The auxin influx carriers AUX1 and LAX3 are involved in auxin-ethylene interactions during apical hook development in Arabidopsis thaliana seedlings. Development 137: 597-606

Vogel JP, Woeste KE, Theologis A, Kieber JJ (1998) Recessive and dominant mutations in the ethylene biosynthetic gene ACS5 of Arabidopsis confer cytokinin insensitivity and ethylene overproduction, respectively. Proc Natl Acad Sci U S A 95: 4766-4771

Vriezen WH, Achard P, Harberd NP, Van Der Straeten D (2004) Ethylene-mediated enhancement of apical hook formation in etiolated Arabidopsis thaliana seedlings is gibberellin dependent. Plant J 37: 505-516

Wei N, Kwok SF, von Arnim AG, Lee A, McNellis TW, Piekos B, Deng XW (1994) Arabidopsis COP8, COP10, and COP11 genes are involved in repression of photomorphogenic development in darkness. Plant Cell 6: 629-643 
Wu G, Cameron JN, Ljung K, Spalding EP (2010) A role for ABCB19-mediated polar auxin transport in seedling photomorphogenesis mediated by cryptochrome 1 and phytochrome B. Plant J 62: 179-191

Yamagami T, Tsuchisaka A, Yamada K, Haddon WF, Harden LA, Theologis A (2003) Biochemical diversity among the 1-amino-cyclopropane-1-carboxylate synthase isozymes encoded by the Arabidopsis gene family. J Biol Chem 278: $49102-49112$

Yamaguchi S, Kamiya Y, Sun T (2001) Distinct cell-specific expression patterns of early and late gibberellin biosynthetic genes during Arabidopsis seed germination. Plant J 28: 443-453

Yang X, Lee S, So JH, Dharmasiri S, Dharmasiri N, Ge L, Jensen C, Hangarter R, Hobbie L, Estelle M (2004) The IAA1 protein is encoded by AXR5 and is a substrate of SCF(TIR1). Plant J 40: 772-782

Zadnikova P, Petrasek J, Marhavy P, Raz V, Vandenbussche F, Ding Z, Schwarzerova K, Morita MT, Tasaka M, Hejatko J, Van Der Straeten D, Friml J, Benkova E (2010) Role of PIN-mediated auxin efflux in apical hook development of Arabidopsis thaliana. Development 137: 607-617

Zentella R, Zhang ZL, Park M, Thomas SG, Endo A, Murase K, Fleet CM, Jikumaru Y, Nambara E, Kamiya Y, Sun TP (2007) Global analysis of della direct targets in early gibberellin signaling in Arabidopsis. Plant Cell 19: 3037-3057

Zhao X, Yu X, Foo E, Symons GM, Lopez J, Bendehakkalu KT, Xiang J, Weller JL, Liu X, Reid JB, Lin C (2007) A study of gibberellin homeostasis and cryptochromemediated blue light inhibition of hypocotyl elongation. Plant Physiol 145: 106-118

Zhao Y, Christensen SK, Fankhauser C, Cashman JR, Cohen JD, Weigel D, Chory J (2001) A role for flavin monooxygenase-like enzymes in auxin biosynthesis. Science 291: 306-309

Zhong S, Zhao M, Shi T, Shi H, An F, Zhao Q, Guo H (2009) EIN3/EIL1 cooperate with PIF1 to prevent photo-oxidation and to promote greening of Arabidopsis seedlings. Proc Natl Acad Sci U S A 106: 21431-21436

Reference list for Figure 4.10:

1. Li, H., Johnson, P., Stepanova, A., Alonso, J.M. and Ecker, J.R. (2004) Convergence of signaling pathways in the control of differential cell growth in Arabidopsis. Dev Cell, 7, 193-204.

2. Knee, E.M., Hangarter, R.P. and Knee, M. (2000) Interactions of light and ethylene in hypocotyl hook maintenance in Arabidopsis thaliana seedlings. Physiol Plant, 108, 208-215.

3. Achard, P., Liao, L., Jiang, C., Desnos, T., Bartlett, J., Fu, X. and Harberd, N.P. (2007) DELLAs Contribute to Plant Photomorphogenesis. Plant Physiol, 143, 1163-1172.

4. Alabadí, D., Gallego-Bartolomé, J., García-Cárcel, L., Orlando, L., Rubio, V., Martínez, C., Frigerio, M., Iglesias-Pedraz, J.M., Espinosa, A., Deng, X.W. and Blázquez, M.A. (2008) Gibberellins modulate light signaling pathways to prevent Arabidopsis seedling de-etiolation in darkness. Plant J, 53, 324-335.

5. Zhao, X., Yu, X., Foo, E., Symons, G.M., Lopez, J., Bendehakkalu, K.T., Xiang, J., Weller, J.L., Liu, X., Reid, J.B. and Lin, C. (2007) A study of gibberellin homeostasis and cryptochrome-mediated blue light inhibition of hypocotyl elongation. Plant Physiol, 145, 106-118.

6. This work. 
7. Lehman, A., Black, R. and Ecker, J.R. (1996) HOOKLESS1, an ethylene response gene, is required for differential cell elongation in the Arabidopsis hypocotyl. Cell, 85, 183-194.

8. Vandenbussche, F., Petrasek, J., Žádníková, P., Hoyerova, K., Pesek, B., Raz, V., Swarup, R., Bennett, M., Zazimalova, E., Benkova, E. and Van Der Straeten, D. (2010) The auxin influx carriers AUX1 and LAX3 are involved in auxinethylene interactions during apical hook development in Arabidopsis thaliana seedlings. Development, 137, 597-606.

9. Žádníková, P., Petrasek, J., Marhavy, P., Raz, V., Vandenbussche, F., Ding, Z., Schwarzerova, K., Morita, M.T., Tasaka, M., Hejatko, J., Van Der Straeten, D., Friml, J. and Benkova, E. (2010) Role of PIN-mediated auxin efflux in apical hook development of Arabidopsis thaliana. Development, 137, 607-617.

\subsection{SUPPORTING FIGURES}

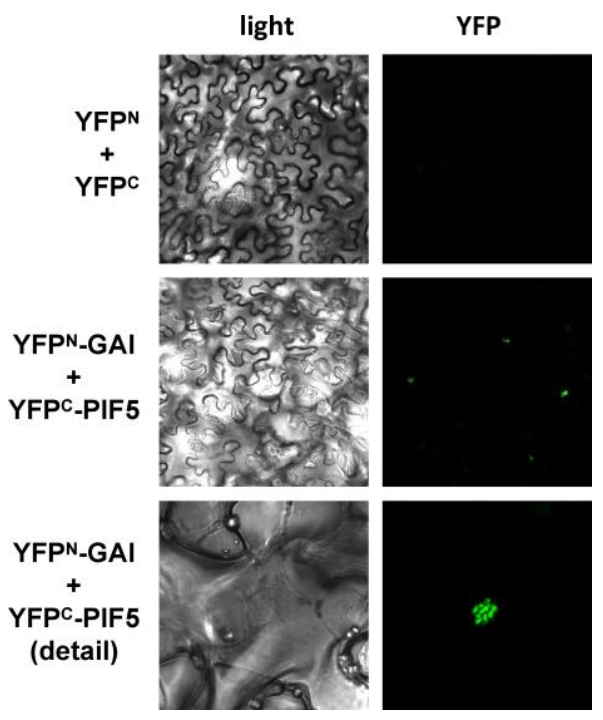

Figure 4.S1. GAI and PIF5 interact in plant cells.

$\mathrm{BiFC}$ analysis in tobacco leaves between GAI and PIF5 fusions to N- and C-terminal fragments of YFP, respectively. Left, visible; right, YFP fluorescence.

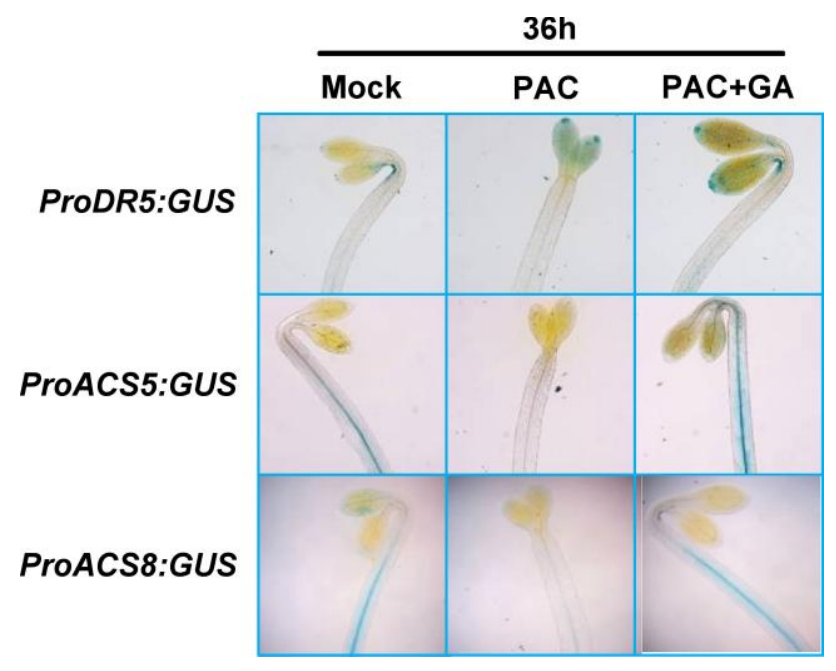

Figure 4.S2 GAs revert the PAC-effect on ProACS5:GUS, ProACS8:GUS, and ProDR5:GUS.

Expression patterns of ProDR5:GUS, ProACS5:GUS, and ProACS8:GUS in seedlings grown on control medium, or on medium supplemented with $0.2 \mu \mathrm{M}$ PAC or with $0.2 \mu \mathrm{M}$ PAC plus $50 \mu \mathrm{M}$ $\mathrm{GA}_{3}$ for $36 \mathrm{~h}$ after germination. 


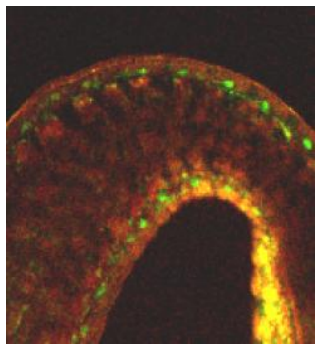

Figure 4.S3 Specific expression of GFP-gai-1 in the epidermis of etiolated seedlings.

Confocal image of a longitudinal section of the apical hook of a 1-day-old ProML1:GFP-gai-1-11 

General discussion 

One of the major challenges during the transition from simple unicellular to complex multicelular organisms was the coordination between different cells in order to provide the appropriate response to internal and external cues. This issue is particularly important in plants, where continuous changes in the environment lead to phenotypical changes caused by plastic interpretation of developmental programs. Phytohormones play an essential role in this adaptation, both as instructive agents and as modifiers of existing programs (Alabadí et al., 2009, Int. J. Dev. Biol). In this thesis we have attempted to shed some light on the mechanisms through which gibberellins (GAs) contribute to plant plastic behaviour. As stated in the introduction, we have addressed two general questions: (1) Where does the specificity of DELLA function reside in Arabidopsis? And (2) How do GAs modulate differential growth processes in Arabidopsis? In the following paragraphs, we will discuss the implications of the results presented in the previous chapters, trying to identify common threads in the mechanisms that we have elucidated, and in the context of plasticity in plant development.

\subsection{Contribution of gibberellins to plant plasticity resides partially on DELLA protein subfuncionalization.}

As mentioned in the introduction, the Arabidopsis genome contains five genes encoding DELLA proteins, while many other plants only possess a single ortholog. This observation could be enough to deduce that the impact of DELLA multiplication on plant plasticity is only marginal, given that there does not seem to be an evident relationship between the number of DELLA genes and the degree of plasticity between different species. However, a different view is that the multiplication of DELLA genes in Arabidopsis (and other plants) may well be an alternative mechanism in these particular plants to achieve the plasticity that plants with single copies of DELLA genes generate by other means. Therefore, the investigation of a link between DELLA multiplication in Arabidopsis and plasticity may provide results that could perhaps be generalized to other similar situations.

If the previous idea is right, and DELLA multiplication confers advantages regarding plasticity in this species, it is reasonable to think that after diversification of expression, specialization would be the mean to improve the downstream signaling 
events. Hence, each DELLA protein would be specialized in controlling processes related to their own expression domain. This hypothesis seems to hold true according to a search for genes coexpressed with each of the DELLA genes using the ATTED webtool (http://atted.jp/) at the TAIR website (http://www.arabidopsis.org/). Interestingly, the functional categories over-represented among the 300 best-scored coexpressed genes were different depending on the particular DELLA gene used in the analysis (Table D1), and these categories correlate with the known roles of each of the DELLA proteins. For instance, the main role of RGA and GAI as repressors of cell elongation (Dill and Sun, 2001) is suggested by the enrichment of "uni- and multidimensional growth" among the functional categories overrepresented in their set of coexpressed genes (Table D1). And the role of RGL1 and RGL2 together with RGA in flower development (Cheng et al., 2004) is also confirmed in this approach by the appearance of related functional categories overrepresented in their set of coexpressed genes (Table D1).

More importantly, this analysis may also reveal previously unknown roles of each DELLA protein, which of course should be confirmed or discarded on the basis of additional experimental evidence. Such would be the case for lateral root development, auxin signaling and transport, stomata movement or gravitropism (Table D1). Interestingly, our results (Chapters 3 and 4) confirm the involvement of DELLAs in two differential growth processes -hook and gravitropism- through their action on auxin signaling and transport, demonstrating again the potential use of this analysis, based on coexpression networks.

\subsection{Regulation of transcriptional networks as a mechanism to} improve plastic development

A plausible mechanism through which a single hormone, GA, can trigger so many different developmental responses resides in a complex GA-GID-DELLA signaling pathway where the DELLA proteins, depending on the spatial or temporal context, will interact with different transcription factors (TFs) to trigger different subsets of GA responses. As shown in Chapter 2, one of the over-represented GO categories within the "molecular function" group in the HS::gai-1 microarray was "transcription factor activity". 
Table D1: Functional categories over-represented in the set of DELLA corregulated genes.

\begin{tabular}{|c|c|c|c|c|c|}
\hline $\begin{array}{l}\text { RGA } \\
\text { GO } \\
\text { term }\end{array}$ & list1_positive_ids & $\begin{array}{l}\operatorname{adj}_{-} \\
\text {pvalue }\end{array}$ & $\begin{array}{l}\text { GAI } \\
\text { GO } \\
\text { term }\end{array}$ & list1_positive_ids & $\begin{array}{l}\operatorname{adj}_{-} \\
\text {pvalue }\end{array}$ \\
\hline 6833 & water transport & $2,21 \mathrm{E}-02$ & 9639 & response to red or far red light & $3,85 \mathrm{E}-02$ \\
\hline 32880 & regulation of protein localization & $1,17 \mathrm{E}-03$ & 9734 & auxin mediated signaling pathway & $7,65 \mathrm{E}-05$ \\
\hline 10014 & meristem initiation & $2,77 \mathrm{E}-02$ & 51258 & protein polymerization & $3,62 \mathrm{E}-02$ \\
\hline 48443 & stamen development & $1,06 \mathrm{E}-02$ & 7047 & cell wal organization & $4,33 \mathrm{E}-02$ \\
\hline 9965 & leaf morphogenesis & $7,64 \mathrm{E}-03$ & 9825 & multidimentional cell growth & $4,43 \mathrm{E}-03$ \\
\hline 10015 & root morphogenesis & $1,84 \mathrm{E}-02$ & 9826 & unidimentional cell growth & $3,20 \mathrm{E}-02$ \\
\hline 48527 & lateral root develoopment & $1,78 \mathrm{E}-02$ & 9926 & auxin polar transport & $3,22 \mathrm{E}-02$ \\
\hline 10540 & $\begin{array}{l}\text { basipetal auxin transport } \\
\text { xylem and phloem pattern }\end{array}$ & 2,21E-02 & 10268 & brassinosteroids homeostasis & $4,33 \mathrm{E}-02$ \\
\hline 10051 & formation & $1,19 \mathrm{E}-03$ & 48589 & developmental growth & $3,11 \mathrm{E}-02$ \\
\hline 9845 & seed germination & $3,02 \mathrm{E}-02$ & 9911 & positive regulation of flower & $1,01 \mathrm{E}-02$ \\
\hline 9799 & determination of symetry & $1,45 \mathrm{E}-02$ & 48513 & $\begin{array}{l}\text { organ development } \\
\text { xylem and phloem pattern }\end{array}$ & $3,22 \mathrm{E}-02$ \\
\hline 10152 & polen maturation & $4,18 \mathrm{E}-02$ & 10051 & formation & $2,36 \mathrm{E}-02$ \\
\hline 10075 & regulation of meristem growth & $1,27 \mathrm{E}-02$ & 15994 & chorophyll biosynthetic process & $3,95 \mathrm{E}-04$ \\
\hline 9825 & multidimentional cell growth & $2,30 \mathrm{E}-04$ & & & \\
\hline 9826 & unidimentional cell growth & $3,30 \mathrm{E}-03$ & $\begin{array}{l}\text { RGL1 } \\
\text { GO }\end{array}$ & & \\
\hline 9913 & epidermal cell diferentiation & $2,32 \mathrm{E}-03$ & term & list1_positive_ids & pvalue \\
\hline 42538 & hyperosmotic salinity response & $1,20 \mathrm{E}-02$ & 8610 & lipid catabolic process & $6,14 \mathrm{E}-07$ \\
\hline 9958 & positive gravitropism & $4,92 \mathrm{E}-03$ & 10166 & wax metabolic process & $2,61 \mathrm{E}-08$ \\
\hline 9637 & response to blue light & $1,95 \mathrm{E}-02$ & 6633 & fatty-acid metabolic process & $7,17 \mathrm{E}-05$ \\
\hline 10218 & response to far red light & $1,20 \mathrm{E}-02$ & 6011 & UDP-glucose metabolic process & $8,03 \mathrm{E}-03$ \\
\hline 10161 & red light signaling pathway & $2,21 \mathrm{E}-02$ & 9908 & flower development & $3,49 \mathrm{E}-02$ \\
\hline 10118 & $\begin{array}{l}\text { regulation of stomata movement } \\
\text { transmembrane receptor protein }\end{array}$ & $1,35 \mathrm{E}-02$ & 9753 & response to jasmonic acid stimulus & $4,58 \mathrm{E}-02$ \\
\hline 7169 & $\begin{array}{l}\text { tyrosine kinase signaling } \\
\text { auxin mediated signaling }\end{array}$ & $3,60 \mathrm{E}-06$ & 10166 & response to hormone stimulus & $2,61 \mathrm{E}-08$ \\
\hline 9734 & pathway & $8,07 \mathrm{E}-12$ & & & \\
\hline 9742 & $\begin{array}{l}\text { brassinosteroids mediated } \\
\text { signaling }\end{array}$ & $2,17 \mathrm{E}-04$ & RGL2 & & \\
\hline 9664 & plant-type cell wall organization & $1,47 \mathrm{E}-02$ & $\begin{array}{l}\text { GO } \\
\text { term }\end{array}$ & list1_positive_ids & $\begin{array}{l}\text { adj }_{\text {pvalue }}\end{array}$ \\
\hline 7010 & cytoskeleton organization & $4,55 \mathrm{E}-03$ & 16042 & lipid catabolic process & $1,70 \mathrm{E}-03$ \\
\hline 51301 & cell division & $2,14 \mathrm{E}-02$ & 10166 & wax metabolic process & 7,54E-04 \\
\hline 9832 & plant-type cell wall biogenesis & $3,30 \mathrm{E}-03$ & 6633 & fatty acid biosynthetic process & $3,57 \mathrm{E}-06$ \\
\hline 7049 & cell cycle & $4,18 \mathrm{E}-02$ & 30154 & cell diferentiation & $1,88 \mathrm{E}-05$ \\
\hline 7017 & microtubule-based process & $1,86 \mathrm{E}-02$ & 9887 & organ morphogenesis & $9,43 \mathrm{E}-03$ \\
\hline 6644 & phospholipid metabolic process & $2,26 \mathrm{E}-02$ & 48440 & carpel development & $3,00 \mathrm{E}-09$ \\
\hline 30244 & cellulose biosynthetic process & $8,24 \mathrm{E}-03$ & & & \\
\hline \begin{tabular}{|l} 
RGL3 \\
GO \\
term
\end{tabular} & list1_positive_ids & $\begin{array}{l}\text { adj }_{-} \\
\text {pvalue }\end{array}$ & $\begin{array}{l}\text { GO } \\
\text { term }\end{array}$ & list1_positive_ids & $\begin{array}{l}\text { adj }_{-} \\
\text {pvalue }\end{array}$ \\
\hline 9611 & response to wounding & $1,89 \mathrm{E}-10$ & 9739 & response to gibberellin stimulus & $3,95 \mathrm{E}-02$ \\
\hline 6952 & defense response & $6,50 \mathrm{E}-03$ & 9738 & $\begin{array}{l}\text { abscisic acid mediated signaling } \\
\text { regulation of ethylene mediated }\end{array}$ & $1,71 \mathrm{E}-03$ \\
\hline 9651 & response to salt stress & $3,04 \mathrm{E}-05$ & 10104 & $\begin{array}{l}\text { signaling pathway } \\
\text { jasmonic acid mediated signaling }\end{array}$ & $9,43 \mathrm{E}-03$ \\
\hline 9414 & response to water deprivation & $1,95 \mathrm{E}-03$ & 9867 & $\begin{array}{l}\text { pathway } \\
\text { negative regulation of signal }\end{array}$ & $9,43 \mathrm{E}-03$ \\
\hline 10200 & response to chitin & $2,36 \mathrm{E}-04$ & 9968 & transduction & $2,24 \mathrm{E}-03$ \\
\hline
\end{tabular}


If this is true, searching for DELLA-regulated TFs we might figure out by which means DELLAs trigger different downstream events. Looking at HS::gai-1 microarray data (Chapter 2) it seems that gai-1, under the control of a heat-shock inducible promoter, preferentially modulates the expression of only a few transcription factor families: bHLH, GRAS, C2C2, MYB and AP2-EREBP (Fig D.1).
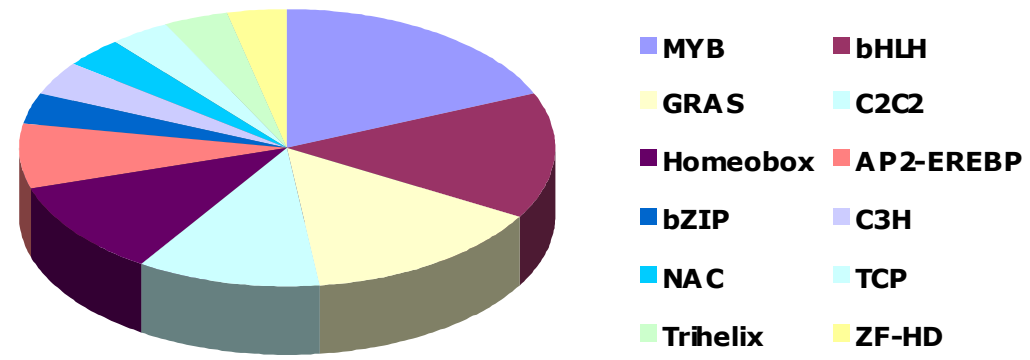

Figure D.1. Transcription factor families regulated by gai-1.

All gai-1 targets annotate as TF in the HS:gai-1 microarray dataset were grouped based on their TF families. Each family is shown as a percentage of the total families present in the dataset.

Thus, the set of transcription factors coexpressed with DELLA could reveal new connections between DELLAs and transcriptional regulation of GA targets. If the relative enrichment of a particular TF family is meaningful, the results shown in Fig D.2 suggest that bHLH proteins are at the core of DELLA regulated responses (only RGL3, probably specialized in defense, does not show corregulation with this TF family). But beyond the common points between all DELLAs, the different DELLA proteins seem to mobilize different TF families to exert their function. For instance, RGA and GAI, with a prominent role in general growth, are coexpressed with homeobox TF families, while RGL1 and RGL2, specialized partially in flower development, show better coexpression with MADS-box, MYB and Squamosa Binding Protein (SBP) TF families (also involved in this process).

In summary, it seems that tissue-specific coexpression of DELLAs and certain TFs might eventually explain the different roles of each of the DELLA proteins in Arabidopsis. On the other hand, it could just indicate that different developmental processes might be triggered preferentially by different TF families (i.e. homeobox for vegetative growth $v s$ MADS-box for flower development), and each DELLA protein would be mobilized by different developmental programs to cooperate with these TF families. In that case, coexpressed TF could be not only DELLA targets but also 
modulators of DELLA expression, or even direct interactors that would mediate DELLA regulation of transcription.

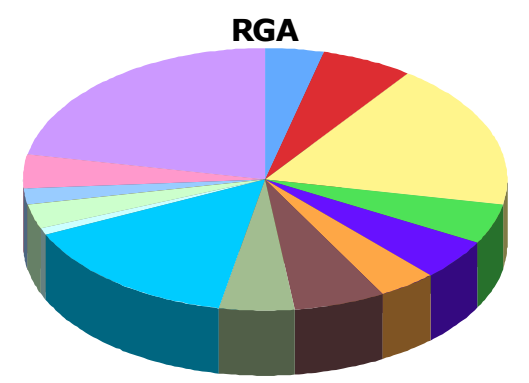

RGL1

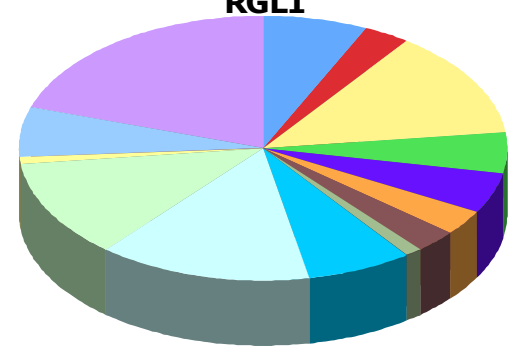

RGL3

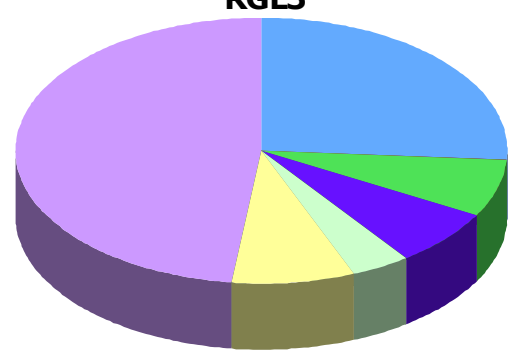

GAI

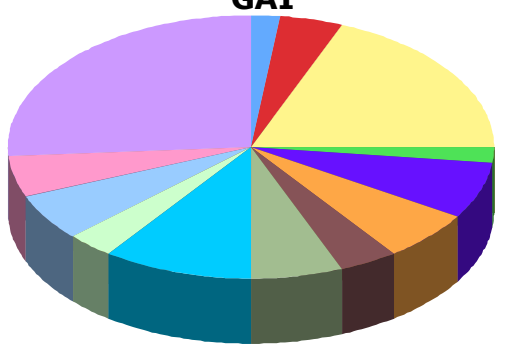

RGL2
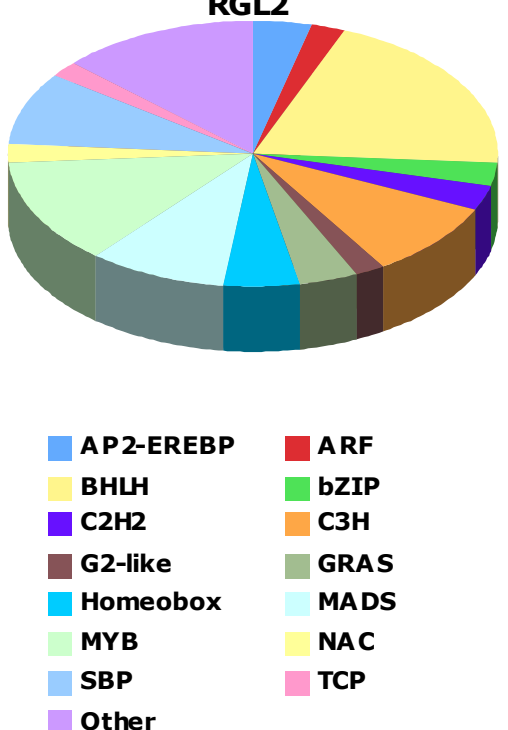

Figure D.2. Coexpressed transcription factor families

Using the ATTEDII webtool, It was found the 100 best scored corregulated transcription factor for each DELLA gene. Only transcription factor families representing $>5 \%$ of the total list in at least one corregulated set are shown. Transcription factor families representing $<5 \%$ are englobed as others.

\subsection{DELLA co-expressed as a source of new interactors.}

So far, no DNA-binding domain has been found in DELLA proteins and it is currently accepted that they regulate gene transcription through the interaction with DNA binding transcription factors, such as PIF proteins (de Lucas et al., 2008; Feng et al., 2008), or modulators of the activity of transcription factor, such as JAZ proteins (Hou et al., 2010). Thus, an even more exciting possibility is that some of the DELLA co-expressed TF, apart from being regulated transcriptionally by DELLA, they could be regulated by physical interaction. In other words, DELLAs would had had bigger chances to interact with the coexpressed TFs. The most over-represented families are 
bHLH, homeobox, SBP, TCP and Trihelix families (Fig D3). Interaction with bHLH TFs has been already shown (de Lucas et al., 2008; Feng et al., 2008; Arnaud et al., 2010; Josse et al., 2011). Although physical interaction with members of the other TF families has not been shown, there is a large overlap between GA-related responses and the functions of DELLA-coexpressed TFs, (Hay et al., 2004; Zhang et al., 2007; Tatematsu et al., 2008; Breuer et al., 2009). For instance Squamosa-Binding Proteins (SBP) are related to several processes controlled by GAs such as juvenile to adult phase transition, flowering and male sterility (Chen et al., 2010). As an example, SPL8 overexpression induces GA constitutive response that leads to anther indehiscence and hence infertility (Zhang et al., 2007).
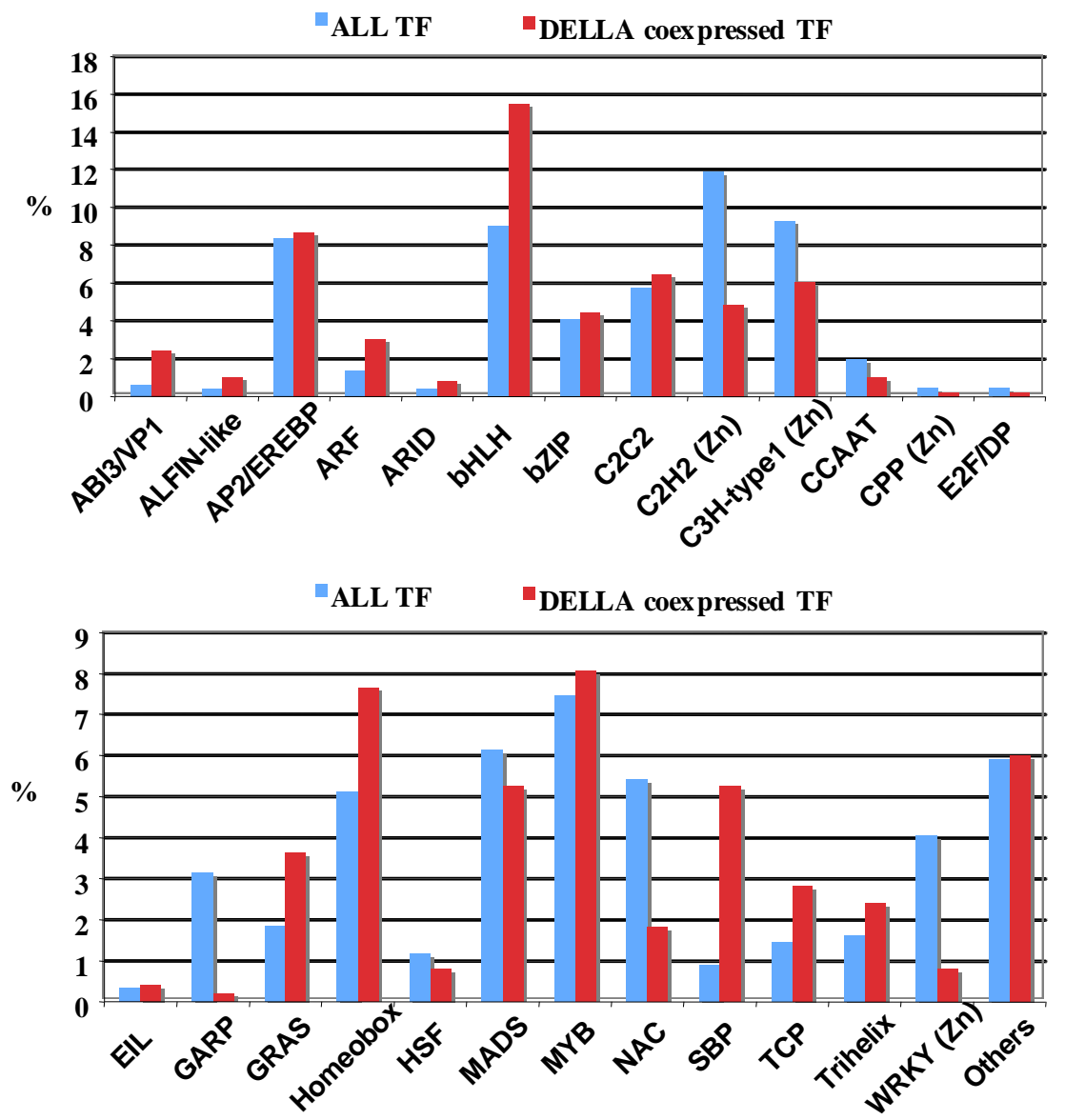

Figure D.3. Comparison of representation of DELLA coexpressed TF with the overall TF list from Arabidopsis.

All DELLA coexpressed TF were combined. Each TF family is represented as percentage of the total of families in this dataset. A comparison with the predicted list of all Arabidopsis TF (Qu and Zhu, 2006) was done to find over-represented families among the DELLA coexpressed TF.

Lastly, an additional source of information to find putative TFs involved in transcriptional regulation by DELLA proteins is the enrichment of certain cis elementes 
in the promoters of genes differentially expressed in $H S::$ gai-1 plants (Chaper II). For example, we found known binding sites for DOF (C2C2 family) (AAAG) or ARR1 (GARP family) (NGATT) TFs. These two families seem not to be over-represented in the previous analysis of co-expressed TF families, but this could reflect that the overrepresented elements present in the promoter analysis of Chapter 2 belong to a certain context ( 2 day old etiolated seedlings) where GAI interacts with a certain pool of factors while the DELLA co-expressed genes are a compilation of the co-expressed genes through the whole Arabidopsis life. This points out to the importance of the context where a DELLA is expressed to adopt the control over a certain process and how the same proteins can control different processes through the interaction with different proteins.

\subsection{Gibberellin modulation of differential growth processes}

During this thesis we have studied the contribution of GAs to two differential growth processes: gravitropism and apical hook development. A comparative look at the mechanisms found in both processes reveals an interesting parallelism: GAs act as modulators of differential growth through their regulation upon auxin signalling and/or transport. This type of interaction between GAs and other signaling pathways is relatively novel, given that GAs have been previously shown to act on cell growth through direct regulation of genes enconding enzymes involved in cell wall modifications, such as expansins or xyloglucan endotransglucosylases (Lee and Kende, 2001; Vogler et al., 2003; Jan et al., 2004) often as a downstream subsidiary signal for the action of other hormones such as auxin or ethylene (Achard et al., 2003; Fu and Harberd, 2003; Frigerio et al., 2006). Conceptually, what we have found is novel in that during differential growth, GAs primarily modulate the activity of auxin, the master hormone in these processes, constituting a fine-tuning mechanism, rather than a bona fide instructive signal. Support for this claim not only comes from the molecular links found between DELLAs and auxin-signaling elements and their targets, but this mechanistic interaction may probably be extended to other processes beyond differential growth, based on the functional analysis of DELLA-corregulated genes discussed in the previous paragraphs. 
The parallelisms between the two regulatory mechanisms described in Chapters 3 and 4 are more than a simple conceptualization of the interaction between GAs and auxin during differential growth. Although at first look it seems like GAs regulate completely different steps of auxin activity in each process (gravitropism $v s$ hook formation), a more careful analysis of the evidence suggests that GAs regulate both processes through the same mechanism. For instance, the repression of IAA19/MSG2 expression by DELLAs has been proven essential for the modulation of hypocotyl gravitropism (Chapter 3), but this interaction may indeed also contribute to the formation of the apical hook, based on the hook-defective phenotype of msg2-1 mutants (Tatematsu et al., 2004). Similarly, the repression of PIN3 and PIN7 by DELLAs is instrumental for the regulation of hook formation by GAs (Chapter 4), but one cannot forget that these two genes encode key auxin efflux carriers involved in the redistribution of auxins during the hypocotyl gravitropic response (Rakusova et al., 2011). And, finally, HLS1 repression by DELLAs is important for hook unfolding (Chapter 4), but it may also be relevant for the regulation of gravitropism according to the reported phenotype of hls 1 mutants on gravitropic reorientation (Hamaguchi et al., 2008). Thus, it seems reasonable that the regulation by DELLAs of all these genes (IAA19/MSG2, HLS1, PIN3 and PIN7) may represent a general core mechanism for the regulation of differential growth by GAs. Further studies should be done to confirm whether these interactions, although plausible, are actually happening in these contexts.

A part from the effect of GAs on auxin activity, we have also reported the positive effect of GAs on ethylene synthesis to prevent hook opening, through activation of ACC synthase genes, . Interestingy, part of the ethylene effect on hook developmentt is mediated by auxin and through regulation of the auxin efflux (Zadnikova et al., 2010) showing a parallelism with GAs action on auxin activity. The fact that both hormones, GAs and ethylene, show cross-regulation between them (1) GAs induce ethylene synthesis, (2) ethylene affects GAs response (Vriezen et al., 2004) and both together modulate auxins as common output to fine-tune the hook development, highlights the complexity of hormonal crosstalk and the importance of understanding the overall circuits and interactions among them.

One of the reasons why hormonal crosstalk is currently a very active field of plant research is that it may represent a common theme in plant development to fine- 
tune certain plastic responses. Achieving this fine-tuning may be the purpose of recruiting GAs/DELLAs as a modulator of the network that regulates differential growth. However, the demonstration that these new interactions constitute a selective advantage in natural environments still represents a big challenge.

\subsection{Future perspectives}

Most of the previous work on GA signaling, including the work presented here, has been done analyzing GA responses in whole whole seedlings. However, plant organs are heterogeneous regarding the identity of different tissues and cell types. If this apparently obvious statement is taken into account, several questions arise that have hardly been addressed until now. For instance, how is growth coordinated through the different cell types that conform a given organ? Does GA signaling proceed through different circuits in the different tissues? When a particular whole-seedling response is analyzed, is GA signaling necessary only in a specific subset of cells, or does it happen homogeneously throughout the organ? All these questions represent only the initial motivation to analyze the spatial regulation of GA signaling.

A hint of the importance of spatial constrains in GA signaling has been beautifully exposed in recent work which showed that GA signalling in the root endodermis -and not in other tissues- is essential for coordinated growth of the root (Úbeda-Tomás et al., 2008). Importantly, this spatial component of GA signaling operates in other developmental contexts, as we have observed in our lab in the aerial part of vegetative tissues. For instance, results in Chapter 4 show that an active GA response in the endodermis is needed for the proper apical hook develoment, while a block of GA signalling in the epidermis does not affect this process. And in the course of this Thesis we have generated unpublished results showing that, again, hypocotyl growth can be impaired by blocking GA signaling specifically in the endodermis, but not in the epidermis (Fig D.4A). Moreover, the attenuation of the gravitropic response conferred by GAs (Chapter 3) seems to happen, again, in the endodermis, given that forced expression of $g a i-1 D$ in the endodermis alone, but not in the epidermis, was able to enhance gravitropic reorientation (Figure D.4B).

Of course, spatial constrains do not restric to GA signaling, but have also been 
reported for other hormones. For instance, it has been shown that brassinosteroids control whole hypocotyl growth through the epidermis (Savaldi-Goldstein et al., 2007). Moreover, auxin signalling in root elongation epidermal cells is essential to develop a normal gravitropic response (Swarup et al., 2005).

A

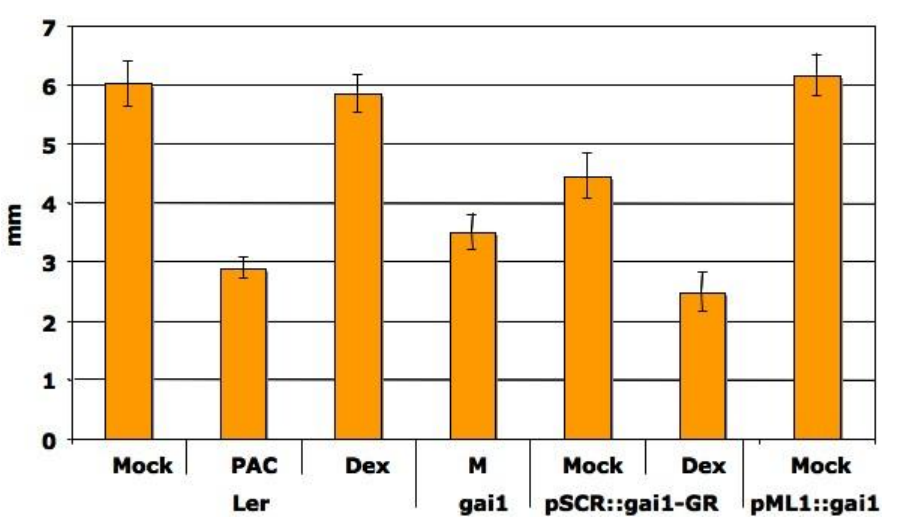

B

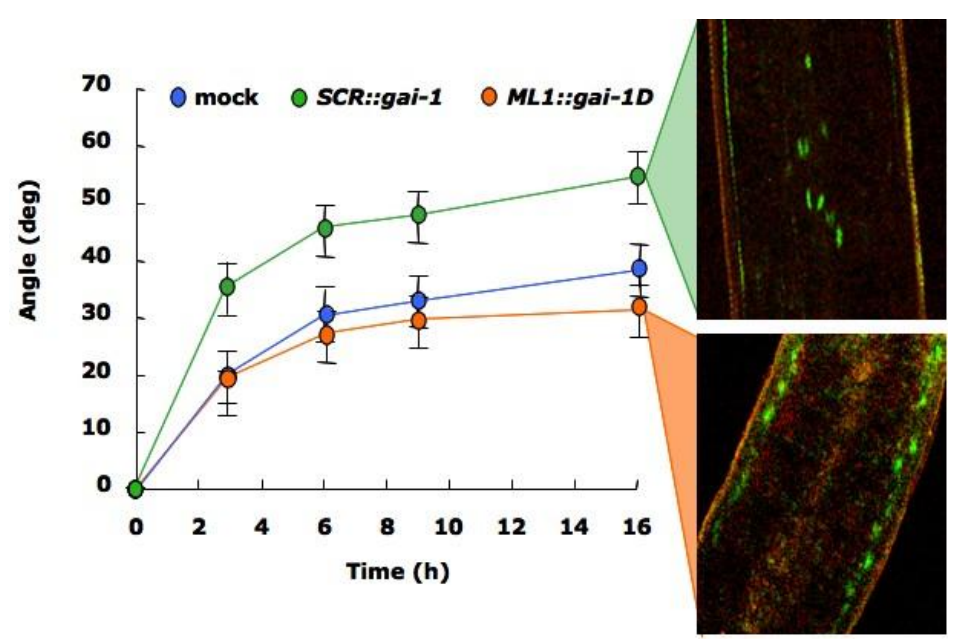

Figure D4. Cell-type specific effect of GA signaling upon gravitropic reorientation.

A) Hypocotyl length of two day old Arabidopsis seedling expressing gai-1D from an endodermisspecific $(S C R)$ or an epidermis-specific (ML1) promoter. Ler, SCR::gai-1D:GR:YFP and ML1::gaiID:GFP seedlings were grown for 3 days in darkness in plates with either mock, $0.4 \mu \mathrm{M}$ PAC or 10 $\mu \mathrm{M}$ dexamethasone solutions.

B) Gravitropic reorientation in seedlings expressing gai- $1 D$ from an endodermis-specific SCR) or an epidermis-specific (ML1) promoter. SCR::gai-1D:GR:YFP and ML1::gai-1D:GFP seedlings were grown for 3 days in darkness on vertical MS plates and then transferred to plates with either mock or $10 \mu \mathrm{M}$ dexamethasone solutions for $15 \mathrm{~h}$. Then the plates were turned $90^{\circ}$ at time 0 . The pictures illustrate gai-1D:YFP and gai-1D:GFP localization in the nuclei of endodermis and epidermis cells.

As mentioned before, a previous study placed the epidermis as the main tissue controlling hypocotyl growth (Savaldi-Goldstein et al., 2007). Although GAs are also mandatory for growth, we have observed that GA signalling in the epidermis does not produce any effect on hypocotyl growth while it is necessary in endodermal cells. 
Interestingly, the periclinal chimera of the grapevine Pinot Meunier points to the same direction. It expresses gai-1 only in the epidermis and, however its size is indistinguishable from the nonchimeric variant (Boss and Thomas, 2002). However, plants regenerated from epidermal cells, but not from other tissues are dwarf. Notably, both Pinot Meunier mutant and pML1::gai-1 Arabidopsis show defects on trichome development similar to GA deficient gal mutant.

The complexity that arises when both temporal and spatial regulation are combined is probably at the core of the generation of plastic developmental responses in plants, and points to an exciting direction for future investigations

\subsection{Bibliography}

Achard P, Vriezen WH, Van Der Straeten D, Harberd NP (2003) Ethylene regulates arabidopsis development via the modulation of DELLA protein growth repressor function. Plant Cell 15: 2816-2825

Arnaud N, Girin T, Sorefan K, Fuentes S, Wood TA, Lawrenson T, Sablowski R, Ostergaard L (2010) Gibberellins control fruit patterning in Arabidopsis thaliana. Genes Dev 24: 2127-2132

Boss PK, Thomas MR (2002) Association of dwarfism and floral induction with a grape 'green revolution' mutation. Nature 416: $847-850$

Breuer C, Kawamura A, Ichikawa T, Tominaga-Wada R, Wada T, Kondou Y, Muto S, Matsui M, Sugimoto K (2009) The trihelix transcription factor GTL1 regulates ploidydependent cell growth in the Arabidopsis trichome. Plant Cell 21: 2307-2322

Chen X, Zhang Z, Liu D, Zhang K, Li A, Mao L (2010) SQUAMOSA promoter-binding protein-like transcription factors: star players for plant growth and development. J Integr Plant Biol 52: 946-951

Cheng H, Qin L, Lee S, Fu X, Richards DE, Cao D, Luo D, Harberd NP, Peng J (2004) Gibberellin regulates Arabidopsis floral development via suppression of DELLA protein function. Development 131: 1055-1064

de Lucas M, Davière JM, Rodríguez-Falcón M, Pontin M, Iglesias-Pedraz JM, Lorrain S, Fankhauser C, Blázquez MA, Titarenko E, Prat S (2008) A molecular framework for light and gibberellin control of cell elongation. Nature 451: 480-484

Dill A, Sun T (2001) Synergistic derepression of gibberellin signaling by removing RGA and GAI function in Arabidopsis thaliana. Genetics 159: 777-785

Feng S, Martinez C, Gusmaroli G, Wang Y, Zhou J, Wang F, Chen L, Yu L, IglesiasPedraz JM, Kircher S, Schafer E, Fu X, Fan LM, Deng XW (2008) Coordinated regulation of Arabidopsis thaliana development by light and gibberellins. Nature 451: 475-479

Frigerio M, Alabadí D, Pérez-Gómez J, García-Cárcel L, Phillips AL, Hedden P, Blázquez MA (2006) Transcriptional regulation of gibberellin metabolism genes by auxin signaling in Arabidopsis. Plant Physiol 142: 553-563

Fu X, Harberd NP (2003) Auxin promotes Arabidopsis root growth by modulating gibberellin response. Nature 421: 740-743

Hamaguchi A, Yamashino T, Koizumi N, Kiba T, Kojima M, Sakakibara H, Mizuno T (2008) A small subfamily of Arabidopsis RADIALIS-LIKE SANT/MYB genes: a link 
to HOOKLESS1-mediated signal transduction during early morphogenesis. Biosci Biotechnol Biochem 72: 2687-2696

Hay A, Craft J, Tsiantis M (2004) Plant hormones and homeoboxes: bridging the gap? Bioessays 26: 395-404

Hou X, Lee LY, Xia K, Yan Y, Yu H (2010) DELLAs modulate jasmonate signaling via competitive binding to JAZs. Dev Cell 19: 884-894

Jan A, Yang G, Nakamura H, Ichikawa H, Kitano H, Matsuoka M, Matsumoto H, Komatsu S (2004) Characterization of a xyloglucan endotransglucosylase gene that is up-regulated by gibberellin in rice. Plant Physiol 136: 3670-3681

Josse EM, Gan Y, Bou-Torrent J, Stewart KL, Gilday AD, Jeffree CE, Vaistij FE, Martinez-Garcia JF, Nagy F, Graham IA, Halliday KJ (2011) A DELLA in Disguise: SPATULA Restrains the Growth of the Developing Arabidopsis Seedling. Plant Cell

Lee Y, Kende $\mathbf{H}$ (2001) Expression of beta-expansins is correlated with internodal elongation in deepwater rice. Plant Physiol 127: 645-654

Rakusova H, Gallego-Bartolomé J, Vanstraelen M, Robert H, Alabadí D, Blázquez M, Benkova E, Friml J (2011) Polarization of PIN3-dependent auxin transport for hypocotyl gravitropic response in Arabidopsis thaliana. Plant $\mathrm{J}$.

Savaldi-Goldstein S, Peto C, Chory J (2007) The epidermis both drives and restricts plant shoot growth. Nature 446: 199-202

Swarup R, Kramer EM, Perry P, Knox K, Leyser HM, Haseloff J, Beemster GT, Bhalerao R, Bennett MJ (2005) Root gravitropism requires lateral root cap and epidermal cells for transport and response to a mobile auxin signal. Nat Cell Biol 7: 1057-1065

Tatematsu K, Kumagai S, Muto H, Sato A, Watahiki MK, Harper RM, Liscum E, Yamamoto KT (2004) MASSUGU2 encodes Aux/IAA19, an auxin-regulated protein that functions together with the transcriptional activator NPH4/ARF7 to regulate differential growth responses of hypocotyl and formation of lateral roots in Arabidopsis thaliana. Plant Cell 16: 379-393

Tatematsu K, Nakabayashi K, Kamiya Y, Nambara E (2008) Transcription factor AtTCP14 regulates embryonic growth potential during seed germination in Arabidopsis thaliana. Plant J 53: 42-52

Úbeda-Tomás S, Swarup R, Coates J, Swarup K, Laplaze L, Beemster GT, Hedden P, Bhalerao R, Bennett MJ (2008) Root growth in Arabidopsis requires gibberellin/DELLA signalling in the endodermis. Nat Cell Biol 10: 625-628

Vogler H, Caderas D, Mandel T, Kuhlemeier C (2003) Domains of expansin gene expression define growth regions in the shoot apex of tomato. Plant Mol Biol 53: 267-272

Vriezen WH, Achard P, Harberd NP, Van Der Straeten D (2004) Ethylene-mediated enhancement of apical hook formation in etiolated Arabidopsis thaliana seedlings is gibberellin dependent. Plant J 37: 505-516

Zadnikova P, Petrasek J, Marhavy P, Raz V, Vandenbussche F, Ding Z, Schwarzerova K, Morita MT, Tasaka M, Hejatko J, Van Der Straeten D, Friml J, Benkova E (2010) Role of PIN-mediated auxin efflux in apical hook development of Arabidopsis thaliana. Development 137: 607-617

Zhang Y, Schwarz S, Saedler H, Huijser P (2007) SPL8, a local regulator in a subset of gibberellin-mediated developmental processes in Arabidopsis. Plant Mol Biol 63: 429439 




\section{Conclusions}



- Diversification of DELLAs' roles in Arabidopsis relies mainly on their differential expression patterns, although certain degree of biochemical specialization due to the exposure to different protein contexts cannot be discarded.

- The identity of early targets of GAI in darkness confirms that DELLAs mobilize different transcriptomes depending on the developmental condition. HY5 and PIF transcription factors mediate the regulation of a large subset of DELLA targets. However, our results also indicate that DELLAs act through additional, yet unidentified, transcription factors.

- Gibberellins decrease auxin sensitivity through the induction of IAA19/MSG2 expression in hypocotyls. As a result, gibberellins increase the variance in the gravitropic response of the hypocotyl in a population of seedlings, and they attenuate gravitropism in case of conflicting tropic stimuli, such as during shade avoidance.

- The mechanism by which gibberellins promote the formation of the apical hook is through upregulation of key genes for auxin homeostasis and transport HLS1, PIN3, and PIN7-, most likely in the endodermis. Moreover gibberellins cooperate with ethylene during the maintenance and opening phases to prevent hook opening. This is achieved through the activation of ethylene biosynthetic genes, ACS5 and ACS8, that leads to enhanced ethylene levels. 